\title{
Simplifying management strategies in contemporary practice of endovascular abdominal aortic aneurysm repair
}

Citation for published version (APA):

Stokmans, R. A. (2018). Simplifying management strategies in contemporary practice of endovascular abdominal aortic aneurysm repair. [Doctoral Thesis, Maastricht University]. Ipskamp Printing BV. https://doi.org/10.26481/dis.20181214rs

Document status and date:

Published: 01/01/2018

DOI:

10.26481/dis.20181214rs

Document Version:

Publisher's PDF, also known as Version of record

\section{Please check the document version of this publication:}

- A submitted manuscript is the version of the article upon submission and before peer-review. There can be important differences between the submitted version and the official published version of record.

People interested in the research are advised to contact the author for the final version of the publication, or visit the DOI to the publisher's website.

- The final author version and the galley proof are versions of the publication after peer review.

- The final published version features the final layout of the paper including the volume, issue and page numbers.

Link to publication

\footnotetext{
General rights rights.

- You may freely distribute the URL identifying the publication in the public portal. please follow below link for the End User Agreement:

www.umlib.nl/taverne-license

Take down policy

If you believe that this document breaches copyright please contact us at:

repository@maastrichtuniversity.nl

providing details and we will investigate your claim.
}

Copyright and moral rights for the publications made accessible in the public portal are retained by the authors and/or other copyright owners and it is a condition of accessing publications that users recognise and abide by the legal requirements associated with these

- Users may download and print one copy of any publication from the public portal for the purpose of private study or research.

- You may not further distribute the material or use it for any profit-making activity or commercial gain

If the publication is distributed under the terms of Article $25 \mathrm{fa}$ of the Dutch Copyright Act, indicated by the "Taverne" license above, 
SIMPLIFYING MANAGEMENT

STRATEGIES IN CONTEMPORARY

PRACTICE OF ENDOVASCULAR

ABDOMINAL AORTIC

ANEURYSM REPAIR

RUTGER A. STOKMANS 



\section{STELLINGEN BEHORENDE BIJ HET PROEFSCHRIFT}

\section{SIMPLIFYING MANAGEMENT STRATEGIES IN CONTEMPORARY PRACTICE OF ENDOVASCULAR ABDOMINAL AORTIC ANEURYSM REPAIR \\ RUTGER A. STOKMANS, 14 DECEMBER 2018}

1. Eén op de vijf patiënten die een EVAR behandeling ondergaan is hier volgens de richtlijnen van de fabrikant niet geschikt voor. - Dit proefschrift

2. Met gebruik van hedendaagse stentgrafts in de handen van ervaren operateurs is er GEEN verschil in uitkomst tussen symptomatische AAA en electieve asymptomatische AAA patiënten na endovasculaire behandeling. - Dit proefschrift

3. De endovasculaire behandeling van abdominale aneurysmata onder regionale of lokale anesthesie ten opzichte van algehele narcose leidt tot sneller herstel van de patiënt zonder dat dit nadelige gevolgen heeft op de technische uitkomst van de EVAR behandeling. - Dit proefschrift

4. Het achterwege laten van preventieve coil-embolisatie bij het overstenten van de arterie iliaca voor de behandeling van aorta-iliacale of iliacale aneurysmata leidt NIET tot meer endoleaks of secundaire ingrepen. - Dit proefschrift

5. A mandatory registry on AAA-treatment that is globally supported by doctors and is financially supported by governments and industries might be a solution for creating a benchmark for future treatment and qualifying performance of new devices. - Valorisation Addendum

6. Large high-quality, well-designed observational studies are increasingly believed to provide complimentary evidence to RCTs (and might be of better use in clinical practice). - Dr. Robert J Ligthelm 2007

7. Bij de endovasculaire behandeling van aorta-iliacale of iliacale aneurysmata moet de eerste vraag niet zijn of het mogelijk is een iliac-branched-device te plaatsen, maar of dit noodzakelijk is.

8. In de relatie tussen diameter van het abdominale aneurysma en de kans op ruptuur en overlijden geldt wel 'Size does matter'.

9. As technology advances in complexity and scope, fear becomes more primitive. - Don DeLillo

10. Simplicity is the ultimate sophistication. - Leonardo Da Vinci

11. It always seems impossible, until it its done. - Nelson Mandela 

SIMPLIFYING MANAGEMENT

STRATEGIES IN CONTEMPORARY

PRACTICE OF ENDOVASCULAR

ABDOMINAL AORTIC ANEURYSM REPAIR

RUTGER STOKMANS 
Simplifying management strategies in contemporary practice of endovascular abdominal aortic aneurysm repair. Thesis, University of Maastricht, The Netherlands

Author: Rutger Stokmans

Cover \& layout: $\quad$ Rutger Stokmans

Print: $\quad$ Ipskamp Printing, Enschede, the Netherlands

ISBN: $\quad 978-94-028-1248-0$

(C) 2018 Copyright R.A. Stokmans, Eindhoven, The Netherlands

All rights reserved. No part of this thesis may be reproduced, stored in retrieval system or transmitted, in any form and by any means, without prior permission of the author. 


\section{SIMPLIFYING MANAGEMENT}

\section{STRATEGIES IN CONTEMPORARY \\ PRACTICE OF ENDOVASCULAR}

\section{ABDOMINAL AORTIC ANEURYSM REPAIR}

\section{PROEFSCHRIFT}

ter verkrijging van de graad van doctor

aan de Universiteit Maastricht,

op gezag van Rector Magnificus, prof. dr. R.M. Letschert

volgens het besluit van het College van Decanen,

in openbaar te verdedigen

op vrijdag 14 december 2018 om 12.00 uur

door

Rutger Adriaan Stokmans

geboren te Maastricht op 11 december 1984 


\section{PROMOTIECOMMISSIE}

\section{Promotores}

Prof. dr. Joep A.W. Teijink

Prof. dr. Marc R.H.M. van Sambeek - Technische Universiteit Eindhoven

\section{Copromotor}

Dr. Philippe W.M. Cuypers - Catharina Ziekenhuis Eindhoven

\section{Beoordelingscommissie}

Prof. dr. Martin H. Prins (voorzitter)

Dr. Joost A. van Herwaarden - Universitair Medisch Centrum Utrecht

Prof. dr. Geert-Willem H. Schurink

Prof. dr. Hence J.M. Verhagen - Erasmus Universitair Medisch Centrum Rotterdam

Financial support by the Dutch Heart Foundation for the publication of this thesis is gratefully acknowledged.

Additional financial support was generously provided by; Catharina Ziekenhuis Eindhoven, Rabobank Helmond, Medtronic Vascular, Le Maitre Vascular, Pie Medical Imaging, ChipSoft, Krijnen Medical Innovations, Care and Public Health Research Institute, Medstec Aortic, Stöpler Instrumenten \& Apparaten.

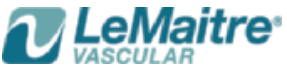

PIE MEDICAL
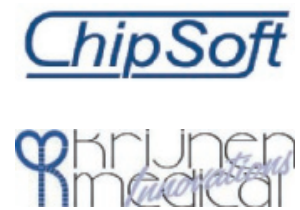
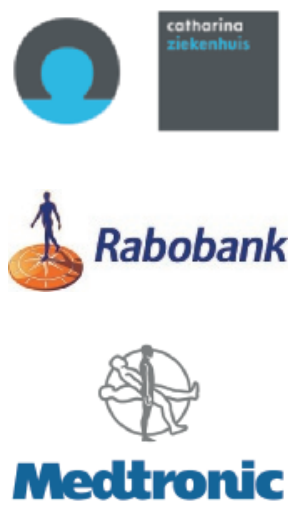

$\oplus$ CAPHRI

medstec nortic

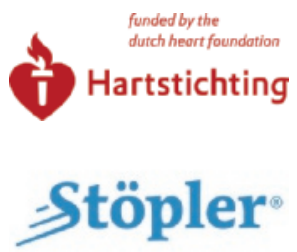


Voor Anne-Lotte, Pepijn \& Philou 


\section{CONTENT OF THIS THESIS}

CHAPTER 1

GENERAL INTRODUCTION AND OUTLINE OF THE THESIS

\section{PART ONE}

PERIOPERATIVE OUTCOME IN CONTEMPORARY EVAR PRACTICE

CHAPTER 2

EARLY RESULTS FROM THE ENGAGE REGISTRY:

REAL-WORLD PERFORMANCE OF THE ENDURANT STENT GRAFT

FOR ENDOVASCULAR AAA REPAIR IN 1262 PATIENTS

\section{CHAPTER 3}

NO DIFFERENCES IN PERIOPERATIVE OUTCOME BETWEEN

SYMPTOMATIC AND ASYMPTOMATIC AAAS AFTER EVAR:

AN ANALYSIS FROM THE ENGAGE REGISTRY

\section{CHAPTER 4}

EFFECTS OF ANESTHESIA TYPE ON PERIOPERATIVE OUTCOME

AFTER ENDOVASCULAR ANEURYSM REPAIR

\section{PART TWO}

COVERAGE OF THE INTERNAL ILIAC ARTERY

\section{CHAPTER 5}

CHALLENGING THE EVIDENCE FOR PRE-EMPTIVE

COIL EMBOLISATION OF THE INTERNAL ILIAC ARTERY

DURING ENDOVASCULAR ANEURYSM REPAIR

\section{CHAPTER 6}

OVERSTENTING THE HYPOGASTRIC ARTERY

DURING ENDOVASCULAR ANEURYSM REPAIR

WITH AND WITHOUT PRIOR COIL EMBOLIZATION:

A COMPARATIVE ANALYSIS FROM THE ENGAGE REGISTRY 


\section{PART THREE}

\section{CHAPTER 7}

EVAR REINTERVENTION MANAGEMENT STRATEGIES

IN CONTEMPORARY PRACTICE

\section{CHAPTER 8}

RATIONALE AND DESIGN OF THE EAGLE REGISTRY:

EVAR WITH THE ENDURANT IN CHALLENGING ANATOMY

CHAPTER 9

GENERAL DISCUSSION

CHAPTER 10

SUMMARY

SAMENVATTING

ADDENDA

VALORISATION

LIST OF PUBLICATIONS 

CHAPTER 1

GENERAL INTRODUCTION AND

OUTLINE OF THE THESIS 



\section{GENERAL INTRODUCTION}

\section{Abdominal aortic aneurysms}

The normal size of the infrarenal aorta is approximately $20 \mathrm{~mm}$ and larger in men than in women. ${ }^{1}$ An abdominal aortic aneurysm (AAA) is a focal dilatation that can be defined as a permanent dilatation of the aortic diameter to at least 1.5 times its normal size. ${ }^{2}$ Abdominal aortic aneurysms (AAAs) are a significant health challenge with an estimated incidence of 2040 cases per 100,000 population per year. The prevalence of AAA was increasing until the late 90's due to aging of the population and better diagnostics. Since 1997 the prevalence of AAA is decreasing, mostly due to better secondary prevention and less people smoking.

Rupture of an aneurysm, leading to massive bleeding and eventually death if left untreated, is the most severe complication of AAA. The risk of rupture increases with the aneurysm diameter. ${ }^{5}$ To date, AAAs are responsible for $1.3 \%$ of all deaths among men aged between 65-85 years in developed countries. ${ }^{6}$ Since AAAs generally exist without symptoms, the AAArelated mortality is probably underestimated.

Initial treatment of an AAA is aimed at preventing rupture. ${ }^{8,9}$ Because treatment itself also comes with a risk of mortality and morbidity, a selective treatment policy is constructed. There is a generally accepted indication for treatment if the threshold diameter is reached ( $55 \mathrm{~mm}$ in men and $52 \mathrm{~mm}$ in women), if rapid aneurysm growth is observed (>5mm per 6

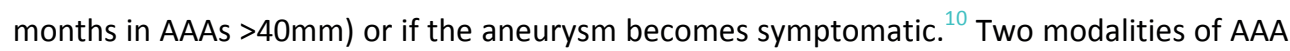
treatment are available; conventional open surgical repair or minimally invasive endovascular repair.

\section{Open aneurysm repair}

In 1951 Dubost performed the first open aneurysm repair by replacing the aneurysm with a preserved human aorta. ${ }^{11}$ Two years later, open repair was performed by DeBakey using a synthetic graft as a replacement. ${ }^{12}$ Since then open aneurysm repair has undergone many improvements and has become the gold standard of AAA treatment. Based on long-term follow-up data, open repair remains a safe and durable option for the management of 
AAAs. ${ }^{13}$ However, open repair requires laparotomy, clamping of the aorta and is frequently accompanied by substantial blood loss. Consequently, open repair is still associated with a perioperative mortality of 2 to $5 \%$ and significant morbidity.

\section{Endovascular aneurysm repair (EVAR)}

In 1991 the management of AAAs changed dramatically, when independently of each other, Parodi $^{15}$ and Volodos ${ }^{16}$ introduced endovascular aneurysm repair (EVAR). This minimally invasive technique implies femoral artery access in the groin. Using catheters, guidewires and under X-ray fluoroscopic guidance, a synthetic stentgraft is fed through the aorta up to the AAA neck and positioned correctly just below the renal arteries and subsequently unfolded, excluding the aneurysm sac from blood flow and pressure.

Initially, EVAR was considered to be an alternative treatment for those AAA not suitable for open repair due to severe comorbidities. Meanwhile, EVAR has proven to be a feasible and safe technique, showing decreased mortality and morbidity rates compared to conventional open treatment. ${ }^{18}$ EVAR now has become the treatment of preference for patients with infrarenal AAA in most clinics.

\section{EVAR-related complications}

Endovascular aneurysm repair has its own complications, unique for endovascular treatment. Following an EVAR procedure, patients may experience endoleaks, device migration, stent fractures or graft deterioration that may lead to aneurysm growth and rupture. Although some of these complications occur shortly after the initial procedure, lifelong surveillance is recommended to identify potential life threatening late complications.

\section{Type-l endoleak}

A Type-I endoleak is defined as blood flow into the aneurysm due to an inadequate seal at the proximal or distal ends of the endoprothesis. Because the aneurysm sac remains pressurised it is at risk for continued expansion and rupture. Thus, failure of AAA treatment. Studies report incidence rates of Type-I endoleaks between $0.5 \%$ and $13 \%{ }^{20-28}$ and association with unfavourable AAA configurations (e.g. short, angulated, and heavily calcified infrarenal necks, or aneurysmatic and tortuous iliac arteries). ${ }^{29}$ If Type-I endoleaks 
are seen during the initial procedure, they should be addressed before leaving the operating room. Most intraoperative and late Type-I endoleaks can be corrected through additional ballooning at the proximal attachment site, stent-graft extension, deployment of large balloon expandable stents, or placement of endo-anchors.

\section{Type-Il endoleak}

Reversed branch flow through a patent inferior mesenteric artery (IMA), lumbar artery, accessory renal artery, or hypogastric artery is defined as a Type-II endoleak. It is the most common type of endoleak with an incidence of $10-25 \%{ }^{26,34-37}$ Early reports describe an aggressive approach to persistent Type-II endoleaks, irrespective of whether any enlargement of the aneurysm sac is observed. ${ }^{38,39}$ In contemporary practice, a much more conservative approach is accepted regarding Type-II endoleak management, because many of them seem to be relatively benign. ${ }^{40}$ Some type-II endoleaks tend to resolve spontaneously, while others persist without causing clinical symptoms. Only a small proportion may cause significant increase in sac size. ${ }^{41}$ Options for treating Type-II endoleaks include embolisation executed by a selective transarterial approach or direct endoleak puncture Onyx glue injection.

\section{Type-III endoleak}

Endoleaks that originate either from fabric defects or inadequate sealing between endograft components are defined as Type-III endoleaks. They occur with an incidence rate of $0.1 \%$ to $6.4 \% .^{20-28,44}$ Inadequate seal is mostly preventable by ensuring sufficient overlap of graft components during the initial EVAR procedure, particularly in case severe tortuosity of the iliac arteries, which result in significantly increased forces on the graft-to-graft sealing site. The presence of a Type-III endoleak always implies the need for a secondary intervention. There is little debate on the preferred treatment of Type-III endoleaks, namely elimination by using an additional stent graft component to bridge the defect.

\section{Type-IV endoleak}

Type-IV endoleaks are defined by passage of blood or fluid through the graft fabric due to porosity, a phenomenon that is recognised in the early period of stent grafting as generally taking place immediately after implantation on the final angiography. ${ }^{45}$ In general Type-IV 
endoleaks disappear spontaneously and are no longer seen at the first surveillance CTangiography. Therefore they are of no clinical importance, consequently requiring no secondary intervention. The use of less porous fabrics in newer generations of stentgrafts declined the incidence of Type-IV endoleaks. ${ }^{46}$

\section{Migration}

Movement of an endograft towards distally following blood flow direction, or distal migration, has been demonstrated after EVAR. Migration is considered relevant if a stentgraft moved $>10 \mathrm{~mm}$ relative to anatomical landmarks or any migration leading to symptoms or requiring therapy. ${ }^{19}$ Risk of migration increases over time and can result in loss of device fixation proximally, distally, or at modular junctions. ${ }^{46}$ Stent graft migration may result in Type-I and -III endoleaks, with their risk of aneurysm rupture, but may also be associated with kinking, stenosis or occlusion of the respective stentgraft limbs. The reported incidence of migration varies between $1 \%$ and $42 \% .{ }^{47-50}$ Factors that contribute to migration are AAA morphology and post-operative neck enlargement by on-going disease, but also characteristics of the stentgraft used..$^{10}$ Design of the latest generation of stentgrafts incorporate hooks that fixate the stentgraft into the arterial wall, decreasing the incidence of proximal migration. In cases of shortening or loss of proximal sealing length ancillary devices that deploy endostaples may be used to secure endografts to the aortic wall or to secure components together.

\section{Limitation to EVAR suitability}

According to several studies, the success of EVAR is closely dependent on AAA's morphology and dimensions. ${ }^{53,54}$ Severely angulated or short infrarenal aortic necks and small, tortuous or calcified iliac arteries are related to adverse EVAR outcomes, and thus guidelines for commercially available stentgrafts indicate use within a specific aneurysm morphology. A substantial proportion (40\%) of AAA patients that require repair fall outside these generally accepted inclusion criteria. ${ }^{55}$ This advanced disease state often with major comorbidity present an increased risk for open surgical repair. Global registries show that EVAR is performed in patients with anatomic features outside the recommended limits. 


\section{Improving stent grafts}

The technology of EVAR is a dynamic ever-changing endeavour. The challenge is to decrease complications and reinterventions while safely treating more complex anatomy, especially those cases unfit for open repair. Problems displayed in the early days with first generation stent grafts are addressed and solved in later designs. Substantial progress in device integrity has been made since $1991 .^{57-59}$ Endograft manufacturers continue to refine the stentgraft and its delivery system, making them easier to handle and eligible in a broader range of patients. Also experience of physicians has risen in the past 25 years. In contemporary practice, experienced vascular surgeons with latest-generation of stentgrafts dare to make way on less favourable anatomy and still improve in outcome measures.

\section{ENGAGE Registry}

Medtronic Endovascular (Santa Rosa, California, USA) designed its latest generation Stent Graft System, the Endurant (II), to address the limitations of previous stentgraft designs. It received CE mark approval in July 2008 and FDA approval in December 2010. After a safety assessment trial conducted in Europe, ${ }^{61}$ the Endurant Stent Graft Natural Selection Global Postmarket Registry (ENGAGE) was undertaken to quantify the performance of this endograft within the context of contemporary, real world use. Great efforts were made to ensure reliability and completeness of data. The Aorta Research Group of the Catharina Hospital Eindhoven had unrestricted access to the raw data of ENGAGE in order to perform all analysis needed for this thesis. 


\section{AIM OF THIS THESIS}

- To describe the real world, global experience in early outcome of endovascular AAA repair with the Endurant Stent Graft in a large, contemporary, and prospective series of AAA patients.

- To compare the early outcome of urgent EVAR for symptomatic AAAs versus elective EVAR for asymptomatic AAAs, within the context of contemporary, real world, global experience with a latest generation of endograft device.

- To assess the effects and feasibility of anaesthesia type on the perioperative outcome of elective EVAR in a large, global, multi-centre prospective observational study.

- To assess the feasibility of a strategy in which coverage of the internal iliac artery during EVAR is routinely performed without coil embolisation, and compare the early and longer term effects of coverage of the internal iliac artery with and without prior coil embolisation.

- To give an overview and discussion on the management strategies of reinterventions for explicit stent graft related complications.

- To design a study that collects real-world data on prospectively enrolled AAA-patients with challenging anatomy of the infrarenal neck treated with a latest generation of endograft device.

\section{OUTLINE OF THIS THESIS}

This thesis consists of three parts. Part one focuses on the perioperative outcome of patients included in the ENGAGE registry (chapter 2, 3 and 4). The focus in part two of this thesis is on the coverage of the ostium of the internal iliac artery during EVAR with and without coil embolisation of the internal iliac artery (chapter 5 and 6). In part three of this thesis the focus is on the management and the prevention of technical complications of EVAR (chapter 7 and 8). At the end of this thesis main findings, limitations and future perspectives are discussed and summarised (chapter 9 and 10). 


\section{PART ONE - Perioperative outcome in contemporary EVAR practice}

Chapter 2 reports on the perioperative and one-year, real-world performance of the Endurant Stent Graft for the treatment of elective AAA-patients that were prospectively enrolled in the ENGAGE Registry. Baseline patient demographics and risk factors, as well as aneurysm morphology was extensively tabulated to achieve a broad insight on the consistency of patients in the ENGAGE cohort, which enables to make meaningful comparisons with historic cohorts. Effective treatment outcome was approached as a composite of both clinical outcomes of patients, and technical outcomes of the stent graft in excluding the aneurysm while maintaining patency without the occurrence of secondary interventions.

Historically, the reported outcome of symptomatic AAA repair has been consistently worse than that of elective AAA repair. ${ }^{62,63}$ The inability to take the necessary time for an adequate preoperative work-up is suggested to be one of the reasons for this difference. ${ }^{63}$ We emphasized that with the use of new devices with fewer sizing constraints within the context of contemporary practice this effect might be superseded. In Chapter 3 we compared symptomatic and asymptomatic AAA patients from the ENGAGE cohort in a multivariate regression model to determine the differences in procedural and perioperative outcomes.

Chapter 4 presents a large, global, multi-centre prospective observational study that compared different types of anaesthesia applied in EVAR cases. The feasibility of EVAR with local and regional anaesthesia has been proven already in $1999 .{ }^{65}$ But, after 20 years of practice, there is still no consensus about which type of anaesthesia is most suitable for EVAR. According to the European and American guidelines, the use of locoregional anaesthesia is preferred. ${ }^{11,66}$ Nevertheless, EVAR is still mainly conducted under general anaesthesia. ${ }^{67}$ Technical operation success and thirty-day clinical outcomes between types of anaesthesia were evaluated in this chapter.

\section{PART TWO - Coverage of the internal iliac artery}

Pre-emptive coil embolization is more or less standard practice in case stentgraft coverage of the internal iliac artery is planned, ${ }^{68,69}$ even though no solid evidence is available on its necessity in terms of preventing Type-II endoleaks. To challenge this routine a strategy was 
applied in the Catharina Hospital Eindhoven in which coverage of the internal iliac artery during EVAR was routinely performed without coil embolization. Chapter 5 describes an analysis of the technical and clinical outcomes of this new strategy in a consecutive series of patients. It also contains a literature review of the occurrence of Type-I and -II endoleaks, and incidence of buttock claudication following stent coverage without prior coil embolization.

To find out if the omission of coil embolization leads to an increased risk for coverage related endoleaks and reinterventions a retrospective analysis was performed on data from the ENGAGE Registry. Chapter 6 presents a comparison of the early and longer-term effects of coverage of the internal iliac artery during EVAR with and without prior coil embolisation.

\section{PART THREE - Technical complications of EVAR: how to manage and how to prevent}

Different from open surgical aneurysm repair, EVAR procedures come with their unique technical complications. Chapter 7 gives an overview of all types of endoleaks and other technical graft failures, and different treatment options to manage these EVAR-specific complications that are often associated to AAA morphology. ${ }^{54,55}$ To minimize these technical complications all commercially available endografts come with stringent instructions for use (IFU) criteria. These stringent criteria exclude a substantial proportion (40\%) of patients requiring $A A A$ repair, ${ }^{56}$ while they may not even apply to the latest generation of devices. Chapter 8 describes the rationale and design of the EAGLE Registry (Endurant for challenging Anatomy: GLobal Experience), a study that collects real-world data on prospectively enrolled AAA-patients with challenging anatomy of the infrarenal neck treated with a latest generation of endograft device.

An overview of the main findings and limitations of this thesis, and future perspectives are discussed and outlined in Chapter 9. Thereafter, summarized in Chapter 10. 
1. Hager A, Kaemmerer $H$, Rapp-Nernhardt $U$, Blucher S, Rapp K, Bernhardt TM, et al. Diameters of the aorta throughout life as measeured with helical computed tomography. J Thorac Cardiovasc Surg. 2002; 123: 1060-6.

2. Van der Vliet JA, Boll AP. Abdominal aortic aneurysm. Lancet. 1997; 349:863-66.

3. Sakalihasan N, Limet R, Defawe OD. Abdominal aortic aneurysm. Lancet. 2005; 365: 1577-89.

4. Anjum A, von Allmen R, Greenhalgh R, Powell JT. Explaining the decrease in mortality from abdominal aortic aneurysm rupture. Br J Surg. 201 May;99(5):637-45.

5. Fillinger MF, Marra SP, Raghavan ML, Kennedy FE. Prediction of rupture risk in abdominal aortic aneurysm during observation: wall stress versus diameter. J vasc Surg. 2003; 37(4): 724-32.

6. Best VA, Price JF, Fowkes FG. Persistent increase in the incidence of abdominal aortic aneurysm in Scotland, 1981-2000. Br J Surg. 2003; 90:1510-5.

7. Acosta S, Ogren $\mathrm{M}$, Brengston $\mathrm{H}$, et al. Increasing incidence of ruptured abdominal aortic aneurysm: a population-based study. J Vasc Surg. 2006; 44: 237-43.

8. Melton LJ, 3rd, Bickerstaff LK, Hollier LH, et al. Changing incidence of abdominal aortic aneurysms: a population-based study. Am J Epidemiol. 1984; 120: 379-86.

9. DeBakey ME, Cooley DA. Successful resection of aneurysm of thoracic aorta and replacement by graft. JAMA. 1953; 152: 673-6.

10. Lederle FA, Johnson GR, Wilson SE, Chute EP, Littooy FN, Bandyk D, et al. Prevalence and associations of abdominal aortic aneurysm detected through screening. Aneurysm Detection and Management (ADAM) Veterans Affairs Cooperative Study Group. Ann Intern Med 1997;126:441-9.

11. Moll FL, Powell JT, Fraedrich G, Verzini F, Haulon S, Waltham M, et al. Management of abdominal aortic aneurysms clinical practice guidelines of the European society for vascular surgery. Eur J Vasc Endovasc Surg 2011 Jan;41 Suppl 1:S1-S58.

12. Dubost C, Allary M, Oeconomos N: Treatment of aortic aneurysms; removal of the aneurysm; re-establishment of continuity by grafts of preserved human oarta. Mem Acad Chir (Paris). 1951; 77: 381-83.

13. Conrad MF, Crawford RS, Pedraza JD et al. Long-term durability of open abdominal aortic aneurysm repair. J Vasc Surg 2007; 46: 669-75.

14. Greenhalgh RM, Brown LC, Kwong GP et al. Comparison of endovascular aneurysm repair with open repair in patients with abdominal aortic aneurysm (EVAR trial 1), 30-day operative mortality results: randomised controlled trial. Lancet 2004; 364:843-848.

15. Parodi JC, Palmaz JC, Barone HD. Transfemoral intraluminal graft implantation for abdominal aortic aneurysms. Ann Vasc Surg 1991;5:491-9.

16. Volodos NL, Karpovich IP, Troyan VI, Kalashnikova Yu V, Shekhanin VE, Ternyuk NE, et al. Clinical experience of the use of selffixing synthetic prostheses for remote endoprosthetics of the thoracic and the abdominal aorta and iliac arteries through the femoral artery and as intraoperative endoprosthesis for aorta reconstruction. Vasa Suppl 1991;33:93-5.

17. Ten Bosch JA, Cuypers PWM, van Sambeek MRHM, Teijink JAW. Current insights in endovascular repair of ruptured abdominal 
aortic aneurysms. Eurolntervention. 2011; 7: 852-8.

18. Drury D, Michaels JA, Jones L, Ayiku L. Systematic review of recent evidence for the safety and efficacy of elective endovascular repair in the management of infrarenal abdominal aortic aneurysm. Br J Surg. 2005; 92: $937-46$

19. Chaikof EL, Blankensteijn JD, Harris PL, et al. Reporting standards for endovascular aortic aneurysm repair. J Vasc Surg. 2002;35:10481060.

20. Pitton $M B$, Scheschkowski $T$, Ring $M$, Herber $S$, Oberholzer K, Leicher-Düber A, Neufang A, Schmiet W, Düber C. Ten-year follow-up of endovascular aneurysm treatment with Talent stent-grafts. Cardiovasc Intervent Radiol 2009;32:906-17.

21. Subramanian K, Woodburn KR, Travis SJ, Hancock J. Secondary interventions following endovascular repair of abdominal aortic aneurysm. Diagn Interv Radiol 2006;12:99-104.

22. Conrad MF, Adams WB, Guest JM, Paruchuri V, Brewster DC, LaMuraglia GM et al. Secondary intervention after endovascular abdominal aortic aneurysm repair. Ann Surg 2009;250:383-9.

23. Mertens J, Houthoofd S, Daenens K, Fourneau I, Maleux G, Lerut P, Nevelsteen A. Long-term results after endovascular abdominal aortic aneurysm repair using the Cook Zenith endograft. J Vasc Surg 2011;54:48-57.

24. Brown LC, Powell JT, Thompson SG, Epstein DM, Sculpher MJ, Greenhalgh RM. The UK EndoVascular Aneurysm Repair (EVAR) trials: randomised trials of EVAR versus standard therapy. Health Technol Assess 2012:16.

25. Chisci E, Setacci F, lacoponi F, de Donato G, Cappelli A, Setacci C. Surveillance imaging modality does not affect detection rate of asymptomatic secondary interventions following EVAR. Eur J Vasc Endovasc Surg 2012;43:276-81.
26. Nevala T, Biancari F, Manninen H, Aho PS, Matsi $P$, Mäkinen $K$ et al. Finish multicenter study on the midterm results of use of the Zenith stent-graft in the treatment of an abdominal aortic aneurysm. J Vasc Interv Radiol 2009;20:448-54.

27. Baril DT, Silverberg D, Ellozy SH, Carroccio A, Jacobs TS, Sachdev U et al. Endovascular stentgraft repair of failed endovascular abdominal aortic aneurysm repair. Ann Vasc Surg 2008;22:30-6.

28. Schermerhorn ML, O'Malley AJ, Jhaveri A, Cotterill P, Pomposelli F, Landon BE. Endovascular vs. open repair of abdominal aortic aneurysms in the medicare population. N Eng J Med 2008;358:464-74.

29. Aburahma AF, Campbell JE, Mousa AY, Hass SM, Stone PA, Jain A, et al. Clinical outcomes for hostile versus favorable aortic neck anatomy in endovascular aortic aneurysm repair using modular devices. J Vasc Surg 2011;54:13-21.

30. Londero $H$, Lev $G$, Bertoni $H$, et al. Safety and feasibility of balloon-expandable stent implantation for the treatment of type I endoleaks following endovascular aortic abdominal aneurysm repair. Eurolntervention 2011; 6: 740-3.

31. Arthurs ZM, Lyden SP, Rajani RR, et al. Longterm outcomes of Palmaz stent placement for intraoperative type la endoleak during endovascular aneurysm repair. Ann Vasc Surg 2011; 25:120-6.

32. Kim JK, Noll RE, Jr., Tonessen BH, et al. A technique for increased accuracy in the placement of the "giant" Palmaz stent for treatment of type IA endoleak after endovascular abdominal aneurysm repair. J Vasc Surg 2008; 48: 755-7.

33. Rajani RR, Arthurs ZM, Srivastava SD, et al. Repairing immediate proximal endoleaks during abdominal aortic aneurysm repair. J Vasc Surg 2011; 53: 1174-7. 
34. Rech T, Dias N: Treatment of endoleaks: techniques and outcome. J Cardiovasc Surg (Torino) 2012; 53: 91-9.

35. van Marrewijk C, Buth J, Harris PL, Norgren L, Nevelsteen A, Wyatt MG. Significance of endoleaks after endovascular repair of abdominal aortic aneurysms: the EUROSTAR experience. J Vasc Surg 2002;35:461-73.

36. Silverberg D, Baril DT, Ellozy SH, Carroccio A, Greyrose SE, Lookstein RA et al. An 8-year experience with type II endoleaks: natural history suggests selective intervention is a safe approach. J Vasc Surgery 2006;44:453-9.

37. Rosen RJ, Green RM. Endoleak management following endovascular aneurysm repair. J Vasc Interv Radiol 2008;19(suppl):S37-S43.

38. Resch T, Ivancev $\mathrm{K}$, Lindh $\mathrm{M}$, Nyman $\mathrm{U}$, Brunkwall J, Malina $M$ et al. Persistent collateral perfusion of abdominal aortic aneurysm after endovascular repair does not lead to progressive change in aneurysm diameter. J Vasc Surg 1998;28:242-9.

39. Görich J, Rilinger N, Sokiranski R, Krämer S, Schütz A, Sunder- Plassmann $L$ et al. Embolization of type II endoleaks fed by the inferior mesenteric artery: using the superior mesenteric artery approach. J Endovasc Ther 2000;7:297-301.

40. Rayt HS, Sandford RM, Salem M, et al. Conservative management of type 2 endoleaks is not associated with increased risk of aneurysm rupture. Eur J Vasc Endovasc Surg 2009; 38: 718-23.

41. Stavropolous SW, Park J, Fairman R, et al. Type 2 endoleak embolization comparison: translumbar embolization versus modified transarterial embolization. J Vsc Interv Radiol 2006; 44: 453-9.

42. Nevala T, Biancari F, Manninen $H$, Aho PS, Matsi $P$, Mäkinen $K$ et al. Type II endoleak after endovascular repair of abdominal aortic aneurysm: effectiveness of embolization. Cardiovasc Interv Radiol 2010;33:278-84.
43. Sarac TP, Gibbons C, Vargas L, et al. Long-term follow-up of type II endoleak embolization reveals the need for close surveillance. J Vasc Surg 2012; 55:33-40.

44. Hobo R, Buth J, on behalf of EUROSTAR collaborators. Secondary interventions following endovascular abdominal aortic aneurysm repair using current endografts. A EUROSTAR report. J Vasc Surg 2006;43:896902.

45. Matsumura JS, Ryu RK, Ouriel K. Identification and implications of transgraft microleaks after endovascular repair of aortic aneurysms. J Vasc Surg 2001;34:190-7.

46. Buth J, Harris PL, van Marrewijk C, Fransen G. The significance and management of different types of endoleaks. Semin Vasc Surg 2003;16:95-102.

47. Mehta M, Sternbach Y, Taggert JB, Kreienberg PB, Roddy SP, Paty PSK et al. Long-term outcomes of secondary procedures after endovascular aneurysm repair. J Vasc Surg 2010;52:1442-8.

48. Litwinski RA, Donayre CE, Chow SL, Song TK, Kopchok G, Walot I L et al. The role of aortic neck dilation and elongation in the etiology of stent graft migration after endovascular abdominal aortic aneurysm repair with a passive fixation device. J Vasc Surg 2006;44:1176-81.

49. Thomas BG, Sanchez LA, Geraghty PJ, Rubin BG, Money SR, Sicard GA. A comparative analysis of the outcomes of aortic cuffs and converters for endovascular graft migration. J Vasc Surg 2010;51:1373-80.

50. Quinney BE, Parmar GM, Nagre SB, Patterson $M$, Passman MA, Taylor $S$ et al. Long-term single institution comparison of endovascular aneurysm repair and open aortic aneurysm repair. J Vasc Surg 2011;54:1592-8.

51. De Vries JP, Schrijver A, Van den Heuvel DAF, et al. Use of endostaplers to secure migrated endografts and proximal cuffs after failed 
endovascular abdominal aortic aneurysm repair. J Vasc Surg 2011; 54: 1792-4.

52. Katsargyris A, Oikonomou K, Nagel S, et al. Endostaples: are they the solution to graft migration and Type I endoleaks? J Cardiovasc Surg (Torino). 2015; 56(3): 363-8.

53. Zarins CK, Bloch DA, Crabtree T, et al. Stent graft migration after endovascular aneurysm repair: importance of proximal fixation. J Vasc Surg 2003; 38: 1264-72; discussion 1272.

54. Ouriel K, Tanquilut E, Greenberg RK, Walker E. Aortoiliac morphologic correlations in aneurysms undergoing endovascular repair. J Vasc Surg 2003;38:323-8.

55. Schanzer A, Greenberg RK, Hevelone N, et al. Predictors of abdominal aortic aneurysm sac enlargement after endovascular repair. Circulation 2011; 123: 2848-55.

56. Moise MA, Woo EY, Velazquez OC, Fairman RM, Golden MA, Mitchell ME, et al. Barriers to endovascular aortic aneurysm repair: past experience and implications for future device development. Vasc Endovascular Surg 2006;40:197-203.

57. Stokmans RA, Teijink JA, Forbes TL, et al. Early Results from the ENGAGE Registry: Real-world Performance of the Endurant Stent Graft for Endovascular AAA Repair in 1262 Patients. Eur J Vasc Endovasc Surg 2012; 44: 369 - 75.

58. Prinssen $\mathrm{M}$, Verhoeven EL, Buth J, Cuypers PW, van Sambeek MR, Balm $R$, et al. A randomized trial comparing conventional and endovascular repair of abdominal aortic aneurysms. N Engl J Med 2004;351:1607-18.

59. Blankensteijn JD, de Jong SE, Prinssen $M$, van der Ham AC, Buth J, van Sterkenburg SM, et al. Two-year outcomes after conventional or endovascular repair of abdominal aortic aneurysms. N Engl J Med 2005 Jun 9;352(23):2398-405.

60. EVAR trial participants. Endovascular aneurysm repair versus open repair in patients with abdominal aortic aneurysm (EVAR trial 1): randomised controlled trial. Lancet 2005 Jun 25;365(9478):2179-86.

61. Rouwet EV, Torsello G, de Vries JP, Cuypers P, van Herwaarden JA, Eckstein $\mathrm{HH}$, et al. Final results of the prospective European trial of the Endurant stent graft for endovascular abdominal aortic aneurysm repair. Eur J Vasc Endovasc Surg 2011;42:489-97.

62. Greenhalgh RM, Brown LC, Powell JT, et al. Endovascular versus open repair of abdominal aortic aneurysm. N Engl J Med 2010; 362: 1863-71

63. Bown MJ, Sutton AJ, Bell PR, Sayers RD. A meta-analysis of 50 years of ruptured abdominal aortic aneurysm repair. $\mathrm{Br} J$ Surg 2002 Jun;89(6):714-30.

64. Leo E, Biancari F, Kechagias A, Ylonen K, Rainio $P$, Romsi $P$, et al. Outcome after emergency repair of symptomatic, unruptured abdominal aortic aneurysm: results in 42 patients and review of the literature. Scand Cardiovasc J 2005 Apr;39(1-2):91-5.

65. Henretta JP, Hodgson KJ, Mattos MA, et al. Feasibility of endovascular repair of abdominal aortic aneurysms with local anesthesia with intravenous sedation. J Vasc Surg. 1999;29:793-798.

66. Chaikof EL, Brewster DC, Dalman RL, et al. The care of patients with an abdominal aortic aneurysm: the Society for Vascular Surgery practice guidelines. J Vasc Surg. 2009;50(4 suppl):S2-S49.

67. Ruppert V, Leurs LJ, Steckmeier B, et al. Influence of anesthesia type on outcome after endovascular aortic aneurysm repair: an analysis based on EUROSTAR data. J Vasc Surg. 2006;44:16-21.

68. Rayt HS, Bown MJ, Lambert KV, Fishwick NG, McCarthy MJ, London NJ, et al. Buttock claudication and erectile dysfunction after internal iliac artery embolization in patients 
prior to endovascular aortic aneurysm repair. Cardiovasc Intervent Radiol 2008;31:728-34.

69. Ghosh J, Murray D, Paravastu S, Farquharson
F, Walke
$\mathrm{MG}$

Contemporary management of aorto-iliac aneurysms in the endovascular era. Eur J Vasc Endovasc Surg 2009;37:182-8. 

PART ONE

PERIOPERATIVE OUTCOME IN

CONTEMPORARY PRACTICE 



\section{CHAPTER 2}

EARLY RESULTS FROM THE ENGAGE

REGISTRY: REAL-WORLD PERFORMANCE

OF THE ENDURANT STENT GRAFT FOR

ENDOVASCULAR AAA REPAIR IN 1262

PATIENTS

R.A. Stokmans

J.A.W. Teijink

T.L. Forbes

D. Böckler

P.J. Peeters

V. Riambau

P.D. Hayes

M.R.H.M van Sambeek

European Journal of Vascular and Endovascular Surgery 2012 October; 44(4): 369-375 


\section{ABSTRACT}

Objective: The ENGAGE registry was undertaken to examine the real world outcome after endovascular AAA repair (EVAR) with the Endurant Stent Graft in a large, contemporary, global series of patients.

Methods: From March 2009 to April 2011, 1262 AAA patients (89.6\% men; mean age 73.1 years, range 43-93) were enrolled from 79 sites in 30 countries and treated with Endurant. Results are described following the reporting standards for EVAR. Follow-up data was tabulated for all 1262 patients at 30-days and for the first 500 patients at one-year follow-up.

Results: Intraoperative technical success was achieved in $99.0 \%$ of cases. Within 30 days, adverse events were reported in $3.9 \%$ of patients, including a $1.3 \%$ mortality rate. Type-I or -III endoleaks were identified in $1.5 \%$ of cases. Estimated overall survival, aneurysm-related survival, and freedom from secondary interventions at 1year were $91.6 \%, 98.6 \%$, and $95.1 \%$, respectively. At one-year, aneurysm size increased $\geq 5 \mathrm{~mm}$ in $2.8 \%$ and decreased $\geq 5 \mathrm{~mm}$ in $41.3 \%$ of cases.

Conclusion: Early results from this real world, global experience are promising and indicate that endovascular AAA repair with the Endurant stent graft is safe and effective across different geographies and standards of practice. Longer-term follow-up is necessary to assess durability of these results. 


\section{INTRODUCTION}

Abdominal aortic aneurysms (AAA) are a significant health challenge with an estimated incidence of $20-40$ cases per 100,000 population per year. Patients present with varying levels of risk due to aneurysm size, age, and concurrent comorbidities. ${ }^{1}$ Since Parodi $^{2}$ and Volodos $^{3}$ published the first transfemoral intraluminal graft implantations for AAA in 1991, the practice of endovascular aneurysm repair (EVAR) has continually improved. Today, this approach is a generally accepted alternative to conventional open surgical repair due to reductions in perioperative mortality and morbidity, blood loss, use of the intensive care unit (ICU), and length of hospital stay. ${ }^{4}$ Several randomised trials have confirmed these benefits, and one trial partly confirmed these benefits except for perioperative mortality and major adverse events. ${ }^{8}$

The success of EVAR, however, is dependent upon patient specific factors, including morphology and dimensions of the aneurysm. Severely angulated or short infrarenal aortic necks and small, tortuous or calcified iliac arteries are related to adverse EVAR outcomes ${ }^{9}$, and thus guidelines for commercially available stent grafts indicate use within a specific range of anatomy. A substantial portion of AAA patients fall outside these generally accepted inclusion criteria $^{10}$, and their advanced disease state or major comorbidities present a high risk for open surgical repair. Therefore, there is a need for improved stent grafts and endovascular techniques to decrease complications and increase eligibility.

Medtronic Endovascular (Santa Rosa, California, USA) designed its latest generation product, the Endurant Stent Graft System, to address the limitations of previous stent graft designs. A small amplitude M-shaped proximal stent was designed to improve sealing at the proximal neck while potentially allowing for greater sizing flexibility. Radial strength was also improved while allowing a lower profile delivery system. The Endurant Stent Graft System received CE mark approval in July 2008 and FDA approval in December 2010. After a safety assessment trial conducted in Europe ${ }^{11}$, the Endurant Stent Graft Natural Selection Global Postmarket Registry (ENGAGE) was undertaken to quantify the performance of this recently released endograft within the context of contemporary, real world use. Herein, we report 
the perioperative and one-year results of this global, multicentre, prospective 1262-patient study of the Endurant Stent Graft System.

\section{METHODS}

\section{Patient Population}

Between March 2009 and April 2011, eligible patients from 79 sites in 30 countries (appendix) were enrolled in the ENGAGE registry. The study protocol strongly encouraged consecutive enrolment of at least five patients in a row in order to minimize selection bias. Ruptured AAAs were not considered for enrolment into ENGAGE. Prior to the index procedure, CTA imaging of the abdomen and pelvis was undertaken to determine the morphological eligibility for elective endovascular treatment with an Endurant Stent Graft. To reflect the real world clinical practice, eligibility criteria for participation were kept comprehensive. Although the study design included that individual morphological variables (proximal neck diameter and length, infrarenal and suprarenal angulation, and distal iliac fixation diameter and length) were consistent with Endurant's Instructions for Use (IFU) (Table 1), enrolment of patients who fell outside the IFU guidance was accepted.

\section{Table 1. Endurant ${ }^{\circledR}$ Indications for use}

\section{One of the following criteria:}

- Infrarenal neck length $\geq 10 \mathrm{~mm}$ with non-significant calcification, and/or non-significant thrombus in combination with $\leq 45^{\circ}$ suprarenal angulation and $\leq 60^{\circ}$ infrarenal angulation.

- Infrarenal neck length $\geq 15 \mathrm{~mm}$ with non-significant calcification, and/or non-significant thrombus in combination with $\leq 60^{\circ}$ suprarenal angulation and $\leq 75^{\circ}$ infrarenal angulation.

\section{And all of the following criteria:}

- Adequate iliac/femoral access

- Proximal AAA neck diameter $\geq 19 \mathrm{~mm}$ and $\leq 32 \mathrm{~mm}$

- Distal iliac fixation site diameter $\geq 8 \mathrm{~mm}$ and $\leq 25 \mathrm{~mm}$

- Distal non-aneurysmal iliac fixation length $\geq 15 \mathrm{~mm}$ bilaterally

Patients considered unlikely to adhere to the follow-up regimen and patients with concurrent trial participation were excluded from study enrolment. A signed consent for authorization of data release was required. The trial was conducted according to the 
Declaration of Helsinki and the International Conference on Harmonization (ICH) Good Clinical Practice (GCP) guidelines, and approved by local medical ethics committees.

\section{Study Procedure}

Technical specifications of the Endurant Stent Graft System have been published previously. ${ }^{11,12}$ Preoperatively each patient had a customized plan made with respect to stent diameters and length, dependent on their aortic and iliac dimensions. For optimal sealing it was advised to oversize the stent diameter by approximately $20 \%$ based on inner vessel diameter. All endovascular procedures were performed under fluoroscopic control. Local, regional or general anaesthetics, antibiotics, and heparin were administered according to each site's standard regimen. Arterial access was conducted by operator's preference. If necessary, coil embolization of the hypogastric or inferior mesenteric artery, or other adjunctive procedures were performed and documented before or during the implant procedure. A completion angiogram was performed to document the status after stent graft implantation.

\section{Imaging and Follow-up}

Follow-up was planned according to standard practice at each clinical site, with the exception of the requirement for 30-day and 1-year imaging studies No specific tests or procedures that fell outside a site's standard regimen for AAA follow-up were required. Diagnostic images were analysed at both time points for technical outcomes and AAA changes. The presence of endoleak was classified by type and recorded as well as changes in aneurysm size.

\section{Endpoints and definitions}

The ENGAGE registry was designed to assess effectiveness of the Endurant Stent Graft at 12months post-implantation, with follow-up extended to 5 years. This manuscript describes the initial procedural data and outcomes, the technical observations, adverse events and major adverse events (MAE) within 30 days and 12 months, along with stent graft migration and aneurysm expansion ( $>5 \mathrm{~mm}$ ) between 30 days and 12 months. 
The primary effectiveness endpoint was the initial procedural success, a composite of technical success and clinical success at the time of the index procedure. Technical success was defined as successful delivery and deployment of the Endurant Stent Graft in the planned position without unintentional coverage of one or both internal iliac arteries or visceral aortic branches and with successful removal of the delivery system. In case of primary conversion, technical success failed. Initial clinical success was defined as technical success without intra-operative death or presence of a Type-I/III endoleak at the conclusion of the index procedure.

The secondary endpoints consisted of technical observations, adverse events and major adverse events (MAE). Technical observations included: stent graft kinking; stent graft wire form fracture; suprarenal bare stent fracture or detachment from fabric; occlusion (defined as $100 \%$ obstruction); stenosis (defined as partial obstruction); and presence of an endoleak. Secondary conversion to open repair, aneurysm rupture and secondary interventions, were stated as adverse events. All-cause mortality, bowel ischemia, myocardial infarction, paraplegia, renal failure (requiring dialysis or elevated serum creatinine two times baseline value), respiratory failure (need for $>24$ hours mechanical ventilation postoperatively or reintubation for any reason), stroke and procedural blood loss $\geq 1000 \mathrm{cc}$ were noted as MAEs. All deaths within 30 days postoperative were judged to be aneurysm-related. Allcause mortality, aneurysm-related mortality and secondary procedures were separately assessed as one-year Kaplan-Meier estimates.

\section{Data management, quality control and statistical analysis}

Data collected on each patient was recorded on a web-based electronic case report form (Veracity $^{\mathrm{TM}}$ Clinical Asset Management, MERGE Healthcare, Chicago, IL, USA) to ensure reliable data collection, data management, secure authentication and traceability. Data were entered by, or under supervision of, sites' principal investigators. Data management and biostatistical analysis was performed by the Medtronic Biostatistics \& Data-Management Department (Santa Rosa, CA, USA). It reviewed $100 \%$ of data to detect missing or inconsistent data to generate queries to the investigators for resolution. In addition to this, Medtronic Bakken Research Centre BV (Maastricht, The Netherlands) randomly monitored over $40 \%$ of patients' source documentation against the data entered. They also performed 
a verification of all 1,262 patient informed consents and essential study documents at each site.

All variables are reported descriptively with no hypothesis testing. For categorical variables, frequency and percentage were calculated. For continuous variables, mean, standard deviation, minimum, and maximum were calculated. A per protocol analysis was performed for the technical observations. All other variables were evaluated on an intention-to-treat basis.

\section{RESULTS}

From March 2009 until April 2011, 1266 patients from 79 sites in 30 countries were initially recorded in the database. Four patients however, were excluded from the study for the following reasons; 1 patient refused immediate treatment, but underwent emergency EVAR for a ruptured AAA three months later; 1 patient underwent open surgical treatment instead, because of unsuitable anatomy on preoperative imaging; 1 patient was operated on at a non-participating site; and with 1 patient the informed consent form was missing. Data for the remaining 1262 patients comprise the basis of this report. At time of writing, a subcohort of the first 500 operated patients (39.6\%) had the opportunity to complete 12-month follow-up. Their data form the basis of the one-year outcome analysis.

\section{Baseline characteristics}

Patients' demographics and risk factors (Table 2) were typical of an AAA population. They were predominantly male, elderly, and ASA (American Society of Anaesthesiologists) class II or III, with a high prevalence of cardiovascular risk factors and comorbidities. The primary indication for EVAR was an AAA diameter $>5 \mathrm{~cm}$ in $88.1 \%$ of cases and $83.9 \%$ of patients were asymptomatic. Table 3 describes baseline aneurysm characteristics. The mean maximum AAA diameter was $60.3 \pm 11.7 \mathrm{~mm}$. The proximal aortic neck had a mean diameter of $23.7 \pm 3.6 \mathrm{~mm}$, with a non-aneurysmal length of $27.0 \pm 12.4 \mathrm{~mm}(27(2.2 \%)$ patients with neck length $<10 \mathrm{~mm}$ ) and a mean infrarenal neck angulation of $30.3 \pm 23.8^{\circ}$. Notably, 226 patients (17.9\%) were implanted outside of IFU criteria (Table 4). 
Table 2. Patient demographics and risk factors (ITT analysis)

\begin{tabular}{|c|c|c|}
\hline Variable & & $\mathrm{N}=1262^{\mathrm{a}}$ \\
\hline Age (years) Mean \pm SD (range) & $73.1 \pm 8.1$ & $(43-93)$ \\
\hline \multicolumn{3}{|l|}{ Gender } \\
\hline Male & $89.6 \%$ & $(1131 / 1262)$ \\
\hline Female & $10.4 \%$ & $(131 / 1262)$ \\
\hline \multicolumn{3}{|l|}{ ASA Classification } \\
\hline Class I & $6.1 \%$ & $(77 / 1261)$ \\
\hline Class II & $41.8 \%$ & $(527 / 1261)$ \\
\hline Class III & $41.5 \%$ & $(523 / 1261)$ \\
\hline Class IV & $10.6 \%$ & $(134 / 1261)$ \\
\hline \multicolumn{3}{|l|}{ Symptoms } \\
\hline A-symptomatic AAA & $83.9 \%$ & $(1059 / 1262)$ \\
\hline Symptomatic AAA & $16.1 \%$ & $(203 / 1262)$ \\
\hline \multicolumn{3}{|l|}{ Indication by AAA diameter } \\
\hline$>5 \mathrm{~cm}$ & $88.1 \%$ & $(1112 / 1262)$ \\
\hline $4-5 \mathrm{~cm}$ ( $\geq 0.5 \mathrm{~cm}$ increase in last 6 months) & $6.3 \%$ & $(79 / 1262)$ \\
\hline$\geq 1.5 x$ reference infrarenal aorta & $2.9 \%$ & $(42 / 1262)$ \\
\hline Other & $2.3 \%$ & $(29 / 1262)$ \\
\hline \multicolumn{3}{|l|}{ Risk Factors } \\
\hline Tobacco use & $49.3 \%$ & $(607 / 1231)$ \\
\hline Hypertension & $75.4 \%$ & $(939 / 1245)$ \\
\hline Hyperlipidaemia & $60.4 \%$ & $(718 / 1188)$ \\
\hline Diabetes & $19.0 \%$ & $(236 / 1244)$ \\
\hline Cancer & $20.5 \%$ & $(254 / 1241)$ \\
\hline \multicolumn{3}{|l|}{ Cardiac disease } \\
\hline Myocardial infarction (MI) & $26.3 \%$ & $(318 / 1210)$ \\
\hline Arrhythmia & $16.0 \%$ & $(198 / 1234)$ \\
\hline Coronary artery disease (CAD) & $34.6 \%$ & $(422 / 1218)$ \\
\hline Cardiac revascularisation & $27.1 \%$ & (337/1244) \\
\hline Pulmonary disease & $25.1 \%$ & $(311 / 1241)$ \\
\hline Renal insufficiency & $15.3 \%$ & $(191 / 1251)$ \\
\hline \multicolumn{3}{|l|}{ Cerebrovascular disease } \\
\hline Transient ischaemic attack (TIA) & $4.9 \%$ & (61/1249) \\
\hline Cerebral vascular accident (CVA) & $5.3 \%$ & $(67 / 1255)$ \\
\hline Gastro-intestinal complications & $19.5 \%$ & $(246 / 1261)$ \\
\hline
\end{tabular}

Abbreviations: ITT, Intension To Treat; ASA, American Society of Anaesthesiologists; AAA, Abdominal Aortic Aneurysm.

a Denominator differs when there are missing values

\section{Intraoperative outcome}

The procedure was performed under general, regional and local anaesthesia in, respectively, $62.3 \%, 26.2 \%$, and $11.5 \%$ of cases. The mean procedural duration was $99.5 \pm 45.0$ minutes (range 20-387 minutes), with a mean total fluoroscopic time of 20.5 \pm 12.4 minutes (range 092 minutes) and a mean contrast volume used of $130.7 \pm 70.6 \mathrm{ml}$ (range 0-400 ml). Mean intra-operative blood loss was $208.4 \pm 220.1 \mathrm{ml}$ (range 0-2700 ml). Intensive care unit (ICU) admission rate was $34.2 \%$, and $6.0 \%$ were admitted longer than 24 hours. The mean hospital stay from the date of the initial procedure was 4.83 \pm 5.07 days (median 4.00; range 0.5-68 days). 
Table 3. Baseline aneurysm characteristics (ITT analysis)

\begin{tabular}{|c|c|c|}
\hline Variable & Mean \pm SD & $\begin{array}{l}\mathrm{N}=1262 \\
\text { (range) }\end{array}$ \\
\hline Maximum AAA diameter (mm) & $60.3 \pm 11.7$ & $(30-118)$ \\
\hline Proximal neck diameter (mm) & $23.7 \pm 3.6$ & $\left(15-45^{a}\right)$ \\
\hline Proximal non-aneurysmal neck length (mm) & $27.0 \pm 12.4$ & $\left(0^{b}-80\right)$ \\
\hline \multicolumn{3}{|l|}{ Distal iliac fixation site diameter (mm) } \\
\hline Right & $14.1 \pm 3.6$ & $(2-29)$ \\
\hline Left & $13.8 \pm 3.5$ & $(6-30)$ \\
\hline Infrarenal neck angle $\left({ }^{\circ}\right)$ & $30.3 \pm 23.8$ & $(0-130)$ \\
\hline$\leq 60^{\circ}$ & $89.8 \%$ & \\
\hline $60-75^{\circ}$ & $6.0 \%$ & \\
\hline Suprarenal neck angle $\left({ }^{\circ}\right)$ & $18.8 \pm 18.5$ & $(0-120)$ \\
\hline$\leq 45^{\circ}$ & $92.5 \%$ & \\
\hline $45-60^{\circ}$ & $4.5 \%$ & \\
\hline
\end{tabular}

Abbreviations: ITT, Intension To Treat; SD, Standard Deviation; AAA, abdominal aortic aneurysm

a Upper range of $45 \mathrm{~mm}$ : Tapered aortic neck, with a proximal diameter of $45 \mathrm{~mm}$, a diameter of $22 \mathrm{~mm}$ immediately above the aneurysm and a $15 \mathrm{~mm}$ non aneurysmal neck length.

b Lower range of $0 \mathrm{~mm}$ : Case performed with a "chimney technique".

Table 4. Patient implanted outside IFU (ITT analysis)

\begin{tabular}{|c|c|c|}
\hline Variable & & $\mathrm{N}=1262^{\mathrm{a}}$ \\
\hline Total implanted outside of IFU guidance & $17.9 \%$ & $(226 / 1262)$ \\
\hline Non-primary indications & $2.3 \%$ & $(29 / 1262)$ \\
\hline Proximal neck diameter $<19 \mathrm{~mm}$ or $>32 \mathrm{~mm}$ & $5.7 \%$ & $(72 / 1255)$ \\
\hline Proximal neck length $<10 \mathrm{~mm}$ & $2.2 \%$ & $(27 / 1248)$ \\
\hline Proximal neck length $\geq 10 \mathrm{~mm}$ and $<15 \mathrm{~mm}^{\mathrm{b}}$ & $2.1 \%$ & $(26 / 1248)$ \\
\hline Angulation suprarenal $>60^{\circ}$ or infrarenal $>75^{\circ}$ & $4.7 \%$ & (59/1248) \\
\hline Distal iliac fixation site diameter $<8 \mathrm{~mm}$ & $1.5 \%$ & $(19 / 1262)$ \\
\hline Distal iliac fixation site diameter $>25 \mathrm{~mm}$ & $0.6 \%$ & $(8 / 1262)$ \\
\hline \multicolumn{3}{|c|}{ Abbreviations: IFU, Instructions For Use; ITT, Intention To Treat. } \\
\hline \multicolumn{3}{|c|}{ Denominator differs when there are missing values } \\
\hline \multicolumn{3}{|c|}{${ }^{b}$ In combination with suprarenal angle $>45^{\circ}$ or infrarenal angle $>60^{\circ}$} \\
\hline
\end{tabular}

Technical success was achieved in 1250 patients (99.0\%). The Endurant was delivered to the planned location and successfully deployed in $99.4 \%$ of patients (Table 5). Attempts at endovascular repair were discontinued in $6(0.5 \%)$ patients: 4 cases with access problems due to tortuous or stenotic iliac arteries, two of whom were eventually converted to open repair after two and forty-nine days respectively. One patient required immediate conversion after unintentional coverage of both renal arteries, when the suprarenal stent was released before accurate placement of the covered stent. In another case, one of the proximal struts got stuck in the tip-capture portion of the delivery system, resulting in the inability to remove the device and necessitating immediate conversion to open surgery. There were no intra-operative deaths. 
Adjunctive procedures were performed before or during implant procedures in 96 (7.6\%) and 171 (13.5\%) cases, respectively (Table 5). Primarily coil embolization of the internal iliac artery or inferior mesenteric artery. Unplanned additional stents (other than Endurant) were placed in 44 (3.5\%) patients, mainly to resolve intraoperative Type I/III endoleaks. The final completion angiogram revealed Type-I and Type-III endoleaks in 14 (1.1\%) and 4 (0.3\%) cases, respectively, predominantly in patients with regular neck configurations. Among patients with Type-I endoleaks, one patient underwent secondary placement of a proximal cuff. Another patient died of a myocardial infarction before 30-day imaging was performed. In all remaining cases the endoleaks were absent at 30-day CTA and no secondary interventions were performed.

\section{Perioperative outcome}

One-month imaging was performed in $91.6 \%$ of the 1256 implanted patients (Table 6). One or more graft-related problems, including endoleaks, were reported in 191 (16.6\%) of these patients. Occlusion of one of the iliac limbs was reported in 23 patients (2.0\%) and graft stenosis was detected in 16 (1.4\%). Stent graft kinking occurred in 20 (1.7\%) cases. One report of occlusion of a (right) renal artery occurred. This did not result in a major clinical event or reintervention. There were no stent fractures or stent graft migrations reported in any patient through 30 days.

Endoleaks were present in 138 (12.0\%) patients at 30 days, of which in 7 cases the type could not be specified. Type-I and/or -III endoleaks were identified in 17 (1.5\%) patients, including one patient with both types present. One of the Type-I endoleaks had been observed at the time of operation and persisted to day 32, when it was successfully treated. The remaining endoleaks were newly diagnosed on the 30-day imaging study.

Among these, 8 Type-I endoleaks were treated with an extension or remodelling of the graft, 4 spontaneously resolved without intervention, and 2 had not yet reached the 12-month follow-up visit. The patient with both a Type-I and -III endoleak present had persistent endoleaks at the 12-month images, and was scheduled for reintervention thereafter. The other Type-III endoleak was resolved on follow-up images. 
Table 5. Initial procedural data and evaluation (ITT \& PP analysis)

\begin{tabular}{|c|c|c|}
\hline Placement Procedure (ITT) & & $\mathrm{N}=1262$ \\
\hline Pre-implant adjunctive procedure performed & $7.6 \%$ & $(96 / 1262)$ \\
\hline Coil embolization IIA & $4.3 \%$ & $(54 / 1262)$ \\
\hline Coil embolization IMA & $1.1 \%$ & $(14 / 1262)$ \\
\hline Other & $2.4 \%$ & $(30 / 1262)$ \\
\hline \multicolumn{3}{|l|}{ Associated procedures performed during procedure } \\
\hline Coil embolization IIA & $5.1 \%$ & $(64 / 1262)$ \\
\hline Coil embolization IMA & $0.6 \%$ & $(7 / 1262)$ \\
\hline Other & $8.7 \%$ & $(110 / 1262)$ \\
\hline None & $86.5 \%$ & $(1091 / 1262)$ \\
\hline \multicolumn{3}{|l|}{ Additional device used during implant procedure } \\
\hline Balloon catheter & $76.5 \%$ & $(965 / 1262)$ \\
\hline Unplanned & $6.0 \%$ & $(76 / 1262)$ \\
\hline Stent (other than Endurant) & $6.2 \%$ & $(78 / 1262)$ \\
\hline Unplanned & $3.5 \%$ & $(44 / 1262)$ \\
\hline Other & $6.8 \%$ & $(86 / 126)$ \\
\hline \multicolumn{3}{|l|}{ Placement of proximal end of device } \\
\hline With suprarenal stent crossing both renal arteries & $75.7 \%$ & $(955 / 1262)$ \\
\hline With suprarenal stent crossing one renal artery & $6.0 \%$ & $(76 / 1262)$ \\
\hline Below both renal arteries & $17.5 \%$ & $(221 / 1262)$ \\
\hline \multicolumn{3}{|l|}{ Placement of distal end of device } \\
\hline Right limb distal to the IIA & $8.8 \%$ & $(111 / 1262)$ \\
\hline Left Limb distal to the IIA & $8.3 \%$ & $(105 / 1262)$ \\
\hline Endurant stent-graft implanted into a patient & $99.5 \%$ & $(1256 / 1262)$ \\
\hline 2 components implanted & $43.0 \%$ & $(540 / 1256)$ \\
\hline 3 components implanted & $27.5 \%$ & $(345 / 1256)$ \\
\hline 4 components implanted & $21.9 \%$ & $(275 / 1256)$ \\
\hline$\geq 5$ components implanted & $6.6 \%$ & $(83 / 1256)$ \\
\hline Primary effectiveness endpoints (ITT) & & $\mathrm{N}=1262$ \\
\hline Technical success & $99.0 \%$ & $(1250 / 1262)$ \\
\hline Endurant stent-graft successfully delivered & $99.4 \%$ & $(1255 / 1262)$ \\
\hline Endurant stent-graft successfully deployed & $99.4 \%$ & $(1255 / 1262)$ \\
\hline No unintended coverage of IIA or any VABs & $99.5 \%$ & $(1253 / 1259)$ \\
\hline Endurant delivery system successfully removed & $99.9 \%$ & $(1261 / 1262)$ \\
\hline Intra-operative clinical success & $97.6 \%$ & $(1232 / 1262)$ \\
\hline Technical success & $99.0 \%$ & $(1250 / 1262)$ \\
\hline Freedom from intra-operative death & $100.0 \%$ & $(1262 / 1262)$ \\
\hline Freedom from type I/III endoleak & $98.6 \%$ & $(1238 / 1256)$ \\
\hline Initial technical observations (PP) & & $\mathrm{N}=1256$ \\
\hline \multicolumn{3}{|l|}{ Stent graft malfunctions } \\
\hline Kinking & $1.0 \%$ & $(13 / 1253)$ \\
\hline Twisting & $0.5 \%$ & $(6 / 1252)$ \\
\hline Wire form fracture & $0.0 \%$ & $(0 / 1253)$ \\
\hline Suprarenal bare stent fracture & $0.0 \%$ & $(0 / 1253)$ \\
\hline Other malfunctions & $0.3 \%$ & $(4 / 1256)$ \\
\hline Endoleak (Uncorrected) & $16.0 \%$ & $(201 / 1256)$ \\
\hline Type I & $1.1 \%$ & $(14 / 1256)$ \\
\hline Type II & $12.4 \%$ & $(156 / 1256)$ \\
\hline Type III & $0.3 \%$ & $(4 / 1256)$ \\
\hline Type IV & $1.8 \%$ & $(22 / 1256)$ \\
\hline Undetermined & $0.7 \%$ & $(9 / 1256)$ \\
\hline
\end{tabular}

Abbreviations: ITT, Intention To Treat; PP, Per Protocol; IIA, Internal Iliac Artery; IMA, Inferior Mesenteric Artery; VABS, Visceral Aortic Branches; Uncorrected, Detected, but chosen not to treat within the initial procedure. 
The overall 30-day mortality rate was 1.3 . One or more major adverse events within 30 days, including all-cause mortality, were reported in 3.9\% of patients (Table 7); bowel ischemia was recorded in 3 patients (0.2\%), myocardial infarction in 14 patients (1.1\%), renal failure in 4 patients $(0.3 \%)$, stroke in 2 patients $(0.2 \%)$, and blood loss $\geq 1000 \mathrm{cc}$ was recorded in 18 (1.4\%) patients. No patient developed paraplegia or respiratory failure.

Table 6. Technical performance at 30-days (PP-analysis)

\begin{tabular}{lcc}
\hline Variable & & N=1151 \\
\hline One or more technical observations & $(\mathbf{1 9 1 / 1 1 5 1 )}$ \\
Stent graft kinking & $\mathbf{1 6 . 6 \%}$ & $(20 / 1151)$ \\
Stent graft twisting & $1.7 \%$ & $(1 / 1151)$ \\
Stent graft wire form fracture & $0.1 \%$ & $(0 / 1151)$ \\
Suprarenal bare stent fracture & $0.0 \%$ & $(0 / 1151)$ \\
Suprarenal bare stent detachment from fabric & $0.0 \%$ & $(1 / 1151)$ \\
Stent graft occlusion & $0.1 \%$ & $(23 / 1151)$ \\
Stent graft stenosis & $2.0 \%$ & $(16 / 1151)$ \\
Stent graft migration & $1.4 \%$ & $(0 / 1151)$ \\
Endoleak & $0.0 \%$ & $(138 / 1151)$ \\
Type I & $12.0 \%$ & $(16 / 1151)$ \\
Type II & $1.4 \%$ & $(114 / 1151)$ \\
Type III & $9.9 \%$ & $(2 / 1151)$ \\
Type IV & $0.2 \%$ & $(1 / 1151)$ \\
Undetermined & $0.1 \%$ & $(7 / 1151)$ \\
Type I and/or III & $0.6 \%$ & $(17 / 1151)$ \\
Other technical observation & $1.5 \%$ & $(7 / 1151)$ \\
\hline
\end{tabular}

Abbreviations: PP, Per Protocol.

a Only implanted patients with 1-month imaging study included in the analyses.

Within the first month $3(0.2 \%)$ cases were converted to open surgery; two as emergencies and one electively, as mentioned earlier. Secondary interventions were required in 19 (1.5\%) cases, within the first 30 days of follow-up; 8 (0.6\%) cases required endovascular intervention for graft occlusion, stenosis or kinking; 1 case was for contralateral leg implant; $6(0.5 \%)$ cases required a bypass procedure; and $4(0.3 \%)$ cases required endovascular intervention to correct a Type-I endoleak.

\section{One-year outcome}

A sub-cohort of 500 patients was followed for at least 12-months; with compliance to followup of $98.6 \%$. Baseline characteristics and perioperative outcome measures of this sub-cohort were comparable to those of the total study population. Therefore, further analysis on this sub-cohort was considered to be valuable. 
Table 7. Patient outcome within 30-days (ITT analysis)

\begin{tabular}{lcc}
\hline Variable & $\mathrm{N}=1262$ \\
\hline One or more major adverse events (MAE) & $(49 / 1262)$ \\
All-cause mortality & $3.9 \%$ & $(16 / 1262)$ \\
Bowel ischemia & $1.3 \%$ & $(3 / 1262)$ \\
Myocardial infarction & $0.2 \%$ & $(14 / 1262)$ \\
Paraplegia & $1.1 \%$ & $(0 / 1262)$ \\
Renal failure & $0.0 \%$ & $(4 / 1262)$ \\
Respiratory failure & $0.3 \%$ & $(0 / 1262)$ \\
Stroke & $0.0 \%$ & $(2 / 1262)$ \\
Procedural blood loss $\geq 1000$ cc & $0.2 \%$ & $(18 / 1262)$ \\
Conversion to open surgery & $1.4 \%$ & $(3 / 1262)$ \\
Secondary surgical procedure & $0.2 \%$ & $(19 / 1262)$ \\
Endovascular for occlusion, stenosis or kinking & $1.5 \%$ & $(8 / 1262)$ \\
Endovascular to correct Type I/III endoleak & $0.6 \%$ & $(4 / 1262)$ \\
Open bypass procedure & $0.3 \%$ & $(6 / 1262)$ \\
Other & $0.5 \%$ & $(1 / 1262)$ \\
Aneurysm rupture & $0.1 \%$ & $(0 / 1262)$ \\
\hline
\end{tabular}

The one-year Kaplan-Meier estimate for overall survival was $91.6 \pm 1.4 \%$. The one-year estimate for aneurysm-related survival was $98.8 \pm 0.5 \%$, with no device related deaths (Figure 1). One or more major adverse events, including all-cause mortality, were reported in $11.2 \%$ of patients within 1 year follow-up; including 5 (1.0\%) cases of renal failure, 9 (1.8\%) myocardial infarctions, $2(0.4 \%)$ cases of stroke, $2(0.4 \%)$ case of bowel ischemia, and 1 $(0.2 \%)$ case of respiratory failure.

Kaplan-Meier estimate for one-year secondary intervention-free survival was $95.1 \pm 1.1 \%$. (Figure 2). Within the first year after implantation, secondary interventions were required in $23(4.6 \%)$ patients. Endovascular procedures were performed in 10 patients to resolve graft occlusion, stenosis or kinking; in 6 patients to correct a Type-I/III endoleak; and in 3 patients to resolve a persistent Type-II endoleak. Five patients underwent a by-pass procedure for an occluded iliac limb. Notably, stent graft migration or loss of device integrity was never observed within the first year after implantation. In addition there were no reports of aneurysm rupture. At one-year, aneurysm size increased by $\geq 5 \mathrm{~mm}$ in $2.8 \%$ of cases, was stable in $55.9 \%$ of cases, and decreased by $\geq 5 \mathrm{~mm}$ in $41.3 \%$ of cases. 
Figure 1. Kaplan-Meier Estimates for All-cause Mortality \& AAA-related Mortality

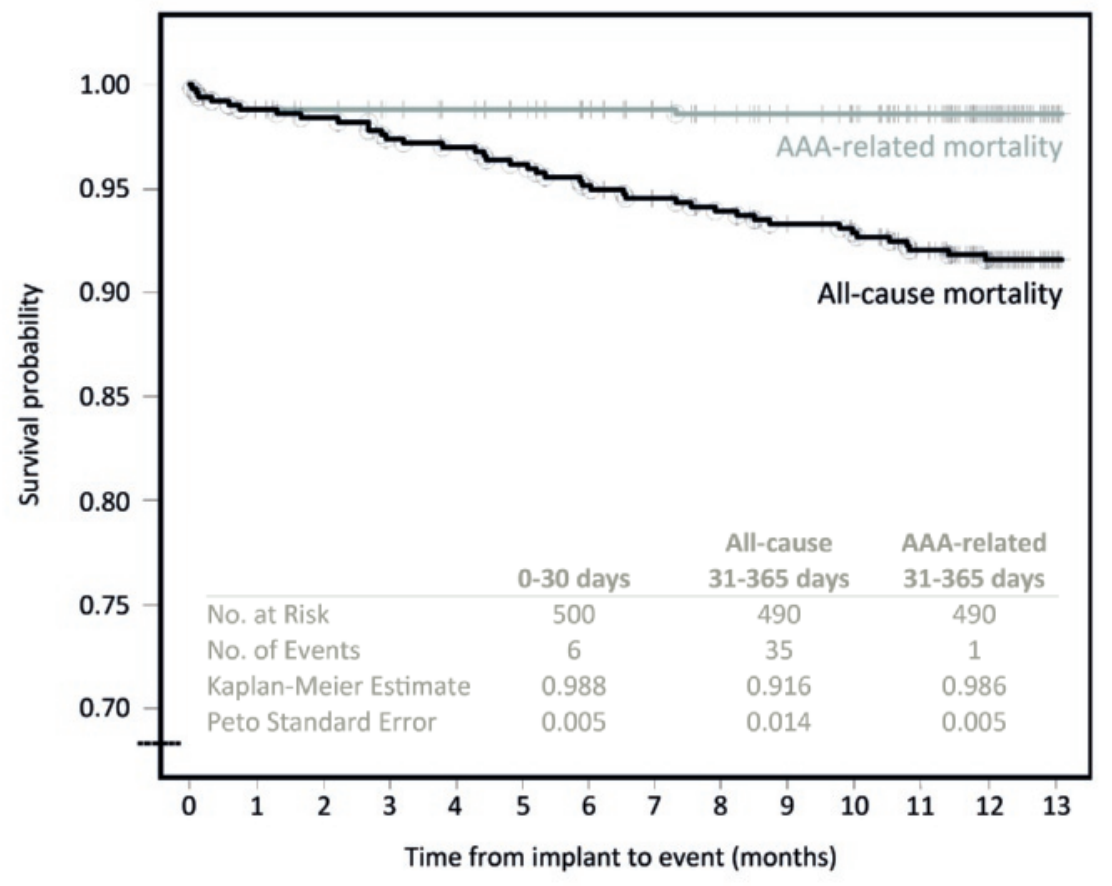

Figure 2. Kaplan-Meier Estimates for Secondary Procedures

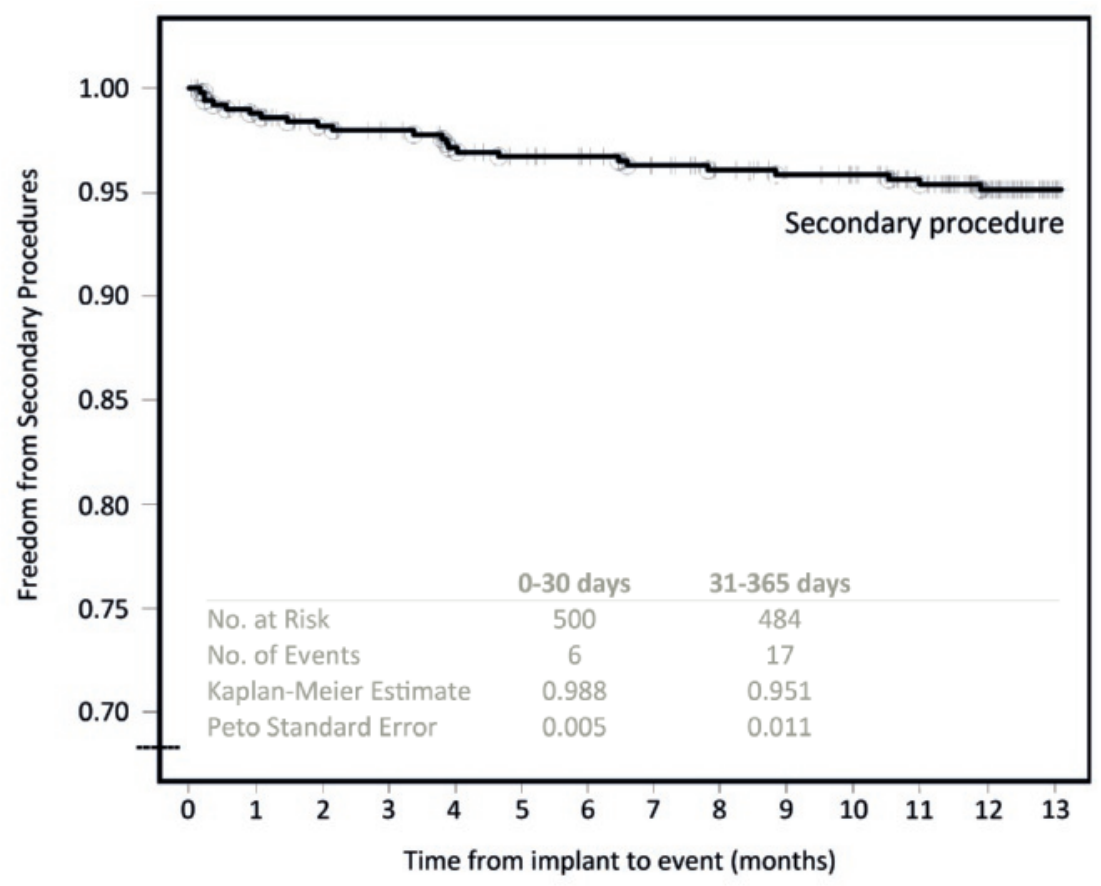




\section{DISCUSSION}

The technology of EVAR for AAAs is a dynamic ever-changing endeavour. The challenge is to decrease complications and reinterventions while safely treating more complex anatomy, especially for those cases unfit for open repair. As improved devices with wider inclusion criteria become available and operators become more proficient with endovascular techniques, the proportion of patients suitable for EVAR increases. ${ }^{13}$ However, overall outcomes may not improve if broadening the application rate results in poorer outcomes despite improvements in operator skill and device design. This ever-evolving trade-off implies that results from older series using previous generations of devices may not reflect the current status of EVAR. As a consequence, results of the performance of latest generation devices in contemporary, real-world settings are important. High-quality, welldesigned observational studies are increasingly believed to provide complimentary evidence to RCTs. ${ }^{14}$ Therefore, they are essential in making a balanced judgement about the management of AAAs.

The ENGAGE registry was undertaken to quantify the performance of a recently released endograft within the context of contemporary, real world use. This prospective observational study represents the collective experience of 79 centres in 30 countries across 5 different continents with the Endurant Stent Graft. Since eligibility was for the most part, left to the discretion of the investigator, the outcomes in the 1262 AAA patient series are expected to have high external validity. Follow-up protocols were kept as close as possible to standard site regimens, in order to keep treatment to real world practice. In order to be able to produce meaningful analysis, a large quantity of data was recorded. To guarantee high quality and completeness of data, efforts were made to achieve onsite quality control and continual monitoring of reported data, which shows in the high level of compliance to follow-up in this registry.

The necessity for secondary interventions is considered the Achilles' heel of EVAR. Secondary interventions were the main reason that EVAR was not considered cost-effective at long-term follow-up in the DREAM trial. ${ }^{17} \mathrm{~A}$ reintervention rate of $4.6 \%$ is comparable to 
reintervention rates of earlier reports and the recent OVER trial, and compares favourably to the landmark studies EVAR-1 and DREAM. ${ }^{5,6,7,18-20}$ The Type II endoleak rate of 9.9\%, which is remarkably lower than in these older studies, might have contributed to the lower rate of secondary procedures. Comparison of reintervention rates at 1-year with other studies is hampered by several factors; in particular, the treatment of Type-II endoleaks has changed over time. On the other hand, in the ENGAGE Registry, $17.9 \%$ of patients were treated outside IFU, primarily due to complex anatomy; therefore, it should also be taken into consideration that the eligibility criteria for ENGAGE were less strict than for DREAM and OVER.

The majority of reinterventions in our study were performed for iliac limb occlusion or stenosis. Van Keulen et al. ${ }^{20}$ also found a higher iliac limb occlusion rate together with a oneyear reintervention rate of $5 \%$ after implantation of an Endurant Stent Graft. At this moment we are unable to conclude if there is any causality between occurrence of iliac occlusions and the wider inclusion criteria associated with the Endurant stent graft, or the stent graft itself.

Despite numerous cases of short- or angulated necks, rates of early Type-I endoleaks were low, with no ruptures and $42 \%$ of reported aneurysm-sac shrinkage. So far, few reinterventions were required to resolve endoleaks. A comparison with literature on Type$\mathrm{I} / \mathrm{III}$ reinterventions or shrinkage of the aneurysm awaits availability of longer-term followup.

Compared with the landmark studies EVAR-1 and DREAM, in this study both perioperative mortality and the aneurysm-related mortality rates after one year were comparable. The allcause mortality rate in this study compares favourably to EVAR-1 and DREAM. ${ }^{5,6}$ This is remarkable given the proportion of ASA class IV patients $(10.6 \%)$ in the ENGAGE study population; in all previously assessed RCTs, ASA class IV patients were excluded. 


\section{CONCLUSION}

ENGAGE is an unprecedented registry in scope and magnitude to characterize the performance of the Endurant stent graft in a contemporary series of 1262 AAA patients treated with the Endurant Stent Graft in 30 countries. The early results of the Endurant Stent Graft in a real world, global experience are promising despite the fact that $10.6 \%$ of patients were classified ASA class IV and $17.9 \%$ of the patients were treated outside IFU. Longer follow-up is needed to assess durability of safety and effectiveness in a broader spectrum of AAA patients treated via endovascular methods. 


\section{REFERENCES}

1. Lederle FA, Johnson GR, Wilson SE, Chute EP, Littooy FN, Bandyk D, et al. Prevalence and associations of abdominal aortic aneurysm detected through screening. Aneurysm Detection and Management (ADAM) Veterans Affairs Cooperative Study Group. Ann Intern Med 1997;126:441-9.

2. Parodi JC, Palmaz JC, Barone HD. Transfemoral intraluminal graft implantation for abdominal aortic aneurysms. Ann Vasc Surg 1991;5:491-9.

3. Volodos NL, Karpovich IP, Troyan VI, Kalashnikova Yu V, Shekhanin VE, Ternyuk NE, et al. Clinical experience of the use of selffixing synthetic prostheses for remote endoprosthetics of the thoracic and the abdominal aorta and iliac arteries through the femoral artery and as intraoperative endoprosthesis for aorta reconstruction. Vasa Suppl 1991;33:93-5.

4. Chaikof EL, Brewster DC, Dalman RL, Makaroun MS, Illig KA, Sicard GA, et al. The care of patients with an abdominal aortic aneurysm: the Society for Vascular Surgery practice guidelines. J Vasc Surg 2009;50:S2-49.

5. EVAR-1 trial participants. Endovascular aneurysm repair versus open repair in patients with abdominal aortic aneurysm (EVAR trial 1): randomised controlled trial. Lancet 2005;365:2179-86.

6. Prinssen $M$, Verhoeven EL, Buth J, Cuypers $P W$, van Sambeek MR, Balm $R$, et al. A randomized trial comparing conventional and endovascular repair of abdominal aortic aneurysms. N Engl J Med 2004;351:1607-18.

7. Lederle FA, Freischlag JA, Kyriakides TC, Padberg FT, Jr., Matsumura JS, Kohler TR, et al. Outcomes following endovascular vs open repair of abdominal aortic aneurysm: a randomized trial. JAMA 2009;302:1535-42.
8. Becquemin JP, Pillet JC, Lescalie F, Sapoval M, Goueffic $Y$, Lermusiaux $P$, et al. A randomized controlled trial of endovascular aneurysm repair versus open surgery for abdominal aortic aneurysms in low- to moderate-risk patients. J Vasc Surg 2011;53:1167-73 e1.

9. Choke E, Munneke G, Morgan R, Belli AM, Loftus I, McFarland R, et al. Outcomes of endovascular abdominal aortic aneurysm repair in patients with hostile neck anatomy. Cardiovasc Intervent Radiol 2006;29:975-80.

10. Carpenter JP, Baum RA, Barker CF, Golden MA, Mitchell ME, Velazquez OC, et al. Impact of exclusion criteria on patient selection for endovascular abdominal aortic aneurysm repair. J Vasc Surg 2001;34:1050-4.

11. Rouwet EV, Torsello G, de Vries JP, Cuypers P, van Herwaarden JA, Eckstein $\mathrm{HH}$, et al. Final results of the prospective European trial of the Endurant stent graft for endovascular abdominal aortic aneurysm repair. Eur J Vasc Endovasc Surg 2011;42:489-97.

12. Bockler $D$, Fitridge $R$, Wolf $Y$, Hayes $P$, Silveira PG, Numan F, et al. Rationale and design of the Endurant Stent Graft Natural Selection Global Postmarket Registry (ENGAGE): interim analysis at 30 days of the first 180 patients enrolled. J Cardiovasc Surg (Torino) 2010;51:481-91.

13. van Marrewijk CJ, Leurs LJ, Vallabhaneni SR, Harris PL, Buth J, Laheij RJ. Risk-adjusted outcome analysis of endovascular abdominal aortic aneurysm repair in a large population: how do stent-grafts compare? J Endovasc Ther 2005;12:417-29.

14. Ligthelm RJ, Borzi V, Gumprecht J, Kawamori $R$, Wenying $Y$, Valensi $P$. Importance of observational studies in clinical practice. Clin Ther 2007;29 Spec No:1284-92. 
15. De Bruin JL, Baas AF, Buth J, Prinssen M, Verhoeven EL, Cuypers PW, et al. Long-term outcome of open or endovascular repair of abdominal aortic aneurysm. N Engl J Med 2010;362:1881-9.

16. Peterson BG, Matsumura JS, Brewster DC, Makaroun MS. Five-year report of a multicenter controlled clinical trial of open versus endovascular treatment of abdominal aortic aneurysms. J Vasc Surg 2007;45:885-90.

17. Prinssen $M$, Buskens $E$, de Jong $S E$, Buth J, Mackaay AJ, van Sambeek MR, et al. Costeffectiveness of conventional and endovascular repair of abdominal aortic aneurysms: results of a randomized trial. J Vasc Surg 2007;46:883-90.
18. Kvinlaug KE, Lawlor DK, Forbes TL, Willoughby $R$, MacKenzie KS, DeRose G, et al. Early results from a Canadian multicenter prospective registry of the Endurant stent graft for endovascular treatment of abdominal aortic aneurysms. J Endovasc Ther 2012;19:58-66.

19. Torsello G, Troisi N, Tessarek J, Torsello GF, Dorigo W, Pulli R, et al. Endovascular aortic aneurysm repair with the Endurant stent-graft: early and 1-year results from a European multicenter experience. J Vasc Interv Radiol 2010;21:73-80.

20. van Keulen JW, de Vries JP, Dekker $H$, Goncalves FB, Moll FL, Verhagen HJ, et al. Oneyear multicenter results of 100 abdominal aortic aneurysm patients treated with the Endurant stent graft. J Vasc Surg 2011;54:60915. 



\section{CHAPTER 3}

\section{NO DIFFERENCES IN PERIOPERATIVE}

\section{OUTCOME BETWEEN SYMPTOMATIC}

\section{AND ASYMPTOMATIC AAAS AFTER}

EVAR: AN ANALYSIS FROM THE

ENGAGE REGISTRY

\section{R.A. Stokmans \\ J.A.W. Teijink \\ Ph.W.M. Cuypers \\ V. Riambau \\ M.R.H.M. van Sambeek}

European Journal of Vascular and Endovascular Surgery 2012 June; $43(6)$ : 667-673 


\section{ABSTRACT}

Aim: This study aimed to compare the differences in perioperative outcome after endovascular repair of symptomatic abdominal aneurysms (S-AAA) and elective non-symptomatic AAAs (E-AAA). Data from the ENGAGE Registry was used for the analysis.

Methods: Between March 2009 and December 2010, 1200 AAA patients were enrolled from 79 sites in 30 countries and treated with an Endurant Stent Graft. S-AAAs defined as AAAs accompanied by abdominal or back pain, without rupture, were present in 185 (15.4\%) patients and E-AAAs in 1015 (84.6\%) patients. Multivariate logistic regression was used to compare results.

Results: At baseline, E-AAA patients had larger aneurysms on average $(P=0.006)$ and scored higher ASA classification more often $(P=0.001)$. Further analyses were corrected for baseline differences. Operation time and technical success were comparable, and S-AAAs were admitted to the ICU as often as E-AAAs (35.7\% vs. $33.4 \%, \mathrm{P}=0.479)$. Post-operative hospitalization was similar $(4.83 \pm 5.29$ in $\mathrm{E}-\mathrm{AAAs}$ and $4.37 \pm 3.49$ in $\mathrm{S}-\mathrm{AAAs}$, $\mathrm{P}=0.360$ ). No differences in the occurrence of major adverse events, including mortality, within 30-days postimplantation were seen between S-AAA and E-AAA patients, respectively $3.2 \%$ and $4.2 \%(P=0.572)$.

Conclusion: With contemporary devices and technical proficiency, there is no difference in outcome between symptomatic AAA and elective non-symptomatic AAA patients if treated with endovascular techniques. 


\section{INTRODUCTION}

The introduction of endovascular aneurysm repair (EVAR) as treatment for patients with abdominal aortic aneurysms (AAAs) has reduced perioperative mortality and morbidity.$^{1-4}$ In the last two decades numerous studies have been conducted in order to evaluate the postoperative results of EVAR. Most of these studies distinguish between elective AAA (EAAA) patients and patients with a ruptured aneurysm (R-AAA), who present in an emergency setting. The perioperative outcome varies with the clinical presentation and the acuity in which surgical treatment is required.

In contemporary practice the mortality rate of elective EVAR is approximately $1.4 \%$, whereas the mortality rate in conventional open repair is approximately $3.5 \%{ }^{5}$ Mortality in acute RAAA repair declined only gradually in recent decades. 6,7 Several studies observed a substantial reduction in perioperative mortality after EVAR compared to open surgical repair. ${ }^{8-12}$ However, in practice EVAR is applied in only a small fraction of R-AAA patients. A recent Vascunet report showed a mortality rate of approximately $20 \%$ in endovascular RAAA repair, but EVAR was employed in only $10 \%$ of all R-AAA repairs; the overall perioperative mortality in R-AAA patients still averaged approximately $32 \%$.

In patients who undergo urgent AAA repair for the treatment of a non-ruptured symptomatic AAA (S-AAA), prognosis is different. S-AAA patients present with symptoms of abdominal and/or back pain associated with aneurysmal tenderness at physical examination. As these symptoms might be a sign of impending rupture, S-AAAs require urgent surgery. Historically, the reported outcome after repair of S-AAA has been consistently worse than that of E-AAA repair, with a mortality rate averaging $16 \%{ }^{6,13}$ The inability to take the necessary time for an adequate preoperative work-up is suggested to be one of the reasons for this difference. ${ }^{13}$ More recent series with higher proportion of endovascular-treated SAAAs report results that are comparable to those for elective EVAR., ${ }^{8,14-17}$ However, these series are small and lack a concurrent group of elective procedures. Nevertheless, the use of EVAR in this subset of patients is promising, especially with the use of new devices with fewer sizing constraints. 
The aim of the present study was to compare the outcome of urgent EVAR for symptomatic AAAs versus elective EVAR for asymptomatic AAAs, within the context of contemporary, multicentre, real world, global, experience with a latest generation endograft device.

\section{MATERIALS AND METHODS}

\section{Patients and database}

Data from 1200 patients prospectively enrolled in the Endurant Stent Graft Natural Selection Global Post-market Registry (ENGAGE) was used for this analysis. The ENGAGE Registry was undertaken to quantify the real life performance of the Endurant Stent Graft (Medtronic Vascular, Santa Rosa, California, USA), which is specially designed to broaden the EVAR eligibility range. From March 2009 until November 2010, ENGAGE prospectively enrolled 1200 patients from 79 sites in 30 countries throughout the world. All patients had to be considered eligible candidates for EVAR treatment with the Endurant endograft in the opinion of their own physician. In practice, however, $16.8 \%$ of the enrolled AAA patients fell outside of Endurant's Instructions for Use (IFU) criteria; criteria already broader than other stent grafts. Of note, both symptomatic and asymptomatic patients were enrolled in the ENGAGE registry, but no patients with ruptured aneurysms or haemodynamically instable patients were enrolled. Further methodological details of the ENGAGE Registry have been published previously.

\section{Definitions and outcome}

Retrospectively, patients were separated into symptomatic and asymptomatic patients based on responses to baseline questionnaires. Data on physical examination was recorded in this questionnaire. All AAA patients with preoperative symptoms of abdominal and/or back pain associated with aneurysm tenderness at physical examination were considered to have S-AAA. Patients without such symptoms of abdominal and/or back pain were considered to have E-AAA.

Pre-existing medical comorbidities and cardiovascular risk factors were recorded when patients were enrolled in the registry. Tobacco use, hypertension and hyperlipidaemia were 
included as cardiovascular risk factors. Patients' medical records were evaluated for a history of diabetes mellitus, cancer (not specified), cardiac diseases (myocardial infarction, arrhythmia, angina pectoris, congestive heart failure, coronary artery disease, cardiac revascularization, and valvular heart disease), chronic pulmonary diseases (not specified), renal insufficiency, carotid artery disease, cerebrovascular diseases (transient ischemic attack, cerebral vascular accident), peripheral vascular diseases, and gastrointestinal complications. In addition, the patients' preoperative health status was classified according to the American Society of Anaesthesiologists Classification of Health (ASA class I to IV).

Prior to the EVAR procedure, CTA imaging of the abdomen and pelvis was undertaken to determine baseline aortic and aneurysmal dimensions. Patients were classified by primary indication for aneurysm repair according to the Society of Vascular Surgery international AAA guidelines. ${ }^{20,21}$ Indications for repair included a maximum AAA diameter $>5 \mathrm{~cm}$, or 4-5 $\mathrm{cm}$ with an increase of $\geq 0.5 \mathrm{~cm}$ in last 6 months, or $\geq 1.5$ times normal infrarenal aorta diameter. Patients were considered to fall outside of the device IFU when the proximal neck diameter or length, infrarenal or suprarenal angulation, or distal iliac fixation diameter or length did not fall within the specifications of Endurant's IFU. (Table 1).

\section{Table 1. Endurant ${ }^{\circledR}$ indications for use}

\section{One of the following criteria:}

- Infrarenal neck length $\geq 10 \mathrm{~mm}$ with non-significant calcification, and/or non-significant thrombus in combination with $\leq 45^{\circ}$ suprarenal angulation and $\leq 60^{\circ}$ infrarenal angulation.

- Infrarenal neck length $\geq 15 \mathrm{~mm}$ with non-significant calcification, and/or non-significant thrombus in combination with $\leq 60^{\circ}$ suprarenal angulation and $\leq 75^{\circ}$ infrarenal angulation.

\section{And all of the following criteria:}

- Adequate iliac/femoral access

- Proximal AAA neck diameter $\geq 19 \mathrm{~mm}$ and $\leq 32 \mathrm{~mm}$

- Distal iliac fixation site diameter $\geq 8 \mathrm{~mm}$ and $\leq 25 \mathrm{~mm}$

- Distal non-aneurysmal iliac fixation length $\geq 15 \mathrm{~mm}$ bilaterally

The primary outcome of the analysis was perioperative mortality, defined as mortality from any cause occurring within 30 days of surgery. Secondary outcome measures for this analysis included procedural data, major perioperative adverse events (MAEs), technical success and clinical success. Procedural data included duration of the implant procedure, total volume of contrast used, postoperative hospitalization, and admission rate to the Intensive Care Unit 
(ICU). Technical success was defined as successful delivery and deployment of the Endurant endograft, without unintentional coverage of renal arteries, internal iliac arteries or visceral branches), followed by successful removal of the delivery system. Initial clinical success was defined as technical success without intra-operative death or presence of a Type I/III endoleak at the end of the procedure. MAEs included all-cause mortality, bowel ischemia, myocardial infarction, paraplegia, renal failure, respiratory failure, stroke, and procedural blood loss $\geq 1000 \mathrm{~mL}$. Follow-up data 30 days after implantation was completed for all patients.

\section{Data collection and statistical analysis}

Data collected on each patient was recorded on a web-based electronic case report form (Viracity ${ }^{\mathrm{TM}}$ Clinical Asset Management, MERGE Healthcare, Chicago, Illinois, USA). Data was entered by, or under supervision of, sites' principal investigators. In addition, research analysts from Medtronic Bakken Research Centre BV (Maastricht, The Netherlands) crosschecked over $40 \%$ of patients' source documentation against the entered data during monitoring visits. Data collection and analysis was approved by each site's Institutional Review Board and informed consent for authorization of data release was obtained in all patients.

Statistical analysis was performed using $\mathrm{SAS}^{\circledR}$ version 9.0 software for Windows (SAS Institute Inc., Cary, NC, USA). To analyse outcome differences in E-AAA versus S-AAA patients, a multivariate logistic regression model was used for categorical response variables. To adjust for demographic and baseline risk factors, age, gender, and ASA classification were included as covariates in the model. For continuous response variables, a generalized linear model or covariance analysis model was applied and rank transformed data were also examined as a sensitivity analysis. Missing values were excluded from analysis. Categorical variables are presented as frequency with percentages. Continuous variables are presented as mean \pm standard deviation (SD). Values of $P<0.05$ were considered statistically significant. 


\section{RESULTS}

\section{Patient characteristics}

Among the 1200 consecutive patients enrolled in the ENGAGE registry, 1015 (84.6\%) were asymptomatic and 185 (15.4\%) were symptomatic. No patients with ruptured aneurysm were enrolled in this study.

Table 2. Patient demographics \& risk factors (ITT analysis)

\begin{tabular}{|c|c|c|c|}
\hline Variable & $\begin{array}{l}\text { Asymptomatic AAA } \\
\qquad N=1015^{\circ}\end{array}$ & $\begin{array}{l}\text { Symptomatic AAA } \\
\qquad \mathrm{N}=185^{\circ}\end{array}$ & P-value \\
\hline Age (years) & $73.6 \pm 7.9$ & $71 \pm 8.9$ & .012 \\
\hline Gender & & & n.s. \\
\hline Male & $90.4 \%(918 / 1015)$ & $85.9 \%(159 / 185)$ & \\
\hline Female & $9.6 \%(97 / 1015)$ & $14.1 \%(26 / 185)$ & \\
\hline $\mathrm{ASA}^{2}$ classification & & & $<.001$ \\
\hline Class I & $4.7 \%(48 / 1012)$ & $6.5 \%(12 / 185)$ & \\
\hline Class II & $40.4 \%(409 / 1012)$ & $51.9 \%(96 / 185)$ & \\
\hline Class III & $42.9 \%(434 / 1012)$ & $35.7 \%(66 / 185)$ & \\
\hline Class IV & $12.0 \%(121 / 1012)$ & $5.9 \%(11 / 185)$ & \\
\hline Maximum AAA diameter (mm) & $60.0 \pm 11.1$ & $62.7 \pm 14.3$ & .004 \\
\hline Indication by AAA diameter & & & .002 \\
\hline$\geq 1.5 x$ normal infrarenal aorta & $2.4 \%(24 / 1015)$ & $5.9 \%(11 / 185)$ & \\
\hline $4-5 \mathrm{~cm}$ ( $\geq 0.5 \mathrm{~cm}$ increase in 6 months) & $5.8 \%(59 / 1015)$ & $10.3 \%(19 / 185)$ & \\
\hline$>5 \mathrm{~cm}$ & $89.6 \%(909 / 1015)$ & $81.6 \%(151 / 185)$ & \\
\hline Other & $2.3 \%(23 / 1015)$ & $2.2 \%(4 / 185)$ & \\
\hline $\begin{array}{l}\text { Circumferential aortic mural thrombus at } \\
\text { the proximal neck (\%) }\end{array}$ & $10.41 \pm 17.4$ & $10.09 \pm 18.1$ & n.s. \\
\hline \multicolumn{4}{|l|}{ Risk Factors } \\
\hline Tobacco use & $48.6 \%(481 / 990)$ & $51.4 \%(92 / 179)$ & n.s. \\
\hline Hypertension & $75 \%(756 / 1002)$ & $77.9 \%(141 / 181)$ & n.s. \\
\hline Hyperlipidaemia & $61.9 \%(594 / 960)$ & $63.1 \%(106 / 168)$ & n.s. \\
\hline Diabetes & $20.0 \%(200 / 999)$ & $14.1 \%(26 / 184)$ & n.s. \\
\hline Cancer & $20.8 \%(207 / 997)$ & $16.9 \%(31 / 183)$ & n.s. \\
\hline \multicolumn{4}{|l|}{ Cardiac disease } \\
\hline Myocardial infarction (MI) & $27.3 \%(266 / 973)$ & $26.0 \%(46 / 177)$ & n.s. \\
\hline Arrhythmia & $16.8 \%(167 / 992)$ & $14.4 \%(26 / 180)$ & n.s. \\
\hline Angina & $15.9 \%(157 / 990)$ & $16.5 \%(30 / 182)$ & n.s. \\
\hline Congestive heart failure (CHF) & $5.7 \%(56 / 987)$ & $7.2 \%(13 / 180)$ & n.s. \\
\hline Coronary artery disease (CAD) & $35.4 \%(348 / 982)$ & $30.5 \%(53 / 174)$ & n.s. \\
\hline Cardiac revascularisation & $28.4 \%(285 / 1002)$ & $21.7 \%(39 / 180)$ & n.s. \\
\hline Valvular heart disease & $6.0 \%(60 / 992)$ & $7.1 \%(13 / 182)$ & n.s. \\
\hline Pulmonary disease & $24.4 \%(243 / 996)$ & $31.1 \%(57 / 183)$ & n.s. \\
\hline Renal insufficiency & $15.8 \%(159 / 1006)$ & $14.2 \%(26 / 183)$ & n.s. \\
\hline Carotid artery disease & $11.9 \%(100 / 841)$ & $6.3 \%(10 / 159)$ & .039 \\
\hline \multicolumn{4}{|l|}{ Cerebrovascular disease } \\
\hline Transient ischaemic attack (TIA) & $5.4 \%(54 / 1002)$ & $3.8 \%(7 / 185)$ & n.s. \\
\hline Cerebral vascular accident (CVA) & $5.5 \%(55 / 1008)$ & $4.9 \%(9 / 185)$ & n.s. \\
\hline Peripheral vascular disease & $18.0 \%(180 / 998)$ & $22.8 \%(42 / 184)$ & n.s. \\
\hline Gastrointestinal complications & $20.4 \%(207 / 1014)$ & $20.0 \%(37 / 185)$ & n.s. \\
\hline
\end{tabular}

Abbreviations: ITT, Intention To Treat; n.s., not significant; AAA, abdominal Aortic Aneurysm

${ }^{a}$ Values are reported as mean \pm standard deviation, or as frequencies. Denominators differ when values are missing 
Demographic data and baseline risk factors are presented in Table 2. On average, S-AAA patients were younger than E-AAA patients, with a mean age of $71.7 \pm 8.9$ years vs. $73.6 \pm 7.9$ years $(P=0.012)$. Patients were predominantly men and the distribution of sexes was comparable between the groups. Symptomatic presentation was less likely to occur in patients with a history of carotid artery disease compared with E-AAA patients $(P=0.039)$, but patients did not differ significantly by smoking status or other pre-existing comorbid diseases. Nevertheless, E-AAA patients were significantly more likely to be in ASA Class III and IV than were S-AAA patients. The distribution of ASA Class I to IV in E-AAA versus S-AAA patients was $4.7 \%, 40.4 \%, 42.9 \%$, and $12.0 \%$ versus $6.5 \%, 51.9 \%, 35.7 \%$, and $5.9 \%$, respectively $(P<0.001)$. Only ASA class remained a significant baseline covariate in multivariate analysis, therefore further analyses on the outcome variables was corrected for ASA classifications.

Compared with E-AAA patients, S-AAA patients had more often an AAA diameter of $\geq 1.5$ times the normal infrarenal aorta diameter or AAA diameter of 4-5 cm with a $\geq 0.5 \mathrm{~cm}$ increase within the last 6 months, and less often an AAA diameter of $>5 \mathrm{~cm}(5.9 \%, 10.3 \%$ and $81.6 \%$, and $2.4 \%, 5.8 \%$ and $89.6 \%$, respectively, $P=0.002$ ). Mean maximum AAA diameter was, however, larger in S-AAA than was in E-AAA patients, $62.7 \pm 14.3 \mathrm{~mm}$ vs. $60.0 \pm 11.1 \mathrm{~mm}$ $(P=0.004)$. The proportion of patients treated outside IFU was comparable in both groups, as was the relative distribution of the specific criteria that fell outside of the IFU (Table 3).

Table 3. Patients implanted outside IFU (PP-analysis)

\begin{tabular}{|c|c|c|c|}
\hline Variable & $\begin{array}{c}\text { Asymptomatic AAA } \\
\qquad N=1009^{a}\end{array}$ & $\begin{array}{l}\text { Symptomatic AAA } \\
\qquad \mathrm{N}=185^{\circ} \\
\end{array}$ & P-value \\
\hline Total implanted outside of IFU guidance & $15.8 \%(159 / 1009)$ & $20.0 \%(37 / 185)$ & n.s. \\
\hline Non-primary indications & $2.3 \%(23 / 1009)$ & $2.2 \%(4 / 185)$ & n.s. \\
\hline Proximal neck diameter $<19 \mathrm{~mm}$ or $>32 \mathrm{~mm}$ & $3.9 \%(39 / 1004)$ & $6.0 \%(11 / 183)$ & n.s. \\
\hline Proximal neck length $<10 \mathrm{~mm}$ & $2.2 \%(22 / 1000)$ & $1.7 \%(3 / 180)$ & n.s. \\
\hline Proximal neck length $\geq 10 \mathrm{~mm}$ and $<15 \mathrm{~mm}^{b}$ & $1.8 \%(18 / 1000)$ & $2.2 \%(4 / 180)$ & n.s. \\
\hline Angulation suprarenal $>60^{\circ}$ or infrarenal $>75^{\circ}$ & $5.0 \%(50 / 1000)$ & $6.7 \%(912 / 180)$ & n.s. \\
\hline Distal iliac fixation site diameter $<8 \mathrm{~mm}$ & $1.5 \%(15 / 1009)$ & $2.2 \%(4 / 185)$ & n.s. \\
\hline Distal iliac fixation site diameter $>25 \mathrm{~mm}$ & $1.1 \%(11 / 1009)$ & $0.0 \%(0 / 185)$ & n.s. \\
\hline
\end{tabular}

Abbreviations: IFU, Instructions for Use; PP, Per Protocol; AAA, Abdominal Aortic Aneurysm; n.s., not significant.

${ }^{a}$ Values are reported as mean \pm standard deviation, or as frequencies. Denominators differ when values are missing

${ }^{\mathrm{b}}$ combination with suprarenal angle $>45^{\circ}$ or infrarenal angle $>60^{\circ}$ 


\section{Procedure details}

Initial procedural data and evaluation are detailed in Table 4. The endovascular procedure was terminated in 4 patients due to access problems caused by tortuous or stenotic iliac arteries. Two patients required immediate conversion to open surgery; 1 case for unintentional coverage of both renal arteries; and 1 case in which the surgeon was unable to remove the delivery device when a suprarenal strut became entrapped in the delivery system. In 5 other cases the internal iliac artery was unintentionally covered. All seven procedural problems occurred in E-AAA patients, resulting in a technical success rate of $98.9 \%$ in this group of patients, compared to $100 \%$ in the S-AAA group, a difference that did not attain statistical significance (adjusted $P=.163$ ). Initial clinical success rate was $97.3 \%$ in E-AAA patients, with 16 cases of Type I and/or III endoleaks at end of the initial procedure as well as the 11 technical failures. Initial clinical success was $99.5 \%$ in the S-AAA patients, with one Type I endoleak; a rate that did not differ from that of E-AAA group (adjusted $P=.085$ ). The mean duration of the implant procedure and mean volume of contrast used were similar between E-AAA and S-AAA repairs. S-AAA patients underwent the procedure with local or regional anaesthesia more often than E-AAA patients (adjusted $P=.003$ ). No differences were noted in ICU admission rate and days of post-operative hospitalization between both groups of patients after adjustment for ASA class.

Table 4. Initial procedural data and evaluation (ITT analysis)

\begin{tabular}{|c|c|c|c|c|}
\hline Variable & $\begin{array}{c}\text { Asymptomatic AAA } \\
\qquad \mathrm{N}=1015^{\mathrm{a}}\end{array}$ & $\begin{array}{l}\text { Symptomatic AAA } \\
\qquad \mathrm{N}=185^{\circ} \\
\end{array}$ & P-value & $\begin{array}{l}\text { Adjusted } \\
\text { P-value }^{b}\end{array}$ \\
\hline Duration of implant procedure (mins) & $100.9 \pm 45.3$ & $95.0 \pm 42.5$ & .097 & .323 \\
\hline \multicolumn{5}{|l|}{ Type of anaesthesia } \\
\hline General & $64.5 \%(654 / 1014)$ & $51.4 \%(95 / 185)$ & .001 & .003 \\
\hline Spinal/Epidural & $25.7 \%(261 / 1014)$ & $34.6 \%(64 / 185)$ & & \\
\hline Local & $9.8 \%(99 / 1014)$ & $14.1 \%(26 / 185)$ & & \\
\hline Volume of contrast (mL) & $130.2 \pm 71.0$ & $132.2 \pm 66.3$ & .738 & .858 \\
\hline Post-operative stay (days) & $4.83 \pm 5.29$ & $4.37 \pm 3.49$ & .253 & .360 \\
\hline Time in ICU (hours) & $10.0 \pm 45.9$ & $10.6 \pm 27.8$ & .861 & .872 \\
\hline Admission to ICU & $33.4 \%(339 / 1015)$ & $35.7 \%(66 / 185)$ & .547 & .479 \\
\hline \multicolumn{5}{|l|}{ Evaluation } \\
\hline Intra-operative mortality & $0.0 \%(0 / 1015)$ & $0.0 \%(0 / 185)$ & - & - \\
\hline Technical success & $98.9 \%(1004 / 1015)$ & $100.0 \%(185 / 185)$ & .155 & .163 \\
\hline Clinical success & $97.3 \%(988 / 1015)$ & $99.5 \%(184 / 185)$ & .079 & .085 \\
\hline
\end{tabular}




\section{Mortality and morbidity}

There were no intraoperative deaths in the 1200 patients. Within 30-days after implant $15 \mathrm{E}$ AAA patients died versus $1 \mathrm{~S}$-AAA patient, resulting in perioperative mortality rates of $1.5 \%$ and $0.5 \%$ (adjusted $P=0.316$ ) in E-AAA and S-AAA patients, respectively. The occurrence of one or more MAEs, including mortality, within 30-days after the initial procedure was similar in the groups; 30-day MAE's rate was 4.2\%in E-AAA patients and $3.2 \%$ in S-AAA patients (adjusted $P=0.572$ ). Finally, there were no significant differences in the relative proportions of different types of MAEs in the two groups (Table 5).

Table 5. Major adverse events within 30 days (ITT analysis)

\begin{tabular}{|c|c|c|c|c|}
\hline Variable & $\begin{array}{c}\text { Asymptomatic AAA } \\
\text { N=1015 }\end{array}$ & $\begin{array}{l}\text { Symptomatic AAA } \\
\qquad N=185\end{array}$ & P-value & $\begin{array}{l}\text { Adjusted } \\
\text { P-value }\end{array}$ \\
\hline One or more (MAE's) & $4.2 \%(43 / 1015)$ & $3.2 \%(6 / 185)$ & .530 & .572 \\
\hline All-cause Mortality & $1.5 \%(15 / 1015)$ & $0.5 \%(1 / 185)$ & .307 & .316 \\
\hline Bowel ischemia & $0.2 \%(2 / 1015)$ & $0.5 \%(1 / 185)$ & .390 & .378 \\
\hline Myocardial infarction & $1.2 \%(12 / 1015)$ & $1.1 \%(2 / 185)$ & .906 & .975 \\
\hline Paraplegia & $0.0 \%(0 / 1015)$ & $0.0 \%(0 / 185)$ & - & - \\
\hline Renal failure & $0.3 \%(3 / 1015)$ & $0.5 \%(1 / 185)$ & .068 & .066 \\
\hline Respiratory failure & $0.0 \%(0 / 1015)$ & $0.0 \%(0 / 185)$ & .595 & .484 \\
\hline Stroke & $0.1 \%(1 / 1015)$ & $0.5 \%(1 / 185)$ & - & - \\
\hline Procedural blood loss $\geq 1000 \mathrm{~mL}$ & $1.8 \%(18 / 1015)$ & $0.0 \%(0 / 185)$ & .175 & .191 \\
\hline
\end{tabular}

Abbreviations: ITT, Intention To Treat; AAA, Abdominal Aortic Aneurysm; MAE's, Major Adverse Events.

${ }^{\mathrm{b}}$ P-value adjusted for baseline ASA classification

\section{DISCUSSION}

Whenever an AAA patient presents with symptoms that suggest a rupture is imminent, surgeons are confronted with a difficult challenge in clinical practice. They have to make a choice whether to urgently operate a patient, who may not be optimized for major surgery, or to postpone surgery until regular preoperative work-up is completed. Historically, urgent S-AAA repair has had a worse perioperative outcome than elective E-AAA repair. ${ }^{13,22-27}$ Postponing surgery, however, includes a risk of interval rupture, which is associated with an even higher mortality rate. ${ }^{5,6}$ After EVAR has proven itself in elective patients, this technique is nowadays also more often applied in urgent cases. ${ }^{8,12,15,28}$ This study might resolve a part of the practical dilemma, as it shows that there no longer is a difference in outcome between S-AAA patients and E-AAA patients after endovascular repair. 
Previous studies that have compared symptomatic aneurysms with elective cases in open surgical repair found 30-day mortality rates in S-AAAs ranging from $9.5 \%$ to $26.0 \%{ }^{13,22-27}$ versus approximately $5 \%$ in E-AAAs. ${ }^{1-4}$ Recent data showed 30-day mortality rates within the range of $0 \%$ to $5 \%$ in S-AAA when treated with EVAR. ${ }^{8,14,16,17}$ However, these studies describe only a low number of endovascular S-AAA repairs. And in all, but one study, results arrived from single centre experience and were gathered over a long period of time. Often, no direct comparison to E-AAA patients was performed.

The current study represents worldwide and contemporary experiences of 79 sites in 30 countries. It represents the largest series of endovascular S-AAA repairs ever reported. Results showed no differences in 30-day mortality and morbidity rates after EVAR between S-AAA and E-AAA patients. It shows that perioperative mortality risk has reduced remarkably with current endovascular S-AAA repair when compared to mortality risks in the era of open surgical repair. However, this conclusion must be taken with caution since the effects of selection bias in this study are unknown. All patients underwent optimal preoperative imaging and were considered to have adequate anatomy for EVAR treatment, which might be different for the S-AAA patients included in series of open surgical repair. Furthermore, the level of external validity might be argued upon. Since ENGAGE describes only the results of the Endurant Stent Graft, the results of this study might not necessarily be generalized to all endografts available on the market.

This study showed that the type of AAA had no influence on progress of EVAR procedure. Operation time and the amount of contrast used were not different in S-AAA repair compared with E-AAA repair, and afterwards S-AAA patients did not require more referral to the ICU or longer hospitalization than the E-AAA patients. The technical success rate in both AAA subsets was similar, with no failure at all in S-AAA repair. Although not statistically significant, it is remarkable that only in the E-AAA group some patients required conversion to open surgery because of inaccessible iliac arteries or intraoperative problems. Except from a low overall incidence rate of conversions in the ENGAGE cohort, no other possible explanations can be given for this. 
A proportion of $15.4 \%$ S-AAA from a cohort of unruptured AAA repairs is within the range of $\mathbf{5 \%}$ to $\mathbf{2 3 \%}$ noted in previous reports. ${ }^{12-15,23,25,26}$ There is a lack of universally adapted criteria for a definition of symptomatic AAA patients. Therefore, in this study the definition described by Peppelenbosch et al. ${ }^{12}$ was used, which has been used other studies as well. $8,14,15$ The ENGAGE database was not specifically designed for this retrospective analysis. Unfortunately, it does not routinely records time from EVAR indication to initial procedure. Therefore, it remains unclear if all S-AAAs were treated in a semi-acute setting and if E-AAAs were not.

\section{CONCLUSION}

Endovascular AAA repair is a dynamic endeavour; new devices and perioperative care have improved and operators have become more proficient resulting in less operative burden in patients. The ENGAGE data indicate that with contemporary devices and technical proficiency, there is no difference in outcome between symptomatic AAA patients and elective non-symptomatic AAA patients if treated with endovascular techniques. 
1. Blankensteijn JD, de Jong SE, Prinssen $M$, van der Ham AC, Buth J, van Sterkenburg SM, et al. Two-year outcomes after conventional or endovascular repair of abdominal aortic aneurysms. N Engl J Med 2005 Jun 9;352(23):2398-405.

2. EVAR trial participants. Endovascular aneurysm repair versus open repair in patients with abdominal aortic aneurysm (EVAR trial 1): randomised controlled trial. Lancet 2005 Jun 25;365(9478):2179-86.

3. Greenhalgh RM, Brown LC, Kwong GP, Powell JT, Thompson SG. Comparison of endovascular aneurysm repair with open repair in patients with abdominal aortic aneurysm (EVAR trial 1), 30-day operative mortality results: randomised controlled trial. Lancet 2004 Sep 4;364(9437):843-8.

4. Prinssen $\mathrm{M}$, Verhoeven EL, Buth J, Cuypers $P W$, van Sambeek MR, Balm $R$, et al. A randomized trial comparing conventional and endovascular repair of abdominal aortic aneurysms. N Engl J Med 2004 Oct 14;351(16):1607-18..

5. Mani K, Lees T, Beiles B, Jensen LP, Venermo $M$, Simo $G$, et al. Treatment of Abdominal Aortic Aneurysm in Nine Countries 2005-2009: A Vascunet Report. Eur J Vasc Endovasc Surg 2011 Jul 18.

6. Bown MJ, Sutton AJ, Bell PR, Sayers RD. A meta-analysis of 50 years of ruptured abdominal aortic aneurysm repair. $\mathrm{Br} J$ Surg 2002 Jun;89(6):714-30.

7. Heller JA, Weinberg A, Arons R, Krishnasastry KV, Lyon RT, Deitch JS, et al. Two decades of abdominal aortic aneurysm repair: have we made any progress? J Vasc Surg 2000 Dec;32(6):1091-100.
8. Franks S, Lloyd G, Fishwick G, Bown M, Sayers R. Endovascular treatment of ruptured and symptomatic abdominal aortic aneurysms. Eur J Vasc Endovasc Surg 2006 Apr;31(4):345-50.

9. Alsac JM, Desgranges $P$, Kobeiter $H$, Becquemin JP. Emergency endovascular repair for ruptured abdominal aortic aneurysms: feasibility and comparison of early results with conventional open repair. Eur J Vasc Endovasc Surg 2005 Dec;30(6):632-9.

10. Brandt M, Walluscheck KP, Jahnke T, Graw K, Cremer J, Muller-Hulsbeck S. Endovascular repair of ruptured abdominal aortic aneurysm: feasibility and impact on early outcome. J Vasc Interv Radiol 2005 Oct;16(10):1309-12.

11. Kapma MR, Verhoeven EL, Tielliu IF, Zeebregts CJ, Prins TR, Van der HB, et al. Endovascular treatment of acute abdominal aortic aneurysm with a bifurcated stentgraft. Eur J Vasc Endovasc Surg 2005 May;29(5):510-5.

12. Peppelenbosch N, Yilmaz N, van MC, Buth J, Cuypers P, Duijm L, et al. Emergency treatment of acute symptomatic or ruptured abdominal aortic aneurysm. Outcome of a prospective intent-to-treat by EVAR protocol. Eur J Vasc Endovasc Surg 2003 Sep;26(3):30310.

13. Leo $E$, Biancari $F$, Kechagias $A$, Ylonen $K$, Rainio $P$, Romsi $P$, et al. Outcome after emergency repair of symptomatic, unruptured abdominal aortic aneurysm: results in 42 patients and review of the literature. Scand Cardiovasc J 2005 Apr;39(1-2):91-5.

14. De Martino RR, Nolan BW, Goodney PP, Chang CK, Schanzer A, Cambria R, et al. Outcomes of symptomatic abdominal aortic aneurysm repair. J Vasc Surg 2010 Jul;52(1):5-12. 
15. Ten Bosch JA, Willigendael EM, Kruidenier LM, de Loos ER, Prins MH, Teijink JAW. Early and mid-term results of a prospective observational study comparing emergency endovascular aneurysm repair with open surgery in both ruptured and unruptured acute abdominal aortic aneurysms. Vascular 2011; in press.

16. Nevala T, Perala J, Aho P, Matsi P, Ylonen K, Roth WD, et al. Outcome of symptomatic, unruptured abdominal aortic aneurysms after endovascular repair with the Zenith stent-graft system. Scand Cardiovasc J 2008 Jun;42(3):178-81.

17. Oranen BI, Bos WT, Verhoeven EL, Tielliu IF, Zeebregts CJ, Prins TR, et al. Is emergency endovascular aneurysm repair associated with higher secondary intervention risk at mid-term follow-up? J Vasc Surg 2006 Dec;44(6):115661.

18. Bockler $D$, Fitridge $R$, Wolf $Y$, Hayes $P$, Silveira PG, Numan F, et al. Rationale and design of the Endurant Stent Graft Natural Selection Global Postmarket Registry (ENGAGE): interim analysis at 30 days of the first 180 patients enrolled. J Cardiovasc Surg (Torino) 2010 Aug;51(4):481-91.

19. Wolters $U$, Wolf $T$, Stutzer $H$, Schroder T. ASA classification and perioperative variables as predictors of postoperative outcome. $\mathrm{Br} \mathrm{J}$ Anaesth 1996 Aug;77(2):217-22.

20. Chaikof EL, Brewster DC, Dalman RL, Makaroun MS, Illig KA, Sicard GA, et al. The care of patients with an abdominal aortic aneurysm: the Society for Vascular Surgery practice guidelines. J Vasc Surg 2009 Oct;50(4 Suppl):S2-49.

21. Moll FL, Powell JT, Fraedrich G, Verzini F, Haulon S, Waltham $M$, et al. Management of abdominal aortic aneurysms clinical practice guidelines of the European society for vascular surgery. Eur J Vasc Endovasc Surg 2011 Jan;41 Suppl 1:S1-S58.
22. Soisalon-Soininen S, Salo JA, Perhoniemi V, Mattila S. Emergency surgery of non-ruptured abdominal aortic aneurysm. Ann Chir Gynaecol 1999;88(1):38-43.

23. Sullivan CA, Rohrer MJ, Cutler BS. Clinical management of the symptomatic but unruptured abdominal aortic aneurysm. J Vasc Surg 1990 Jun;11(6):799-803.

24. Antonello $M$, Frigatti $P$, Maturi $C$, Lepidi $S$, Noventa F, Pittoni G, et al. Open repair for ruptured abdominal aortic aneurysm: is it possible to predict survival? Ann Vasc Surg 2009 Mar;23(2):159-66.

25. Bradbury AW, Adam DJ, Makhdoomi KR, Stuart WP, Murie JA, Jenkins AM, et al. A 21-year experience of abdominal aortic aneurysm operations in Edinburgh. $\mathrm{Br} J$ Surg 1998 May;85(5):645-7.

26. Sayers RD, Thompson MM, Nasim A, Healey $P$, Taub N, Bell PR. Surgical management of 671 abdominal aortic aneurysms: a 13 year review from a single centre. Eur J Vasc Endovasc Surg 1997 Mar;13(3):322-7.

27. Aune S, Amundsen SR, Evjensvold J, Trippestad $A$. The influence of age on operative mortality and long-term relative survival following emergency abdominal aortic aneurysm operations. Eur J Vasc Endovasc Surg 1995 Oct;10(3):338-41.

28. Yilmaz N, Peppelenbosch N, Cuypers PW, Tielbeek AV, Duijm LE, Buth J. Emergency treatment of symptomatic or ruptured abdominal aortic aneurysms: the role of endovascular repair. J Endovasc Ther 2002 Aug;9(4):449-57. 




\section{CHAPTER 4}

\section{EFFECTS OF ANESTHESIA TYPE ON}

\section{PERIOPERATIVE OUTCOME AFTER}

ENDOVASCULAR ANEURYSM REPAIR

P.P.H.L. Broos

R.A. Stokmans

Ph.W.M. Cuypers

M.R.H.M. van Sambeek

J.A.W. Teijink

Journal of Endovascular Therapy 2015 October; 22(5): 770-777 


\section{ABSTRACT}

Purpose: To examine outcomes of endovascular aortic aneurysm repair (EVAR) using general, regional, or local anesthesia.

Methods: From March 2009 to April 2011, patients were enrolled from 79 sites in 30 countries worldwide and treated with an Endurant Stent Graft System. Data were compared among 3 groups based on the method of anesthesia: general anesthesia (GA) was used in 785 (62\%) patients, regional anesthesia (RA) in 331 (27\%) patients, and local anesthesia (LA) in 145 (11\%) patients. Multivariate logistic regression analysis was performed to adjust for possible confounding factors; outcomes are presented as the odds ratio and $95 \%$ confidence interval.

Results: There were intercontinental differences in the distribution of type of anesthesia used for EVAR. Higher ASA (American Society of Anesthesiologists) classification was associated with predominant use of GA. Procedure time was reduced in LA $(80.4 \pm 40.0$ minutes) compared with RA $(94.2 \pm 41.6$ min, adjusted $p=0.001)$ and GA (105.3 \pm 46.0 minutes, adjusted $p<0.001)$. Intensive care unit (ICU) admission was less frequent for RA than for GA (adjusted OR $0.71,95 \% \mathrm{Cl} 0.53$ to $0.97, \mathrm{p}=0.030$ ) and LA (adjusted OR $0.51,95 \% \mathrm{Cl} 0.33$ to 0.79 , $\mathrm{p}=0.002$ ). Postoperative hospital stay was significantly shorter for RA and LA compared with GA (adjusted $p=0.003$ and $p=0.010$, respectively). There were no significant differences in systemic and surgical complications. Mortality rates within 30 days did not differ among the groups.

Conclusion: Type of anesthesia used during EVAR has no influence on perioperative mortality and morbidity. The use of local or regional anesthesia during EVAR appeared to be beneficial concerning procedure time, ICU admission, and postoperative hospital stay. 


\section{INTRODUCTION}

Since the introduction of endovascular aortic repair (EVAR) in the 1980s, there have been substantial changes in the treatment of abdominal aortic aneurysms (AAAs). ${ }^{1}$ With improved delivery technique and better technical features of the next-generation stent-grafts, EVAR shows lower intraoperative mortality and morbidity compared with the conventional open operation for AAA.

After 20 years, there is still no consensus about which type of anesthesia is most suitable for EVAR. Feasibility of local and regional anesthesia was proven in $1999 .^{5}$ According to the guidelines of the European Society for Vascular Surgery, the preferential use of local anesthesia for EVAR is feasible and appears to be well tolerated, restricting regional or general anesthesia only to those with predefined contraindications for local anesthesia. ${ }^{6}$ The Society for Vascular Surgery practice guidelines suggest the use of epidural and local anesthetic along with conscious sedation for patients undergoing EVAR. ${ }^{7}$ However, these guidelines are based on a low level of evidence and recommendation.

The main objective of this study was to compare different anesthesia techniques in a realworld setting based on data retrieved from the prospective Endurant Stent Graft Natural Selection Global Post-Market Registry (ENGAGE) database.

\section{METHODS}

\section{Registry Design}

The prospective, multicenter, nonrandomized ENGAGE Registry was undertaken to quantify the performance of the Endurant Stent Graft System (Medtronic, Santa Rosa, CA, USA) within the context of contemporary, real-world use. Ruptured AAAs were not eligible for the Registry, which was conducted according to the Declaration of Helsinki and the International 
Conference on Harmonization (ICH) Good Clinical Practice (GCP) guidelines. The Institutional Review Board at all participating sites approved the protocol, data collection, and analysis; informed consent for authorization of data release was obtained in all patients at the time of enrollment. Preexisting medical comorbidities and cardiovascular risk factors were recorded along with procedure and device information on web-based case report forms. Full methodological details of the ENGAGE Registry ${ }^{8}$ and of data collection ${ }^{9}$ were described previously. All of the data were reviewed, and more than $40 \%$ of patients' source documentation was monitored randomly.

Quality of life was assessed using the EuroQoL 5-Dimensions Questionnaire (EQ-5D) index score, a standardized instrument for use as a measure of health outcome in 3 different ways. ${ }^{10}$ The descriptive system has 5 dimensions (mobility, self-care, usual activity, pain/discomfort, and anxiety/depression) and 3 levels (no problems, some problems, extreme problems), which create 243 unique health states and can be converted into a single summary EQ-5D index (second measure) by applying scores from a set of general population preference weights. This study used the Dutch value set to calculate the EQ-5D index. The third measure was a 0 to 100 visual analogue scale (VAS) for self-rating of patient health. Ratings took place at the first contact (baseline), at discharge, and at the 30-day outpatient visit.

\section{Definitions and Outcome Variables}

Data about type of anesthesia were derived from operation and anesthesia reports. Local anesthesia (LA) was defined as infiltration of local anesthetics into the groin in combination or not with sedation. Spinal and epidural anesthesia were both defined as regional anesthesia (RA). If multiple anesthesia techniques were used, patients were assigned to the most invasive technique.

The primary outcome measure for the current analysis was 30-day morbidity and mortality. Secondary outcome measures included adverse events and quality of life. Technical success, procedure time, fluoroscopic time, volume of contrast, postoperative stay, and intensive care unit (ICU) admission were recorded. Initial technical success was defined as successful delivery and deployment of the Endurant endograft, without unintentional coverage of renal 
arteries, internal iliac arteries, or visceral branches, with absence of either a type I or III endoleak, followed by successful removal of the delivery system. ${ }^{11}$ Duration of the implant procedure was defined as the time between cut down or puncture and removal of the last guide catheter. Thirty-day complications included all-cause mortality, cardiac complications (cardiac death, myocardial infarction, cardiogenic shock, arrhythmia, other) bowel ischemia, neurologic complications (paraplegia, stroke), renal failure, respiratory failure, and surgical complications (access site, blood loss $>1000 \mathrm{~mL}$, conversion to open surgery). Thirty-day follow-up was completed for all patients.

\section{Patient Groups}

Excluding 2 patients who had missing anesthesia type, data were collected on 1261 patients (mean age 73.1 years; 1130 men) enrolled in the ENGAGE registry. Of these, 145 (11.5\%) had LA, 331 (26.2\%) had RA, and 785 (62.3\%) had general anesthesia (GA). The GA group included 6 patients who scored both spinal and general anesthesia. Demographic data and baseline risk factors are presented in Table 1.

\section{Statistical Analysis}

Categorical variables are presented as frequencies (percentages); continuous variables are presented as mean \pm standard deviation and/or median and interquartile range in the event of skewed data. Differences in baseline characteristics among the 3 study groups were analyzed using the chi-square test for discrete variables and the analysis of variance or the Kruskal-Wallis test for continuous variables. Multivariate logistic and linear regression analyses were used to adjust for possible confounding factors; Multicollinearity as checked using the variance inflation factor and the tolerance. While $p<0.05$ was considered statistically significant for most analyses, the value was adjusted to $p<0.017$ for the regression analysis (Bonferroni correction) owing to multiple testing between groups. All statistical analyses were performed using SPSS software (version 20 for MAC; IBM Corporation, Somers, NY, USA) 
Table 1. Baseline characteristics according to anesthesia type

\begin{tabular}{|c|c|c|c|c|}
\hline Variables & $\begin{array}{c}\text { General (GA) } \\
N=785^{\mathrm{a}}\end{array}$ & $\begin{array}{l}\text { Regional (RA) } \\
\quad \mathrm{N}=331^{\mathrm{a}}\end{array}$ & $\begin{array}{l}\text { Local (LA) } \\
N=145^{\mathrm{a}}\end{array}$ & P-value \\
\hline Age (years) & $73.6 \pm 8.1(46-93)$ & $72.3 \pm 8.1(43-91)$ & $72.3 \pm 7.7(51-93)$ & .026 \\
\hline Gender & & & & .742 \\
\hline Male & $89.9 \%(706 / 785)$ & $88.5 \%(293 / 331)$ & $90.3 \%(131 / 145)$ & \\
\hline Female & $10.1 \%(79 / 785)$ & $11.5 \%(38 / 331)$ & $9.7 \%(14 / 145)$ & \\
\hline Baseline symptoms & & & & .004 \\
\hline Asymptomatic & $86.5 \%(679 / 785)$ & $80.7 \%(267 / 331)$ & $77.2 \%(112 / 145)$ & \\
\hline Symptomatic & $13.5 \%(106 / 785)$ & $19.3 \%(64 / 331)$ & $22.8 \%(33 / 145)$ & \\
\hline ASA classification & & & & .002 \\
\hline Class I & $5.9 \%(46 / 784)$ & $5.1 \%(17 / 331)$ & $9.7 \%(14 / 145)$ & \\
\hline Class II & $39.5 \%(310 / 784)$ & $47.1 \%(156 / 331)$ & $42.1 \%(61 / 145)$ & \\
\hline Class III & $41.2 \%(323 / 784)$ & $42.9 \%(142 / 331)$ & $40.0 \%(58 / 145)$ & \\
\hline Class IV & $13.4 \%(105 / 784$ & $4.8 \%(16 / 331)$ & $8.3 \%(12 / 145)$ & \\
\hline \multicolumn{5}{|l|}{ Risk factors } \\
\hline Tobacco use & $46.5 \%(355 / 764)$ & $50.8 \%(164 / 323)$ & $60.8 \%(87 / 143)$ & .006 \\
\hline Hypertension & $76.0 \%(586 / 771)$ & $74.5 \%(246 / 330)$ & $74.1 \%(106 / 143)$ & .816 \\
\hline Hyperlipidaemia & $63.0 \%(465 / 738)$ & $61.4 \%(191 / 311)$ & $44.9 \%(62 / 138)$ & $<.001$ \\
\hline Diabetes & $20.9 \%(161 / 772)$ & $17.1 \%(56 / 327)$ & $13.2 \%(19 / 144)$ & .060 \\
\hline Cancer & $19.7 \%(152 / 773)$ & $20.9 \%(68 / 325)$ & $23.9 \%(34 / 142)$ & .497 \\
\hline Cardiac disease & $55.0 \%(431 / 784)$ & $54.4 \%(180 / 331)$ & $42.8 \%(62 / 145)$ & .023 \\
\hline $\mathrm{MI}$ & $27.2 \%(205 / 754)$ & $26.1 \%(82 / 314)$ & $22.0 \%(31 / 141)$ & .435 \\
\hline Arrhythmia & $16.7 \%(128 / 768)$ & $16.2 \%(52 / 321)$ & $12.5 \%(18 / 144)$ & .457 \\
\hline Angina & $15.8 \%(121 / 764)$ & $16.0 \%(52 / 324)$ & $13.1 \%(19 / 145)$ & .681 \\
\hline $\mathrm{CHF}$ & $5.1 \%(39 / 761)$ & $7.1 \%(23 / 322)$ & $6.2 \%(9 / 145)$ & .418 \\
\hline$C A D$ & $34.5 \%(261 / 756)$ & $39.0 \%(124 / 318)$ & $25.9 \%(37 / 143)$ & .023 \\
\hline Cardiac revascularisation & $28.1 \%(216 / 770$ & $28.7 \%(94 / 328)$ & $18.6 \%(27 / 145)$ & .049 \\
\hline Pulmonary disease & $25.7 \%(198 / 771)$ & $24.0 \%(78 / 325)$ & $23.6 \%(34 / 144)$ & .774 \\
\hline Renal insufficiency & $15.3 \%(119 / 778)$ & $15.0 \%(49 / 327)$ & $15.2 \%(22 / 145)$ & .991 \\
\hline Cerebrovascular disease & $12.1 \%(95 / 784)$ & $14.2 \%(47 / 331)$ & $12.4 \%(18 / 145)$ & .631 \\
\hline
\end{tabular}

Abbreviations: ASA American society of anaesthesiologists; MI, Myocardial Infarctions, CHF, Congestive Heart Failure; CAD, Coronary Artery Disease

a Values are reported as mean \pm standard deviation, or as frequencies. Denominators differ when values are missing

\section{RESULTS}

\section{Baseline Characteristics}

Patients were predominantly men, and the distribution of sexes was comparable between the groups. On average, there was an overall significant difference in age in GA, RA, and LA patients (Table 1, p=0.026). Distribution among the American Society of Anesthesiologists (ASA) classes was not equal ( $p=0.002)$; ASA class IV was associated with predominant use of GA (Figure 1). Symptomatic presentation was lower in LA and RA patients compared with GA patients $(p=0.004)$. Risk factors, such as tobacco use, hyperlipidemia, coronary artery disease, and cardiac revascularization, were overall significantly different among groups 
(Table 1). Baseline aneurysm characteristics are summarized in Table 2. There were no significant differences in AAA diameter $(p=0.449)$. Distal iliac fixation site diameters, proximal normal neck length, and angulation were significantly different among groups.

Figure 1. Distribution of anaesthesia type by American Society of Anaesthesiologists (ASA) classification. GA, general anesthesia; LA, local anesthesia; RA, regional anesthesia.

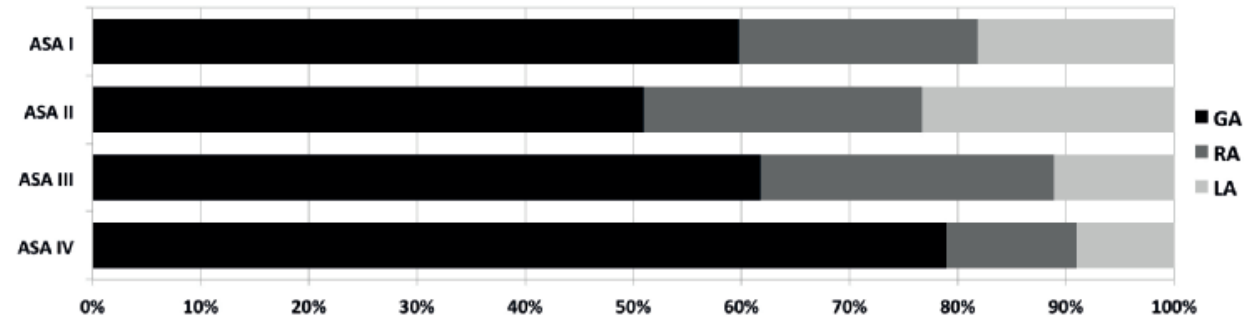

Table 2. Baseline aneurysm characteristics

\begin{tabular}{|c|c|c|c|c|}
\hline Variables & $\begin{array}{c}\text { General (GA) } \\
N=785^{\circ}\end{array}$ & $\begin{array}{c}\text { Regional (RA) } \\
N=331^{\mathrm{a}}\end{array}$ & $\begin{array}{l}\text { Local (LA) } \\
N=145^{\mathrm{a}}\end{array}$ & P-value \\
\hline Maximum AAA diameter, $\mathrm{mm}$ & $60.5 \pm 11.9$ & $60.1 \pm 10.6$ & $59.3 \pm 12.6$ & .449 \\
\hline Proximal neck diameter, mm & $23.7 \pm 3.5$ & $23.6 \pm 3.6$ & $24.3 \pm 3.9$ & .160 \\
\hline Proximal neck length, mm & $27.5 \pm 12.5$ & $26.8 \pm 12.6$ & $24.7 \pm 11.0$ & .045 \\
\hline \multicolumn{5}{|c|}{ Distal iliac fixation site diameter, $\mathrm{mm}$} \\
\hline Right & $14.4 \pm 3.6$ & $14.0 \pm 3.7$ & $13.4 \pm 3.0$ & .017 \\
\hline Left & $14.0 \pm 3.5$ & $13.6 \pm 4.0$ & $13.1 \pm 2.9$ & .014 \\
\hline Infrarenal neck angle, deg & $28.8 \pm 23.3$ & $33.2 \pm 24.7$ & $31.9 \pm 23.9$ & .014 \\
\hline Suprarenal neck angle, deg & $18.0 \pm 18.3$ & $19.1 \pm 18.5$ & $22.6 \pm 19.5$ & .024 \\
\hline
\end{tabular}

\section{Intraoperative Outcomes}

The mean adjusted procedure duration (Table 3 ) was significantly shorter in LA $(80.4 \pm 40.0$ minutes) compared to RA $(94.2 \pm 41.6$ minutes, adjusted $p=0.001)$ and $G A(105.3 \pm 46.0$ minutes, adjusted $p<0.001$ ). There were no significant differences in type I and/or type III endoleaks at completion angiography among groups. Type of anesthesia used did not influence technical success rates. No intraoperative deaths occurred.

Focusing on hospitalization, GA patients were significantly longer in the hospital than RA and LA patients (adjusted $p=0.003$ and $p=0.010$, respectively). GA and LA patients were admitted more frequently to the ICU than RA patients (GA vs RA: adjusted OR 1.40,95\% Cl 1.03 to 1.90, $p=0.030 ;$ RA vs LA: adjusted OR $0.51,95 \% \mathrm{Cl} 0.33$ to $0.79, \mathrm{p}=0.002$ ). 
Table 4. Outcome at 30 days by anesthesia type

\begin{tabular}{|c|c|c|c|c|c|c|}
\hline \multirow{2}{*}{ Variables } & \multirow{2}{*}{$\begin{array}{l}\text { General } \\
\qquad \begin{array}{c}\text { (GA) } \\
N=785^{a}\end{array}\end{array}$} & \multirow{2}{*}{$\begin{array}{l}\text { Regional } \\
\quad(\mathrm{RA}) \\
\mathrm{N}=331^{\mathrm{a}}\end{array}$} & \multirow{2}{*}{$\begin{array}{c}\text { Local } \\
\text { (LA) } \\
N=145^{a}\end{array}$} & \multicolumn{3}{|c|}{ Corrected $p$-value } \\
\hline & & & & GA vs. $R A^{b}$ & ${ }^{b} G$ vs. $L A^{b}$ & $R A$ vs. $L A^{b}$ \\
\hline One or more complications & $44(5.6)$ & $16(4.8)$ & $4(2.8)$ & $\begin{array}{c}1.23(0.65 \\
\text { to } 2.31 \\
p=.529)\end{array}$ & $\begin{array}{c}2.79(0.84 \\
\text { to } 9.29 \\
p=.094)\end{array}$ & $\begin{array}{c}2.28(0.63 \\
\text { to } 8.18 \\
p=.207)\end{array}$ \\
\hline All-cause mortality & $11(1.4)$ & $3(0.9)$ & $2(1.4)$ & $\begin{array}{c}1.52(0.41 \\
\text { to } 5.65 \\
p=.534)\end{array}$ & $\begin{array}{c}0.91(0.19 \\
\text { to } 4.36 \\
p=.904)\end{array}$ & $\begin{array}{c}0.60(0.10 \\
\text { to } 3.75 \\
p=.598)\end{array}$ \\
\hline \multicolumn{7}{|l|}{ Cardiac complications } \\
\hline One ore more cardiac sequel & $18(2.3)$ & $6(1.8)$ & $2(1.4)$ & $\begin{array}{c}1.12(0.42 \\
\text { to } 3.01 \\
p=.818)\end{array}$ & $\begin{array}{c}1.00(0.21 \\
\text { to } 4.65 \\
p=.997)\end{array}$ & $\begin{array}{c}0.89(0.17 \\
\text { to } 4.69 \\
p=.889)\end{array}$ \\
\hline Cardiac death & $6(0.8)$ & $1(0.3)$ & $1(0.7)$ & $\begin{array}{c}2.74(0.32 \\
\text { to } 23.50 \\
p=.358)\end{array}$ & $\begin{array}{c}0.94(0.10 \\
\text { to } 8.80 \\
p=.958)\end{array}$ & $\begin{array}{c}0.34(0.02 \\
\text { to } 5.95 \\
p=.463)\end{array}$ \\
\hline Myocardial infarction & $11(1.4)$ & $1(0.3)$ & $2(1.4)$ & $\begin{array}{c}4.55(0.56 \\
\text { to } 36.70 \\
p=.155)\end{array}$ & $\begin{array}{c}0.47(0.09 \\
\text { to } 2.48 \\
p=.376)\end{array}$ & $\begin{array}{c}0.10(0.01 \\
\text { to } 1.27 \\
p=.104)\end{array}$ \\
\hline Cardiogenic shock & $2(0.2)$ & $1(0.3)$ & $0(0.0)$ & - & - & - \\
\hline Arrhythmia & $3(0.4)$ & $3(0.9)$ & $0(0.0)$ & - & - & - \\
\hline Other cardiac & $2(0.2)$ & $1(0.3)$ & $0(0.0)$ & - & - & - \\
\hline Renal failure & $3(0.4)$ & $0(0.0)$ & $0(0.0)$ & $\begin{array}{c}1.74(0.17 \\
\text { to } 17.79 \\
p=.642)\end{array}$ & 7 & - \\
\hline Respiratory failure & $0(0.0)$ & $0(0.0)$ & $0(0.0)$ & - & - & - \\
\hline Bowel ischemia & $3(0.4)$ & $0(0.0)$ & $0(0.0)$ & - & - & - \\
\hline \multicolumn{7}{|l|}{ Neurologic } \\
\hline Paraplegia & $0(0.0)$ & $0(0.0)$ & $0(0.0)$ & - & - & - \\
\hline Stroke & $1(0.1)$ & $0(0.0)$ & $1(0.7)$ & - & - & - \\
\hline \multicolumn{7}{|l|}{ Surgical } \\
\hline Blood loss $\geq 1000 \mathrm{~mL}$ & $16(2.0)$ & $2(0.6)$ & $0(0.0)$ & $\begin{array}{c}3.28(0.74 \\
\text { to } 14.65 \\
p=.119)\end{array}$ & - & - \\
\hline Access site bleeding & $7(0.8)$ & $3(0.9)$ & $1(0.7)$ & $\begin{array}{c}0.76(0.18 \\
\text { to } 3.19 \\
p=.702)\end{array}$ & $\begin{array}{c}1.02(0.12 \\
\text { to } 9.09 \\
p=.983)\end{array}$ & $\begin{array}{c}1.36(0.13 \\
\text { to } 13.81 \\
p=.797)\end{array}$ \\
\hline Secondary intervention & $10(1.3)$ & $7(2.1)$ & $2(1.4)$ & $\begin{array}{c}0.77(0.25 \\
\text { to } 2.32 \\
p=.639)\end{array}$ & $\begin{array}{c}1.02(0.21 \\
\text { to } 4.85 \\
p=.984)\end{array}$ & $\begin{array}{c}1.32(0.25 \\
\text { to } 7.15 \\
p=0.744)\end{array}$ \\
\hline
\end{tabular}

\footnotetext{
Values are reported as counts/sample (percentage).

${ }^{b}$ Odds ratio (95\% confidence interval) adjusted for age, baseline symptoms, ASA classification, tobacco use, hyperlipidemia, coronary artery disease, cardiac revascularization.
} 
Table 5. Outcome of activities of daily living and quality of life at 3 point by anesthesia type

\begin{tabular}{|c|c|c|c|c|}
\hline Variables & General $(\mathrm{GA})^{\mathrm{a}}$ & Regional (RA) & Local $(L A)^{a}$ & P-value \\
\hline Baseline & $N=750$ & $N=327$ & $N=130$ & \\
\hline Mobility & & & & .673 \\
\hline 1 (no problem) & $69.9 \%(524)$ & $69.1 \%(226)$ & $67.7 \%(88)$ & \\
\hline 2 (some problems) & $29.5 \%(221)$ & $30.6 \%(100)$ & $30.8 \%(40)$ & \\
\hline 3 (extreme problems) & $0.7 \%(5)$ & $0.3 \%(1)$ & $1.5 \%(2)$ & \\
\hline Self-care & & & & .953 \\
\hline 1 (no problem) & $90.1 \%(676)$ & $91.4 \%(299)$ & $90.0 \%(117)$ & \\
\hline 2 (some problems) & $8.5 \%(64)$ & $7.6 \%(25)$ & $8.5 \%(11)$ & \\
\hline 3 (extreme problems) & $1.3 \%(10)$ & $0.9 \%(3)$ & $1.5 \%(2)$ & \\
\hline Usual activities & & & & .848 \\
\hline 1 (no problem) & $79.5 \%(596)$ & $81.7 \%(267)$ & $82.3 \%(107)$ & \\
\hline 2 (some problems) & $17.9 \%(134)$ & $16.2 \%(53)$ & $16.2 \%(21)$ & \\
\hline 3 (extreme problems) & $2.7 \%(20)$ & $2.1 \%(7)$ & $1.5 \%(2)$ & \\
\hline Pain/discomfort & & & & .634 \\
\hline 1 (no problem) & $64.9 \%(487)$ & $63.9 \%(209)$ & $68.5 \%(89)$ & \\
\hline 2 (some problems) & $32.0 \%(240)$ & $33.9 \%(111)$ & $27.7 \%(36)$ & \\
\hline 3 (extreme problems) & $3.1 \%(23)$ & $2.1 \%(7)$ & $3.8 \%(5)$ & \\
\hline Anxiety/depression & & & & .201 \\
\hline 1 (no problem) & $73.5 \%(551)$ & $70.6 \%(231)$ & $70.8 \%(92)$ & \\
\hline 2 (some problems) & $24.1 \%(181)$ & $26.0 \%(85)$ & $23.1 \%(30)$ & \\
\hline 3 (extreme problems) & $2.4 \%(18)$ & $3.4 \%(11)$ & $6.2 \%(8)$ & \\
\hline VAS score of health $(0-100)$ & & & & .270 \\
\hline Mean $\pm S D$ & $73.0 \pm 16.4$ & $72.1 \pm 16.9$ & $74.8 \pm 17.1$ & \\
\hline Median (IQR) & $75(65-85)$ & $75(60-85)$ & $80(60-90)$ & \\
\hline EQ-5D index ${ }^{a}$ & & & & .492 \\
\hline Mean \pm SD & $0.84 \pm 0.21$ & $0.84 \pm 0.20$ & $0.82 \pm 0.22$ & \\
\hline Median (IQR) & $0.86(0.78-1)$ & $0.84(0.78-1)$ & $0.84(0.77-1)$ & \\
\hline At discharge & $N=641$ & $\mathbf{N}=\mathbf{2 8 5}$ & $N=118$ & \\
\hline EQ-5D index ${ }^{a}$ & & & & .128 \\
\hline Mean $\pm S D$ & $0.78 \pm 0.22$ & $0.81 \pm 0.19$ & $0.81 \pm 0.17$ & \\
\hline Median (IQR) & $0.81(0.69-1)$ & $0.84(0.73-1)$ & $0.81(0.78-1)$ & \\
\hline Change from baseline to discharge & & & & .006 \\
\hline Mean \pm SD & $-0.06 \pm 0.22$ & $-0.03 \pm 0.17$ & $0.00 \pm 0.19$ & \\
\hline Median (IQR) & $0.00(-0.16-0.00)$ & $0.00(-0.12-0.00)$ & $0.00(-0.09-0.00)$ & \\
\hline After 30 days & $N=646$ & $N=282$ & $N=125$ & \\
\hline EQ-5D index ${ }^{a}$ & & & & .978 \\
\hline Mean \pm SD & $0.85 \pm 0.19$ & $0.85 \pm 0.19$ & $0.86 \pm 0.19$ & \\
\hline Median $(I Q R)^{a}$ & $0.89(0.81-1)$ & $0.89(0.78-1)$ & $0.89(0.81-1)$ & \\
\hline Change from baseline to 30 days & & & & .328 \\
\hline Mean \pm SD & $0.08 \pm 0.21$ & $0.05 \pm 0.17$ & $0.04 \pm 0.17$ & \\
\hline Median (IQR) & $0.03(0.00-0.16)$ & $0.00(0.00-0.16)$ & $0.03(0.00-0.16)$ & \\
\hline
\end{tabular}

\footnotetext{
Abbreviations: EQ-5D, EuroQoL 5-Dimensions Questionnaire; VAS, Visual Analogue Scale.

a Values are reported as mean \pm standard deviation and median (interquartile range), or as counts (percentage). Denominators differ when values are missing

${ }^{\mathrm{b}}$ A Dutch value set used to calculate EQ-5D Index Score.
} 


\section{DISCUSSION}

The effect of different anesthetic techniques in EVAR is described in small studies with possible selection bias. Unprecedented in size, scope, and geographic representation, the ENGAGE Registry represents the collective experience of 79 centers in 30 countries across 5 continents using a single stent-graft. Patients with a wide spectrum of comorbidities were included, resulting in a representation of everyday real-world clinical practice.

According to the European and American guidelines, the use of local anesthesia for EVAR is preferred. ${ }^{6,7}$ Despite this consensus, EVAR is still mainly conducted under $\mathrm{GA}^{12-15}$ as reflected in our study in which more than half the patients were treated under GA. However, there were large intercontinental differences for the primary choice of anesthetic (Figure 2). The differences between regions in Europe were even more remarkable. This could be explained by sustained regional customs of vascular surgeons and anesthesiologists. Another interesting finding is that patients in the GA group had a significantly higher ASA score, which is not according to the European guidelines. ${ }^{6}$ Unfortunately, the Registry did not foresee the need for a specific explanation on the individual choice of anesthesia, so we can only speculate on individual preferences.

Figure 2. Distribution of anesthesia type by geographic region. GA, general anesthesia; RA, regional anesthesia; LA, local anesthesia.

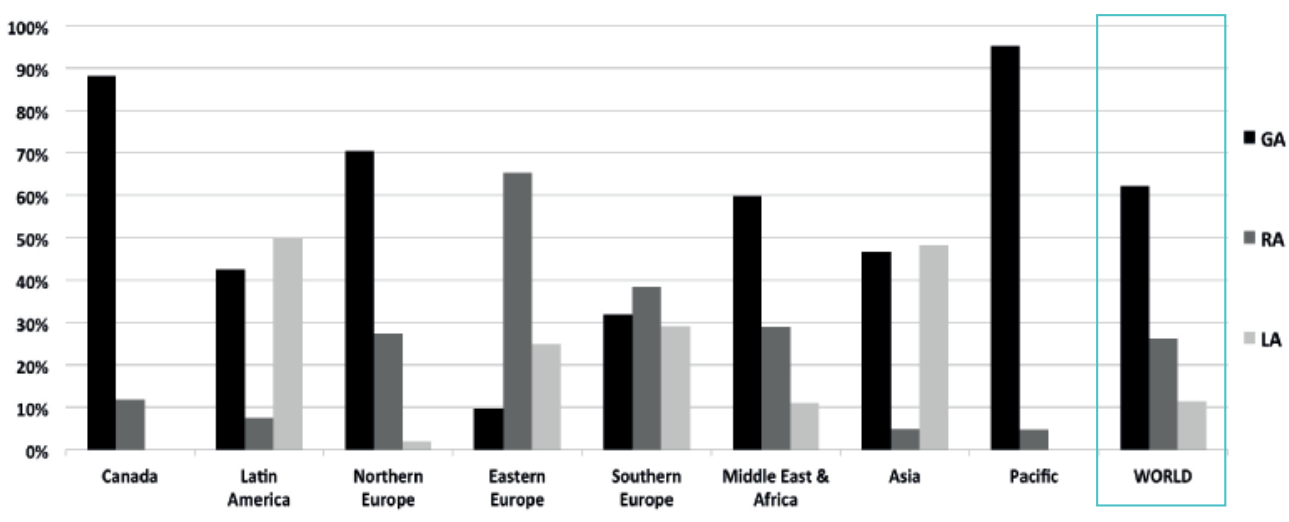


In a cohort of 217 consecutive patients treated with a "local anesthesia-first strategy," LA could be applied in $\sim 75 \%$ of patients undergoing elective EVAR. ${ }^{16}$ Lachat et al. ${ }^{17}$ published their first results of 100 consecutive patients treated percutaneous under local anesthesia in an outpatient setting, showing excellent results. Compared to the older EUROpean collaborators on Stent-graft Techniques for abdominal Aneurysm Repair (EUROSTAR) registry data, ${ }^{14}$ our analysis found a more frequent use of LA (11.5\% vs $\left.5.6 \%\right)$, which implies that LA is applied more commonly today.

EUROSTAR data indicated no differences in surgical outcome among types of anesthesia. ${ }^{14}$ Our results are consistent with these findings, showing comparable rates of technical success and endoleaks among the groups. In addition, no significant differences were seen in the need for secondary procedures within 30 days after implant.

LA and RA had shorter procedure times and hospital stays than GA. ${ }^{12,14,18,19}$ In contrast to previous reports, ${ }^{13,14,18-21}$ the LA group had a remarkably higher requirement for ICU admission. This difference might be caused by 2 centers that had $100 \%$ ICU admission in 38 (26.2\%) LA patients. When these groups were excluded, a significantly lower ICU admission rate emerged for LA (22.4\%) compared with GA (35.8\%; adjusted OR 0.55, $95 \% \mathrm{Cl} 0.33$ to $0.91, p=0.020)$.

LA and RA are proven to be feasible and safe as an alternative for general anesthesia during EVAR. $^{22}$ All-cause mortality rates were low in all 3 groups and were comparable with other studies. ${ }^{14,15}$ There were no differences in short-term complications. There was a suggestion that LA might have fewer complications, but no significant advantage for LA was established, probably due to the low incidence of complications and its infrequent use. LA scored best on EQ-5D compared to RA and GA, which may imply that patients recover quicker after LA.

Bakker et al. ${ }^{23}$ described a significantly higher cardiac event rate at 30 days comparing general and locoregional anesthesia (OR 3.8, 95\% Cl 1.1 to $12.9, \mathrm{p}=0.03$ ). Despite a larger group of patients, there was no significant difference in cardiac event rates between general and locoregional anesthesia (OR $1.09,95 \% \mathrm{Cl} 0.45$ to $2.67, \mathrm{p}=0.849$ ) in the ENGAGE cohort. 
The success of EVAR is highly dependent on AAA anatomy. Short and angulated infrarenal aortic necks increase the risk of type I endoleaks. ${ }^{24}$ Complex AAA anatomy may also extend the duration of surgery, resulting in more discomfort for patients treated with locoregional anesthesia. ${ }^{25}$ There was a shorter infrarenal neck length and a smaller iliac access diameter in the LA group. However, these differences were minimal and did not result in relevant differences in AAA complexity. LA may influence imaging quality because it is very dependent on patient movement and breath-holding ability during imaging. ${ }^{16}$ This could be an explanation why we found significantly more contrast use in the LA group.

General anesthesia might be preferred for extremely complex cases when there is a possibility of immediate conversion to open surgery. However, there was a low conversion rate of $0.3 \%$ in our study population. Furthermore, with an appropriate standby anesthetic team, conversion to $\mathrm{GA}$ is always possible.

\section{Limitations}

Unfortunately, preoperative clarification regarding the choice of anesthesia type is missing. Information regarding possible anesthesia type conversion was not documented. Therefore, no intention-to-treat analysis could be performed, and selection bias may have affected the results. The technique of femoral/iliac access was not documented. Percutaneous EVAR influences the amount of blood loss, operating time, and postoperative stay, possibly confounding results. Also, one has to take into account that the ENGAGE Registry was not designed nor powered for this specific retrospective analysis, restraining our findings.

\section{CONCLUSION}

The main findings of this study were that LA and RA had advantages compared with GA regarding duration of procedure and postoperative stay. No effects of anesthesia type on procedure success and perioperative mortality and morbidity were reported. Patients seemed to recover quicker after LA. Based on these results, a strategy based on preferential use of locoregional anesthesia for EVAR is advised, restricting GA only to those with predefined contraindications. 


\section{REFERENCES}

1. Volodos NL, Shekhanin VE, Karpovich IP, et al. A self-fixing synthetic blood vessel endoprosthesis [in Russian]. Vestn Khir Im I I Grek. 1986;137(11):123-125.

2. Endovascular aneurysm repair versus open repair in patients with abdominal aortic aneurysm (EVAR trial 1): randomized controlled trial. Lancet. 2005;365:2179-2186.

3. Lederle FA, Freischlag JA, Kyriakides TC, et al. Outcomes following endovascular vs open repair of abdominal aortic aneurysm: a randomized trial. JAMA. 2009;302:1535-1542.

4. Prinssen $\mathrm{M}$, Verhoeven EL, Buth J, et al. A randomized trial comparing conventional and endovascular repair of abdominal aortic aneurysms. N Engl J Med. 2004;351:16071618.

5. Henretta JP, Hodgson KJ, Mattos MA, et al. Feasibility of endovascular repair of abdominal aortic aneurysms with local anesthesia with intravenous sedation. J Vasc Surg. 1999;29:793-798.

6. Moll FL, Powell JT, Fraedrich G, et al. Management of abdominal aortic aneurysms clinical practice guidelines of the European Society for Vascular Surgery. Eur J Vasc Endovasc Surg. 2011;41(suppl 1):S1-S58.

7. Chaikof EL, Brewster DC, Dalman RL, et al. The care of patients with an abdominal aortic aneurysm: the Society for Vascular Surgery practice guidelines. J Vasc Surg. 2009;50(4 suppl):S2-S49.

8. Stokmans RA, Teijink JA, Forbes TL, et al. Early results from the ENGAGE registry: real-world performance of the Endurant Stent Graft for endovascular AAA repair in 1262 patients. Eur J Vasc Endovasc Surg. 2012;44:369-375.
9. Bockler $D$, Fitridge $R$, Wolf $Y$, et al. Rationale and design of the Endurant Stent Graft Natural Selection Global Postmarket Registry (ENGAGE): interim analysis at 30 days of the first 180 patients enrolled. J Cardiovasc Surg (Torino). 2010;51:481-491.

10. Cavrini G, Broccoli S, Puccini A, et al. EQ-5D as a predictor of mortality and hospitalization in elderly people. Qual Life Res. 2012;21:269280.

11. Chaikof EL, Blankensteijn JD, Harris PL, et al. Reporting standards for endovascular aortic aneurysm repair. J Vasc Surg. 2002;35:10481060.

12. De Virgilio C, Romero L, Donayre C, et al. Endovascular abdominal aortic aneurysm repair with general versus local anesthesia: a comparison of cardiopulmonary morbidity and mortality rates. J Vasc Surg. 2002;36:988-991.

13. Parra JR, Crabtree T, McLafferty RB, et al. Anesthesia technique and outcomes of endovascular aneurysm repair. Ann Vasc Surg. 2005;19:123-129.

14. Ruppert V, Leurs LJ, Steckmeier B, et al. Influence of anesthesia type on outcome after endovascular aortic aneurysm repair: an analysis based on EUROSTAR data. J Vasc Surg. 2006;44:16-21.

15. Edwards MS, Andrews JS, Edwards AF, et al. Results of endovascular aortic aneurysm repair with general, regional, and local/monitored anesthesia care in the American College of Surgeons National Surgical Quality Improvement Program database. J Vasc Surg. 2011;54:1273-1282.

16. Geisbusch P, Katzen BT, Machado R, et al. Local anaesthesia for endovascular repair of infrarenal aortic aneurysms. Eur J Vasc Endovasc Surg. 2011;42:467-473. 
17. Lachat ML, Pecoraro F, Mayer D, et al. Outpatient endovascular aortic aneurysm repair: experience in 100 consecutive patients. Ann Surg. 2013;258:754-759.

18. Bettex DA, Lachat M, Pfammatter $\mathrm{T}$, et al. To compare general, epidural and local anaesthesia for endovascular aneurysm repair (EVAR). Eur J Vasc Endovasc Surg. 2001;21:179-184.

19. Verhoeven EL, Cina CS, Tielliu IF, et al. Local anesthesia for endovascular abdominal aortic aneurysm repair. J Vasc Surg. 2005;42:402409.

20. Ruppert V, Leurs LJ, Rieger J, et al. Riskadapted outcome after endovascular aortic aneurysm repair: analysis of anesthesia types based on EUROSTAR data. J Endovasc Ther. 2007;14:12-22.

21. Asakura $\mathrm{Y}$, Ishibashi $\mathrm{H}$, Ishiguchi $\mathrm{T}$, et al. General versus locoregional anesthesia for endovascular aortic aneurysm repair: influences of the type of anesthesia on its outcome. J Anesth. 2009;23:158-161.

22. Karthikesalingam A, Thrumurthy SG, Young EL, et al. Locoregional anesthesia for endovascular aneurysm repair. J Vasc Surg. 2012;56:510519.

23. Bakker EJ, van de Luijtgaarden KM, van Lier F, et al. General anaesthesia is associated with adverse cardiac outcome after endovascular aneurysm repair. Eur J Vasc Endovasc Surg. 2012;44:121-125.

24. Stather PW, Wild JB, Sayers RD, et al. Endovascular aortic aneurysm repair in patients with hostile neck anatomy. J Endovasc Ther. 2013;20:623-637.

25. Georgiadis GS, Trellopoulos G, Antoniou GA, et al. Early results of the Endurant endograft system in patients with friendly and hostile infrarenal abdominal aortic aneurysm anatomy. J Vasc Surg. 2011;54:616-627. 

PART TWO

COVERAGE OF THE INTERNAL ILIAC ARTERY 



\section{CHAPTER 5}

\section{CHALLENGING THE EVIDENCE FOR}

PRE-EMPTIVE COIL EMBOLISATION OF

THE INTERNAL ILIAC ARTERY DURING

ENDOVASCULAR ANEURYSM REPAIR

\section{R.A. Stokmans}

E.M. Willigendael

J.A.W. Teijink

J.A. Ten Bosch

M.R.H.M. van Sambeek

Ph.W.M. Cuypers

European Journal of Vascular and Endovascular Surgery 2013 March; 45(3): 220-226 


\section{ABSTRACT}

Objectives: We retrospectively analysed the results of a strategy in which coverage of the internal iliac artery during EVAR was routinely performed without coil embolisation.

Methods: From January 2010 until May 2012, 32 patients (96.9\% men; mean age 73.0 years; range 52-89 years) underwent EVAR with stent-grafts extended into the external iliac artery (EIA), all without prior coil embolisation. Aneurysm morphology was determined on preoperative CT-images. During follow-up, patients were interviewed about buttock claudication, and the occurrence of endoleaks and evolution of aneurysm diameter were registered.

Results: At baseline, mid-CIA diameter was $33.5 \pm 16.8 \mathrm{~mm}$, and 7 patients presented with ruptured aneurysms. Mean follow-up was $14.3 \pm 7.4$ months. There were 8 deaths, none related to IIA coverage. Buttock claudication occurred in 7 (22.6\%) patients, which persisted after 6 months in 2 cases of bilateral IIA coverage. No Type-I or II endoleaks occurred related to IIA coverage. Aneurysm growth was not observed.

Conclusion: Endovascular treatment of aorto-iliac and iliac aneurysm without pre-emptive coil embolisation of the IIA appears safe and effective. No IIA-related endoleaks or reinterventions occurred in our series. This approach saves operating-time, contrast load and costs, and may reduce complications. However, a larger population and longer follow-up is required to confirm our findings. 


\section{INTRODUCTION}

Approximately $20-30 \%$ of abdominal aortic aneurysms (AAAs) involve at least one common iliac artery $(\mathrm{CIA}) .^{1}$ It has been demonstrated that the technical success rate of endovascular abdominal aneurysm repair (EVAR) is lower when a CIA is involved. ${ }^{2}$ Whenever possible, the $\mathrm{CIA}$ will serve as a distal sealing site. lliac limbs up to $28 \mathrm{~mm}$ diameter are commercially available for the so-called bell-bottom technique. ${ }^{3}$ According to the manufacturers' instructions, these stent grafts may be used for iliac aneurysms up to $24 \mathrm{~mm}$ diameter, thereby avoiding coverage of the IIA. In cases of CIAs larger than $24 \mathrm{~mm}$, however, extension of the stent graft into the external iliac artery (EIA) is often required to achieve adequate seal. ${ }^{4}$ Alternatively, in elective cases with suitable anatomy, common iliac aneurysms may be treated with iliac branch devices or sandwich techniques in order to maintain inflow into the IIA.

Theoretically, covering the IIA involves a risk for a Type-II endoleak. As a preventative measure, intentional IIA occlusion is assumed to be mandatory. Usually, IIA coil embolisation prior to EVAR is performed to prevent endoleak. ${ }^{6,7}$ Less frequently, vascular plugs or acrylic glue are used, or intra-operative ligation, transposition or bypass of the IIA is applied.

To date, however, no solid evidence exists for the necessity of these preventive measures. Previous studies focused mainly on the outcome of coil embolisation itself. ${ }^{12-18}$ Although most studies conclude that this method is relatively safe, ${ }^{12,13,15,16,18}$ some serious complications have been reported, including gluteus muscle necrosis, ischemic colitis and spinal ischemia. ${ }^{14-16,18-20}$ Complications are less frequent when IIA occlusion is performed as proximal as possible to its orifice.$^{18}$ It has been hypothesized that sole stent graft coverage of the IIA's orifice provides the most proximal occlusion and may limit the symptoms of pelvic ischemia. ${ }^{21,22}$ Remarkably, higher incidences of pelvic ischemia are reported in endovascular series with IIA coverage than in open surgical series with IIA ligation. ${ }^{15}$ This difference may partly be due to adjunctive measures such as coil embolisation of the IIA, leading to occlusion of secondary branches and interrupt pelvic collateral circulation. 
While recent studies have questioned the necessity and safety of coiling ${ }^{21-26}$ most reports of stent graft coverage without coil embolisation have been limited to instances of unintentional coverage during stent deployment or to cases of technical failure of attempted coil embolisation. ${ }^{21-25}$ Others applied this approach only in a selected group of patients. ${ }^{26}$ Nonetheless, IIA-related endoleaks in these studies are rare, and none required secondary intervention. $^{2}$

Since January 2010, a new policy has been applied in our department. None of the patients requiring EVAR with extension of a limb graft into the EIA were treated with pre-emptive coil embolisation. We analysed the technical and clinical outcome of this new policy in a consecutive series of 32 patients, describing iliac configurations, aneurysm diameter, occurrence of Type-I and -II endoleaks, and incidence of buttock claudication.

\section{METHODS}

\section{Study population}

From January 2010 to May 2012, all patients who were scheduled for EVAR with extension of a limb graft into the EIA were registered in a database and included in this study. In addition, we retrospectively reviewed procedural records of all EVAR procedures to identify and include cases in which inadvertent stent graft coverage of the IIA had occurred.

\section{Preoperative imaging}

All patients underwent preoperative imaging of the abdomen and pelvis to evaluate morphological eligibility for endovascular treatment, and to determine the need for IIA coverage. The primary imaging modality was contrast-enhanced spiral-computed tomography (CT) in conjunction with computer-aided measurements and central lumen line reconstruction (PACS Easy Vision, Philips Medical Systems BV, Eindhoven, The Netherlands). Vessel diameter was measured on CT scan reformats perpendicular to the artery. Maximum AAA and CIAA diameters were recorded, as well as, diameters of the most proximal and distal part of the CIA. Additionally, presence of flow in the proximal and distal branches of 
the IIA was registered. In cases of inadvertent coverage, missing variables were determined retrospectively.

\section{Procedure}

All endovascular procedures were performed in a vascular operating room under fluoroscopic control. A digital C-arm unit was used for making intraoperative angiograms (AXIOM Artis, Siemens AG, The Hague, The Netherlands). Anaesthetics, antibiotics, and heparin were administered following standard regimen. Stent grafts used were Endurant (Medtronic AVE, Santa Rosa, CA, USA), Excluder (WL Gore Associates Inc., Flagstaff, AZ, USA), or Zenith (Cook Medical Inc., Bloomington, IN, USA). A completion angiogram with delayed series after aortic injection was obtained to detect presence of endoleaks, and to document the status of the covered IIA, the contralateral IIA and collateral vascularization.

\section{Follow-up}

Patients were seen at 1, 6 and 12 months post-operative and after that once a year following standard follow-up regimen. Consultations were conducted by senior vascular surgeons and included a patient interview, physical examinations and imaging studies. During the first year of follow-up contrast-enhanced CT was used as standard imaging modality. After that, duplex ultrasonography was used. Experienced interventional radiologists and vascular surgeons assessed all images for aneurysm diameter increase or any signs endoleaks.

During the follow-up, patients were specifically interviewed about the appearance or increase of pain in the hip or buttock region. These symptoms were recorded as buttock claudication when they appeared immediately following EVAR and when the affected limb matched the side of IIA occlusion. Buttock claudication was categorised as severe if it interfered with daily activities and as mild if there was minor impact on lifestyle. Patients' files were reviewed for reports of adverse clinical events at follow-up to complete the database. If any uncertainty remained after file review, patients were interviewed by telephone. Occurrence of sexual dysfunction was not systematically included in the interview. 


\section{RESULTS}

\section{Baseline}

From January 2010 to May 2012, 191 EVAR procedures were performed at our institution. Our study population consisted of a total of $32(16.8 \%)$ consecutive patients, (31 men and 1 woman, mean age of 73.0 \pm 8.9 years, range 52-89 years) who underwent an endovascular procedure with unilateral IIA stent coverage (Table 1). Seven of these patients $(21.9 \%)$ were operated in an emergency setting for aneurysm rupture. Indications for planned IIA coverage are shown in Table 2. In two cases of bilateral CIAAs sole IIA coverage was performed at one side, and an Iliac-branched-device (Cook Zenith) was placed at the contralateral side. In another case, a planned bifurcated stent-graft was converted into an aorto-uni-iliac (AUI) device due to severe tortuosity of one iliac artery. One IIA was intentionally stent covered, while the contralateral IIA remained patent with retrograde filling from a femoro-femoral crossover bypass. Furthermore, 4 cases of inadvertent IIA coverage were identified.

All patients had patent IIAs on preoperative CTA, and none underwent any pre- or intraoperative intervention to occlude the IIA at the affected side. In 2 patients, however, the contralateral IIA had already been occluded for concomitant IIA aneurysm at another institution (Table 2). Both patients eventually had bilateral IIA coverage, but only the noncoiled IIAs were analysed. The anatomic configuration of the affected $\mathrm{CIA}$ was straight in 3 (9.4\%) cases, balloon-shaped in 26 (81.3\%) cases and funnel-shaped in 3 (9.4\%) cases. In 19 (59.4\%) cases the right side was affected. Maximum CIA diameter in cases of CIA aneurysms ranged between 26 and $83 \mathrm{~mm}$. The $\mathrm{CIA}$ diameter ranged between 10 and $39 \mathrm{~mm}$ at its most distal point, and between 6 and $20 \mathrm{~mm}$ at the orifice of the IIA (Table 1).

\section{Follow-up}

No intra-operative deaths occurred, but 1 patient (rAAA case) deceased in the ICU several days postoperatively. This patient was not accounted for in further analysis, since the cause of death was not related to IIA coverage and no post-operative CTA was made. The remaining 31 (96.9\%) patients had a mean follow-up of $14.3 \pm 7.4$ months (range 3-31 months). The number of patients who completed their 1, 6 and 12 months postoperative 
was 31, 28 and 21, respectively, with no cases lost-to-follow-up. Seven patients died during follow-up, but none of these deaths were related to the IIA coverage. At 3 months, 2 fatal myocardial infarctions occurred and 1 patient had multi-organ-failure (MOF) after an intervention for a stomach bleeding. At 9 months 1 patient died of MOF after an intervention for bilateral limb occlusion. Later on (at 16, 17 and 31 months post-implant) 3 more patients died, of cancer, stroke and myocardial infarction, respectively.

Table 1. Patient demographics, risk factors and baseline CIA morphology

\begin{tabular}{|c|c|}
\hline Variable & $N=32$ \\
\hline \multicolumn{2}{|l|}{ Age (years) } \\
\hline Mean \pm SD & $73.0 \pm 8.9$ \\
\hline Range & $(52-89)$ \\
\hline Male & $31(96.9 \%)$ \\
\hline \multicolumn{2}{|l|}{ ASA classification } \\
\hline Class I & $0(0.0 \%)$ \\
\hline Class II & $11(34.4 \%)$ \\
\hline Class III & $9(28.1 \%)$ \\
\hline Class IV & $5(15.6 \%)$ \\
\hline Class V & $7(21.9 \%)$ \\
\hline \multicolumn{2}{|l|}{ Risk factors } \\
\hline Smoking history & $25(78.1 \%)$ \\
\hline Coronary artery disease & $20(62.5 \%)$ \\
\hline Hypercholesterolemia & 19 (59.4\%) \\
\hline Hypertension & $26(81.3 \%)$ \\
\hline COPD & $8(25.0 \%)$ \\
\hline Arrhythmia & $10(31.3 \%)$ \\
\hline Peripheral vascular disease & $9(28.1 \%)$ \\
\hline Cerebrovascular disease & $7(21.9 \%)$ \\
\hline Diabetes Mellitus & $9(28.1 \%)$ \\
\hline \multicolumn{2}{|l|}{ Common iliac artery morphology } \\
\hline \multicolumn{2}{|c|}{ Maximum $\mathrm{ClA}$ diameter $(\mathrm{mm})$} \\
\hline Mean \pm SD & $33.5 \pm 16.8$ \\
\hline Range & $(8-83)$ \\
\hline Range (planned, $\mathrm{N}=28$ ) & $(26-83)$ \\
\hline \multicolumn{2}{|l|}{ Proximal $\mathrm{ClA}$ diameter (mm) } \\
\hline Mean \pm SD & $17.8 \pm 6.9$ \\
\hline Range & $(10-39)$ \\
\hline \multicolumn{2}{|l|}{ Distal ClA diameter $(\mathrm{mm})$} \\
\hline Mean \pm SD & $12.5 \pm 4.0$ \\
\hline Range & $(6-20)$ \\
\hline \multicolumn{2}{|l|}{ Anatomic configurations } \\
\hline Straight & $3(9.4 \%)$ \\
\hline Balloon-shaped & $26(81.3 \%)$ \\
\hline Funnel-shaped & $3(9.4 \%)$ \\
\hline \multicolumn{2}{|l|}{ Patency internal iliac artery } \\
\hline Covered IIA patent & $32(100 \%)$ \\
\hline Contralateral IIA patent & 30 (93.8\%) \\
\hline
\end{tabular}


Table 2. Indications for IIA coverage

\begin{tabular}{lc}
\hline Indications for IIA coverage & Patients (N) \\
\hline Elective cases (planned coverage) & 9 \\
AAA with unilateral CIAA & 1 \\
AAA with left CIAA and right CIAA+IIAA ${ }^{\text {a }}$ & 4 \\
CIAA (unilateral) & 2 \\
CIAA (bilateral) & 5 \\
Limb extension after previous EVAR & \\
Emergency cases (planned coverage) & 4 \\
Ruptured AAA with unilateral CIAA & 1 \\
AAA with ruptured CIAA (unilateral) & 2 \\
Ruptured CIAA (unilateral) & 3 \\
Inadvertent coverage & 1 \\
Isolated AAA & \\
AAA with right CIAA+IIAAc & \\
\hline Abbreviations: IIA, Internal IIiac Artery; CIAA, Common Iliac Artery Aneurysm; IIAA, Internal Iliac Artery Aneurysm \\
a. IIAA was coil-embolised in another clinic. In our clinic bilateral IIA stent coverage was performed (left IIA included for \\
analysis). \\
b. Both cases had one IIA covered and received an IBD at the contralateral side. \\
c. IIAA was coil-embolised. Intentional coverage of right IIA was performed. Left IIA was covered inadvertently (left IIA \\
included for analysis)
\end{tabular}

\section{Technical outcome}

Coverage of the IIA's orifice with a stent graft that was $10 \%$ oversized relative to the EIA was achieved in all patients. The completion angiogram showed no signs of endoleak and more particularly no signs of Type-II endoleak due to retrograde flow from the IIA. One-month CTA images and later imaging-studies demonstrated occlusion of the most proximal part of the IIA and absence of any IIA related endoleaks (Figure 1). Two cases of non-related endoleaks were seen on 1-month CTA images: a small Type-Il endoleak originating from the inferior mesenteric artery (left untreated), and a large Type-I endoleak of the IBD (treated with extension of the IIA limb).

Increase of maximum AAA and CIAA diameters was not seen at any time point during followup. Furthermore, filling of distal branches of the affected IIA was observed in 20 (64.5\%) patients. Notably, the AUI case with femoro-femoral cross-over showed bilateral filling of the distal IIA branches.

\section{Clinical outcome}

Seven $(22.6 \%)$ patients reported symptoms of buttock claudication that appeared directly after the procedure. Of these cases, 5 were mild and 2 (6.5\%) were severe. None of the patients had symptoms of hip or buttock claudication prior to the procedure. 
Figure 1. Intra-operative angiograms of a 73-year-old, male patient with a ruptured $59 \mathrm{~mm}$ aneurysm of the right $\mathrm{CIA}$ demonstrating;
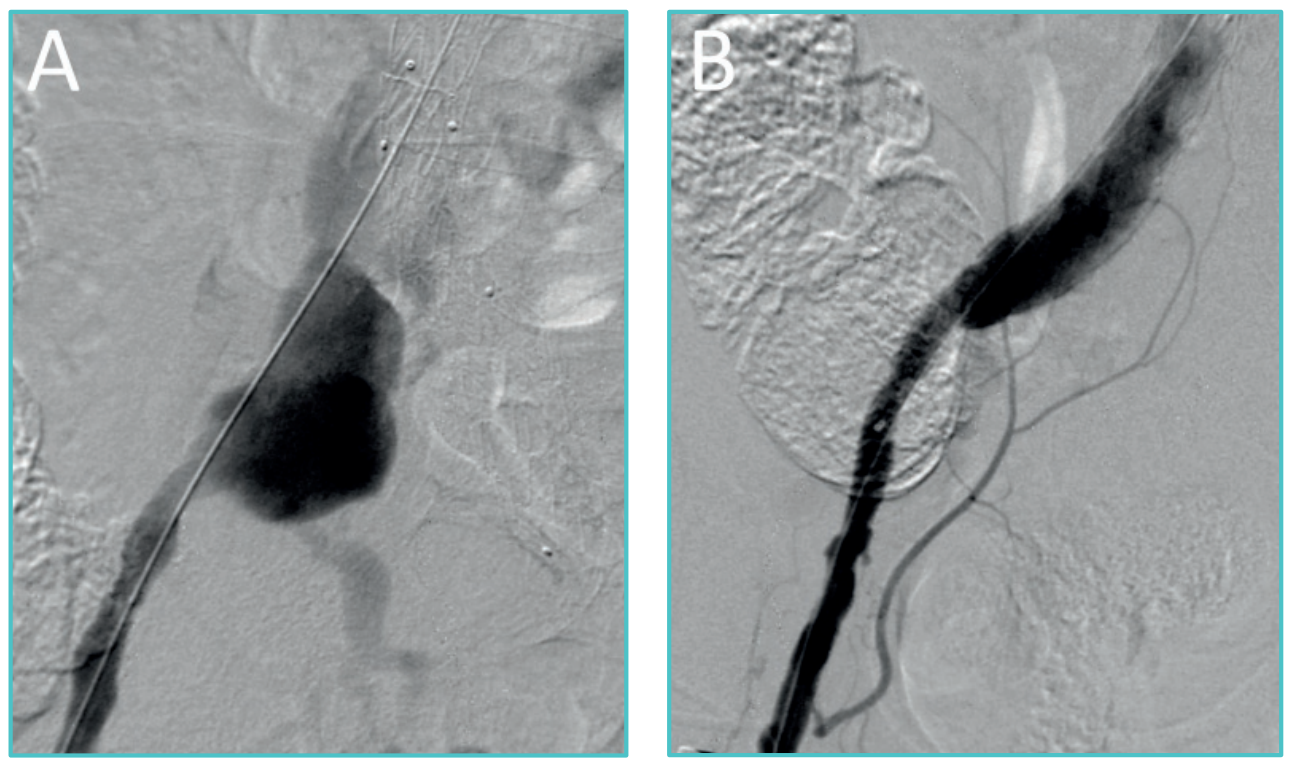

A) CIAA with patent IIA before stent graft implantation, B) stent graft implanted with extension into EIA, exclusion of CIAA with no signs of Type-Il endoleaks, and filling of circumflex artery branches.

\section{Clinical outcome}

Seven (22.6\%) patients reported symptoms of buttock claudication that appeared directly after the procedure. Of these cases, 5 were mild and $2(6.5 \%)$ were severe. None of the patients had symptoms of hip or buttock claudication prior to the procedure.

Symptoms disappeared in 4 of the 5 mild cases within the first month post-implant. In the fifth case symptoms disappeared before the 6-month visit. The 2 patients with severe buttock claudication reported gradual improvement of symptoms over time, with persistent mild claudication at 12 and 18 months. These two patients were the ones with bilateral IIA occlusion. A review of their CT-scans showed only marginal perfusion of the distal IIA at one side, and no significant flow at the contralateral side.

There was no incidence of ischemic colitis, spinal cord ischemia, or gluteal necrosis. Sexual dysfunction, although not systematically asked for was never reported. No additional secondary procedures were performed to secure IIA sealing or to improve pelvic perfusion in this cohort of AAA patients. 


\section{DISCUSSION}

Pre-emptive coil embolisation is more or less standard practice in case the IIA is covered, even though no solid evidence is available on its necessity in terms of preventing Type-II endoleaks. To challenge this routine, we analysed a consecutive series of 32 patients after endovascular treatment of aorto-iliac and $\mathrm{CIA}$ aneurysm without pre-emptive coil embolisation of the IIA. Our series did not indicate any short- or midterm complications in terms of aneurysm growth or endoleaks. Our findings therefore suggest that endovascular treatment of aorto-iliac and iliac aneurysms without coil embolisation of the IIA is safe and effective, and that pre-emptive IIA coil embolisation may be redundant.

Several studies on preoperative coil embolisation of the lumbar arteries or inferior mesenteric artery failed to demonstrate any added value in terms of aneurysm growth or rupture. $^{27,28}$ There is no obvious reason why coil embolisation of the IIA would behave different and would, unlike lumbar or inferior mesenteric artery coiling, be beneficial to aneurysm behaviour. For the worse, coil embolisation has several disadvantages. First and

foremost, it may increase the risk of pelvic ischemia. ${ }^{11,18}$ It has been demonstrated that with more distal IIA occlusion, more complications occur. ${ }^{18}$ In this respect a one could argue that simple stent-graft coverage of the IIA is to be preferred since this policy produces the most proximal occlusion as possible. Secondly, coil embolisation is accompanied by increased contrast load and radiation exposure, and prolongs operating time. Moreover, it is a costly procedure, since often multiple coils are required to occlude a single IIA., ${ }^{4,11,29}$ Considering the devices alone, the average costs to coil a single IIA are estimated to be 3500 USD.

To our knowledge, the present series is the first to report the results of a policy of routinely abandoning embolisation of the IIA. Previous studies on EVAR with IIA coverage for aortoiliac aneurysms applied a selective approach in deciding whether or not to embolise the IIA; Bharwani et $\mathrm{al}^{22}$ and Farahmand et $\mathrm{al}^{21}$ only included cases without coil embolisation in which attempted embolisation had technically failed or in which the IIA had been covered inadvertently. The group from the University of Wisconsin presented two reports on patients with and without coil embolisation, ${ }^{24,25}$ but no reasons were provided for their decision whether or not to perform concomitant IIA embolisation. Weyers et al. ${ }^{23}$ decided not to 
embolise the IIA if a sealing zone of at least $5 \mathrm{~mm}$ was present in the most distal part of the $\mathrm{CIA}$. A recent study by Papazoglou et al. ${ }^{26}$ applied more liberal criteria: if no sufficient distal landing zone was present, IIAs with a diameter $<5 \mathrm{~mm}$ were not coiled, which applied to 112 out of 137 cases $(81.7 \%)$ that required limb graft extension into the EIA.

Two factors may account for the fact that we did not observe IIA-related Type-II endoleaks. One is that in our series, the CIA just above the level of the iliac bifurcation was never aneurysmatic, even in cases of larger CIA aneurysms. Apparently, a short narrow-calibre segment at the iliac bifurcation is sufficient to provide adequate seal and to allow thrombosis of the main trunk of the IIA. Alternatively, one could hypothesize that a comparable situation exists in the abdominal aorta itself: literature data ${ }^{27,28,30}$ have shown that only a minority of patients with patent lumbar arteries on preoperative imaging studies will eventually develop a Type-Il endoleak following EVAR.

Overall, reports of IIA-associated endoleaks are rare, and so far, no study has been able to demonstrate an association between the occurrence of IIA-related endoleaks and omission of adjuvant occlusion measures. Similar to our study, most studies on sole IIA coverage did not observe Type-II endoleaks originating from the IIA at all. ${ }^{13,16,17,22-25}$ In studies which report IIA-associated endoleaks incidences range between $4.0 \%$ and $6.2 \%$ (Table 3). ${ }^{21,26}$ None of these cases, however, resulted in aneurysm expansion, nor did they require secondary interventions to resolve the endoleaks. Some of the Type-II endoleaks resolved spontaneously during follow-up.

In our series, no severe symptoms of pelvic ischaemia occurred, nor were any secondary interventions required to solve problems related to IIA coverage. The incidence of buttock claudication (22.6\%) was within the range reported in previous studies on sole IIA coverage, and compares favourable to the incidence reported in the majority of studies on coil embolisation. These findings support the suggestion that coil embolisation increases the risk for pelvic ischemia. In patients with concomitant coil embolisation the incidence of buttock claudication ranged from $16 \%$ to $53 \%,{ }^{6,24}$ whereas in patients undergoing stent coverage without coil embolisation it merely ranged from $0 \%$ to $28 \%$ (Table 3 ). ${ }^{21,23-26}$ Although these 
symptoms may disappear within 6 months, a study by Mehta et al ${ }^{15}$ reported persistent buttock claudication in $12 \%$ of patients after 1 year.

Higher incidence and more severe presentation of symptoms are commonly associated with bilateral IIA occlusion. ${ }^{14,15}$ This is in line with the findings in our study, in which symptoms of buttock claudication only persisted in the $2(6.5 \%)$ patients with bilateral IIA coverage.

Table 3. Literature review of the incidence of buttock claudication and IIA-associated endoleaks following IIA stent coverage without prior coil embolisation.

\begin{tabular}{|c|c|c|c|c|c|c|}
\hline Author/year (ref. no.) & $\begin{array}{l}\text { No. of } \\
\text { patients }\end{array}$ & Planned & $\begin{array}{l}\text { Coil failure } \\
\text { or } \\
\text { inadvertent }\end{array}$ & $\begin{array}{l}\text { Mean } \\
\text { follow-up } \\
\text { (months) }\end{array}$ & $\begin{array}{l}\text { Buttock } \\
\text { claudication } \\
(\%)\end{array}$ & $\begin{array}{l}\text { IIA-assoc. } \\
\text { endoleaks } \\
(\%)\end{array}$ \\
\hline Lee C $2000^{(18)}$ & 18 & 9 & 9 & 7.3 & $n r^{b}$ & $0(0)$ \\
\hline Karch $2000^{(19)}$ & 9 & 0 & 9 & 13.4 & $n r^{b}$ & $0(0)$ \\
\hline Rhee $2002^{(15)}$ & 6 & 0 & 6 & 4.7 & $n r^{b}$ & $0(0)$ \\
\hline Weyers $2002^{(25)}$ & 22 & 19 & 3 & 18.5 & $6(27.3)$ & $0(0)$ \\
\hline Mell $2006^{(27)}$ & 21 & 21 & 0 & 16.0 & $2(9.5)$ & $0(0)$ \\
\hline Bharwani $2008^{(24)}$ & 11 & 0 & 11 & 19.7 & $n r^{b}$ & $0(0)$ \\
\hline Farahmand $2008^{(23)}$ & 25 & 0 & 25 & 36.3 & $7(28.0)$ & $1(4.0)^{c}$ \\
\hline Papazoglou $2012^{(28)}$ & 112 & 107 & 5 & 33.0 & $15(13.4)$ & $7(6.3)^{c}$ \\
\hline Current study & 31 & 27 & 4 & 14.3 & $7(22.6)$ & $0(0)$ \\
\hline Total & 255 & & & & $37(17.5)$ & $8(3.1)^{c}$ \\
\hline
\end{tabular}

Abbreviations: IIA, Internal Iliac Artery.

a. Attempted coil embolisation technically failed due to stenotic IIA or iliac tortuosity.

b. Buttock claudication not given or not specified for sole stent coverage.

c. None of the endoleaks required secondary intervention.

Our study has several limitations. One of these is that sexual dysfunction was not routinely asked about. Therefore, limited value can be attributed to the reported absence of this complication in our population. Another limitation is the retrospective design of our study, which might have caused relative underreporting in general. However, we consider specific questions with focus on pelvic ischemia part of follow-up routine. With regard to the observed absence of IIA related Type-II endoleaks: although one would not expect new Type-II endoleaks, longer follow-up is required to assess the durability of this finding. 


\section{CONCLUSION}

Endovascular treatment of aorto-iliac and iliac aneurysms without pre-emptive coil embolisation of the IIA appears safe and effective, since no IIA-related endoleaks or reinterventions occurred in our series. This approach could save operating- and radiation time, contrast load and expensive coils and may reduce complications. However, further research on a larger population and with longer follow-up is required to confirm our findings. 


\section{REFERENCES}

1. Armon MP, Wenham PW, Whitaker SC, Gregson RH, Hopkinson BR. Common iliac artery aneurysms in patients with abdominal aortic aneurysms. Eur J Vasc Endovasc Surg 1998;15:255-7.

2. Hobo R, Sybrandy JE, Harris PL, Buth J. Endovascular repair of abdominal aortic aneurysms with concomitant common iliac artery aneurysm: outcome analysis of the EUROSTAR Experience. J Endovasc Ther 2008;15:12-22.

3. Rouwet EV, Torsello G, de Vries JP, Cuypers P, van Herwaarden JA, Eckstein $\mathrm{HH}$, et al. Final results of the prospective European trial of the Endurant stent graft for endovascular abdominal aortic aneurysm repair. Eur J Vasc Endovasc Surg 2011;42:489-97.

4. Heye S, Nevelsteen A, Maleux G. Internal iliac artery coil embolization in the prevention of potential type 2 endoleak after endovascular repair of abdominal aortoiliac and iliac artery aneurysms: effect of total occlusion versus residual flow. J Vasc Interv Radiol 2005;16:235-9.

5. Parlani G, Verzini F, De Rango P, Brambilla D, Coscarella $\mathrm{C}$, Ferrer $\mathrm{C}$, et al. Long-term results of iliac aneurysm repair with iliac branched endograft: a 5-year experience on 100 consecutive cases. Eur J Vasc Endovasc Surg 2012;43:287-92.

6. Rayt HS, Bown MJ, Lambert KV, Fishwick NG, McCarthy MJ, London NJ, et al. Buttock claudication and erectile dysfunction after internal iliac artery embolization in patients prior to endovascular aortic aneurysm repair. Cardiovasc Intervent Radiol 2008;31:728-34.

7. Ghosh J, Murray D, Paravastu S, Farquharson F, Walker MG, Serracino-Inglott F. Contemporary management of aorto-iliac aneurysms in the endovascular era. Eur J Vasc Endovasc Surg 2009;37:182-8.

8. Parodi JC, Ferreira M. Relocation of the iliac artery bifurcation to facilitate endoluminal treatment of abdominal aortic aneurysms. J Endovasc Surg 1999;6:342-7.

9. Faries PL, Morrissey N, Burks JA, Gravereaux E, Kerstein MD, Teodorescu VJ, et al. Internal iliac artery revascularization as an adjunct to endovascular repair of aortoiliac aneurysms. J Vasc Surg 2001;34:892-9.

10. Chandra J, Anthony S, Uberoi R. Embolization of the internal iliac artery with glubran 2 acrylic glue: initial experience with an adjunctive outflow occlusive agent. J Vasc Interv Radiol 2010;21:1109-14.

11. Ha CD, Calcagno D. Amplatzer Vascular Plug to occlude the internal iliac arteries in patients undergoing aortoiliac aneurysm repair. J Vasc Surg 2005;42:1058-62.

12. Yano OJ, Morrissey N, Eisen L, Faries PL, Soundararajan K, Wan S, et al. Intentional internal iliac artery occlusion to facilitate endovascular repair of aortoiliac aneurysms. J Vasc Surg 2001;34:204-11.

13. Rhee RY, Muluk SC, Tzeng E, Missig-Carroll N, Makaroun MS. Can the internal iliac artery be safely covered during endovascular repair of abdominal aortic and iliac artery aneurysms? Ann Vasc Surg 2002;16:29-36

14. Razavi MK, DeGroot M, Olcott C, 3rd, Sze D, Kee $S$, Semba $C P$, et al. Internal iliac artery embolization in the stent-graft treatment of aortoiliac aneurysms: analysis of outcomes and complications. J Vasc Interv Radiol 2000;11:561-6. 
15. Mehta M, Veith FJ, Ohki T, Cynamon J, Goldstein K, Suggs WD, et al. Unilateral and bilateral hypogastric artery interruption during aortoiliac aneurysm repair in 154 patients: a relatively innocuous procedure. J Vasc Surg 2001;33:S27-32.

16. Lee CW, Kaufman JA, Fan CM, Geller SC, Brewster DC, Cambria RP, et al. Clinical outcome of internal iliac artery occlusions during endovascular treatment of aortoiliac aneurysmal diseases. J Vasc Interv Radiol 2000;11:567-71.

17. Karch LA, Hodgson KJ, Mattos MA, Bohannon WT, Ramsey DE, McLafferty RB. Adverse consequences of internal iliac artery occlusion during endovascular repair of abdominal aortic aneurysms. J Vasc Surg 2000;32:676-83.

18. Cynamon J, Lerer D, Veith FJ, Taragin BH, Wahl SI, Lautin JL, et al. Hypogastric artery coil embolization prior to endoluminal repair of aneurysms and fistulas: buttock claudication, a recognized but possibly preventable complication. J Vasc Interv Radiol 2000;11:573-7.

19. Su WT, Stone DH, Lamparello PJ, Rockman CB. Gluteal compartment syndrome following elective unilateral internal iliac artery embolization before endovascular abdominal aortic aneurysm repair. J Vasc Surg 2004;39:672-5.

20. Bratby MJ, Munneke GM, Belli AM, Loosemore TM, Loftus I, Thompson MM, et al. How safe is bilateral internal iliac artery embolization prior to EVAR? Cardiovasc Intervent Radiol 2008;31:246-53.

21. Farahmand $P$, Becquemin JP, Desgranges $P$, Allaire E, Marzelle J, Roudot-Thoraval F. Is hypogastric artery embolization during endovascular aortoiliac aneurysm repair (EVAR) innocuous and useful? Eur J Vasc Endovasc Surg 2008;35:429-35.

22. Bharwani N, Raja J, Choke E, Belli AM, Thompson MM, Morgan RA, et al. Is internal iliac artery embolization essential prior to endovascular repair of aortoiliac aneurysms? Cardiovasc Intervent Radiol 2008;31:504-8.

23. Wyers MC, Schermerhorn ML, Fillinger MF, Powell RJ, Rzucidlo EM, Walsh DB, et al. Internal iliac occlusion without coil embolization during endovascular abdominal aortic aneurysm repair. J Vasc Surg 2002;36:1138-45.

24. Tefera G, Turnipseed WD, Carr SC, Pulfer KA, Hoch JR, Acher CW. Is coil embolization of hypogastric artery necessary during endovascular treatment of aortoiliac aneurysms? Ann Vasc Surg 2004;18:143-6.

25. Mell M, Tefera G, Schwarze M, Carr S, Acher C, Hoch J, et al. Absence of buttock claudication following stent-graft coverage of the hypogastric artery without coil embolization in endovascular aneurysm repair. J Endovasc Ther 2006;13:415-9.

26. Papazoglou KO, Sfyroeras GS, Zambas N, Konstantinidis K, Kakkos SK, Mitka M. Outcomes of endovascular aneurysm repair with selective internal iliac artery coverage without coil embolization. J Vasc Surg 2012;56:298-303.

27. Sheehan MK, Hagino RT, Canby E, Wholey MH, Postoak D, Suri R, et al. Type 2 endoleaks after abdominal aortic aneurysm stent grafting with systematic mesenteric and lumbar coil embolization. Ann Vasc Surg 2006;20:458-63.

28. Nevala T, Biancari F, Manninen $H$, Matsi $P$, Makinen $\mathrm{K}$, Ylonen $\mathrm{K}$, et al. Inferior mesenteric artery embolization before endovascular repair of an abdominal aortic aneurysm: effect on type II endoleak and aneurysm shrinkage. J Vasc Interv Radiol 2010;21:181-5.

29. Kickuth R, Dick F, Triller J, Ludwig K, Schmidli J, Do DD. Internal iliac artery embolization before endovascular repair of aortoiliac aneurysms with a nitinol vascular occlusion plug. J Vasc Interv Radiol 2007;18:1081-7. 



\title{
CHAPTER 6
}

\section{OVERSTENTING THE HYPOGASTRIC}

\section{ARTERY DURING ENDOVASCULAR}

ANEURYSM REPAIR WITH AND WITHOUT

PRIOR COIL EMBOLIZATION: A

COMPARATIVE ANALYSIS FROM THE

ENGAGE REGISTRY

\author{
R.A. Stokmans \\ P.P.H.L. Broos \\ M.R.H.M. van Sambeek \\ J.A.W. Teijink \\ Ph.W.M. Cuypers
}

Journal of Vascular Surgery

2018 January; 67: 134-141 


\section{ABSTRACT}

Introduction: Endovascular aneurysm repair (EVAR) of aorto-iliac or iliac aneurysms is often performed with stent-graft coverage of the origin of the hypogastric artery (HA) to ensure adequate distal seal. It is considered common practice to perform adjunctive coiling of the HA in order to prevent a type-II endoleak. Our objective is to question the necessity of pre-emptive coiling by comparing the outcomes of HA coverage with and without prior coil embolization.

Methods: Data from the ENGAGE Registry, which prospectively enrolled 1263 EVAR patients between March 2009 and April 2011 from multiple centers worldwide, was used for this study. We identified patients in whom the Endurant Stent Graft covered one or both HAs, and grouped them in cases in which prior HA embolization coils or plugs - was performed (CE) and cases in which HA embolization was not performed (NE). The occurrence of covered hypogastric-related endoleak and secondary interventions were compared between groups.

Results: In 197 patients, 225 hypogastric arteries were covered. Ninety-one HAs were covered after coil embolization (CE) and $134 \mathrm{HAs}$ were covered without prior coil embolization (NE). Both groups were similar at baseline, and had comparable length of follow-up to last image (665.2 \pm 321.7 days for CE-patients, 641.6 \pm 327.6 days for NE-patients; $p=.464)$. Importantly, both groups showed equivalent iliac morphology concerning $\mathrm{CIA}$ proximal, mid and distal dimensions and tortuosity, making them suitable for comparative analysis.

During follow-up hypogastric-related endoleaks were sparse and occurred equally often in both groups (CE $5.5 \%$ versus NE 3.0\%; $p=.346$ ). Secondary intervention to resolve a hypogastric-related endoleak was performed twice in the CE group and 3 times in the NE group. Late non-HA related endoleaks occurred more often in the CE-group compared to the NE-group, respectively $25.0 \%$ versus $15.0 \%, p=.080$.

Secondary interventions for other reasons than hypogastric-related endoleaks occurred in $7.5 \%$ of NE-cases and $15.4 \%$ of CE-cases $(p=.057)$, mostly for occlusions in the ipsilateral iliac limb. During follow-up 19 NEpatients and 9 CE-patients died, which is not significantly different $(p=.225)$, and no deaths were related directly or indirectly to HA coverage. Also, no reports of gluteal necrosis and bowel ischemia were made.

Conclusion: This study shows that hypogastric artery coverage with the Endurant ${ }^{\circledR}$ endograft without prior coil embolization does not increase the incidence of endoleak or related secondary interventions. These findings together with the already available evidence suggest that omission of coil embolization may be a more resource-effective strategy whenever HA coverage is required. 


\section{INTRODUCTION}

Since Parodi et al. first described minimally invasive endovascular techniques in 1991, endovascular aneurysm repair (EVAR) has become the preferred way to treat abdominal aortic aneurysms (AAAs) whenever feasible. ${ }^{2}$ In $40 \%$ of EVAR cases the aneurysm extends into the iliac tract. ${ }^{3,4}$ Involvement of the common iliac artery (CIA) poses significant challenges for EVAR, since it might jeopardize distal sealing.

In many cases extension of the endograft into the external iliac artery (EIA) is chosen to reach an adequate distal sealing zone, which is considered to be approximately $10-15 \mathrm{~mm}$ in length. ${ }^{3,5}$ This means intentional graft coverage of the hypogastric artery (HA). Exclusion of the HA by graft coverage has been proven relatively safe, but implies a risk for type-II endoleak. ${ }^{6}$ To prevent these type-II endoleaks, it is considered common practice to preemptively occlude the HA with coils or plugs.

In our opinion there is no solid evidence on the benefits of coil embolization, but it may be associated with higher costs and potential risk for pelvic ischemia., ${ }^{9,10}$ Therefore, the necessity of this preventative strategy is questioned. In the past decade several observational studies have compared pre-emptive embolization with simple coverage of the HA, but these studies represent only small series or cases in which attempted coil embolization had technically failed or in which the HA had been covered inadvertently. ${ }^{11-18}$ To date, no large comparative study with sufficient follow-up exists.

The purpose of this study is to find out if the omission of coil embolization leads to an increased risk for hypogastric-artery related endoleaks and reinterventions. A retrospective analysis was performed on data from the Endurant Stent Graft Natural Selection Global Postmarket Registry (ENGAGE). 


\section{METHODS}

\section{Patient sample and group selection}

The database of the ENGAGE Registry for AAA patients treated with an Endurant ${ }^{\circledR}$ Stent Graft (Medtronic Vascular, Santa Rosa, CA, USA) was used for this analysis. From March 2009 to April 2011, ENGAGE prospectively enrolled 1263 patients from 79 sites in 30 countries worldwide. All patient were considered to be eligible for EVAR treatment as assessed by their own physician, including patients outside Endurant IFU criteria. No patients with ruptured aneurysms or hemodynamically instable patients were enrolled. Further methodological details of the ENGAGE Registry have been described in previous publications.

From the ENGAGE Database we retrospectively identified patients in whom the distal ends of the device, including extensions, were placed covering one or both HAs. These patients were divided into two groups: one in which HA embolization - coils or plugs - was performed prior to the EVAR procedure (CE) and one in which HA embolization was not performed (NE).

\section{Procedure}

Computed tomography angiography (CTA) imaging of the abdomen and pelvis was done in each patient to determine baseline aorto-iliac and aneurysmal dimensions in order to make a customized plan with respect to stent diameters and length. If found necessary, coil embolization or placement of an Amplatzer ${ }^{\text {Tm }}$ plug (St. Jude Medical Inc., St. Paul, MN, USA) was performed prior to or during the initial implant procedure. In all cases the decision whether or not to coil embolize was left to the discretion of the surgeon. All procedures were performed under fluoroscopic control by experienced vascular surgeons or interventional radiologist. Anesthetics, antibiotics and heparin were administered following local regimen. A completion angiogram was made at the end of implantation to document the initial technical outcome. 


\section{Follow-up and outcome}

Follow-up was planned according to standard practice at each clinical site. If any adverse events were noticed, such as gluteal necrosis or buttock-claudication, local investigators were obligated to report this. Bowel ischemia was considered a major adverse event (MAE), together with all-cause mortality, myocardial infarction, paraplegia, renal failure respiratory failure, stroke and procedural blood loss $\geq 1000 \mathrm{~mL}$.

To identify technical complications computed tomography angiography (CTA) scans were required at 30-days, 1-year follow-up, and yearly thereafter CTA or Duplex Colored Doppler Ultra Sound (Duplex CDUS). The presence of an endoleak was classified by location and type and recorded. Occlusions or stenoses that required secondary interventions were also recorded. Endoleaks classified as distal type-I, type-II deriving from the hypogastric artery and distal type-III located ipsilateral of the hypogastric artery that was covered were considered to be related to covering of the hypogastric artery.

\section{Data collection, quality control and statistical analysis}

Local investigators collected data on each patient and recorded this on web-based electronic case report forms to ensure reliable data collection, data management and secure authentication. Data managers reviewed $100 \%$ of data to detect missing or inconsistent data to generate queries to the investigators for resolution. In addition, Medtronic Bakken Research Centre BV (Maastricht, The Netherlands) randomly monitored over $40 \%$ of patients' source documentation against the data entered.

Statistical analysis was performed using SPSS ${ }^{\odot}$ version 21 for Mac (IBM corporation, Somers, NY, USA). Categorical variables are presented as frequencies with percentages. Continuous variables are presented as mean \pm standard deviation (SD). For outcomes concerning individual iliac arteries a 'per covered internal iliac or hypogastric artery analysis (PCHanalysis)' was performed. For general outcomes a 'per patient analysis (PP-analysis) was done. Groups were compared for baseline differences and outcome variables using the independent-sample T-test, Mann-Whitney U-test, Fisher's exact-test and Pearson's Chisquare-test where appropriate. $P$-value $\leq .050$ was considered statistically significant. 
The registry was conducted according to the Declaration of Helsinki and the International Conference on Harmonization (ICH) Good Clinical Practice (GCP) guidelines. Local ethics committees at all participating sites approved data collection and analysis. Written informed consent for authorization of data release was obtained in all patients.

\section{RESULTS}

\section{Population description}

Among the 1263 ENGAGE patients we identified 197 (15.6\%) patients who had one or both HAs covered during the EVAR procedure (Table 1). Unilateral coverage was performed in 169 (85.8\%) cases and bilateral coverage occurred in 28 (14.2\%) cases. Therefore, a total of 225 covered hypogastric arteries were at risk for hypogastric-related complications.

Table 1. Overview of patient selection

\begin{tabular}{lc}
\hline ENGAGE population & $\mathrm{N}=1263^{\mathrm{a}}$ \\
\hline No coverage of HA & $\mathbf{1 0 6 6}(\mathbf{8 4 . 4 \% )}$ \\
Coverage of one or both HA(s) & $\mathbf{1 9 7}(\mathbf{1 5 . 6 \% )}$ \\
Coverage of left HA only & $81(41.1 \%)$ \\
$\quad$ No prior coil embolization & 47 \\
$\quad$ Prior coil embolization & 34 \\
Coverage of right HA only & $88(44.7 \%)$ \\
No prior coil embolization & 49 \\
Prior coil embolization & 39 \\
Coverage of both HAs & $28(14,2 \%)$ \\
$\quad$ No prior coil embolization & 17 \\
Prior coil embolization of one HA & 6 \\
Prior coil embolization of both HAs & 5 \\
\hline
\end{tabular}

\begin{tabular}{lc}
\hline Per patient analysis (PP) & $\mathrm{N}=197$ \\
\hline No prior coil embolization at all & $113(57.4 \%)$ \\
Prior coil embolization of one or both IHA(s) & $84(42.6 \%)$ \\
\hline
\end{tabular}

\begin{tabular}{lc}
\hline Per covered HA analysis (PCH) & $\mathrm{N}=225$ \\
\hline No prior coil embolization & $134(59.6 \%)$ \\
Prior coil embolization & $91(40.4 \%)$ \\
\hline
\end{tabular}


Coil embolization or plugging (CE) was performed in 91 (40.4\%) of these, with approximately two-third of cases on the same day or during the EVAR procedure and one-third on average 15 days (range 1 - 31 days) before the initial procedure. In all 5 cases of bilateral coil embolization, coiling was performed in a two-stage approach; one HA was coiled on average 7 days (range 6 - 10 days) before the EVAR procedure, the other HA was coiled within the same setting. Covering of an HA without prior coil embolization or plugging (NE) occurred 134 (59.6\%) times. For baseline characteristics and general outcomes 113 (57.4\%) patients who had no prior coil embolization at all were compared to $84(42.6 \%)$ patients in whom prior coil embolization was performed in one or both of covered HAs.

Table 2. Baseline patient demographics \& risk factors (PP-analysis)

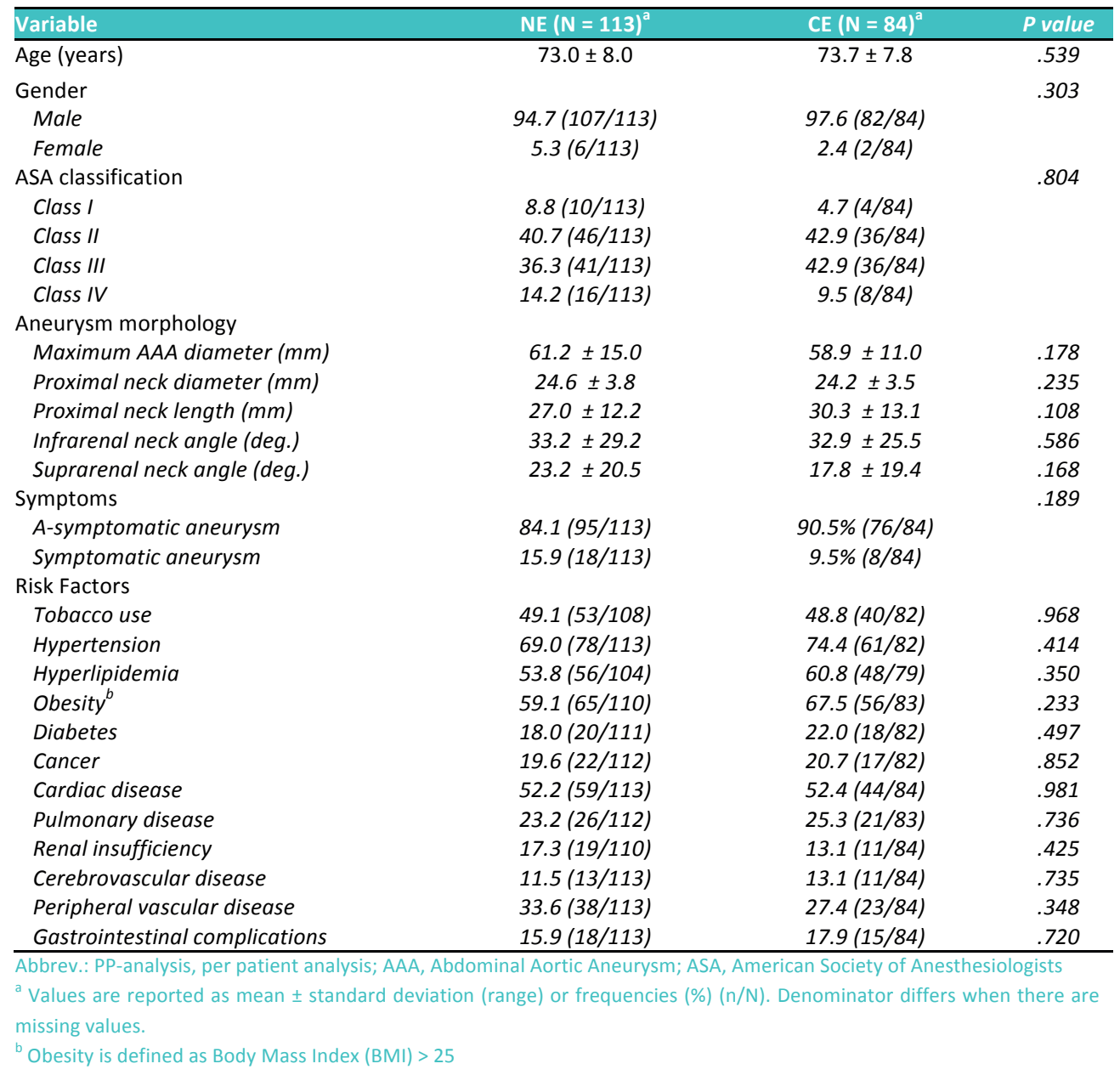




\section{Baseline demographics and morphology}

Patient demographics and risk factors are displayed in Table 2. Patient in both groups were predominantly 73-year old males, with an American Society of Anesthesiologists (ASA) class II or III that presented with an asymptomatic aneurysm. There were no differences in age, gender, ASA-classification and risk factors between NE- and CE-patients. Also AAA morphology concerning maximum AAA diameter, proximal neck length, diameter and angulation were comparable between both groups.

Detailed morphology of the common iliac artery (CIA) ipsilateral of the covered HA is shown in Table 3. There were no significant differences between the NE- and CE-group. A common iliac diameter of $24 \mathrm{~mm}$ was considered the maximum diameter for adequate sealing with the bell-bottom technique (using a $28 \mathrm{~mm}$ iliac limb graft with $20 \%$ oversizing). ${ }^{5}$

Table 3. Baseline common iliac artery morphology (PCH-analysis)

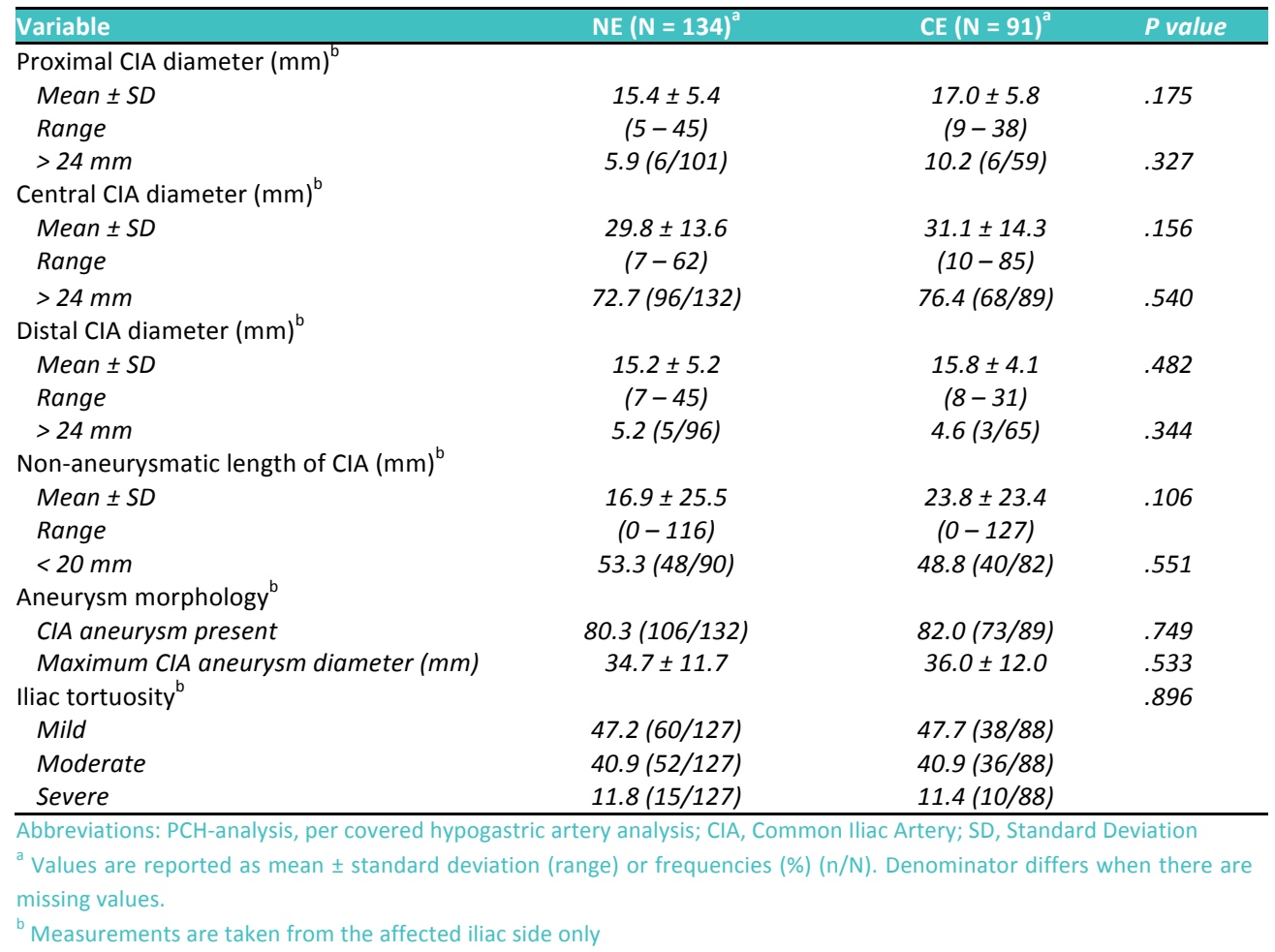


Proximal ClA diameter was comparable and not larger than $24 \mathrm{~mm}$ in $94.1 \%$ and $89.2 \%$ of cases, respectively ( $p=.327)$. Also the distal CIA diameter was comparable in both groups and not larger than $24 \mathrm{~mm}$ in $94.8 \%$ and $95.4 \%$ of cases ( $p=.344)$. ClA aneurysms were present in $80.3 \%$ of NE-cases and $82.0 \%$ of CE-cases, $(p=.749)$, and the mean maximal CIA aneurysm diameter was not different between both groups ( $34.7 \pm 11.7$ versus $36.0 \pm 12.0 \mathrm{~mm}, p=.533$ ). In approximately $50 \%$ of cases $(53.3 \%$ NE vs. $48.8 \% \mathrm{CE}, p=.551)$ the non-aneurysmatic length of the $\mathrm{CIA}$ was $<20 \mathrm{~mm}$. Also, no differences were seen in the severity of tortuosity between CE- and NE-cases.

\section{Early outcome comparison}

All 197 patients underwent a successful EVAR procedure, with no intraoperative mortality and no immediate conversions. The distribution of type of anesthesia used was comparable in NE- and CE-patients, with approximately $65 \%$ of patients receiving general anesthesia. Equally, no difference was seen in intra-operative contrast use (NE: $149.2 \pm 76.0 \mathrm{~mL}$ versus CE: $153.4 \pm 70.4 \mathrm{~mL}, p=.703$ ) and per operative blood loss (NE: $198.6 \pm 165.4$ versus CE: 241.3 $\pm 325.2 \mathrm{~mL}, p=.237$ ). However, surgery time was 23 minutes longer in CE-patients (NE: 105.0 $\pm 44.1 \mathrm{~min}$ versus CE: $128.1 \pm 59.2 \mathrm{~min}, p=.002$ ) and CE-patients were significantly longer exposed to X-rays (NE: $22.9 \pm 13.2 \mathrm{~min}$ versus CE: $26.3 \pm 15.0 \mathrm{~min}, p=.001$ ). Post-operative stay was not significantly different for NE-patients (4.6 \pm 3.6 days) and CE-patients (5.3 \pm 4.4 days) $(p=.239)$, and a comparable proportion of patients was postoperatively admitted to ICU (37.2\% NE versus $42.9 \% \mathrm{CE}, p=.416)$.

At final angiography minor endoleaks were seen in both groups and left untreated; Unrelated endoleaks (proximal and contralateral type-I and -III endoleaks, lumbar and IMA type II endoleaks) were equally divided over both groups. Hypogastric-related type-I, -II or III endoleaks were seen at final angiograms in 7 (5.2\%) NE-cases versus 6 (6.6\%) CE-cases $(p=.666)$. One NE-patient died at post-implant day 199 from pneumosepsis with an initial type-II HA endoleak still present on 30-day imaging. All other hypogastric-related endoleaks were not seen anymore on 30-day imaging studies. (Table 4). 
Table 4. Initial procedural data and evaluation (PP-analysis)

\begin{tabular}{|c|c|c|c|}
\hline Variable & $\operatorname{NE}(N=113)^{a}$ & CE $(N=84)^{a}$ & Pvalue \\
\hline Duration of implant procedure (min) & $105.0 \pm 44.1$ & $128.1 \pm 59.2$ & $.002^{c}$ \\
\hline Type of anesthesia & & & .858 \\
\hline General & $64.6(73 / 113)$ & $65.5(55 / 84)$ & \\
\hline Spinal / Epidural & $23.0(26 / 113)$ & $20.2(17 / 84)$ & \\
\hline Local & $12.4(14 / 113)$ & $14.3(12 / 84)$ & \\
\hline Volume of contrast (mL) & $149.2 \pm 76.0$ & $153.4 \pm 70.4$ & .703 \\
\hline Total fluoroscopic time (min) & $22.9 \pm 13.2$ & $26.3 \pm 15.0$ & $.001^{c}$ \\
\hline Per operative blood loss (mL) & $198.6 \pm 165.4$ & $241.3 \pm 325.2$ & .237 \\
\hline Post-operative stay (days) & $4.6 \pm 3.6$ & $5.3 \pm 4.4$ & .239 \\
\hline Admission to ICU & $37.2(42 / 113)$ & $42.9(36 / 84)$ & .416 \\
\hline \multicolumn{4}{|l|}{ Evaluation } \\
\hline Intraoperative mortality & $0.0(0 / 113)$ & $0.0(0 / 84)$ & - \\
\hline Conversion to open surgery & $0.0(0 / 113)$ & $0.0(0 / 84)$ & - \\
\hline \multicolumn{4}{|l|}{ Endoleakage at final angiography } \\
\hline Type I or III endoleak & $5.3(6 / 113)$ & $8.3(7 / 84)$ & .398 \\
\hline Type II endoleak & $11.5(13 / 113)$ & $11.9(10 / 84)$ & .931 \\
\hline CHA-related Type I, II or III endoleak ${ }^{b}$ & $5.2(7 / 134)^{b}$ & $6.6(6 / 91)^{b}$ & $.666^{b}$ \\
\hline \multicolumn{4}{|c|}{$\begin{array}{l}\text { a Values are reported as mean } \pm \text { standard deviation (range) or frequencies }(\%)(\mathrm{n} / \mathrm{N}) \text {. Denominator differs when there are } \\
\text { missing values } \\
{ }^{b} \text { Analyzed per covered internal iliac or hypogastric artery }\end{array}$} \\
\hline \multicolumn{2}{|l|}{ ' Significantly different } & & \\
\hline
\end{tabular}

\section{Outcome of follow-up}

Clinical follow-up of patients was comparable in both groups with a mean of 681.8 \pm 299.6 days in NE-patients and 701.2 \pm 295.1 days in CE-patients $(p=.530)$, ranging from

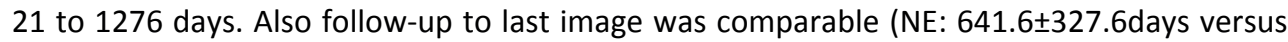
CE: $665.2 \pm 321.7$ days, $p=.464)$, ranging from 6 to 1276 days. Table 5 specifies outcomes throughout the follow-up period.

Overall, $15.0 \%$ (17) of NE-patients and $20.2 \%$ (17) of CE-patients $(p=.340)$ underwent secondary interventions for any reason during follow-up. Two of these were conversions to open surgery for non-hypogastric-related endoleaks, one in each group; One CE-patient with a persistent type-II lumbal endoleak - already mentioned. One NE-patient received an aortobi-iliacal prosthesis at post-implant day 49 because a large type-la endoleak was noted at 1month imaging and no possibility for placement of a proximal extension of the endoprothesis. Endoleaks of any type occurred more often in CE-patients (25\% CE versus $15 \% \mathrm{NE})$, however this was no statistically significant difference $(p=.080)$. 
During follow-up hypogastric-related endoleaks were scarce and occurred as frequent in CEcases $(5,5.5 \%)$ as in NE-cases $(4,3.0 \%)(p=.346)$ (Table 5). In the NE- group three type-lb endoleaks presented at post-implant day 11, 348 and 1165 respectively, and were resolved by deploying a limb extension further into the external iliac artery (EIA). One case - already mentioned earlier - died with a distal type-Il endoleak still present. Among the CE-cases three distal type-II endoleaks were seen at 1-month, but all resolved without intervention. A type-Ib and a distal type-III endoleak were noticed on day 732 and 844 post-implant, respectively, and resolved by placing an endovascular extension. Overall, hypogastric-related secondary interventions occurred more often in CE-cases (7.5\% NE versus 15.4\% CE, $p=.057$ ), predominantly for resolving occlusions or significant stenosis in the ipsilateral limb $(5.2 \% \mathrm{NE}$ versus $13.2 \% \mathrm{CE}, p=.035)$. Remarkably, there was no difference between both groups in reinterventions for hypogastric-related endoleaks (2.2\% NE versus $2.2 \% \mathrm{CE}, p=.984)$.

More patients died in the NE-group compared to the CE-group during follow-up, $16.8 \%$ (19 patients) and $10.7 \%$ (9 patients) respectively, but this difference was not significant ( $p=.225)$. No deaths were related directly or indirectly to hypogastric coverage (Table 5). Throughout the follow-up period no incidence of bowel ischemia was reported. Also gluteal skin necrosis was not mentioned in any of the reported adverse events. Furthermore, a total of 16 reports on adverse events mentioned symptoms of claudication, but none of these specified on buttock claudication. There was an equal distribution of cases between NE-patients and CEpatients, respectively $8.0 \%(9)$ versus $8.3 \%(7)(P=.925)$. Notably, in both groups there were patients mentioning symptoms contralateral to the side on which HA coverage was performed. In all these claudication cases a significant iliac or femoral stenosis was present. Those operated upon were free from complaints afterwards, suggesting that none of the complaints were related to HA occlusion.

\section{DISCUSSION}

The incidence of AAA is increasing and is particularly obvious in the elderly. With the development of new techniques and increase in standards of livings, more AAA patient 
would like to undergo an EVAR procedure. ${ }^{20}$ With EVAR extending to the external iliac artery it is controversial whether excluding the HA with coils is more effective at preventing hypogastric-related endoleaks than without coil embolization. The 2011 European Guidelines on the management of abdominal aortic aneurysms state that hypogastric embolization is usually preferred over simple endograft coverage, based on level 4 evidence (case series) and a grade $\mathrm{C}$ of recommendation (level 4 studies). ${ }^{21} \mathrm{~A}$ recently published metaanalysis on this topic states that no benefits of coil embolization exist, but also concludes that available studies are of small series only and with a verity of reasons sole HA coverage, and therefore difficult to compare. ${ }^{22}$ Hence, larger studies with sufficient follow-up will contribute to the discussion and help in making balanced choices in HA management.

Table 5. Patient outcomes through follow-up period

\begin{tabular}{|c|c|c|c|}
\hline$\overline{\text { Variable (PP-analysis) }}$ & $\operatorname{NE}(N=113)^{a}$ & $\mathrm{CE}(\mathrm{N}=84)^{\mathrm{a}}$ & Pvalue \\
\hline Clinical follow-up (days) & & & .530 \\
\hline Mean $\pm S D$ & $681.8 \pm 299.6$ & $701.2 \pm 295.1$ & \\
\hline Range & $(21-1265)$ & $(69-1276)$ & \\
\hline Follow-up to last image (days) & & & .464 \\
\hline Mean \pm SD & $641.6 \pm 327.6$ & $665.5 \pm 321.7$ & \\
\hline Range & $(13-1265)$ & $(6-1276)$ & \\
\hline All-cause mortality & $16.8(19 / 113)$ & $10.7(9 / 113)$ & .225 \\
\hline Cardiac failure & 5 & 2 & \\
\hline Respiratory insufficiency & 5 & 2 & \\
\hline Renal failure & 1 & 1 & \\
\hline Sepsis (UTI) & 4 & 2 & \\
\hline Cancer & 4 & 2 & \\
\hline CHA-related mortality & 0 & 0 & \\
\hline All-cause secondary intervention & $15.0(17 / 113)$ & $20.2(17 / 84)$ & .340 \\
\hline Any type endoleak & $15.0(17 / 113)$ & $25.0(21 / 84)$ & .080 \\
\hline Type I or III & 5 & 7 & \\
\hline Type II & 12 & 14 & \\
\hline
\end{tabular}

\begin{tabular}{lccc}
\hline Variable (PCH-analysis) & $\mathrm{NE}(\mathrm{N}=134)^{\mathrm{a}}$ & $\mathrm{CE}(\mathrm{N}=91)^{\mathrm{a}}$ & P value \\
\hline CHA-related endoleak & $3.0(4 / 134)$ & $5.5(5 / 91)$ & .346 \\
Type I distal & 3 & 1 & \\
Type III limb connection & 0 & 1 & \\
Type II from HA & 1 & $15.4(14 / 91)$ & .057 \\
CHA-related secondary intervention & $7.5(10 / 134)$ & $2.2(2 / 91)$ & .984 \\
For endoleak & $2.2(3 / 134)$ & $13.2(12 / 91)$ & $.035^{b}$ \\
For occlusion or stenosis & $5.2(7 / 134)$ & \\
\hline Abbreviations: PP-analysis, per patient analysis; PCH-analysis, per covered hypogastric artery analysis; SD, standard \\
deviation; CHA-related, at covered hypogastric artery side; UTI, urine tract infection; HA, hypogastric artery \\
${ }^{a}$ Values are reported as mean \pm standard deviation (range) frequencies (\%) (n/N). Denominator differs when there are \\
missing values
\end{tabular}


The ENGAGE registry was undertaken to quantify the performance of the Endurant ${ }^{\odot}$ endograft within the context of contemporary practice. Since some consider it a weakness of a study to be industry funded, Medtronic wanted to prove otherwise with this initiative. The quality of registries depends on the quality of reporting. Therefore, incomparable to historic registries, large efforts for onsite quality control and continual monitoring were made to guarantee completeness of data reports thus high quality and reliability of data. ${ }^{19}$ Although not specially designed for our hypothesis, we believe that the ENGAGE database is of sufficient quality to use for meaningful analyses concerning our topic. Extrapolation of our findings to other commercially available may not be justified as only Endurant ${ }^{\odot}$ cases are included, and may be considered a limitation of using the ENGAGE registry for our study.

The proportion of EVAR patients in the ENGAGE registry that underwent coverage over the HA origin was within the ranges as reported in literature ${ }^{11-18,23}$, and no iliac branched devices (IBD) were included. Remarkably, a minority of our cohort received pre-emptive coil embolization, despite this is considered a standard of practice. The tide might already have shifted towards sole graft coverage in recent years, and coil-embolization is less popular than thought. Both groups in this study demonstrate comparable baseline characteristic with respect to clinical risk factors as well as CIA morphology, making them suitable for comparative analysis.

Similar to previous studies we found longer operation time and $\mathrm{X}$-ray exposure for $\mathrm{CE}$ patients. ${ }^{22}$ We did not find significant differences in contrast use, blood-loss and postoperative hospitalization. Approximately $50 \%$ of CE patients were treated following a twostep approach that includes an extra intervention for coil embolization with fluoroscopy and hospital admission. Unfortunately, numbers of coils required, the size of the coils and the extend of coil embolization were not registered in the database, making it impossible to perform a cost analysis. Previous studies estimate the average cost for HA embolization alone to be an estimated 3500 USD. ${ }^{10}$

Our study reported several patients with unrelated endoleaks at completion angiography that were left untreated by the operator. Only a small minority of the endoleaks was hypogastric-related. Also during follow-up the occurrence of hypogastric-related endoleaks 
were scarce, and no significant differences were found between both groups. The $3.0 \%$ incidence rate of hypogastric-related endoleaks in the NE-group is higher than the zeropercentage that is often mentioned in small series, ${ }^{11,12,14,23-26}$ but does not exceed the incidence rate in study of Papazoglou et al., ${ }^{16}$ notwithstanding the fact that we also included distal type-I and type-III endoleaks in our analysis. Notably, also in the CE-group type-II endoleaks appeared. Nonetheless, there was only a $2.2 \%$ incidence of secondary interventions to resolve hypogastric-related endoleaks. All of them were type-lb or type-III endoleaks, and tackled by minimally invasive means with endovascular limb extension.

Possible reasons why so small numbers of type-Il endoleak occur in simple graft covered hypogastric arteries were mentioned earlier by our research group. ${ }^{22}$ We found that in the majority of cases and despite the presence of a common iliac aneurysm, a short narrowcaliber segment is present at the iliac bifurcation. This tapering nearby the origin of the hypogastric artery is probably sufficient to provide adequate seal and to allow thrombosis of the main trunk of the HA.

The occurrence of clinically relevant occlusions of the endograft limbs in the studied cohort is not surprisingly high. In another ENGAGE publication, Faure et al. ${ }^{27}$ identified extension of a limb graft into the external iliac as the strongest predictor for the occurrence of limb occlusions. Coil embolization was not included as an independent factor in their analysis. We found a significant difference of limb graft occlusion in favor of the NE-group, whereas the incidence of secondary intervention required for limb occlusions was approximately 2.5 times higher in cases with pre-emptive coil embolization. We cannot give any good explanation for the higher rates for limb occlusion found after coil embolization.

No colonic ischemia or gluteal necrosis was reported in our study. Also erectile dysfunction and buttock claudication were not mentioned as adverse events in this sub-cohort of the ENGAGE registry. Reports of claudication of the lower extremities were made, but considered not related to coil embolization or its omission, since onset of complaints was late and it appearance reducible to cases of limb occlusion. Incidence rates in literature of more than $50 \%$ of buttock claudication and $40 \%$ of erectile dysfunction in patients with unilateral HA embolization and even higher so in bilateral HA occlusion ${ }^{28,29}$ let us believe that 
there must have been considerable underreporting of these symptoms in the ENGAGE Registry. Sexual dysfunction and buttock claudication was not routinely queried in all participating clinics. Therefore limited value should be attributed to the reported absence of physical complications in our population.

Another limitation of this study is that there were no given explanations on the chosen EVAR strategy, whether HA coverage was intentional or accidental and why the choice for coil embolization or sole coverage was made. This causes a risk for selection bias and the comparison of unequal groups, namely a large number of cases of incidental HA coverage in NE-group and selected cases of worse anatomy left for coil embolization. However, of great importance, iliac morphology and other anatomic measurements were comparable between both groups leaving us to believe that an honest comparison is perfectly possible. Also, the studied population represented over $80 \%$ of cases of patients with (concomitant) $\mathrm{ClA}$ aneurysms together with over $50 \%$ of insufficient non-aneurysmatic CIA left for adequate distal sealing, suggesting there was no large proportion of cases with incidental HA coverage. Despite the extensive number of anatomic measurements recorded in the database, it remains insufficient to convert these in a perfect image of the iliac morphology, which would otherwise allow us to detect a subgroup of iliacs that require prior coil embolization. Furthermore, it has not been documented if the HA was still patent before it orifice was covered. Equally, we cannot report on CIA growth, since the ENGAGE database did not include iliacal artery diameters at follow-up.

\section{CONCLUSION}

This study shows that hypogastric artery coverage with the Endurant ${ }^{\odot}$ endograft without prior coil embolization does not increase the incidence of endoleak or related secondary interventions. When taking into account that embolization is usually costly, often requires multiple interventions and longer procedures with fluoroscopic guidance, these findings suggest that omission of coil embolization may be a more resource-effective strategy whenever HA coverage is required. 


\section{REFERENCES}

1. Parodi JC, Palmaz JC, Barone HD. Transfemoral intraluminal graft implantation for abdominal aortic aneurysms. Ann Vasc Surg 1991;5:491-9.

2. Sachs T, Schermerhorn M, Pomposelli F, Cotterill P, O'Malley J, Landon B. Resident and fellow experiences after the introduction of endovascular aneurysm repair for abdominal aortic aneurysm. J Vasc Surg 2011;54:881-8.

3. Hobo R, Sybrandy JE, Harris PL, Buth J. Endovascular repair of abdominal aortic aneurysms with concomitant common iliac artery aneurysm: outcome analysis of the EUROSTAR Experience. J Endovasc Ther 2008;15:12-22.

4. Armon MP, Wenham PW, Whitaker SC, Gregson RH, Hopkinson BR. Common iliac artery aneurysms in patients with abdominal aortic aneurysm. Eur J Vasc Endovasc Surg 1998;15:155-7.

5. Rouwet EV, Torsello G, de Vries JP, Cuypers P, van Herwaarden JA, Eckstein $\mathrm{HH}$, et al. Final results of the prospective European trial of the Endurant stent graft for endovascular abdominal aortic aneurysm repair. Eur J Vasc Endovasc Surg 2011;42:89-97.

6. Ghosh J, Murray D, Paravastu S, Farquharson F, Walker MG, Serracino-Inglott F. Contemporary management of aorto-iliac aneurysms in the endovascular era. Eur J Vasc Endovasc Surg 2009;37:182-8.

7. Criado FJ, Wilson EP, Velazquez OC, Carpenter JP, Barker C, Wellons E, et al. Safety of coil embolization of the internal iliac artery in endovascular grafting of abdominal aortic aneurysms. J Vasc Surg 2000;32(4):684-8.

8. Wolpert LM, Dittrich KP, Hallisey MJ, Allmendinger PP, Gallagher JJ, Heydt K, et al. Hypogastric artery embolization in endovascular abdominal aortic aneurysm repair. J Vasc Surg 2001; 33(6):1193-8.

9. Cynamon J, Lerer D, Veith FJ, Taragin BH, Wahl $\mathrm{SI}$, Lautin JL, et al. Hypogastric artery coil embolization prior to endoluminal repair of aneurysms and fistulas: buttock claudication, a recognized but possibly preventable complication. J Vasc Interv Radiol 2000;11:573-7.

10. Ha CD, Calcagno D. Amplatzer Vascular Plug to occlude the internal iliac arteries in patients undergoing aortoiliac aneurysm repair. J Vasc Surg 2005;42:1058-62.

11. Wyers MC, Schermerhorn ML, Fillinger MF, Powell RJ, Rzucidlo EM, Walsh DB, et al. Internal iliac occlusion without coil embolization during endovascular abdominal aortic aneurysm repair. J Vasc Surg 2002;36:1138-45.

12. Lee CW, Kaufman JA, Fan CM, Geller SC, Brewster DC, Cambria RP, et al. Clinical outcome of internal iliac artery occlusions during endovascular treatment of aortoiliac aneurysmal diseases. J Vasc Interv Radiol 2000;11:567-71.

13. Farahmand $P$, Becquemin JP, Desgranges $P$, Allaire E, Marzelle J, Roudot-Thoraval F. Is hypogastric artery embolization during endovascular aortoiliac aneurysm repair (EVAR) innocuous and useful? Eur J Vasc Endovasc Surg 2008;35:429-35.

14. Bharwani N, Raja J, Choke E, Belli AM, Thompson MM, Morgan RA, et al. Is internal iliac artery embolization essential prior to endovascular repair of aortoiliac aneurysms? Cardiovasc Intervent Radiol 2008;31:504-8.

15. Tefera G, Turnipseed WD, Carr SC, Pulfer KA, Hoch JR, Acher CW. Is coil embolization of 
hypogastric artery necessary during endovascular treatment of aortoiliac aneurysms? Ann Vasc Surg 2004;18:143-6.

16. Papazoglou KO, Sfyroeras GS, Zambas N, Konstantinidis K, Kakkos SK, Mitka M. Outcomes of endovascular aneurysm repair with selective internal iliac artery coverage without coil embolization. J Vasc Surg 2012;56:298-303.

17. Luo $H$, Huang $B$, Yuan $D$, Yang $Y$, Xiong $F$, Zeng $\mathrm{G}$, et al. 8-Year long-term outcome comparison: two ways to exclude the internal iliac artery during endovascular aorta repair (EVAR) surgery. PLoS One 2015;10(7):e013058.

18. Rajesparan K, Partridge W, Refson J, Abidia A, Aldin Z. The risk of endoleak following stent covering of the internal iliac artery during endovascular aneurysm repair. Clin Radiol 2014;69:1011-8.

19. Stokmans RA, Teijink JA, Forbes TL, Bockler D, Peeters PJ, Riambau $V$ et al. Early results from the ENGAGE registry: real-world performance of the Endurant Stent Graft for endovascular AAA repair in 1262 patients. Eur J Vasc Endovasc Surg 2012;44:369-75.

20. Schoder $M$, Zaunbauer $L$, Holzenbein $T$, Fleischmann D, Cejna M, Kretschmer G, et al. Internal iliac artery embolization before endovascular repair of abdominal aorta aneurysm: frequency, efficacy, and clinical results. AJM Am J Roentgenol 2001;177(3):599-605.

21. Kontopodis N, Tavlas E, Papadpoulos G, Galanakis N, Tsetis D, loannou CV. Embolization or simple coverage to exclude the internal iliac artery during endovascular repair of aortoiliac aneurysms? Systematic review and meta-analysis of comparative studies. J Endovasc Ther 2016 Epub ahead of print.

22. Stokmans RA, Willigendael EM, Teijink JA, Ten Bosch JA, van Sambeek MRHM, Cuypers
PhWM. Challenging the evidence for preemptive coil embolisation of the internal iliac artery during endovascular aneurysm repair. Eur J Vasc Endovasc Surg 2013;45:220-6.

23. Karch LA, Hodgson KJ, Mattos MA, Bohannon WT, Ramsey DE, McLafferty RB. Adverse consequences of internal iliac artery occlusion during endovascular repair of abdominal aortic aneurysms. J Vasc Surg 2000;32:676-83.

24. Sheehan MK, Hagino RT, Canby E, Wholey MH, Postoak D, Suri R, et al. Type 2 endoleaks after abdominal aortic aneurysm stent grafting with systematic mesenteric and lumbar coil embolization. Ann Vasc Surg 2006;20:458-63.

25. Nevala T, Biancari $F$, Manninen $H$, Matsi $P$, Makinen K, Ylonen K, et al. Inferior mesenteric artery embolization before endovascular repair of an abdominal aortic aneurysm: effect on type II endoleak and aneurysm shrinkage. J Vasc Interv Radiol 2010;21:181-5.

26. Marchiori A, von Ristow A, Guimaraes $M$, Schonholz C, Uflacker R. Predictive factors for the development of type II endoleaks. J Endovasc Ther 2011;18:299-305.

27. Faure EM, Becquemin JP, Cochennec F; ENGAGE collaborators. Predictive factors for limb occlusions after endovascular aneurysm repair. J Vasc Surg 2015 May;61(5):1138-45.

28. Rayt HS, Bown MJ, Lambert KV, Fishwick NG, McCarthy MJ, London NJ, et al. Buttock claudication and erectile dysfunction after internal iliac artery embolization in patients prior to endovascular aortic aneurysm repair. Cardiovasc Intervent Radiol 2008;31:728-34.

29. Mehta M, Veith FJ, Ohki T, Cynamon J, Goldstein K, Suggs WD, et al. Unilateral and bilateral hypogastric artery interruption during aortoiliac aneurysm repair in 154 patients: A relatively innocuous procedure. J Vasc Surg 2001 February;33: S27-32. 

PART THREE

TECHNICAL COMPLICATIONS OF EVAR:

HOW TO MANAGE AND HOW TO

PREVENT 



\section{CHAPTER 7}

\section{EVAR REINTERVENTION MANAGEMENT STRATEGIES IN CONTEMPORARY PRACTICE}

\section{B.L.W. Bendermacher}

R.A. Stokmans

Ph.W.M. Cuypers

J.A.W. Teijink

M.R.H.M. van Sambeek

Journal of Cardiovascular Surgery (Torino)

2012 August; 53(4): 411-418 


\section{ABSTRACT}

It is known that following an endovascular aneurysm repair (EVAR) procedure, patients may experience endoleaks, device migration, stent fractures, graft deterioration, or aneurysm growth that might require a reintervention. In this review management strategies of reinterventions after EVAR in contemporary practice will be discussed.

The current endovascular treatment options of Type I endoleak involve securing of the attachment site with percutaneous transluminal balloon angioplasty, stent-graft extension, or placement of a stent at the proximal attachment site. Moreover, the use of endostaplers to secure the position of the proximal cuff to the primary endograft has been developed. Type II endoleaks can be managed conservatively if the aneurysm is shrinking or remains stable. Otherwise, reinterventions include transarterial embolization, translumbar embolization, transcaval embolization, direct thrombin injection, and endoscopic or open ligation of the lumbar and mesenteric arteries. There is little debate regarding the treatment of Type III endoleaks, including deployment of additional stent graft components to bridge the defect. Endovascular treatment of endotension includes endovascular conversion stent or relining of the stent graft. Alternative options are puncture of the aneurysm sac and removal of the aneurysm sac content. In case of migration large balloon-expandable stents can be used to improve the seal between the components, or devices that deploy staples to secure endovascular grafts to the aortic wall to secure endovascular components together.

In conclusion, the first treatment options for reinterventions after EVAR are catheter based nowadays. 


\section{INTRODUCTION}

Endovascular abdominal aortic repair (EVAR) is a minimal invasive treatment option for patients with an aneurysm of the abdominal aorta (AAA). Graft surveillance after EVAR is universally recommended to prevent AAA rupture and stentgraft associated morbidity and mortality. It is known that following an EVAR procedure, patients may experience endoleaks, device migration, stent fractures, graft deterioration, or aneurysm growth that requires a reintervention. In earlier reports there was a concern for an increased number of reinterventions. However, a meta-analysis of 12 years EVAR experience showed a decrease of endoleak rate from $43 \%$ in 1992 to $13.5 \%$ in $2002 .^{1}$ Consequently, a recent review including publications after 2002 reported that the requirements for secondary interventions are declining, with a reintervention rate between $3.8 \%$ and $26 \%$ within varying time intervals. ${ }^{2}$ Possible reasons for this decrease in reinterventions could be advanced graft technology and increased understanding of management of endoleaks. Also, development of post-deployment adjuncts to ensure optimal aneurysm exclusion at the primary procedure reduces the necessity for acute reinterventions. In addition, centralization of endovascular procedures with focusing expertise and enhancing intradepartmental standards which may in turn reduce long-term complications. ${ }^{2}$

The majority of secondary interventions are performed within 30 days of deployement, whereas the majority of secondary procedures for graft related problems are now performed endovascular. Catheter-based reinterventions include balloon angioplasty, stenting, proximal and distal cuff extensions or placement of a new stent-graft, embolization of branch vessels and thrombolysis. ${ }^{2}$ This review will focus on management strategies of reinterventions after EVAR in contemporary practice. 


\section{MANAGEMENT OF ENDOLEAKS}

\section{Management of type I endoleak}

A Type I endoleak is defined as inadequate sealing at the proximal or distal extremities of the endoprothesis. Because the flow is direct and under systemic pressure, it represents a failure in treatment of the aneurysm, which continues to be pressurized and is therefore at risk of continued expansion and rupture. Recent studies report an incidence of early and delayed Type I endoleaks between $0.5 \%$ and $13 \%$ in recent studies. ${ }^{4-12}$ The appearance of this type of endoleak reflects a learning curve to some extent and might be reduced by exact preinterventional measurement of the attachment sites and exclusion of patients with unfavourable anatomical configurations. ${ }^{4}$ The risk of rupture is high in such patients and secondary intervention is mandatory in most cases. ${ }^{13,14}$ If Type I endoleaks are seen during the initial procedure, they should be addressed before leaving the operating room. In most cases additional ballooning at the proximal attachment site, stent-graft extension, or deployment of large balloon expandable stents is done to stabilize the neck, to correct excessive angulation, and to achieve an adequate seal consequently correcting the endoleak.

Delayed Type I endoleaks may also be encountered as a result of device failure or graft migration and should all be treated ${ }^{15}$ with an approach based on the cause. Although transcatheter embolization of type I endoleaks via the transarterial route was first described in $1997,{ }^{16}$ the current favoured endovascular treatment options involve securing the attachment site with percutaneous transluminal balloon angioplasty (PTA), stent-graft extension, or deployment of an uncovered stent at the proximal attachment site. These techniques have some limitations, however, whereas sufficient exclusion by balloon PTA or stent placement is reported in only $45 \%$ of cases. ${ }^{11}$ Unsuccessful attempts often involve the inability to achieve adequate seal at the junction points between the cuff and the existing device, probably due to neck angulation. ${ }^{11}$ If these endovascular methods fail to exclude Type I endoleaks, surgical conversion or other endovascular techniques, such as embolization, should be considered. ${ }^{17,18}$ Embolization can be performed through a transarterial approach or direct percutaneous puncture of the aneurysm sac via a transabdominal, translumbar (left side), or transcaval (right side) approach. ${ }^{19}$ Several reports 
of coil embolization of Type I endoleaks with good results have been published. ${ }^{16,20,21}$ If a transvascular approach is not possible, the endoleak can be approached directly by the sac puncture technique.

A more recent developed intervention to treat Type I endoleak after EVAR is the use of endostaplers to secure the position of the proximal cuff to the primary endograft. This might prevent migration, and is showing good results at short-term follow-up. ${ }^{22}$ In case endovascular techniques fail, surgical solutions are at hand. Some authors have reported on favourable results of "banding" the infrarenal neck or partial endograft preservation, with a reported morbidity and mortality of $8.3 \% .^{23}$ The advantage of these techniques is that it can be performed by minimal invasive endoscopic techniques. Conversion to an open procedure may be the only option when a large aneurysm cannot be controlled. The traditional approach for late surgical conversion entails complete endograft removal, followed by aortic replacement with a standard surgical prosthetic graft, and is generally associated with high morbidity and mortality.

\section{Management of Type II endoleak}

Branch flow through a patent inferior mesenteric artery (IMA), lumbar artery, accessory renal artery, or hypogastric artery is defined as a Type II endoleak. It is the most common type of endoleak with an incidence of $10-25 \%$ in several series. ${ }^{10,24-26}$ There are controversial studies about the effectiveness of preoperative embolization of aortic side branches to prevent Type II endoleak. ${ }^{27-30}$ The problem is that to achieve complete success, every side branch should be embolized before endograft placement. Additionally, clinical data have recently confirmed a higher rate of type II endoleaks in patients with more than three patent aortic branches $(20.3 \%$ vs. $7.6 \%) .^{31}$ Although these pre- and perioperative embolization techniques appear attractive, most patients with patent side branches will not develop a Type II endoleak, with consequently unnecessary procedure-related risks to many patients. ${ }^{3}$

Early reports describe an aggressive approach to persistent Type II endoleaks performing coil embolization, irrespective of whether any enlargement of the aneurysm sac is observed.

In contemporary practice, Type II endoleaks are managed is conservatively if the aneurysm is shrinking or remains stable, ${ }^{24,35,36}$ since as many as $75 \%$ of early endoleaks will resolve 
spontaneously within 5 years after detection, ${ }^{25,26,37}$ and approximately $80 \%$ will remain free of sac enlargement greater than $5 \mathrm{~mm} .{ }^{25}$ Options for treating Type II endoleaks include mainly transarterial embolization, ${ }^{21}, 35,38,39$ translumbar embolization, ${ }^{40-42}$ transcaval embolization, ${ }^{43}$ direct thrombin injection, ${ }^{44}$ and endoscopic or open surgical ligation of the lumbar and mesenteric arteries. ${ }^{45,46}$ Embolization materials used are coils, glue, ethylenevinyl alcohol copolymer and thrombin. ${ }^{47}$ Although secondary coil embolization is the first choice of treatment, this may be very challenging due to complex access to the collateral vessels, with quite poor results. ${ }^{41,48,49}$ The reported incidence of persistent or recurrent endoleak after secondary coil embolization is up to $72 \% .^{50}$ Endoleaks emanating from the IMA can be accessed through Riolan's arcade from the superior mesenteric artery. However, transvascular embolization in the IMA distribution should not be performed if the origin of the vessel cannot be reached, as there is a significant risk of creating colonic ischemia. Lumbar artery endoleaks can be catheterised through collateral vessels from the ilio-lumbar arteries. The aim is to position the catheter into the endoleak cavity and to embolize the entire endoleak cavity. If this is not possible, the inflow vessels should be embolized as close as possible to the aneurysm sac. In cases where the tip of the microcatheters cannot be adequately positioned for safe and effective coil occlusion, embolic fluids might be used alternatively. Glue can directly be administered in the aneurysm sac, ${ }^{51}$ to form a cast of the endoleak space. Although this treatment option showed to be effective, ${ }^{25,52}$ it may also affect the collateral circulation beyond the orifices, with a potential risk for inadvertent spreading, and potential damage to the spinal cord and ischemia of the lumbar plexus and mesenteric artery. If the endoleak cannot be reached by transvascular methods, direct puncture of the aneurysm sac with $\mathrm{CT}$, fluoroscopic, or US guidance can be performed.

Alternative approaches after unsuccessful endovascular treatment of Type II endoleak include laparoscopic clipping of patent side branches and laparoscopic fenestration of the aneurysm sac. ${ }^{46,53,54}$ A patent IMA is clipped laparoscopically and all visible arteries through a retroperitoneal approach, following a fenestration of the aneurysm giving the possibility to check for residual back-bleeding and remaining Type II endoleaks can be sutured. However, long-term results are suboptimal raising doubt over the applicability of this technique. Besides, these techniques require advanced laparoscopic experience and are more invasive than embolization techniques. 
Conversion to open surgery is considered to be a final treatment option for persisting Type II endoleaks that show aneurysm sac enlargement despite earlier treatments. The aneurysm sac is opened, the lumbar arteries or the IMA are suture ligated, and the sac wrapped around the endograft.

\section{Management of Type III endoleak}

Type III endoleaks are defined as midgraft endoleaks that originate either from fabric holes or an inadequate seal between endograft components. The incidence of type III endoleak is between $0.1 \%$ and $6.4 \% .^{4-12,55}$ Inadequate seal might be preventable by the operator in terms of ensuring adequate overlap of graft components. However, extreme angulation of the neck or iliac segments may also be a contributing factor. There is little debate regarding the treatment of Type III endoleaks, which involves deployment of additional stent graft components to bridge the defect and eliminate the endoleak.

\section{Management of type IV endoleak}

In Type IV endoleak there is passage of blood or fluid through the graft fabric due to porosity of some grafts. A Type IV endoleak is seen immediately after implantation on the final angiography. ${ }^{56}$ In generally these Type IV disappear spontaneously and are usually not seen anymore at the first surveillance CT-angiography, consequently requiring no secondary intervention. The use of refined grafts with less porous fabrics declined the incidence of Type IV endoleaks.

\section{MANAGEMENT OF OTHER TECHNICAL FAILURES}

\section{Management of endotension}

Endotension is usually defined as aneurysm enlargement without a demonstrable endoleak on any imaging modality. This might be caused by pulsation of the graft wall, with transmission of the pulse wave through the perigraft space to the native aneurysm wall, or by accumulation of fluid within the sac (e.g. hygroma). The incidence of endotension is 1.5$5 \%{ }^{57-61}$ The EUROSTAR registry recently reported a calculated mean annual rupture risk in 
case of endotension of $1.1 \%$ measured over 7 years, with a low annual rupture rate in the first 4 years of less than $1 \%$, increasing up to $13.6 \%$ in the years thereafter. ${ }^{60}$ This may suggest that a 'wait-and-see' policy could be a good strategy during the first four years after the primary procedure in asymptomatic patients in case of endotension. ${ }^{60,61}$ An international consensus in 2002 states that growing aneurysms without detection of endoleaks should be treated surgically or by repeated EVAR procedure. ${ }^{62}$ However, the options for reintervention and a "wait-and-see" strategy for endotension are reported as well. ${ }^{10}$ The hypothesis is, that the aneurysm will grow slowly because of the relative low pressure in the aneurysm sac. At rupture there will be no internal bleeding, only excavation of fluid from the aneurysm sac. Investigators believe that these ruptures can occur without any symptoms. The risk of this 'wait-and-see' strategy is that with an increase of the AAA diameter, the infrarenal neck can enlarge and this could compromise the proximal seal.

A pragmatic approach of treatment of endotension is conversion to open surgery to remove the endograft in favour of conventional vascular graft, despite the significant mortality and morbidity attending the procedure. ${ }^{63}$ A significant higher conversion rate in patients with endotension compared to patients without endotension is reported. ${ }^{57}$ Endovascular treatment includes endovascular conversion of PTFE stent graft to polyester stent graft or relining of the stent graft by implantation of proximal and distal cuff for reinforcement of the stent graft. ${ }^{64,65}$ However, this can only be performed in absence of a mass effect from the sac. The goal of endograft realigning is enhancement of sac shrinkage due to a reduced transudative filtration by minimizing the porous fabric surface that is in contact with the blood flow. ${ }^{64}$ An alternative treatment option of endotension is puncture of the aneurysm sac followed by removal of the aneurysm sac content. ${ }^{65,66}$ However, aspiration of fluid will provide only temporary relief if the cause of fluid accumulation is not eliminated. Furthermore, fenestration of the aneurysm to depressurize the sac and therefore preventing continued expansion due to accumulation of material and fluid is another alternative treatment. ${ }^{66}$ After fenestration of the aneurysm sac, laparoscopically or open, all the fluid and remaining thrombus is removed from the aneurysm sac and in case of possible backbleeding from a persistent lumbar artery the orifice of the artery can be sutured. After the aneurysm is cleared and haemostasis has been achieved, an omental pedicle is placed in the sac opening to prevent closure of the aneurysm sac and to drain recurrent fluids. 
However, the limited available long-term results are poor, and a recurrence of the hygroma have been described, probably due to healing of the fenestration. ${ }^{54}$ Modified open procedures with fenestration in combination with decompression, proximal aortic neck banding and transmural endograft fixation ${ }^{68}$ or in combination with placation of the AAA and wrapping using bio-prosthetic material ${ }^{69}$ have been reported as an alternative to conversion. Finally, conversion to aorto-unifemoral grafts with femoral to femoral bypass to reline the initial graft, and open resection with aneurysm repair are reported.

\section{Management of migration}

Endograft migration has been demonstrated after EVAR and has been attributed to lack of proximal fixation, incomplete iliac fixation, progressive dilation of the proximal aneurysm neck, significant sideway movements, or a combination of these factors. ${ }^{71-76}$ Migration may not only cause Type I endoleaks but may also be associated with kinking, stenosis, and thrombosis of the respective stent-graft limbs. The reported incidence of migration varying between $1 \%$ and to $42 \%$, is partly device dependent. ${ }^{7,58,76-78}$ It is, however, mentioned that many of these patients did not develop an endoleak or require additional interventions. It is analysed that migration of the graft without a loss of proximal fixation length has a benign natural history which does not necessitates a reintervention. However, in cases of increased infrarenal aortic neck diameter beyond oversizing, infrarenal aortic neck shortening and loss of proximal fixation length there are more clinically relevant predictors of proximal stent graft failure and a reintervention is required. ${ }^{76}$ In a large cohort study with long-term follow-up, $1.5 \%$ of the population met one or more of these criteria and underwent successful proximal extensions without any notable morbidity and mortality.58 Nevertheless, the stability of the new reconstruction, which includes an aortic cuff and a distorted, migrated endovascular graft, depends on the overlap, apposition, and friction seal between components to prevent separation, with consequently an increased risk of developing component disconnection and Type III endoleak. ${ }^{77}$ Additionally, large balloonexpandable stents can be used to increase the force needed to separate the components and improve the seal between them. ${ }^{79}$ Ancillary devices that deploy staples to secure endovascular grafts to the aortic wall may be useful to secure endovascular components together. ${ }^{22}$ Alternative treatments are deployment of an aorto-uni-iliac device within the original device combined with a femoro-femoral bypass, or conversion to open surgery. 
Furthermore, it is important for infrarenal devices that rely to some degree on longitudinal columnar support that they have optimal iliac fixation to achieve stability and to prevent migration. For this, as well the fixation length in the common iliac artery (less than $25 \mathrm{~mm}$ ), as the distal end of the stent graft to the iliac bifurcation (within $10 \mathrm{~mm}$ from the bifurcation) are described to be important factors for a good distal iliac fixation.

\section{Management of limb occlusion}

Graft limb occlusion is thought to be caused by kinking of the stent graft or tortuosity of the iliac artery, migration, or device elongation to the external iliac artery. ${ }^{80}$ The reported frequency is $1.4 \%$ to $7.7 \%$. $4-8,10,58,81-84$ In cases of acute occlusion, a thrombectomy or thrombolysis would be the easiest and most effective treatment strategy followed by additional stent placement to resolve the underlying stenosis, with an effective modality in restoring the patency. ${ }^{85}$ Nevertheless, there is a risk for stentgraft dislodgement. In case of chronic occlusion, there are several endovascular therapeutic options. First, revascularisation by endovascular procedures followed by ballooning of the stentgraft, followed by implantation of an endograft extension stent in the iliac limb is described with an additional advantage of straightening the tortuous iliac arteries, ${ }^{83}$ which could be possible within 2 to 3 months after limb occlusion. Bare stent coverage is another treatment option, although this procedure might result in shower embolization of the remnant thrombus. Finally, an extra-anatomical bypass can be constructed, which has high patency rates of over $90 \%{ }^{87}$

\section{CONCLUSIONS}

Lifelong surveillance is recommended to identify potential late complications of device failure, endoleak, and endograft migration that may lead to aneurysm rupture. In contemporary practice, the incidence of reinterventions after EVAR has decreased and might be influenced by pushing the borders of anatomical complexity. In case a reintervention is necessary, the first treatment options are catheter based nowadays. 
1. Franks SC, Sutton AJ, Bown MJ, Sayers RD. Systematic review and meta-analysis of 12 years of endovascular abdominal aortic aneurysm repair. Eur J Vasc Endovasc Surg 2007;33:154-71.

2. Nordon IM, Karthikesalingam A, Hinchliffe RJ, Holt PJ, Loftus IM, Thompson MM. Secondary interventions following endovascular aneurysm repair (EVAR) and the enduring value of graft surveillance. Eur J Vasc Endovasc Surg 2010;39:547-54.

3. Lifeline Registry of EVAR Publications Committee. Lifeline registry of endovascular aneurysm repair: long-term primary outcome measures. J Vasc Surg 2005;42:1-10.

4. Pitton $M B$, Scheschkowski $T$, Ring $M$, Herber $S$, Oberholzer K, Leicher-Düber A, Neufang A, Schmiet W, Düber C. Ten-year follow-up of endovascular aneurysm treatment with Talent stent-grafts. Cardiovasc Intervent Radiol 2009;32:906-17.

5. Subramanian K, Woodburn KR, Travis SJ, Hancock J. Secondary interventions following endovascular repair of abdominal aortic aneurysm. Diagn Interv Radiol 2006;12:99104.

6. Conrad MF, Adams WB, Guest JM, Paruchuri V, Brewster DC, LaMuraglia GM et al. Secondary intervention after endovascular abdominal aortic aneurysm repair. Ann Surg 2009;250:383-9.

7. Mertens J, Houthoofd S, Daenens K, Fourneau I, Maleux G, Lerut $P$, Nevelsteen A. Long-term results after endovascular abdominal aortic aneurysm repair using the Cook Zenith endograft. J Vasc Surg 2011;54:48-57.

8. Brown LC, Powell JT, Thompson SG, Epstein DM, Sculpher MJ, Greenhalgh RM. The UK
EndoVascular Aneurysm Repair (EVAR) trials: randomised trials of EVAR versus standard therapy. Health Technol Assess 2012:16.

9. Chisci E, Setacci F, lacoponi F, de Donato G, Cappelli A, Setacci C. Surveillance imaging modality does not affect detection rate of asymptomatic secondary interventions following EVAR. Eur J Vasc Endovasc Surg 2012;43:276-81.

10. Nevala T, Biancari F, Manninen H, Aho PS, Matsi $P$, Mäkinen $K$ et al. Finish multicenter study on the midterm results of use of the Zenith stent-graft in the treatment of an abdominal aortic aneurysm. J Vasc Interv Radiol 2009;20:448-54.

11. Baril DT, Silverberg D, Ellozy SH, Carroccio A, Jacobs TS, Sachdev $U$ et al. Endovascular stent-graft repair of failed endovascular abdominal aortic aneurysm repair. Ann Vasc Surg 2008;22:30-6.

12. Schermerhorn ML, O'Malley AJ, Jhaveri A, Cotterill P, Pomposelli F, Landon BE. Endovascular vs. open repair of abdominal aortic aneurysms in the medicare population. N Eng J Med 2008;358:464-74.

13. White GH, Yu W, May J, Chaufour X, Stephen MS. Endoleak as a complication of endoluminal grafting of abdominal aortic aneurysms: classification, incidence, diagnosis, and management. J Endovasc Surg 1997;4:152-68.

14. Chaikof EL, Blankensteijn JD, Harris PL, White $\mathrm{GH}$, Zarins CK, Bernhard VM et al. Ad hoc committee for standardized reporting practices in vascular surgery of the Society for Vascular Surgery/American Association for Vascular Surgery. Reporting strandards for endovascular aortic aneurysm repair. J Vasc 
Surg 2002;35:1048-60.

15. Moll FL, Powell JT, Fraedrich G, Verzini F, Haulon S, Waltham M et al. European Society for Vascular Surgery. Management of abdominal aortic aneurysms clinical practice guidelins of the European society for vascular surgery. Eur J Vasc Endovasc Surg 2011;41 Suppl 1:S1-S58.

16. Golzarian J, Struwen J, Abada HT, Wery D, Dussaussois L, Madani A et al. Endoavascular aortic stent-grafts: transcatheter embolization of persistent perigraft leaks. Radiology 1997;202:731-4.

17. Powell A, Benenati JF, Becker GJ, Katzen BT, Zemel G, Tummala S. Postoperative management: type I and III endoleaks. Tech Vasc Interv Radiol 2001:4:227-31.

18. Kirby L, Goodwin J. Treatment of a primary type IA endoleak with a liquid embolic system under conditions of aortic occlusion. J Vasc Surg 2003;37:456-60.

19. Choi SY, Lee DY, Lee KH, Ko YG, Choi D, Shim $\mathrm{WH}$ et al. Treatment of type I endoleaks after endovascular aneurysm repair of infrarenal abdominal aortic aneurysm: usefulness of $\mathrm{N}$ butyl cyanoacrylate embolization in cases of failed secondary endovascular intervention. J Vasc Interv Radiol 2011;22:155-62.

20. Golzarian J, Maes EB, Sun S. Endoleak: treatment options. Tech Vasc Interv Radiol 2005;8:41-9.

21. Faries PL, Cadot H, Agarwal G, Kent KC, Hollier $\mathrm{LH}$, Marin ML. Management of endoleak after endovascular aneurysm repair: cuffs, coils, and conversion. J Vasc Surg 2003;37:1155-61.

22. de Vries JP, Schrijver AM, van den Heuvel DAF, Vos JA. Use of endostaples to secure migrated endografts and proximal cuffs after failed endovascular abdominal aortic aneurysm repair. J Vasc Surg 2011;54:1792-4.
23. Nabi D, Murphy EH, Pak J, Zarins CK. Open surgical repair after failed endovascular aneurysm repair: is endograft removal necessary? J Vasc Surg 2009;50:714-21.

24. van Marrewijk C, Buth J, Harris PL, Norgren L, Nevelsteen A, Wyatt MG. Signi"cance of endoleaks after endovascular repair of abdominal aortic aneurysms: the EUROSTAR experience. J Vasc Surg 2002;35:461-73.

25. Silverberg D, Baril DT, Ellozy SH, Carroccio A, Greyrose SE, Lookstein RA et al. An 8-year experience with type II endoleaks: natural history suggests selective intervention is a safe approach. J Vasc Surgery 2006;44:453-9.

26. Rosen RJ, Green RM. Endoleak management following endovascular aneurysm repair. J Vasc Interv Radiol 2008;19(suppl):S37-S43.

27. Axelrod DJ, Lookstein RA, Guller J, Nowakowski FS, Ellozy S, Carroccia A et al. Inferior mesenteric artery embolization before endovascular aneurysm repair: technique and initial results. J Vasc Interv Radiol 2004;15:1263-7.

28. Bonvini $R$, Alerci $M$, Antonucci $F$, Tutta $P$, Wyttenbach $\mathrm{R}$, Bogen $\mathrm{M}$ et al. Preoperative embolization of collateral side branches: a valid means to reduce type II endoleaks after endovascular AAA repair. J Endovasc Ther 2003;10:227-32.

29. Parry DJ, Kessel DO, Robertson I, Denton L, Patel JV, Berridge DC et al. Type II endoleaks: predictable, preventable, and sometimes treatable? J Vasc Surg 2002;36:105-10.

30. Sheehan MK, Hagino RT, Canby E, Wholey $\mathrm{MH}$, Postoak D, Sury R et al. Type 2 endoleaks after abdominal aortic aneurysm stent grafting with systemic mesenteric and lumbar coil embolization. Ann Vasc Surg 2006;20:458-63.

31. Torsello G, Osada N, Florek HJ, Horsch S, Kortmann H, Luska $G$ et al. Talent AAA retrospective longterm study group. 
Longterm outcome after Talent endograft implantation for aneurysms of the abdominal aorta: a multicenter retrospective study. J Vasc Surg 2006;43:277-84.

32. Rhee SJ, Ohki T, Veith FJ, Kurvers H. Current status of management of type II endoleaks after endovascular repair of abdominal aortic aneurysms. Ann Vasc Surg 2003;17:335-44.

33. Resch $T$, Ivancev $K$, Lindh $M$, Nyman $U$, Brunkwall J, Malina $M$ et al. Persistent collateral perfusion of abdominal aortic aneurysm after endovascular repair does not lead to progressive change in aneurysm diameter. J Vasc Surg 1998;28:242-9.

34. Görich J, Rilinger N, Sokiranski R, Krämer S, Schütz A, Sunder- Plassmann $L$ et al. Embolization of type II endoleaks fed by the inferior mesenteric artery: using the superior mesenteric artery approach. J Endovasc Ther 2000;7:297-301.

35. Tolia AJ, Landis R, Lamparello P, Rosen R, Macari M. Type II endoleaks after endovascular repair of abdominal aortic aneurysms: natural history. Radiology 2005;235:683-6.

36. Steinmetz E, Rubin BG, Sanchez LA, Choi ET, Geraghty PJ, Baty J et al. Type II endoleak after endovascular abdominal aortic aneurysm repair: a conservative approach with selective intervention is safe and costeffective. J Vasc Surg 2004;39:306-13.

37. Jones JE, Atkins MD, Brewster DC, Chung TK, Kwolek CJ, La- Muraglia GM et al. Persistent type 2 endoleak after endovascular repair of abdominal aortic aneurysm is associated with adverse late outcomes. J Vasc Surg 2007;46:18.

38. Baum RA, Carpenter JP, Tuite CM, Velazquez OC, Soulen MC, Barker CF et al. Diagnosis and treatment of inferior mesenteric arterial endoleaks after endovascular repair of abdominal aortic aneurysms. Radiology 2000;215:409-13.
39. Sheehan MK, Barbato J, Compton CN, Zajko A, Rhee R, Makaroun MS. Effectiveness of coiling in the treatment of endoleaks after endovascular repair. J Vasc Surg 2004;40:4304.

40. Baum RA, Cope C, Fairman RM, Carpenter JP. Translumbar embolization of type 2 endoleaks after endovascular repair of abdominal aortic aneurysms. J Vasc Interv Radiol 2001;12:111-6.

41. Baum RA, Carpenter JP, Golden MA, Velazquez OC, Clark TW, Stavropoulos SW et al. Treatment of type 2 endoleaks after endovascular repair of abdominal aortic aneurysms: comparison of transarterial and translumbar techniques. J Vasc Surg 2002;35:23-9.

42. Schmid R, Gurke L, Aschwanden M, Stierli P, Jacob AL. CTguided percutaneous embolization of a lumbar artery maintaining a type II endoleak. J Endovasc Ther 2002;9:198202.

43. Mansueto $G$, Cenzi D, D'Onofrio M, Petrella $E$, Gumbs AA, Mucelli RP. Treatment of type II endoleaks after endovascular repair of abdominal aortic aneurysms: transcaval approach. Cardiovasc Interv Radiol 2005;28:641-5.

44. Ellis PK, Kennedy PT, Collins AJ, Blair PH. The use of direct thrombin injection to treat a type II endoleak following endovascular repair of abdominal aortic aneurysm. Cardiovasc Interv Radiol 2003;26:482-4.

45. Ho P, Law WL, Tung PH, Poon JT, Ting AC, Cheng SW. Laparoscopic transperitoneal clipping of the inferior mesenteric artery for the management of type II endoleak after endovascular repair of an aneurysm. Surg Endosc 2004;18:870.

46. Wisselink W, Cuesta MA, Berends FJ, van de Berg FG, Rauwerda JA. Retroperitoneal endoscopic ligation of lumbar and inferior mesenteric arteries as a treatment of 
persistent endoleak after endoluminal aortic aneurysm repair. J Vasc Surg 2000;31:1240-4.

47. Nevala T, Biancari F, Manninen $H$, Aho PS, Matsi P, Mäkinen $\mathrm{K}$ et al. Type II endoleak after endovascular repair of abdominal aortic aneurysm: effectiveness of embolization. Cardiovasc Interv Radiol 2010;33:278-84.

48. Chuter TA, Faruqi RM, Sawhney R, Reilly LM, Kerlan RB, Canto CJ et al. Endoleak after endovascular repair of abdominal aortic aneurysm. J Vasc Surg 2001;34:98-105.

49. Solis MM, Ayerdi J, Babcock GA, Parra JR, McLafferty RB, Gruneiro LA et al. Mechanism of failure in the treatment of type II endoleak with percutaneous coil embolization. J Vasc Surg 2002;36:485-91.

50. Aziz A, Menias CO, Sanchez LA, Picus D, Saad $N$, Rubin BG et al. Outcomes of percutaneous endovascular intervention for type II endoleak with aneurysm expansion. J Vasc Surg 2012;55:1263-7.

51. Maldonado TS, Rosen RJ, Rockman CB, Adelman MA, Bajakian D, Jacobowitz GR et al. Initial successful management of type I endoleak after endovascular aortic aneurysm repair with nbutyl cyanoacrylate adhesive. J Vasc Surg 2003;38:665-70.

52. LaBerge JM, Sawhney R, Wall SD, Chuter TA, Canto CJ, Wilson $\mathrm{MW}$ et al. Retrograde catheterization of the inferior mesenteric artery to treat endoleaks: anatomic and technical considerations. J Vasc Interv Radiol 2000;11:55-9.

53. van Nes JGH, Hendriks JM, Tseng LNL, van Dijk LC, van Sambeer MRHM. Endoscopic aneurysm sac fenestration as a treatment option for growing aneurysms due to type II endoleak or endotension. J Endovasc Ther 2005;12:430-4.

54. Voûte MT, Bastos Goncalves FM, Hendriks JM, Metz R, van Sambeek MRHM, Muhs BE et al. Treatment of post-implantation aneurysm growth by laparoscopic sac fenestration: longterm results. Eur J Vasc Endovasc Surg 2012:1-5.

55. Hobo R, Buth J, on behalf of EUROSTAR collaborators. Secondary interventions following endovascular abdominal aortic aneurysm repair using current endografts. A EUROSTAR report. J Vasc Surg 2006;43:896902.

56. Matsumura JS, Ryu RK, Ouriel K. Identification and implications of transgraft microleaks after endovascular repair of aortic aneurysms. J Vasc Surg 2001;34:190-7.

57. Buth J, Harris PL, van Marrewijk C, Fransen G. The signi"cance and management of different types of endoleaks. Semin Vasc Surg 2003;16:95-102.

58. Mehta M, Sternbach Y, Taggert JB, Kreienberg PB, Roddy SP, Paty PSK et al. Long-term outcomes of secondary procedures after endovascular aneurysm repair. J Vasc Surg 2010;52:1442-8.

59. White GH, May J, Petrasek P. Speci"c complications of endovascular aortic repair. Semin Interv Radiol 2000;5:35-46.

60. Koole D, Moll FL, Buth J, Hobo R, Zandvoort HJA, Bots $M L$ et al. for the European collaborators of stent-Graft techniques for aortic aneurysm repair (EUROSTAR). Annual rupture risk of abdominal aortic aneurysm enlargement without detectable endoleak after endovascular abdominal aortic repair. J Vasc Surg 2011;54:1614-22.

61. Mennander A, Pimenoff $G$, Heikkinen $M$, Partio T, Zeitlin R, Salenius JP. Nonoperative approach to endotension. J Vasc Surg 2005;42:194-8.

62. Veith FJ, Baum RA, Ohki T, Amor M, Adiseshiah M, Blankensteijn JD et al. Nature and signi"cance of endoleaks and endotension: Summary of opinions expressed at an international conference. J Vasc Surg 2002;35:1029-35. 
63. Cuypers PWM, Laheij R, Buth J. Which factors increase the risk of conversion to open surgery following endovascular abdominal aortic aneurysm repair? Eur J Vasc Endovasc Surg 2000;20:183-9.

64. Kougias $P$, Lin PH, Dardik A, Lee WA, El Sayed $H F$, Zhou W. Successful treatment of endotension and aneurysm sac enlargement with endovascular stent graft reinforcement. J Vasc Surg 2007;46:124-7.

65. Ryu RK, Palestrant S, Ryu J, Trachtenberg J. Sac hygroma after endovascular abdominal aortic aneurysm repair: successful treatment with endograft relining. Cardiovasc Intervent Radiol 2007;30:488-90.

66. Risberg B, Delle M, Eriksson E, Klingenstierna $H$, Lönn L. Aneurysm sac hygroma: a cause of endotension. J Endovasc Ther 2001;8:447-53.

67. Risberg B, Delle M, Lönn L, Syk I. Management of aneurysm sac hygroma. J Endovasc Ther 2004;11:191-5.

68. van Sambeek MRHM, van Dijk LC, Hendriks JM, et al. Endotension after EVG: Causes, diagnosis, and treatment. In Pearce $W H$, Matsumura JS, Yao, JST (eds): Trends in Vascular Surgery 2003. Chicago, II, Precept Press, 2004, pp 215-223.

69. Mory M, Allenberg JR, Schumacher $H$, von Tengg-Kobligk $H$, Böckler D. Open decompression, proximal banding, and aneurysm sac fenestration as an alternative to conversion in the management of endotension after EVAR. J Endovasc Ther 2008;15:449-52.

70. Hiroaka A, Yoshitaka H, Chikazawa G, Ishida A, Totsugawa $T$, Kuinose $M$. A modi"ed technique of open surgical treatment of aneurysmal sac enlargement after endovascular repair. EJVES Extra 2012;23:e45-e47.

71. Heikkinen MA, Alsac JM, Arko FR, Metsanoja $R$, Zvaigzne $A$, Zarins CK. The importance of iliac "xation in prevention of stent graft migration. J Vasc Surg 2006;43:1130-7.

72. Laheij RFJ, Buth J, Harris PL, Moll FL, Stelter WJ, Verhovenon ELG. Need for secondary interventions after endovascular repair of abdominal aortic aneurysms. Intermediateterm followup results of a European collaborative registry (EUROSTAR). Br J Surg 2000;87:1666-73.

73. Cao P, Verzini F, Zannetti S, De Rango $P$, Parlani G, Lupattelli $L$ et al. Device migration after endoluminal abdominal aortic aneurysm repair : analysis of 113 cases with a minimum followup period of 2 years. J Vasc Surg 2002;35:229-35.

74. Conners MS, Sternbergh WC, Carter G, Tonnessen $\mathrm{BH}$, Yoselevitz $\mathrm{M}$, Money SR. Endograft migration one to four years after endovascular abdominal aortic aneurysm repair with the AneuRx device. A cautionary note. J Vasc Surg 2002;36:476-84.

75. Waasdorp EJ, Gorrepati ML, Ra"i BY, de Vries JPPM, Zarins CK. Sideways displacement of the endograft within the aneurysm sac is associated with late adverse events after endovascular aneurysm repair. J Vasc Surg 2012;55:947-55.

76. Litwinski RA, Donayre CE, Chow SL, Song TK, Kopchok G, Walot I L et al. The role of aortic neck dilation and elongation in the etiology of stent graft migration after endovascular abdominal aortic aneurysm repair with a passive fixation device. J Vasc Surg 2006;44:1176-81.

77. Thomas BG, Sanchez LA, Geraghty PJ, Rubin BG, Money SR, Sicard GA. A comparative analysis of the outcomes of aortic cuffs and converters for endovascular graft migration. J Vasc Surg 2010;51:1373-80.

78. Quinney BE, Parmar GM, Nagre SB, Patterson $M$, Passman MA, Taylor $S$ et al. Long-term single institution comparison of endovascular aneurysm repair and open aortic aneurysm repair. J Vasc Surg 2011;54:1592-8. 
79. Tzortizis E, Hinchliffe RJ, Hopkinson BR. Adjunctive procedures for the treatment of proximal type I endoleak: the role of periaortic ligatures and Palmaz stenting. J Endovasc Ther 2003;10:233-9.

80. Carroccio A, Faries PL, Morrissey NJ, Teodorescu V, Burks JA, Gravereaux EC et al. Predicting iliac limb occlusions after bifurcated aortic stent grafting: anatomic and device-related causes. J Vasc Surg 2002;36:679-84.

81. Becker GJ, Kovacs $M$, Mathison MN, Katzen BT, Benenati JF, Zemel $G$ et al. Risk strati"cation and outcomes of transluminal endografting for abdominal aortic aneurysm: 7-year experience and long-term follow-up. J Vasc Interv Radiol 2001;12:1033-46.

82. Cochennec F, Becquemin JP, Desgranges P, Allaire E, Kobeiter $H$, Roudot-Thoraval F. Limb graft occlusion following EVAR: clinical pattern, outcomes and predictive factors of occurrence. Eur J Vasc Endovasc Surg 2007;34:59-65.

83. Hoshina K, Kato M, Mikuriya A, Ohkubo N. Successful endovascular repair in two cases of graft limb occlusion after endovascular aneurysm repair for abdominal aortic aneurysms. Surg Today 2010;40:487-90.

84. Maleux G, Koolen M, Heye S, Nevelsteen A. Limb occlusion after endovascular repair of abdominal aortic aneurysms with supported endografts. J Vasc Interv Radiol 2008;19:1409-12.

85. Amesur NB, Zajko AB, Orons PD, Makarou MS. Endovascular treatment of iliac limb stenosis or occlusions in 31 patients treated with the ancure endograft. J Vasc Interv Radiol 2000;11:421-8.

86. Kondo $\mathrm{Y}$, Dardik A, Muto A, Nishibe $M$, Nishibe T. Primary stent placement for late complete occlusion after aortoiliac reconstructive surgery: report of a case. Surg Today 2009;39:418-20.

87. Lipsitz EC, Ohki T, Veith FJ, Rhee SJ, Gargiulo NJ, Suggs WD et al. Patency rates of femorofemoral bypass associated with endovascular aneurysm repair surpass those performed for occlusive disease. J Endovasc Ther 2003;10:1061-5. 




\section{CHAPTER 8}

\section{RATIONALE AND DESIGN OF THE EAGLE REGISTRY: EVAR WITH ENDURANT IN CHALLENGING ANATOMY}

\section{R.A. Stokmans \\ P.P.H.L. Broos}

Ph.W.M. Cuypers

T.L. Forbes

A.C. Vahl

P. Swartbol †

M.R.H.M. van Sambeek

J.A.W. Teijink

Journal of Cardiovascular Surgery (Torino)

2014 October; 55(5): 699-704 


\section{ABSTRACT}

Aim: The aim of this study is to collect clinical information on the performance of the Endurant (II) Stent Graft System for endovascular repair in anatomically challenging aneurysms, and to critically assess whether the current guidelines for anatomic eligibility for endovascular treatment with this system are still applicable.

Methods: Initiated by doctors, EAGLE is a prospective, non-interventional study, aiming to enrol 250 patients in 20 experienced centres across several countries worldwide. EAGLE focuses on patients with challenging angulation or neck length. To minimize the risk of selection bias and enhance data quality, EAGLE eligibility will be determined by an independent core-lab and efforts will be made to secure consecutive enrolment of challenging cases. The EAGLE database is designed to merge with the on-going ENGAGE database, which enables comparative analysis of cases and results.

Results: The primary endpoint is treatment success at 30 days, 12 months and yearly up to 5 years post implant.

Conclusion: Separate studies on the performance of EVAR in challenging anatomy are necessary to demonstrate safety and effectiveness of the latest generation stent-grafts, which is essential in making a balanced judgment about the optimal management of AAAs. 


\section{INTRODUCTION}

Over the past twenty years, endovascular aneurysm repair (EVAR) has been very successful in terms of the exclusion of aneurysms and the absence of perioperative and postoperative complications. Following to the instructions for use (IFU), the applicability of endografts to abdominal aortic aneurysms (AAAs) has changed dramatically since Parodi et al. ${ }^{1}$ and Volodos et al. ${ }^{2}$ independently introduced EVAR in 1991.

According to several studies, the success of EVAR is closely dependent on an AAA's morphology and dimensions. ${ }^{3,4}$ For this reason, the IFU for all commercially available endografts have clear recommendations on AAA morphology and aortic dimensions. If the device-specific IFU are strictly followed, a substantial proportion (40\%) of patients must be rejected for having an anatomy that is unsuitable for EVAR, and more woman are rejected EVAR than men.

Despite these stringent guidelines, it is clear that patients with an anatomy outside the recommend limits are also being treated by means of EVAR. When reviewing anatomic measurement data at our centre, we found that numerous patients with shorter and more angulated infrarenal necks, outside IFU, had been treated with an EVAR device. In the United States, a retrospective study of CT-scans of 10,228 AAA-patients showed that $30 \%$ did not met the most liberal IFU criteria. In the ENGAGE registry approximately $10 \%$ of the treated patients had angulated or short necks, outside the IFU criteria, despite the fact that Endurant's IFU are liberal compared to other devices.

Success rates and complication rates in these types of patients tend to be similar to those of patients who do meet the IFU criteria. These outcomes may be explained by the fact that the anatomic requirements in the IFU are based on research performed on first-generation endovascular stent grafts. Due to increased experience and improved devices, these criteria may therefore have become out-dated and may not be applicable to new-generation stent grafts, including the Endurant (II) System. 
Based on the encouraging initial results from the ENGAGE and our own centre's experience, it is possible that with current devices even more challenging cases could be treated endovascularly. So far, however, no large prospective study on these outcomes has been performed. Evidence on this topic may create an opportunity for a broader group of AAA patients to be treated with this minimally invasive technique.

Therefore we designed the EAGLE (Endurant for challenging Anatomy: Global Experience) Registry. The aim of this study was to prospectively collect global "real world" data on the performance of the Endurant Stent Graft System for endovascular repair in anatomically challenging infrarenal AAAs and to critically assess whether the current recommendations for anatomic eligibility for endovascular treatment with this system are still applicable.

\section{METHODS}

EAGLE is a multi-center, postmarket, non-interventional, non-randomized, single-arm, prospective observational study, initiated by the Department of Vascular Surgery at Catharina Hospital Eindhoven, The Netherlands. The study has a single-arm without controls, as it is descriptive in nature. With an anticipated percentage of success of $94 \%$, sample size was calculated based on a hypothesis of non-inferiority with a maximum of $10 \%$ difference. It will recruit approximately 250 anatomically challenging subjects from 20 high-volume sites from 10 countries worldwide from September 2012 until December 2015. Study enrolment is open to consecutively enrolled subjects who in the opinion of the investigator are candidates for endovascular AAA repair with the Endurant Stent Graft System despite having challenging anatomic measurements. With the approval of the ENGAGE executive committee all patients within the ENGAGE dataset exceeding anatomic requirements (approximately 100 subjects) will also be included in the EAGLE comparative analysis.

EAGLE does not intervene with the physician's decision to choose EVAR with an Endurant Stent Graft. Follow-up imaging studies are requested at 1 month, 12 months, and yearly thereafter, as minimally required by the reporting standards for endovascular aortic 
aneurysm repair. ${ }^{8}$ Beyond this, sites can schedule the subject's follow-up visits as usual in their clinical practice, as this study does not intervene or influence the follow-up regimen. For data completion it is, however, possible that a telephone-contact with subjects will be requested.

\section{Participating centers}

Clinical sites with an annual case volume of more than 50 EVAR procedures and ad least 25 successful prior Endurant implants are eligible to participate in the EAGLE Registry. Local ethical committees must approve participation in EAGLE. The initiating centre, Catharina Hospital, Eindhoven, the Netherlands, will also participate as one of the enrolling sites in the EAGLE Regitsry.

\section{Device description}

The Endurant Stent Graft is designed to treat infrarenal abdominal aortic or aorto-iliac aneurysms using an endovascular approach. When placed within the aneurysm, the Endurant Stent Graft provides a permanent, alternative conduit for blood flow within the subject's vasculature by excluding the aneurysm sac from blood flow and pressurization.

Certain key features are present in the Endurant Stent Graft System, such as a design optimized to treat difficult anatomies with $\leq 75^{\circ}$ infrarenal neck angulation, a lower diameter profile to access and track small iliac vessels and a hydrophilic-coated delivery system for improved handling. The Endurant Stent Graft also includes suprarenal anchoring pins for improved proximal fixation.

The Endurant II Stent Graft System differs from its predecessor in three ways: $28 \mathrm{~mm}$ diameter bifurcated segment to fit inside an 18 French OD catheter (down from 20 French), addition of two new contralateral limb lengths (156 mm and $199 \mathrm{~mm}$ ), and improved radiopacity of the distal end of the bifurcated segment's contralateral gate.

The Endurant (II) Stent Graft System is indicated for the endovascular treatment of infrarenal abdominal aortic or aorto-iliac aneurysms in patients with the characteristics according the IFU (Table 1). 


\section{Table 1. Endurant ${ }^{\circledR}$ and Endurant ${ }^{\circledR}$ II indications for use}

\section{One of the following criteria:}

- Infrarenal neck length $\geq 10 \mathrm{~mm}$ with non-significant calcification, and/or non-significant thrombus in combination with $\leq 45^{\circ}$ suprarenal angulation and $\leq 60^{\circ}$ infrarenal angulation.

- Infrarenal neck length $\geq 15 \mathrm{~mm}$ with non-significant calcification, and/or non-significant thrombus in combination with $\leq 60^{\circ}$ suprarenal angulation and $\leq 75^{\circ}$ infrarenal angulation.

\section{And all of the following criteria:}

- Adequate iliac/femoral access

- Proximal AAA neck diameter $\geq 19 \mathrm{~mm}$ and $\leq 32 \mathrm{~mm}$

- Distal iliac fixation site diameter $\geq 8 \mathrm{~mm}$ and $\leq 25 \mathrm{~mm}$

- Distal non-aneurysmal iliac fixation length $\geq 15 \mathrm{~mm}$ bilaterally

\section{Enrollment criteria}

Participation in the EAGLE Registry is intended for all subjects diagnosed with an infrarenal AAA, whom their own physicians consider candidates for endovascular repair and who meet the inclusion criteria. EAGLE focuses on patients with challenging angulation or challenging neck length. To prevent selection bias, sites are requested to provide a minimal set of morphologic data of all patients scheduled for EVAR treatment with the Endurant Stent Graft from the moment a site participates in the EAGLE registry. To be included in the trial, patients need to be 18 years old and have an indication for elective EVAR with the Endurant (II) stent graft. AAA anatomy must be challenging as defined in the measurements described in Table 2.

Table 2. Inclusion and exclusion criteria EAGLE Registry

\section{INCLUSION}

- Age $\geq 18$ years or minimum age as required by local regulations

- Indication for elective EVAR

- Challenging AAA anatomy defined by having one of the following measurements:

- Proximal necks $5-10 \mathrm{~mm}$ in combination with $\leq 60^{\circ}$ infrarenal $A N D \leq 45^{\circ}$ suprarenal angulation

- Proximal necks $10-15 \mathrm{~mm}$ in combination with $60^{\circ}-75^{\circ}$ infrarenal $A N D \leq 60^{\circ}$ suprarenal angulation OR in combination with $\leq 75^{\circ}$ infrarenal AND $45^{\circ}-60^{\circ}$ suprarenal angulation

- Proximal necks $\geq 15 \mathrm{~mm}$ in combination with $75^{\circ}-90^{\circ}$ infrarenal $A N D \leq 75^{\circ}$ suprarenal angulation $O R$ in combination with $\leq 90^{\circ}$ infrarenal AND $60^{\circ}-75^{\circ}$ suprarenal angulation

- Intention to electively implant the Endurant or Endurant II Stent Graft System ${ }^{\circ}$

\section{EXCLUSION}

- High probability of non-adherence to physician's follow-up requirements

- Current participation in a concurrent trial which may confound study results

- Planned for following adjuvant procedures at the proximal aortic neck: chimney technique, branched device or endostaplers 
Exclusion criteria are high probability of non-adherence to physician's follow-up requirements or participation in a concurrent trial, because this may confound study results. Patients will also be excluded if adjuvant procedures at the proximal aortic neck, such as chimney technique, branched device, fenestrated device or endostaplers are planned.

Subjects who meet all of the study eligibility criteria will be eligible for enrolment in the EAGLE study. An independent core-lab will crosscheck these considered patients' appropriate imaging studies (Computed tomography angiography (CTA) with a minimal slice thickness of $3 \mathrm{~mm}$ ) for EAGLE inclusion eligibility. The core-lab will be blinded for patient identity and for responsible physician. Subjects will be included if morphologic inclusion criteria are verified by the core-lab.

\section{Implantation and follow-up}

The implant procedure shall be performed according to usual practice at the site and in line with the IFU. During the endovascular procedure it is at the investigator's discretion to employ anesthesia, to administer antibiotics and systemic heparin, and to obtain and close access to the arterial site. All the devices should be deployed following all the steps in the IFU.

Use of an angiographic catheter with calibrated radiopaque marking is preferred. The investigator will verify dimensions and characterizations of the subject's anatomy in relation to the Endurant Stent Graft System.

Each subject will continue to be followed according to the follow-up regimen that is standard clinical practice at each site. To be compliant to the protocol and current standard care in EVAR therapy, the subjects are recommended to return to the sites for 1-year follow-up visits and annually thereafter until the 5-year visit at the end of the study. The 30-day visit will be considered the first visit after the initial implantation procedure and the timing of this visit may vary according to local follow-up regimes. 


\section{Study endpoints}

The primary endpoint of the EAGLE registry is treatment success at the time of the index procedure, 30 days, 12 months and yearly up to 5 -years post-implant. Treatment success is defined by technical success and clinical success. Technical success is defined as successful delivery and deployment of the Endurant Stent Graft in planned position without unintentional coverage of one or both internal iliac arteries renal or visceral aortic branches and with successful removal of the delivery system. Clinical success is defined as freedom from aneurysm expansion of $>5 \mathrm{~mm}$, freedom from Type I and III endoleaks, freedom from aneurysm rupture, freedom from conversion to open surgery, and freedom from stent graft migration (>10mm) and occlusion.

The secondary endpoints comprise technical observation, adverse events, major adverse events and quality of life. Technical observations include: presence of an endoleak, stent graft kinking, stent graft wire form fracture, suprarenal bare stent fracture or detachment from fabric, stent graft occlusion or stent graft stenosis. Major adverse events include allcause mortality, bowel ischemia, myocardial infarction, paraplegia, procedural blood loss $\geq$ $1000 \mathrm{cc}$, renal failure, respiratory failure and stroke. All deaths within 30 days after procedure are defined as aneurysm-related. Quality of life will be assessed before admission, after discharge, at 30 days, at 12 months and annually thereafter. Health outcome will be measured by the EuroQol 5-Dimensions (EQ-5D) questionnaire, which includes a visual analogue scale and a descriptive system. ${ }^{9}$ The EQ-5D questionnaire forms are designed for self-completion by subjects and will be provided in local language.

\section{Adverse event monitoring}

Study-specific adverse events (AE) information will be collected throughout the study, documented in the subject's medical record, and reported to the coordinating center on an $A E$ e-CRF. For the purpose of the clinical report, we will classify each study-specific $A E$ according to EN ISO 14155-1. Serious AEs will be reported to investigators, ECs and Regulatory Authorities according to national regulations and requirements. 


\section{Data collection and monitoring}

Clinical data collection will only start after the subject has given voluntary, documented informed consent. Data collected will be recorded on appropriate web-based or paper format case report forms (CRFs). Instructions for proper completion of the CRFs may be printed at the sites to use as a working copy. The CRFs will be completed, reviewed, signed and dated by the clinical investigators. Data will be collected at baseline, during the implant procedure, throughout the hospital stay, and in the 5-year post-operative follow-up phase.

All participating centers are monitored by a research team of the Department of Vascular Surgery, Catharina Hospital, Eindhoven to confirm adherence to the clinical investigational plan, to assess the accuracy and completeness of submitted clinical data, and to verify that records and documents are being properly maintained for the duration of the study. The Statistics \& Data Analysis team at the Department of Vascular Surgery, Catharina Hospital, Eindhoven will check the data entered on the CRFs for consistency and completeness on a regular basis, both manually as well as by using statistical monitoring of the clinical database. Sites will be contacted for data inconsistencies in order to recover incomplete, inconsistent, or missing data. In case of multiple futile attempts of data completeness data and nonresponse from clinical sites, sites will be visited by monitors of the Department of Vascular Surgery, Catharina Hospital, Eindhoven. In such cases, they will collect data from source documents in a final attempt to complete the applicable CRFs. To enhance data quality, additional site visits will be conducted to crosschecks CRFs with patient files in approximately $20 \%$ of enrolled subjects.

\section{Statistical analysis}

Statistical analyses will take place after final subject's 30-day follow-up, 1 year follow-up and thereafter annually. Statistical analyses will be performed using Predicting Analytics Software (SPAW/SPSS) for Mac (version 20 or more recent) or other validated statistical software. 


\section{DISCUSSION AND CONCLUSIONS}

Endovascular aneurysm repair (EVAR) is considered a safe and effective alternative to open repair for the treatment of selected cases of AAA. The success of EVAR is, however, dependent upon patient-specific factors, including aortic dimensions and aneurysm morphology. Severely angulated or short infrarenal necks are associated with an increased risk of operative failure and late aneurysm rupture due to proximal Type-I endoleaks and graft migration. To limit these risks, IFU for commercially available stent grafts indicate use within a specific range of aortic anatomy. As a consequence, a substantial proportion of AAA patients are considered ineligible for EVAR as they fail to meet IFU criteria.

In the past two decades, many technological advances have been introduced to improve feasibility and durability of EVAR. Also, surgeons have become more proficient in applying endovascular techniques. These developments have led to an increasing interest and confidence to extend treatment to challenging anatomies. Currently, $>70 \%$ of elective AAA repairs are performed with EVAR, and approximately $30 \%$ of these patients are considered outside IFU criteria. ${ }^{4}$ Multiple studies show comparable results in patients with conservative and challenging anatomy regarding mortality, proximal Type-1 endoleaks and reinterventions (Table 3). These studies indicate that EVAR with simple infrarenal stent graft placement can be used with caution in patients with unfavourable anatomy. ${ }^{10}$ However the quality of the evidence in challenging cases is still scarce, due to a lack of long-term results and consecutive series.

Therefore, the EAGLE (Endurant for Challenging Anatomy: Global Experience) Registry is designed to register the performance of a newest generation stent graft in challenging anatomy in a real-world setting, and to critically assess whether or not it is reasonable and safe to expand current guidelines of anatomic eligibility for endovascular treatment. To minimize the risks of selection bias and enhance data quality, EAGLE eligibility will be determined by an independent core-lab and efforts will be made to secure consecutive enrolment of challenging cases. 
The EAGLE Registry is unique and revolutionary in its design, aiming at a high number of challenging cases with a long-term follow-up. It will create a consecutive case series of the performance of EVAR in challenging anatomy with the latest generation stent graft. Future results from the EAGLE registry may reveal how far boundaries can be safely stretched, and broaden the applicability rate of EVAR.

Table 3. Overview of results in studies presenting Challenging and Friendly anatomy

\begin{tabular}{|c|c|c|c|c|c|c|c|c|c|c|c|c|}
\hline \multirow[t]{2}{*}{ Study } & \multicolumn{2}{|c|}{$\begin{array}{c}\text { Population } \\
\text { Size }\end{array}$} & \multicolumn{2}{|c|}{$\begin{array}{c}\text { Mortality } \\
\text { at } 30 \text {-days } \\
(\%)\end{array}$} & \multicolumn{2}{|c|}{$\begin{array}{c}\text { Type-I } \\
\text { endoleaks } \\
\text { within } 30 \\
\text { days (\%) }\end{array}$} & \multicolumn{2}{|c|}{$\begin{array}{c}\text { Type-I } \\
\text { endoleaks } \\
\text { at } 1 \text { year }(\%)\end{array}$} & \multicolumn{2}{|c|}{$\begin{array}{l}\text { Re- } \\
\text { intervention } \\
\text { within } 1 \\
\text { year }(\%)\end{array}$} & \multicolumn{2}{|c|}{$\begin{array}{l}\text { AAA-related } \\
\text { mortality } \\
\text { at } 1 \text { year }(\%)\end{array}$} \\
\hline & C & $F$ & C & $F$ & C & F & C & $F$ & C & F & C & $F$ \\
\hline $\begin{array}{l}\text { Setacci } \\
(2012)^{11}\end{array}$ & 72 & 65 & $\begin{array}{c}2 \\
(2.7)\end{array}$ & $\begin{array}{c}1 \\
(1.5)\end{array}$ & $\begin{array}{c}0 \\
(0)\end{array}$ & $\begin{array}{c}0 \\
0 \\
(0)\end{array}$ & - & - & - & - & - & - \\
\hline $\begin{array}{l}\text { Stather } \\
(\mathbf{2 0 1 2})^{12}\end{array}$ & 199 & 353 & $\begin{array}{c}1 \\
(0.5)\end{array}$ & $\begin{array}{c}4 \\
(1.1)\end{array}$ & $\begin{array}{c}5 \\
(2.5)\end{array}$ & $\begin{array}{c}3 \\
(0.8)\end{array}$ & - & - & - & - & - & - \\
\hline $\begin{array}{l}\text { Torsello } \\
\text { (2011) }\end{array}$ & 56 & 121 & $\begin{array}{c}1 \\
(1.8)\end{array}$ & $\begin{array}{c}2 \\
(1.7)\end{array}$ & $\begin{array}{c}2 \\
(3.6)\end{array}$ & $\begin{array}{c}0 \\
(0)\end{array}$ & $\begin{array}{c}4 \\
(7.1)\end{array}$ & $\begin{array}{c}0 \\
(0)\end{array}$ & $\begin{array}{c}5 \\
(8.9)\end{array}$ & $\begin{array}{c}6 \\
(5.0)\end{array}$ & $\begin{array}{c}1 \\
(1.8)\end{array}$ & $\begin{array}{c}0 \\
(0)\end{array}$ \\
\hline $\begin{array}{l}\text { Goncalves } \\
\text { (2011) }\end{array}$ & 45 & 65 & $\begin{array}{c}1 \\
(2.2)\end{array}$ & $\begin{array}{c}2 \\
(3.1)\end{array}$ & $\begin{array}{c}0 \\
(0)\end{array}$ & $\begin{array}{c}0 \\
(0)\end{array}$ & - & - & - & - & - & - \\
\hline $\begin{array}{l}\text { Aburahma } \\
(\mathbf{2 0 1 1})^{15}\end{array}$ & 149 & 89 & - & - & $\begin{array}{c}1 \\
(0.7)\end{array}$ & $\begin{array}{c}0 \\
(0)\end{array}$ & $\begin{array}{c}16 \\
(11)\end{array}$ & $\begin{array}{c}3 \\
(3.4)\end{array}$ & $\begin{array}{c}7 \\
(4.7)\end{array}$ & $\begin{array}{c}5 \\
(5.6)\end{array}$ & $\begin{array}{c}1 \\
(0.7)\end{array}$ & $\begin{array}{c}0 \\
(0)\end{array}$ \\
\hline Weighted & & & & & & & & & & & & \\
\hline MEAN & 521 & 693 & $1.3 \%$ & $1.5 \%$ & $1.5 \%$ & $0.4 \%$ & $9.8 \%$ & $1.4 \%$ & $5.9 \%$ & $5.2 \%$ & $1.0 \%$ & $0.0 \%$ \\
\hline
\end{tabular}




\section{REFERENCES}

1. Parodi JC, Palmaz JC, Barone HD. Transfemoral intraluminal graft implantation for abdominal aortic aneurysms. Ann Vasc Surg 1991;5:491-9.

2. Volodos NL, Karpovich IP, Troyan VI, Kalashnikova Yu V, Shekhanin VE, Ternyuk NE, et al. Clinical experience of the use of selffixing synthetic prostheses for remote endoprosthetics of the thoracic and the abdominal aorta and iliac arteries through the femoral artery and as intraoperative endoprosthesis for aorta reconstruction. Vasa Suppl 1991;33:93-5.

3. Ouriel K, Tanquilut E, Greenberg RK, Walker E. Aortoiliac morphologic correlations in aneurysms undergoing endovascular repair. J Vasc Surg 2003;38:323-8.

4. Schanzer A, Greenberg RK, Hevelone N, Robinson WP, Eslami MH, Goldberg RJ, et al. Predictors of abdominal aortic aneurysm sac enlargement after endovascular repair. Circulation 2011;123:2848-55.

5. Moise MA, Woo EY, Velazquez OC, Fairman RM, Golden MA, Mitchell ME, et al. Barriers to endovascular aortic aneurysm repair: past experience and implications for future device development. Vasc Endovascular Surg 2006;40:197-203.

6. Bockler $D$, Fitridge $R$, Wolf $Y$, Hayes $P$, Silveira PG, Numan F, et al. Rationale and design of the
Endurant Stent Graft Natural Selection Global Postmarket Registry (ENGAGE): interim analysis at 30 days of the first 180 patients enrolled. J Cardiovasc Surg (Torino) 2010;51:481-91.

7. Stokmans RA, Teijink JA, Forbes TL, Bockler D, Peeters PJ, Riambau V, et al. Early Results from the ENGAGE Registry: Real-world Performance of the Endurant Stent Graft for Endovascular AAA Repair in 1262 Patients. Eur J Vasc Endovasc Surg 2012.

8. Chaikof EL, Brewster DC, Dalman RL, Makaroun MS, Illig KA, Sicard GA, et al. The care of patients with an abdominal aortic aneurysm: the Society for Vascular Surgery practice guidelines. J Vasc Surg 2009;50:S2-49.

9. Cavrini G, Broccoli S, Puccini A, Zoli M. EQ-5D as a predictor of mortality and hospitalization in elderly people. Qual Life Res 2012;21:26980.

10. Antoniou GA, Georgiadis GS, Antoniou SA, Kuhan G, Murray D. A meta-analysis of outcomes of endovascular abdominal aortic aneurysm repair in patients with hostile and friendly neck anatomy. J Vasc Surg 2013;57:527-38.

11. Setacci F, Sirignano P, de Donato G, Chisci E, lacoponi F, Galzerano $G$, et al. AAA with a challenging neck: early outcomes using the 
Endurant stent-graft system. Eur J Vasc Endovasc Surg 2012;44:274-9.

12. Stather PW, Sayers RD, Cheah A, Wild JB, Bown MJ, Choke E. Outcomes of endovascular aneurysm repair in patients with hostile neck anatomy. Eur J Vasc Endovasc Surg 2012;44:556-61.

13. Torsello G, Troisi N, Donas KP, Austermann M. Evaluation of the Endurant stent graft under instructions for use vs off-label conditions for endovascular aortic aneurysm repair. J Vasc Surg 2011;54:300-6.
14. Bastos Goncalves F, de Vries JP, van Keulen JW, Dekker H, Moll FL, van Herwaarden JA, et al. Severe proximal aneurysm neck angulation: early results using the Endurant stentgraft system. Eur J Vasc Endovasc Surg 2011;41:193200.

15. Aburahma AF, Campbell JE, Mousa AY, Hass SM, Stone PA, Jain A, et al. Clinical outcomes for hostile versus favorable aortic neck anatomy in endovascular aortic aneurysm repair using modular devices. J Vasc Surg 2011;54:13-21. 

CHAPTER 9

GENERAL DISCUSSION 


\section{INTRODUCTION}

The technology of EVAR for AAAs is a dynamic ever-changing endeavour. The first patients undergoing EVAR were treated with tubular grafts that were anchored to the aortic wall by balloon expandable stainless steel stents. At an early stage, aorto-uni-iliac devices combined with femoro-femoral bypass and an occluding plug in the contralateral common iliac artery were used. The applicability of EVAR increased markedly with the introduction of bifurcated and modular stent grafts, which are now used in the vast majority of abdominal EVAR cases. A two- or three-piece modular design permits customisation to meet a variety of anatomical and pathological conditions.

Most current systems are based on self-expandable nitinol stents with Dacron or ePTFE fabric. Proximal anchoring hooks reduce the risk of migration, whereas the possible advantage of transrenal fixation with suprarenal bare metal stent is debated. ${ }^{2}$ As improved devices with wider inclusion criteria become available and operators become more proficient with endovascular techniques, the proportion of patients suitable for EVAR increases. ${ }^{3}$ However, overall outcomes may not improve if broadening the application rate results in poorer outcomes despite improvements in operator skills and device design. This ever-evolving trade-off implies that results from older series using previous generations of devices may not reflect the current status of EVAR. As a consequence, results of the performance of latest generation devices in contemporary, real-world settings are important.

In this chapter the main findings of the studies presented in this thesis are described including implications for clinical practice, methodological considerations, a personal perspective and suggestions for future research. Finally, the overall conclusions are presented. 


\section{MAIN FINDINGS AND GENERAL DISCUSSION}

\section{PART ONE - Perioperative outcome in contemporary EVAR practice}

The ENGAGE registry was undertaken to quantify the performance of a latest generation stent graft within the context of contemporary, real world use. Patients were included in a prospective and consecutive manner in order to minimize risk of selection bias. The collective experience with the Endurant Stent Graft applied in 1262 patients from 79 centres in 30 countries across 5 different continents is expected to have external validity, since eligibility for EVAR was left to the discretion of operators and study follow-up protocols were kept as close as possible to standard site regimens. A large quantity of data was recorded and great efforts were made to guarantee high quality and completeness of data in order to facilitate meaningful analysis.

In Chapter 2 perioperative and one-year results of the Endurant Stent Graft in 1262 consecutively enrolled AAA-patients were reported. Intra-operative technical success was excellent and achieved in $99.0 \%$ of cases and no intra-operative deaths occurred. A 30-day mortality rate of $1.3 \%$ and one-year aneurysm-related mortality rate of $1.2 \%$ are comparable with those reported in the landmark EVAR-1 and DREAM trials. ${ }^{4,5}$ Remarkably, given a relatively large proportion (10.6\%) of ASA class IV patients in ENGAGE, the one-year overall survival rate of $91.6 \%$ is considered high compared to EVAR-1 and DREAM. ${ }^{4,5}$ Despite $17.9 \%$ of cases treated outside IFU criteria, with numerous cases of short- or angulated necks, an incidence of $1.5 \%$ early Type-I and -III endoleaks was low and with no reports of aneurysm ruptures. Also, a Type-II endoleak rate of $9.9 \%$ is considered remarkably lower than reported in other studies. This finding is of little clinical value however, since Type-Il endoleaks are thought to be less clinically relevant than others endoleaks.

The necessity for secondary interventions is considered the Achilles' heel of EVAR, and the main reason that EVAR was not considered cost-effective at long-term follow-up in the DREAM trial. ${ }^{5-8}$ We reported an one-year reinterventions rate of $4.6 \%$ which compares favourably to reinterventions rates reported in EVAR-1 and DREAM trials, and is similar to the reintervention rate reported in the more recent OVER-trial. 
The ENGAGE Registry has found to be the largest prospective EVAR device registry, but numerous smaller prospective and retrospective registries have been performed. Recently, Kent et al. ${ }^{14}$ published a systematic review on studies reporting outcomes of specific EVAR grafts for intact infrarenal AAAs. The review included 147 papers involving 27,058 patients. Six grafts had data from at least 10 separate studies, and are considered the leading brands in EVAR technology; Endurant and its predecessors AneuRx and Talent (Medtronic, Santa Rosa, California, USA), Zenith or Zenith Flex (Cook Medical Inc., Bloomington, Indiana, USA), Excluder or C3 Excluder (W.L. Gore \& Associates, Inc., Flagstaff, Arizona, USA), and Anaconda (Vascutek Ltd., Renfrewshire, Scotland, UK). A meta-regression analysis was performed on the early results of these different stent grafts. The Endurant performed significantly better for cumulative Type-I and -III endoleak rates compared to its predecessors Talent and AneuRx, and also the reintervention rate decreased with the use of Endurant. ${ }^{14-17}$ The Endurant showed superior results with regards to Type-I and -III endoleaks and reintervention rates when compared to the results of Zenith, Excluder and compare similar to those of Anaconda in this meta-analysis. ${ }^{14}$ Of note, the meta-analysis did not distinguish between results of the Zenith and Zenith Flex or Excluder and C3 Excluder since numbers were low and registries often combined results of namesakes in their reports. Recent reports show comparable results of the C3 Excluder, Zenith Flex and Anaconda stentgrafts to the results from ENGAGE. ${ }^{18}$

We concluded in Chapter 2 that the early results of the Endurant Stent Graft in real world, global experience are promising despite inclusion of a large proportion of ASA class IV patients and patients treated outside IFU criteria. Longer follow-up is needed to assess durability of these findings.

Symptoms of abdominal- or back pain might be signs of impending rupture. Whenever a patient presents with a symptomatic aneurysm a surgeon is confronted whether to urgently operate a patient, who may not be optimized for major surgery, or to postpone surgery until regular preoperative work-up is completed. Historically, in patients who undergo urgent repair for non-ruptured symptomatic aneurysms, the reported outcome has been consistently worse than reports on outcome of elective non-symptomatic cases. ${ }^{21-27}$ The inability to take the necessary time for an adequate preoperative work-up is suggested to be 
one of the reasons for this difference. ${ }^{21}$ We emphasized that this effect would be superseded with the use of new devices with fewer sizing constraints within the context of contemporary practice. In Chapter 3 we compared 185 (15.4\%) symptomatic AAA patients (S-AAA) with 1015 (84.6\%) non-symptomatic AAA patients (E-AAA) from the ENGAGE registry to test our hypothesis. A multivariate logistic regression analysis was used to compare results between both groups and to correct for baseline differences.

Our study showed that the technical success in S-AAA and E-AAA was comparable, with no difference in operation time or amount of contrast used. Post-operative hospital-stay and ICU admission rate was also similar in S-AAA patients. Clinical success rates of $97.3 \%$ in EAAA patients and $99.5 \%$ in S-AAA patients did not show any significant difference, whereas no difference was seen in the occurrence of major adverse events, including mortality, between both groups. Chapter 3 represents the largest series of endovascular S-AAA patients reported and the only one with a comparative analysis to date. Since ENGAGE describes the results of the Endurant stentgraft only, the results of this study might not necessarily be generalizable to all endografts available on the market, questioning the level of external validity. Therefore, we concluded that there is a rightful indication that with contemporary devices and technical proficiency of EVAR, there is no difference in early outcome between symptomatic AAA patients and elective non-symptomatic AAA patients. Off-course, long-term results have to show if limited preparation time and limited choice for stentgraft sizes compromise long-term durability.

After 20 years of proven feasibility of EVAR under local and regional anaesthesia, there is still no consensus on which type of anaesthesia is most suitable. Use of local anaesthesia is considered less invasive or harmful. Despite the preferential use of local anaesthesia is recommended in guidelines of European and American Vascular Societies, ${ }^{28,29}$ EVAR is still mainly performed under general anaesthesia. ${ }^{30-34}$ Chapter 4 examined perioperative differences in outcome between patient that underwent EVAR with different types of anaesthesia. Also in our study EVAR was mainly conducted under general anaesthesia (GA) with $62.3 \%$ of cases, whereas regional anaesthesia (RA) was used in $26.2 \%$ of cases and local anaesthesia (LA) in $11.5 \%$. However, our more contemporary data also show that local anaesthesia is applied more commonly nowadays, than in the earlier days of EVAR. 
Notably, intercontinental differences for primary choice of anaesthetic are present, with sustained regional customs of vascular surgeons and anaesthesiologists as a possible explanation. Multivariate logistic regression analysis was performed to adjust for confounding factors at baseline.

With the use of local and regional anaesthesia EVAR procedural time was reduced with approximately 25 minutes and 10 minutes if compared to general anaesthesia, without jeopardising technical success rates. After exclusion of outliers a lower ICU admission rate emerged for LA (22.4\%) and RA (27.0\%) compared with GA (35.8\%). Postoperative stay diminished with approximately 1 day when local or regional anaesthesia was used. Also, local anaesthesia scored best on the EQ-5D index for Quality of Life measures with a VAS score favouring AL patients, implying a faster recovery. Of great importance, our study did not show significant advantage of local anaesthesia in the occurrence of clinical complications. Despite a larger studied cohort, there were no difference in the occurrence of cardiac events within 30 days postoperative, as has been the case in earlier reports. ${ }^{35} \mathrm{~A}$ low incidence rate of perioperative complications overall in ENGAGE could be a good explanation why no difference in complication rates were seen between groups. In the conclusion of Chapter 4, we stated that type of anaesthesia used for EVAR has no influence on technical success and perioperative mortality and morbidity. The use of local or regional anaesthesia appears to be beneficial concerning procedural time, ICU admission, postoperative hospital stay and recovery. Based on these results, a strategy based on preferential use of locoregional anaesthesia for EVAR is advised, restricting general anaesthesia only to those with predefined contra-indications for local and regional anaesthesia. Recently, outcomes of fast-track EVAR initiatives, with percutaneous access, mandatory local or regional anaesthesia, and next-day discharge have proven feasibility in most well selected patients and resulted in efficient perioperative resource utilization with excellent safety and effectiveness. $^{36}$

\section{PART TWO - Coverage of the internal iliac artery}

Approximately $20-30 \%$ of AAAs involve at least one common iliac artery (CIA). ${ }^{37}$ In a standard EVAR procedure the CIA will serve as distal sealing site. However, in case of aneurysmatic $\mathrm{CIAs}$ extension into the external iliac artery (EIA) is often required to achieve adequate 
sealing, implicating stent graft coverage of the origin of the internal iliac artery (IIA). Theoretically, covering of the IIA involves a risk for distal Type-II endoleaks to occur. As a preventative measure, intentional IIA occlusion by using coils or vascular plugs is assumed to be mandatory. An evidence base for this assumption is lacking, and some serious complications of coil embolisation have been reported in recent literature. ${ }^{38-43}$ Safe use of sole stent graft coverage with the omission of coil embolisation or iliac branched devices would implicate a simplified EVAR strategy for aorto-iliac or iliac aneurysm. In part two of this thesis the routine of pre-emptive coil embolisation was challenged.

In Catharina Hospital Eindhoven a strategy was applied in which stent coverage of the internal iliac artery was routinely performed without prior coil embolisation. Chapter 5 displays the technical and clinical outcomes of this strategy in 32 consecutive patients who underwent EVAR with unilateral IIA stent coverage. During a mean follow-up period of 14.3 months no complications in terms of aneurysm growth or endoleaks were found. In a review of literature we found that reports of IIA-associated endoleaks are rare, and so far, no study has been able to demonstrate an association between the occurrence of IIA-related endoleaks and omission of adjuvant occlusion measures. In our series no severe symptoms of pelvic ischemia occurred, nor were any secondary interventions required to solve problems related to IIA coverage. The incidence of buttock claudication in our series was $22.6 \%$ and within the range reported in previous studies on sole IIA coverage, but compared favourable to the incidence reported in the majority of studies on coil embolisation. ${ }^{44-49}$ We therefore concluded in Chapter 5 that endovascular treatment of aorto-iliac and iliac aneurysms without pre-emptive coil embolisation of the IIA is safe and effective, and may reduce complications. Nonetheless, it was also stated that, a larger and comparative study with longer follow-up would be required to confirm our findings.

With retrospective analysis from the ENGAGE database a comparative analysis was performed, the largest analyses to date. Chapter 6 identified 197 (15.6\%) patients in whom 225 IIAs were covered. Remarkably, a minority of these received pre-emptive coil embolisation, despite this is still considered a standard of practice. Prior coil embolisation (CE) was performed in $40.4 \%$ of cases and coverage without any coil embolisation (NE) occurred in $59.4 \%$ of cases. Both groups were similar at baseline, and had a comparable 
follow-up on average of 2 years. Importantly, both groups showed equivalent iliac morphology, making them suitable for comparative analysis.

Except from a 23 minute longer procedural time in CE patient, our analysis did not reveal any other procedural differences. At a final angiogram at the end of the EVAR procedure minor IIA-related Type-I, -II or -III endoleaks were seen equally often in both groups $(5.2 \% \mathrm{NE}$ versus $6.6 \% \mathrm{CE}$ ), but were left untreated without any clinical consequence. During follow-up late IIA-related endoleaks were scarce and occurred as frequent in CE-cases (5.5\%) as in NEcases (3.0\%). Overall, IIA-related secondary interventions occurred more of in CE-cases $(7.5 \%$ NE versus $15.4 \% \mathrm{CE}$ ), predominantly for resolving occlusions or significant stenosis in the ipsilateral limb (5.2\% NE versus $13.2 \%$ CE). We cannot give any good explanation for the higher rates for limb occlusion found after coil embolisation, but we are not surprised about the high rate of clinically relevant occlusions in this cohort since extension of a limb graft into the EIA was identified as the strongest predictor for occurrence of limb occlusions. ${ }^{5}$ Remarkably, there was no difference in re-interventions for IIA-related endoleaks $(2.2 \% \mathrm{NE}$ versus $2.2 \% \mathrm{CE}$ ). No deaths or major complications were related directly or indirectly to IIA coverage. Limited value should be attributed to the reported absence of physical complications in this study, such as buttock claudication or erectile dysfunction, since we believe there might have been considerable underreporting of these symptoms in ENGAGE.

Chapter 6 represents the largest comparative analysis on the topic, and is the strongest evidence available to date. We stated that IIA coverage without prior coil embolisation does not increase the incidence of endoleaks or related secondary interventions. The omission of coil embolisation may be a more resource-effective strategy whenever IIA coverage is required, when taking into account that embolisation is usually costly, often requires multiple interventions and longer procedures under fluoroscopic guidance.

Some centres use iliac-branched devices (IBD) to treat concomitant $\mathrm{ClA}$ aneurysms, but their use often requires specialist experience. Also, they are not applicable for all anatomic configurations, and their long-term results are still unknown. The Excluder Iliac Branched Endoprothesis and the Zenith Branch Endovascular Graft are currently commercially available. Although midterm experience with these IBDs has shown a low incidence of 
secondary intervention due to endoleaks or occlusions, reports of Type-lb endoleaks and buttock claudication have been made. ${ }^{51}$ The added value of the more complex and costly iliac branched technique for treatment of common iliac aneurysms, especially when only one iliac is involved, may therefore be questioned.

\section{PART THREE - Technical complications of EVAR: how to manage and how to prevent}

As thoroughly discussed in previous chapters, EVAR treatment comes with unique technical complications. It is known that EVAR patients may experience all types of endoleaks, device migration, stent fractures, graft deterioration, or even persistent aneurysm growth, requiring secondary interventions. Advanced stent graft designs and increased understanding of management of technical complications are declining the incidence rate for necessity of secondary interventions, which was considered the down-side of EVAR and matter of great concern in the landmark trials that compare EVAR with open repair.

In Chapter 7 of this thesis we performed a review on occurrence and management strategies of technical complications of EVAR in contemporary practice and its development over time. Overall, incidence of all types of endoleaks declined in two decades of EVAR experience. The risk of rupture is high in patients with early or late onset of Type-I endoleaks and problem solving is mandatory in most cases. ${ }^{52,53}$ Treatment options of Type-I endoleaks involve securing of the attachment site with transluminal balloon angioplasty, stent extension at proximal or distal end with covered or uncovered stents, or with endo-anchors. Aortic banding can be a solution of last resort. Type-Il endoleaks can be managed conservatively, if limited growth of the aneurysm sac is present. If demanded however, interventions to resolve Type-II endoleaks include transarterial or translumbar embolisation or direct Onyx glue injection. More invasive solutions are endoscopic or surgical ligation of lumbar and mesenteric arteries. All Type-III endoleaks need to be addressed with additional stent graft components to bridge the defect. Stent graft migration is rare in EVAR with contemporary stent graft designs incorporating metal struts that fixate into the aneurysm wall. To stop any further migration large balloon-expendable stents or endostaplers can be used to secure the seal between devices and the aortic wall. 
There seems to be a trend in more frequent occurrence of limb occlusions or clinically significant stenosis requiring PTA, thrombectomy or thrombolysis. ${ }^{54-57}$ A possible explanation is found in the growing ability of low profile graft systems to make way in smaller and tortuous iliacs. If all options fail, extra-anatomical bypasses still form a solution for recurrent occlusions with high patency of over $90 \%{ }^{58}$ In Chapter 7 we conclude that in contemporary practice the incidence of secondary interventions after EVAR has decreased, but might be negatively influenced by pushing the borders of anatomical complexity. In case treatment of technical complications is necessary, first treatment options are catheter based.

The performance of the Endurant Stent Graft in challenging anatomy is evaluated in many reports, showing no differences in operative success and early outcome. ${ }^{59-61}$ These studies consisted of small, retrospectively determined cohorts, and are often subject to selection bias. We initiated the Endurant for challenging Anatomy: Global Experience (EAGLE) Registry to collect global 'real-world' performance data on the Endurant (II) Stent Graft in anatomically challenging. With the EAGLE Registry we plan to critically assess whether the current guidelines for anatomic eligibility for EVAR are still applicable when latest generation of stent graft is used. Chapter 8 of this thesis describes the rationale and design of the EAGLE Registry. Physician-initiated, EAGLE is a non-interventional study, aiming to enrol 250 patients with a challenging anatomy in at least 20 experienced vascular centres worldwide. Ruptured AAAs will be excluded. To minimize the risk of selection bias, an independent core laboratory will determine anatomic eligibility, and efforts will be made to secure consecutive enrolment. The primary endpoint is technical success at 30 days, 1 year and yearly thereafter up to five years post-implant. The EAGLE database is designed to merge with the ENGAGE database, which enables comparative analysis. EAGLE just closed its study enrolment and will present its first results soon. 


\section{STUDY LIMITATIONS AND FUTURE PERSPECTIVES}

\section{Limitations and benefits of observational studies}

Randomized controlled trials (RCTs) are considered the gold standard in the hierarchy of research designs for evaluating the efficacy and safety of a treatment intervention. Results of RCTs, however, may not reflect 'real world' since patient inclusion is subject to strict inclusion criteria, and can therefore have limited applicability to individual patients in clinical setting. Many of the everyday practice EVAR patients would not have qualified for inclusion in the trials. Generalisation of the RCT results in these patients is confounded. Moreover, one must question if RCT design is feasible in qualifying outcome of EVAR in view of the contemporary preference for EVAR and the swift evolution in stent graft designs. A recent Cochrane review high-lighted that no randomised trials exist comparing one stent graft type with another. ${ }^{62}$ Large high-quality, well-designed observational studies are increasingly believed to provide complimentary evidence to RCTs. ${ }^{63,64}$ They can assess treatment effectiveness in patients encountered in day-to-day clinical practice because of the use of larger and more heterogeneous populations with common comorbidities and longer followup periods.

The ENGAGE Registry was considered the main source of data for analyses made in this thesis. ENGAGE is undertaken by Medtronic Endovascular (Santa Rosa, California, USA) to quantify the performance of their own device, the Endurant (II) Stent Graft System. Some consider it a weakness of a study to be industry funded, Medtronic wanted to prove otherwise with this initiative. The quality of registries depends on the quality for reporting. Therefore, incomparable to historic registries, large efforts for onsite quality control and continue monitoring were made to guarantee completeness of data reports thus high quality and reliability of data. Unrestricted access to the raw database was granted to our study group, a privilege we consider an absolute and most important requisite for independent research in this perspective. A recent meta-regression analysis of the combined results of 147 studies on EVAR graft specific outcomes showed no association between company sponsorship and endoleak- or reintervention rates. 
The level of external validity might be argued upon, since extrapolation of findings to other commercially available EVAR devices may not be justified, as only Endurant cases are included in the greater part of this thesis. This may be considered a limitation. To enhance future research more medical companies are encouraged to initiate such registries, which enables comparative analyses between devices. Unfortunately, with declining complication incidences requirements for patient enrolment increases. To show acceptable non-inferiority for new or altered EVAR stent grafts at the consensus level of Type-I and -III endoleak rate at 2 years over 525 patients are required for a registry. ${ }^{14} \mathrm{~A}$ mandatory registry on AAA treatment that is nationwide or even globally supported by doctors and is financially supported by governments and industries might be the solution for creating a benchmark for future treatment and qualifying performance of new devices. The Japan Committee for Stent Graft Management Registry (JACSM), the Swedish Vascular Registry (SwedVasc) and the Dutch Surgical Aneurysm Audit (DSAA) have become mandatory and are believed to provide meaningful analyses on AAA management and guide future improvements. ${ }^{65-67}$

\section{Limitations of retrospective analyses}

In clinical practice, patients are selected to a treatment based on various factors, including disease extent and comorbidities. Therefore, when treatment methods and outcomes are compared in registries, correction for confounders is necessary. In this thesis several comparative analyses were performed to test our hypotheses. All comparative analyses are performed in a retrospective manner, with statistical correction for possible confounding factors. A limitation is the fact that important confounders may not be available among the variables in the registry, resulting in residual confounding affecting the results. Patient groups that were used for our analyses were retrospectively defined based on scored items in the database. Unfortunately, this does initiate several methodological problems that can restrain the quality of our results. The ENGAGE database was not specifically designed nor powered for our specific hypotheses.

In Chapter 3 all patients that were reported at baseline questionnaires as having symptoms of abdominal or back pain associated with aneurysm tenderness at physical examination were considered to have symptomatic AAAs. Unfortunately, time for EVAR indication to initial procedure was not recorded in the study database. Therefore it is not verifiable if all 
symptomatic patients were truly treated in semi-acute setting and if all elective patients were not, and it remains unclear if groups were defined just. In Chapter 4 differentiation between groups was clear, but preoperative clarification regarding the choice of anaesthesia type was missing. Also, information regarding possible anaesthesia type conversion would have been informative. Selection bias may have affected our results and conclusions. The results found in Chapter 6 can also have been subject to selection bias since no given explanations on the chosen EVAR strategy was given. We were not able to check whether IIA coverage was intentional or accidental and why the choice for coil embolisation or its omission was made. Despite the extensive number of anatomic measurements recorded in the ENGAGE database, this remained insufficient to create a reconstructive image of iliac morphology, which would otherwise have allowed us to make more specific conclusions. Furthermore, there was a suspicion of underreporting of several clinical complications after IIA coverage, such as buttock claudication and erectile dysfunction, since they were not specifically asked for in follow-up questionnaires. In Chapter 5 reports on buttock claudication were considered to be sufficient, but also herein erectile dysfunction was not reported thoroughly enough, hampering us to make any conclusions on this.

Clear agreements on reporting standards for endovascular aortic aneurysm repair, and undisputable definitions would help to make future research of higher quality, easier to compare, more suitable for meta-analysis, and better to translate into clinical practice. Such reporting standards exist, ${ }^{68}$ but are not comprehensive enough, and are still used too little in contemporary research.

\section{Complex endovascular AAA repair}

Even though the recent development of EVAR technologies has been rapid, there are still many challenges and unresolved issues remaining. As mentioned before, a substantial proportion of AAA patients is deemed unsuitable for standard EVAR, most frequently due to hostile neck configurations. Advanced graft designs with stretched IFU criteria have helped to extend the utility and eligibility of EVAR. Thorough scientific surveillance with clinical registries such as EAGLE have to answer to what extend this is justified. It is, however, certain that short, angulated, and tapered proximal necks with large diameters compromise long-term durability of standard EVAR, and applicability of standard EVAR are not endless. ${ }^{69}$ 
In patients with aneurysms extending to the level of the renal arteries, or even proximally to the level of visceral arteries complex endovascular solutions with adjuncts are required to preserve flow to these vital branches and to provide adequate and durable seal. More complex techniques such as endovascular aneurysm sealing (EVAS), chimneys (ChEVAR), and custom-made fenestrated or branched devices (FEVAR) have been designed to extend the endovascular possibilities. Complex AAA repair is likely going to increase, and accurate reporting outcomes are necessary to clarify the role of these complex EVAR techniques.

EVAS with the Nellix device (Endologix, Irvine, California, USA) represents a new concept for the treatment of AAAs with parallel stent grafts and biostable polymer-filled endobags to seal the aneurysm sac. The EVAS FORWARD Registry has shown acceptable results with regards to perioperative outcomes, technical complications, secondary interventions and aneurysm-related mortality. ${ }^{70}$ With EVAS there tend to be less Type-II endoleaks than with EVAR as reported in the ENGAGE and GREAT registries. ${ }^{18}$ Drawbacks of this technique are complications unique to the procedure such as intraprocedural aortic injury or rupture, and established 'bailout' techniques that have evolved for EVAR (eg. proximal balloon molding and proximal cuffs) are not applicable. ${ }^{70}$ The EVAS technique itself and solutions to treat Type-I endoleaks in EVAS such as coil embolisation and liquid embolic agents are reported successful in the short term, but have to prove their durability.

The concept of ChEVAR is designed to create an extension of proximal sealing in the juxtarenal aorta while maintaining perfusion of branch arteries using covered stents (chimneys) parallel to a proximal extension of the endograft. The FEVAR technique makes use of often custom made endografts with fenestration or branches towards the renal- and visceral arteries. The role of ChEVAR against FEVAR is a question of debate. Some authors have suggested that the result of both techniques are similar, ${ }^{72}$ while others state that the outcomes of ChEVAR are cause for concern. ${ }^{73}$ One concern with ChEVAR is the durability of the construction and particularly the risk Type-la endoleaks due to gutter formation between the endograft and chimney grafts. Other drawbacks are anatomic limitations such as upper extremity artery occlusion or aortic arch anomalies with risk of thromboembolic complications. ${ }^{74}$ Advantage of ChEVAR are off-the-shelf availability, low profile accessibility and less complex nature of the procedure. The PERICLES Registry showed acceptable mid- 
term results with 93.1\% freedom from ChEVAR-related reinterventions at 2 years of followup. ${ }^{75}$ Most articles on FEVAR involve the use of the Zenith Fenestrated device (Cook Medical Inc., Bloomington, Indiana, USA), but also other brands provide fenestrated devices. ${ }^{74}$ Studies have demonstrated that the FEVAR technique may be performed safely, but durability remains an issue with a reintervention rate of $30 \%$ at 3-years in the GLOBALSTAR Registry. ${ }^{76}$ Drawbacks of FEVAR are its complexity with often multiple access requires, increased operating and fluoroscopy time, its prolonged time-to-therapy with a manufacturing delay from 3 to 6 weeks, which precludes its use in urgent cases, and its costs. ${ }^{74}$ No RCTs that compare FEVAR or ChEVAR with open surgical repair (OSR) have been performed, but cost-effectiveness of FEVAR was assessed in a matched cohort study. ${ }^{77}$ The French WINDOW trial showed that FEVAR in high risk patients offers similar 2 year mortality to OSR performed in lower risk patients but at more than double the costs, due to costs of FEVAR devices, more reinterventions and higher re-admission rates. ${ }^{7}$

\section{Personal perspective}

Endovascular technologies will continue to play an increasingly important role in the management of patients with aortic aneurysm disease. It is not easy to keep pace with the development of endovascular technology, advancing from infrarenal AAA with favourable anatomy to complex juxtarenal AAA with hostile anatomy. Open surgical repair of AAA with complex anatomy is associated with significant morbidity and mortality, especially in patients with more co-morbidity. A 'next-generation' endovascular technique might be a solution. EVAR has become standard therapy in those with favourable anatomy, but we are far from the optimal and ideal solution for those AAA patients with hostile or complex anatomy. Procedural complications and additional interventions are not uncommon in complex EVAR repair and occur far more often than in standard EVAR. Clearly, it is important to define which AAA patient benefits best from which treatment modality.

Despite reliance on anatomic criteria for clinical decision-making, there is limited data on characterizing the relative importance of different anatomic criteria, and on identifying the thresholds for each of these measurements. Currently, device-specific IFU criteria are often used as a definition of hostile anatomy, often with equal value to each criterion. One could question if this is justified and if the same criteria are equally applicable to different graft 
designs. Aneurysm morphology that just exceeds one IFU criterion may warrant a better fit for standard EVAR than aneurysm morphology that is on all measurement just within the IFU criteria. Data from well-designed prospective population-based registries could have an important role in defining hostile anatomy for individual graft designs. Unfortunately, acquiring funds for long-term, clinical device trials has become difficult and the number of patients required for a meaningful comparison asks for multinational trial designs. In case of limited resources future registries on standard EVAR could focus on AAA patients with borderline hostility. The EAGLE registry is a good example of such a trial and will hopefully play a role in getting a better understanding in the importance of different anatomic criteria. EAGLE has to show what complication and reintervention rates are to be expected in compromised proximal necks and to what level extension of the IFU criteria for the Endurant stent graft is justified.

A repeating theme of aortic endovascular outcomes is that technical success does not confer long-term durability. As mentioned before, despite ChEVAR and FEVAR come with more procedural complications, technical and clinical success rates of these complex EVAR techniques are acceptable. The long-term outcome of ChEVAR and FEVAR for complex anatomy is yet to be assessed, as is its role compared to open surgical repair and standard EVAR (outside IFU). A randomized controlled trial design will be the best scientific solution. Such a trial would raise the issue of defining hostile anatomy, and potentially, randomizing patients might cause an ethical dilemma. For these reasons, thorough surveillance by registries on all modalities of AAA treatment can also play an important role in enabling further tailoring of complex AAA treatment. The challenge for future AAA research is to design a model that predicts the outcome for each individual patient, enabling to guide both the doctor and the patient in their choice for the best treatment modality. Unless proven otherwise, the simplest option should be considered the best available option. 


\section{CONCLUSIONS}

In conclusion, the data presented in our thesis show that early results from the ENGAGE Registry are promising and indicate that EVAR is safe and effective across different continents and standards of practice. With contemporary EVAR devices and technical proficiency there is no difference in outcome between symptomatic AAA and elective AAA patients. Preferred use of locoregional anaesthesia appears to shorten procedure time, ICU admission rates and postoperative hospital stay, while not jeopardizing technical success rates and perioperative mortality and morbidity. Endovascular treatment of aorto-iliac and iliac aneurysms without pre-emptive coil embolisation is safe and effective and does not increase the incidence of related endoleaks and secondary interventions, while also being a more resource-effective strategy. Overall, the incidence of secondary interventions after EVAR has decreased, but might be negatively influenced by pushing borders of anatomical complexity. Therefore, separate studies on the performance of EVAR in challenging anatomy are necessary to demonstrate its rightful use, and thorough clinical surveillance on all modalities of AAA treatment of both standard and complex EVAR will play an important role in making balanced judgement about the optimal aneurysm management. Thus, improving outcomes of patients with an abdominal aortic aneurysm. 
1. Chuter TA, Risberg B, Hopkinson BR, Wendt G, Scott RA, Walker PJ, et al. Clinical experience with a bifurcated endovascular graft for abdominal aortic aneurysm repair. J Vasc Surg 1996;24:655-66.

2. Pol RA, Keus F, Prins TR, Zeebregts CJ. Suprarenal fixation resulting in intestinal ischemia after endovascular aortic aneurysm repair. Ann Vasc Surg 2014;28(4):1033.e5-9.

3. van Marrewijk CJ, Leurs LJ, Vallabhaneni SR, Harris PL, Buth J, Laheij RJ. Risk-adjusted outcome analysis of endovascular abdominal aortic aneurysm repair in a large population: how do stent-grafts compare? J Endovasc Ther 2005;12:417-29.

4. EVAR-1 trial participants. Endovascular aneurysm repair versus open repair in patients with abdominal aortic aneurysm (EVAR trial 1): randomised controlled trial. Lancet 2005;365:2179-86.

5. Prinssen $\mathrm{M}$, Verhoeven EL, Buth J, Cuypers $P W$, van Sambeek MR, Balm $R$, et al. A randomized trial comparing conventional and endovascular repair of abdominal aortic aneurysms. N Engl J Med 2004;351:1607-18.

6. Sidloff D, Stather P, Choke E, Bown M, Sayers R. Type II endoleak after endovascular aneurysm repair. Br J Surg 2013; 100: 1262 70.

7. De Bruin JL, Baas AF, Buth J, Prinssen $M$, Verhoeven EL, Cuypers PW, et al. Long-term outcome of open or endovascular repair of abdominal aortic aneurysm. N Engl J Med 2010;362:1881-9.

8. Peterson BG, Matsumura JS, Brewster DC, Makaroun MS. Five-year report of a multicenter controlled clinical trial of open versus endovascular treatment of abdominal aortic aneurysms. J Vasc Surg 2007;45:885-90.

9. Prinssen $M$, Buskens $E$, de Jong SE, Buth J, Mackaay AJ, van Sambeek MR, et al. Costeffectiveness of conventional and endovascular repair of abdominal aortic aneurysms: results of a randomized trial. J Vasc Surg 2007;46:883-90.

10. Lederle FA, Freischlag JA, Kyriakides TC, Padberg FT, Jr., Matsumura JS, Kohler TR, et al. Outcomes following endovascular vs open repair of abdominal aortic aneurysm: a randomized trial. JAMA 2009;302:1535-42.

11. Kvinlaug KE, Lawlor DK, Forbes TL, Willoughby $R$, MacKenzie KS, DeRose $G$, et al. Early results from a Canadian multicenter prospective registry of the Endurant stent graft for endovascular treatment of abdominal aortic aneurysms. J Endovasc Ther 2012;19:58-66.

12. Torsello G, Troisi N, Tessarek J, Torsello GF, Dorigo W, Pulli R, et al. Endovascular aortic aneurysm repair with the Endurant stent-graft: early and 1-year results from a European multicenter experience. J Vasc Interv Radiol 2010;21:73-80.

13. van Keulen JW, de Vries JP, Dekker $H$, Goncalves FB, Moll FL, Verhagen HJ, et al. Oneyear multicenter results of 100 abdominal aortic aneurysm patients treated with the Endurant stent graft. J Vasc Surg 2011;54:60915.

14. Kent F, Ambler GK, Bosanquet DC, Twine CP; BSET (British Society for Endovascular Therapy). The Safety of Device Registries for Endovascular Abdominal Aortic Aneurysm Repair: Systematic Review and Metaregression. Eur J Vasc Endovasc Surg. 2018 Feb;55(2):177-183.. 
15. Zarins CK, White RA, Moll FL, Crabtree T, Bloch DA, Hodgson KJ, et al. The AneuRx stent graft: four-year results and worldwide experience. J Vasc Surg 2001;33: 135-45

16. Cao P, De Rango P, Parlani G, Verzini F. Durability of abdominal aortic endograft with the Talent Unidoc stent graft in common practice: Core lab reanalysis from the TAURIS multicenter study. J Vasc Surg 2009;49(4):859865

17. 't Mannetje YW, Broos PP, van Poppel RF, van Sambeek MR, Teijink JA, Cuypers PW. Late single-center outcome of the Talent Abdominal Stent Graft after a decade of follow-up. J Vasc Surg 2016;64:557-62.

18. Verhoeven E, Katsargyris A, Bachoo P, Larzon $T$, Fisher $R$, Ettles $D$, et al. Real-world performance of the new C3 Gore Excluder stent-graft: 1-year results from the European C3 module of the Global Registry for Endovascular Aortic Treatment (GREAT). Eur J of Vasc Endovasc Surg 2014;48(2):131-137.

19. Verzini F, Romano L, Parlani G, Simonte G, Loschi D, Isernia $G$, et al. Fourteen-year outcomes of abdominal aortic endovascular repair with the Zenith stent graft. J Vasc Surg 2016;63:143S-4S.

20. Freyrie A, Gallitto E, Gargiulo M, Faggioli G, Massoni CB, Mascoli C, et al. Results of the endovascular abdominal aortic aneurysm repair using the Anaconda aortic endograft. J Vasc Surg 2014;60(5):1132-9.

21. Leo $E$, Biancari $F$, Kechagias $A$, Ylonen $K$, Rainio $\mathrm{P}$, Romsi $\mathrm{P}$, et al. Outcome after emergency repair of symptomatic, unruptured abdominal aortic aneurysm: results in 42 patients and review of the literature. Scand Cardiovasc J 2005 Apr;39(1-2):91-5.

22. Soisalon-Soininen S, Salo JA, Perhoniemi V, Mattila S. Emergency surgery of non-ruptured abdominal aortic aneurysm. Ann Chir Gynaecol 1999;88(1):38-43.
23. Sullivan CA, Rohrer MJ, Cutler BS. Clinical management of the symptomatic but unruptured abdominal aortic aneurysm. J Vasc Surg 1990 Jun;11(6):799-803.

24. Antonello $M$, Frigatti $P$, Maturi $C$, Lepidi $S$, Noventa F, Pittoni G, et al. Open repair for ruptured abdominal aortic aneurysm: is it possible to predict survival? Ann Vasc Surg 2009 Mar;23(2):159-66.

25. Bradbury AW, Adam DJ, Makhdoomi KR, Stuart WP, Murie JA, Jenkins AM, et al. A 21-year experience of abdominal aortic aneurysm operations in Edinburgh. $\mathrm{Br} J$ Surg 1998 May;85(5):645-7.

26. Sayers RD, Thompson MM, Nasim A, Healey $P$, Taub N, Bell PR. Surgical management of 671 abdominal aortic aneurysms: a 13 year review from a single centre. Eur J Vasc Endovasc Surg 1997 Mar;13(3):322-7.

27. Aune S, Amundsen SR, Evjensvold J, Trippestad A. The influence of age on operative mortality and long-term relative survival following emergency abdominal aortic aneurysm operations. Eur J Vasc Endovasc Surg 1995 Oct;10(3):338-41.

28. Moll FL, Powell JT, Fraedrich G, Verzini F, Haulon S, Waltham $M$, et al. Management of abdominal aortic aneurysms clinical practice guidelines of the European society for vascular surgery. Eur J Vasc Endovasc Surg 2011 Jan;41 Suppl 1:S1-S58.

29. Chaikof EL, Brewster DC, Dalman RL, et al. The care of patients with an abdominal aortic aneurysm: the Society for Vascular Surgery practice guidelines. J Vasc Surg. 2009;50(4 suppl 1:S2-S49.

30. Ruppert V, Leurs LJ, Rieger J, et al. Riskadapted outcome after endovascular aortic aneurysm repair: analysis of anesthesia types based on EUROSTAR data. J Endovasc Ther. 2007;14:12-22. 
31. De Virgilio C, Romero L, Donayre C, et al. Endovascular abdominal aortic aneurysm repair with general versus local anesthesia: a comparison of cardiopulmonary morbidity and mortality rates. J Vasc Surg. 2002;36:988-91.

32. Parra JR, Crabtree T, McLafferty RB, et al. Anesthesia technique and outcomes of endovascular aneurysm repair. Ann Vasc Surg. 2005;19:123-9.

33. Ruppert V, Leurs LJ, Steckmeier B, et al. Influence of anesthesia type on outcome after endovascular aortic aneurysm repair: an analysis based on EUROSTAR data. J Vasc Surg. 2006;44:16-21.

34. Edwards MS, Andrews JS, Edwards AF, et al. Results of endovascular aortic aneurysm repair with general, regional, and local/monitored anesthesia care in the American College of Surgeons National Surgical Quality Improvement Program database. J Vasc Surg. 2011;54:1273-82.

35. Bakker EJ, van de Luijtgaarden KM, van Lier $F$, et al. General anaesthesia is associated with adverse cardiac outcome after endovascular aneurysm repair. Eur J Vasc Endovasc Surg. 2012;44:121-5.

36. Krajcer Z, Ramaiah VG, Henao EA, Metzger DC, Nelson WK, Moursi MM, et al. Perioperative outcomes from the prospective multicenter least invasive fast-track EVAR (LIFE) registry. J Endovasc Ther. 2018; 25(1)6-13.

37. Armon MP, Wenham PW, Whitaker SC, Gregson RH, Hopkinson BR. Common iliac artery aneurysms in patients with abdominal aortic aneurysms. Eur J Vasc Endovasc Surg 1998;15:255-7.

38. Razavi MK, DeGroot M, Olcott C, 3rd, Sze D, Kee $S$, Semba $C P$, et al. Internal iliac artery embolization in the stent-graft treatment of aortoiliac aneurysms: analysis of outcomes and complications. J Vasc Interv Radiol 2000;11:561-6.
39. Mehta M, Veith FJ, Ohki T, Cynamon J, Goldstein K, Suggs WD, et al. Unilateral and bilateral hypogastric artery interruption during aortoiliac aneurysm repair in 154 patients: a relatively innocuous procedure. J Vasc Surg 2001;33:S27-32.

40. Lee CW, Kaufman JA, Fan CM, Geller SC, Brewster DC, Cambria RP, et al. Clinical outcome of internal iliac artery occlusions during endovascular treatment of aortoiliac aneurysmal diseases. J Vasc Interv Radiol 2000;11:567-71.

41. Cynamon J, Lerer D, Veith FJ, Taragin BH, Wahl $\mathrm{SI}$, Lautin JL, et al. Hypogastric artery coil embolization prior to endoluminal repair of aneurysms and fistulas: buttock claudication, a recognized but possibly preventable complication. J Vasc Interv Radiol 2000;11:573-7.

42. Su WT, Stone DH, Lamparello PJ, Rockman CB. Gluteal compartment syndrome following elective unilateral internal iliac artery embolization before endovascular abdominal aortic aneurysm repair. J Vasc Surg 2004;39:672-5.

43. Bratby MJ, Munneke GM, Belli AM, Loosemore TM, Loftus I, Thompson MM, et al. How safe is bilateral internal iliac artery embolization prior to EVAR? Cardiovasc Intervent Radiol 2008;31:246-53.

44. Rayt HS, Bown MJ, Lambert KV, Fishwick NG, McCarthy MJ, London NJ, et al. Buttock claudication and erectile dysfunction after internal iliac artery embolization in patients prior to endovascular aortic aneurysm repair. Cardiovasc Intervent Radiol 2008;31:728-34

45. Tefera G, Turnipseed WD, Carr SC, Pulfer KA, Hoch JR, Acher CW. Is coil embolization of hypogastric artery necessary during endovascular treatment of aortoiliac aneurysms? Ann Vasc Surg 2004;18:143-6. 
46. Farahmand $P$, Becquemin JP, Desgranges $P$, Allaire E, Marzelle J, Roudot-Thoraval F. Is hypogastric artery embolization during endovascular aortoiliac aneurysm repair (EVAR) innocuous and useful? Eur J Vasc Endovasc Surg 2008;35:429-35.

47. Wyers $M C$, Schermerhorn ML, Fillinger MF, Powell RJ, Rzucidlo EM, Walsh DB, et al. Internal iliac occlusion without coil embolization during endovascular abdominal aortic aneurysm repair. J Vasc Surg 2002;36:1138-45.

48. Mell M, Tefera G, Schwarze M, Carr S, Acher C, Hoch J, et al. Absence of buttock claudication following stent-graft coverage of the hypogastric artery without coil embolization in endovascular aneurysm repair. J Endovasc Ther 2006;13:415-9.

49. Papazoglou KO, Sfyroeras GS, Zambas N, Konstantinidis K, Kakkos SK, Mitka $M$. Outcomes of endovascular aneurysm repair with selective internal iliac artery coverage without coil embolization. J Vasc Surg 2012;56:298-303.

50. Faure EM, Becquemin JP, Cochennec F; ENGAGE collaborators. Predictive factors for limb occlusions after endovascular aneurysm repair. J Vasc Surg 2015 May;61(5):1138-45.

51. Donas KP, Inchingolo $M$, Cao $P$, Pratesi C, Pratesi G, Torsello G, et al. Secondary Procedures Following lliac Branch Device Treatment of Aneurysms Involving the lliac Bifurcation: The pELVIS Registry. J Endovasc Ther. 2017 Jun;24(3):405-10.

52. White GH, Yu W, May J, Chaufour X, Stephen MS. Endoleak as a complication of endoluminal grafting of abdominal aortic aneurysms: classification, incidence, diagnosis, and management. J Endovasc Surg 1997;4:152-68.

53. Chaikof EL, Blankensteijn JD, Harris PL, White $\mathrm{GH}$, Zarins CK, Bernhard VM et al. Ad hoc committee for standardized reporting practices in vascular surgery of the Society for Vascular Surgery/American Association for Vascular Surgery. Reporting strandards for endovascular aortic aneurysm repair. J Vasc Surg 2002;35:1048-60.

54. Becker GJ, Kovacs M, Mathison MN, Katzen BT, Benenati JF, Zemel $G$ et al. Risk strati"cation and outcomes of transluminal endografting for abdominal aortic aneurysm: 7-year experience and long-term follow-up. J Vasc Interv Radiol 2001;12:1033-46.

55. Cochennec F, Becquemin JP, Desgranges $P$, Allaire $E$, Kobeiter $\mathrm{H}$, Roudot-Thoraval F. Limb graft occlusion following EVAR: clinical pattern, outcomes and predictive factors of occurrence. Eur J Vasc Endovasc Surg 2007;34:59-65.

56. Hoshina K, Kato $M$, Mikuriya A, Ohkubo $N$. Successful endovascular repair in two cases of graft limb occlusion after endovascular aneurysm repair for abdominal aortic aneurysms. Surg Today 2010;40:487-90.

57. Maleux G, Koolen M, Heye S, Nevelsteen A. Limb occlusion after endovascular repair of abdominal aortic aneurysms with supported endografts. J Vasc Interv Radiol 2008;19:140912.

58. Lipsitz EC, Ohki T, Veith FJ, Rhee SJ, Gargiulo NJ, Suggs WD et al. Patency rates of femorofemoral bypass associated with endovascular aneurysm repair surpass those performed for occlusive disease. J Endovasc Ther 2003;10:1061-5.

59. Hyhlik-Durr A, Weber TF, Kotelis D, et al. The Endurant Sent Graft System: 15-month followup report in patients with challenging abdominal aortic anatomies. Langenbeck Arch Surg. 2011; 396: 801-10

60. Torsello G, Troisi N, Donas KP, et al. Evaluation of the Endurant stent graft under instructions for use vs off-label conditions for endovascular aortic aneurysm repair. J Vasc Surg 2011; 54:300-6. 
61. Georgiadis GS, Trellopoulos G, Antoniou GA, et al. Early results of the Endurant endograft system in patients with friendly and hostile infrarenal abdominal aortic aneurysm anatomy. J Vasc Surg. 2011; 54: 616-27.

62. Duffy JM, Rolph R, Waltham M. Stent graft types for endovascular repair of abdominal aortic aneurysms. Cochrane Database Syst Rev 2015; Sep24;(9) CD008447.

63. Ligthelm RJ, Borzi V, Gumprecht J, Kawamori $R$, Wenying $Y$, Valensi $P$. Importance of observational studies in clinical practice. Clin Ther 2007;29 Spec No:1284-92.

64. Siverman SL. From randomized controlled trials to observational studies. Am J Med. 2009; 122(2): 114-20.

65. Hoshina K, Ishimaru S, Sasabuchi Y, Yasunaga $\mathrm{H}$, Komori K. Outcomes of endovascular repair for abdominal aortic aneurysms: a nationwide survey in Japan. Ann Surg. 2017 Sep 6. [Epub ahead of print]

66. Venermo M., and Lees T.: International Vascunet Validation of the Swedvasc Registry. Eur J Vasc Endovasc Surg 2015; 50: 802-8.

67. Lijftogt $\mathrm{N}$, Vahl AC, Wilschut ED, Elsman $\mathrm{BH}$, Amodio S, van Zwet EW, et al.; Dutch Society of Vascular Surgery, the Steering Committee of the Dutch Surgical Aneurysm Audit, and the Dutch Institute for Clinical Auditing. Adjusted Hospital Outcomes of Abdominal Aortic Aneurysm Surgery Reported in the Dutch Surgical Aneurysm Audit. Eur J Vasc Endovasc Surg. 2017 Apr;53(4):520-532

68. Chaikof EL, Blankensteijn JD, Harris PL, et al. Reporting standards for endovascular aortic aneurysm repair. J vasc Surg. 2002; 35: 1048 60.

69. Oliviera NFG, Bastos Goncalves FM, van Rijn MJ et al. Standard endovascular aneurysm repair in patients with wide infrarenal aneurysm necks is associated with increased risk of adverse events. J Vasc Surg. 2017; 65:1608-16.

70. Thompson MM, Heyligers JM, Hayes PD, Reijnen MMPJ, Bockler D, Schelzig $H$, et al. Endovascular aneurysm sealing: early and midterm results from the EVAS FORWARD global registry. J Endovasc Ther 2016; 23(5): 685-92.

71. Ameli-Renani S, Morgan RA. Transcatheter embolisation of proximal type 1 endoleaks following endovascular aneurysm sealing (EVAS) using the Nellix device; technique and outcomes. Cardiovasc Intervent Radiol. 2015;38:1137-42.

72. Lee JT, Lee GK, Chandra V, et al. Comparison of fenestrated endografts and the snorkel/chimney technique. J Vasc Surg. 2014; 60:849-57.

73. Scali ST, Freezor RJ, Chang CK, et al. Critical analysis of results after chimney endovascular aortic aneurysm repair raises cause for concern. J Vasc Surg. 2014;60:865-73.

74. Ou J, Chan C, Cheng S.W. A systematic review of fenestrated endovascular repair for juxtarenal and short-neck aortic aneurysm: evidence so far. Ann Vasc Surg 2015; 29:168088.

75. Donas KP, Lee JT, Lachat M, Torsello G, Veith FJ; for the PERICLES investigators. Collected world experience about the performance of the snorkel/chimney endovascular technique in the treatment of complex aortic pathologies: the PERICLES registry. Ann Surg. 2015;62:546-53.

76. Britisch Society for Endovascular Therapy and the Global Collaborators on Advanced StentGraft Techniques for Aneurysm Repair (GLOBALSTAR) Registry. Early results of fenestrated endovascular repair of juxtarenal aortic aneurysms in the United Kingdom. Circulation. 2012;125:2707-15. 

CHAPTER 10

SUMMARY

SAMENVATTING 



\section{SUMMARY}

In Chapter 1 of this thesis a background on abdominal aortic aneurysms (AAA), options for AAA treatment, and endoleaks is given. Furthermore, the aim and outline of the thesis is presented. This thesis consists of three parts.

\section{PART ONE - Perioperative outcome in contemporary EVAR practice}

The ENGAGE registry was undertaken to examine the real world outcome after endovascular AAA repair (EVAR) with the Endurant Stent Graft in a large, contemporary, and global experience. Eligibility for EVAR was left to the discretion of operators and study follow-up protocols were kept as close as possible to standard regimes. Patients were included in a prospective and consecutive manner in order to minimize risk of selection bias. A large quantity of data was recorded and great efforts were made to guarantee high quality and completeness of data in order to facilitate meaningful analysis.

Chapter 2 reports on the perioperative and one-year outcomes of the ENGAGE Registry. From March 2009 to April 2011, 1262 AAA patients were enrolled from 79 sites in 30 countries and treated with Endurant. Patients were predominantly men (89.6\%) and had a mean age of 73.1 years. Notably, $10.6 \%$ of patients were classified as ASA class IV and $17.9 \%$ of the patients were considered as treated outside IFU criteria. Intraoperative technical success was achieved in $99.0 \%$ of cases. Adverse events within 30 days occurred in $3.9 \%$ of patients including $1.3 \%$ mortality. Type-I or - III endoleaks were identified in $1.5 \%$ of cases. Estimated overall survival, aneurysm-related survival, and freedom from secondary interventions at 1-year were 91.6\%, 98.6\%, and 95.1\%, respectively. At one-year, aneurysm size increased $\geq 5 \mathrm{~mm}$ in $2.8 \%$ and decreased $\geq 5 \mathrm{~mm}$ in $41.3 \%$ of cases. These data are promising and indicate that EVAR with the Endurant stent graft is safe and effective across different geographies and standards of practice. Longer-term follow-up is necessary to assess durability of these results.

It was emphasized that the use of new devices with fewer sizing constraints might supersede the negative effect on EVAR outcome of suboptimal preoperative work-up. Therefore, the 
outcome of endovascular AAA repair in symptomatic (S-AAA) and elective non-symptomatic (E-AAA) patients was compared in Chapter 3. Data from the ENGAGE Registry was used for this retrospective analysis. S-AAAs defined as AAAs accompanied by abdominal or back pain at physical examination, without rupture, were present in 185 (15.4\%) patients and E-AAAs in 1015 (84.6\%) patients. At baseline, E-AAA patients had larger aneurysms on average $(p=.006)$ and scored higher ASA classification more often $(p=.001)$. Multivariate logistic regression was used to compare results and further analyses were corrected for baseline differences. Technical success was achieved equally often in both groups, without difference in operation time, and S-AAA patients were admitted to the ICU as often as E-AAA patients (35.7\% vs. 33.4\%, $p=.479$ ). Also, postoperative hospital-stay did not differ between groups. Major adverse events, including 30-day mortality, were comparable between S-AAA and EAAA patients, respectively $3.2 \%$ and $4.2 \%(p=.572)$. With contemporary devices and technical proficiency, there is no difference in outcome between symptomatic AAA and elective nonsymptomatic AAA patients if treated with endovascular techniques.

In Chapter 4 the differences in outcomes of EVAR using general (GA), regional (RA), or local (LA) anaesthesia were examined. A retrospective analysis of ENGAGE data was performed. GA was used in 785 (62\%) patients, RA in 331 (27\%) patients, and LA in 145 (11\%) patients. Multivariate logistic regression analysis was performed to adjust for possible confounding factors. Remarkably, there were great intercontinental differences in the distribution of type of anaesthesia used for EVAR. Furthermore, higher ASA classification was associated with predominant use of GA. Procedure time was reduced in LA ( $80.4 \pm 40.0$ minutes) compared with RA $(94.2 \pm 41.6 \mathrm{~min}$, adjusted $p=.001)$ and GA $(105.3 \pm 46.0$ minutes, adjusted $p<.001)$. Intensive care unit (ICU) admission was less frequent for RA than for GA (adjusted OR 0.71, $95 \% \mathrm{Cl} 0.53$ to $0.97, p=.030$ ) and LA (adjusted OR 0.51, 95\% Cl 0.33 to 0.79, $p=.002$ ). Postoperative hospital stay was significantly shorter for RA and LA compared with GA (adjusted $p=.003$ and $p=.010$, respectively). Technical success rate was not compromised by the use of local or regional anaesthetic techniques. The type of anaesthesia used during EVAR has no influence on perioperative mortality, morbidity, and technical complications. But, the use of local or regional anaesthesia during EVAR appeared to be beneficial concerning procedure time, ICU admission, and postoperative hospital stay. Preferential use of locoregional anaesthesia for EVAR is advised, restricting general anaesthesia only to those 
with predefined contra-indications for local or regional anaesthesia.

\section{PART TWO - Coverage of the internal iliac artery}

To ensure adequate distal seal of the EVAR device in short or aneurysmatic common iliac arteries (CIA) extension of a limb graft into the external iliac artery (EIA) is often performed, consequently covering the origin of the internal iliac artery (IIA). Despite the lack of evidence, it is considered common practice to perform adjunctive coil embolisation of the IIA in the prevention of related Type-II endoleaks.

Chapter 5 challenged the evidence for pre-emptive coil embolisation in analyzing the results in a strategy of routine IIA coverage without prior coiling. Data of 32 consecutive patients (96.9\% men with a mean age of 73.0 years) in which this routine was inflicted was analyzed. Aneurysm morphology was determined on preoperative CT-images. At baseline, mid-CIA diameter was $33.5 \pm 16.8 \mathrm{~mm}$, and 7 patients presented with ruptured aneurysms. All covered IIAs were considered patent preoperatively. Inadvertent coverage occurred in 4 cases. Mean length of follow-up was $14.3 \pm 7.4$ months. During follow-up, there were 8 deaths reported, none related to IIA coverage. Buttock claudication occurred in 7 (22.6\%) patients, which persisted after 6 months in 2 cases of bilateral IIA coverage. A literature review was performed to compare these findings. The incidence of buttock claudication was within the range reported in previous studies on simple IIA coverage, but compared favourable to incidences reported in the majority of studies on coil embolisation. Importantly, we did not see any occurrence of Type-I or -II endoleaks related to IIA coverage, and aneurysm growth was also not observed. In conclusion of these findings it was stated that endovascular treatment of aorto-iliac and iliac aneurysm without pre-emptive coil embolisation of the IIA is safe and effective, and may reduce complications. Nonetheless, a larger and comparative study with longer follow-up is required to confirm these findings.

Chapter 6 describes the results of a somewhat similar study as mentioned above. Patients in whom the Endurant Stent Graft covered one or both IIAs were retrospectively identified from the ENGAGE database, and grouped in cases in which prior IIA embolisation - coils or plugs - was performed (CE) and cases in which IIA embolisation was not performed (NE). In 197 patients, 225 internal iliac arteries were covered, including 91 (40.4\%) NE-cases and 134 
(59.6\%) CE-cases. Both groups were similar at baseline, and had comparable length of follow-up to last image (665.2 \pm 321.7 days for CE-patients, $641.6 \pm 327.6$ days for NE-patients; $p=.464$ ). Importantly, both groups showed equivalent iliac morphology concerning $\mathrm{ClA}$ proximal, mid and distal dimensions and tortuosity, making them suitable for comparative analysis. Except from a 23 minutes longer procedural time in CE patients, no other procedural differences were found. During follow-up IIA-related endoleaks were rare and occurred equally often in both groups (CE 5.5\% versus NE 3.0\%; $p=.346$ ). Secondary intervention to resolve a IIA-related endoleak was performed twice in the CE-group and 3 times in the NE-group. Late non-IIA related endoleaks occurred more often in the CE-group compared to the NE-group, respectively $25.0 \%$ versus $15.0 \%, p=.080$. Secondary interventions for other reasons than IIA-related endoleaks occurred in $7.5 \%$ of NE-cases and $15.4 \%$ of CE-cases ( $p=.057)$, mostly for occlusions in the ipsilateral iliac limb. During followup $19 \mathrm{NE}$-patients and 9 CE-patients died, which is not significantly different ( $p=.225)$, and no deaths were related directly or indirectly to IIA coverage. Also, no reports of gluteal necrosis and bowel ischemia were made. Unfortunately, due to suspected underreporting no conclusions on the occurrence buttock claudication or erectile dysfunction could be made. Chapter 6 represents the largest comparative analysis on the topic, and is the strongest evidence available to date. IIA coverage without prior coil embolisation does not increase the incidence of endoleaks or related secondary interventions. The omission of coil embolisation may be a more resource-effective strategy whenever IIA coverage is required, when taking into account that embolisation is usually costly, often requires multiple interventions and longer procedures under fluoroscopic guidance.

\section{PART THREE - Technical complications of EVAR: how to manage and how to prevent}

EVAR treatment comes with unique technical complications, often requiring secondary interventions. In contemporary practice, incidence rates for the necessity of secondary interventions are declining with advanced stent graft designs and increased understanding of management of technical complications, but might be negatively influenced by pushing the limits of anatomical complexity.

Chapter 7 reviews on occurrence and management strategies of technical complications of EVAR in contemporary practice and its development over time. Due to a risk of rupture 
treatment of Type-I endoleaks is mandatory and treatment options involve securing of the attachment site with transluminal balloon angioplasty, stent extension at proximal attachment site, or endo-anchors. If limited AAA growth is present, Type-II endoleaks can be managed conservatively. If demanded, options for treatment include transarterial or translumbar embolisation, or direct Onyx glue injection. More invasive solutions are endoscopic or surgical ligation of lumbar and mesenteric arteries. All Type-III endoleaks need to be addressed with additional stent graft components to bridge the defect. Stent graft migration is rare with latest generation of stent grafts. To stop any further migration large balloon-expendable stents or endostaplers can be used to secure the seal between devices and the aortic wall. Occlusion of limb grafts is seen more frequently with eligibility of EVAR in smaller and tortuous iliacs with low profile delivery systems. In general, secondary interventions show a decreasing incidence rate, and if necessary, the first treatment options are catheter based nowadays.

Separate studies on the performance of EVAR in challenging anatomy are necessary to demonstrate safety and effectiveness of the latest generation stent-grafts, which is essential in making a balanced judgment about the optimal management of AAAs. Chapter 8 describes the rationale and design of the EAGLE Registry. Physician-initiated, EAGLE is a prospective study, aiming to enrol 250 patients in 20 experienced centres worldwide. The aim of this registry is critically assess the performance of the Endurant (II) Stent Graft in anatomically challenging AAA. The EAGLE Registry includes EVAR patients with challenging angulation or neck lengths. To minimize the risk of selection bias and enhance data quality, EAGLE eligibility will be determined by an independent core-lab and efforts will be made to secure consecutive enrolment of challenging cases. Ruptured AAAs will not be included. The EAGLE database is designed to merge with the on-going ENGAGE database, which enables comparative analysis of cases and results. The primary endpoint is treatment success at 30 days, 12 months and yearly up to 5 years post implant. EAGLE just completed its enrolment of patients and results will present its first results soon. 



\section{SAMENVATTING}

In Hoofdstuk 1 van dit proefschrift wordt achtergrondinformatie gegeven over het aneurysma van de abdominale aorta (AAA), de behandelingsopties, alsmede uitleg over zogenaamde 'endoleaks'. Ook wordt het doel van dit proefschrift gepresenteerd en de opbouw in hoofdlijnen. Dit proefschrift bestaat uit drie delen.

\section{DEEL ÉÉN - Perioperatieve uitkomsten van hedendaagse EVAR procedures}

Het doel van de door Medtronic AVE opgezette ENGAGE Registry is om de uitkomsten van endovasculaire behandeling van het abdominale aneurysma (EVAR) te onderzoeken, in een wereldwijde en real-life setting die de dagelijkse praktijk zo dicht mogelijk weergeeft. Geschiktheid voor EVAR werd overgelaten aan de beoordeling van de operateurs en followup protocollen waren in overeenstemming met het standaard follow-up beleid van de deelnemende centra. Patiënten werden prospectief en opeenvolgend geïncludeerd om het risico op selectiebias te minimaliseren. Een groot aantal unieke variabelen werd geregistreerd in de ENGAGE database. Jarenlange inspanning werd geleverd om hoge kwaliteit en volledigheid van de data te kunnen garanderen en daarmee een stevige basis voor betekenisvolle analyses.

Hoofdstuk 2 rapporteert de perioperatieve en één-jaar resultaten van de ENGAGE Registry. Vanaf maart 2009 tot april 2011 werden 1262 AAA patiënten uit 79 centra in 30 landen behandeld met een Endurant en opgenomen in ENGAGE. Patiënten waren hoofdzakelijk mannen (89.6\%) met een gemiddelde leeftijd van 73.1 jaar. Opvallend is dat $10.6 \%$ van de patiënten geclassificeerd is als ASA-IV en $17.9 \%$ van de patiënten moet worden beschouwd als behandeld buiten de door de fabrikant opgestelde instructies voor gebruik (Engels: Instructions For Use [IFU criteria]). Intra-operatief technisch succes werd bereikt in 99.0\%. Complicaties binnen 30 dagen traden op in $3.9 \%$ van de patiënten, inclusief $1.3 \%$ mortaliteit. Type-I of -III endoleaks werden gerapporteerd in $1.5 \%$ van de patiënten. Survival curves voor totale mortaliteit, aneurysma-gerelateerde mortaliteit en secundaire interventies na 1 jaar toonden risico's van $8.4 \%, 1.4 \%$ en $4.9 \%$, respectievelijk. Aneurysma diameters na EVAR namen $\geq 5 \mathrm{~mm}$ toe in $2.8 \%$ en $\geq 5 \mathrm{~mm}$ af in $41.3 \%$ na 1 jaar. Deze data zijn veelbelovend en 
indiceren dat EVAR met de Endurant stentgraft veilig en effectief is. Echter, langere followup is nodig om de houdbaarheid van deze resultaten te bevestigen.

Inadequate preoperatieve planning door onvoldoende voorbereidingstijd in de acute setting heeft negatieve invloed op de uitkomst van EVAR. Een groter scala van op-de-plank devices en bredere toepasbaarheid van de nieuwste stentgrafts zou er wel eens voor kunnen zorgen dat deze verschillend steeds minder goed zichtbaar zijn. In Hoofdstuk 3 worden de resultaten vergeleken van endovasculair AAA herstel in symptomatische (S-AAA) en electieve asymptomatische (E-AAA) patiënten. Data uit de ENGAGE Registry werd gebruikt voor een retrospectieve analyse. S-AAAs, gedefinieerd als AAAs in aanwezigheid van abdominale- en/of rugpijn bij onderzoek, zonder tekenen van ruptuur, waren aanwezig in 185 (15.4\%) patiënten en E-AAAs in 1015 (84.6\%) patiënten. Initieel hadden E-AAA patiënten gemiddeld grotere aneurysmata $(p=.006)$ en behoorden zij vaker tot een hogere ASA klasse $(p=.001)$. Multivariate logistische regressie werd gebruikt om uitkomsten te vergelijken en analyses werden gecorrigeerd voor baseline verschillen. Technisch succes werd even vaak bereikt in beide groepen, zonder verschil in operatieduur. S-AAA patiënten werden even vaak opgenomen op de intensive care (IC) als E-AAA patiënten (35.7\% vs. $33.4 \%, p=.479)$ en ook de postoperatieve opnameduur verschilde niet tussen beide groepen. Complicaties, inclusief 30-dagen mortaliteit, waren vergelijkbaar tussen S-AAA en E-AAA patiënten, respectievelijk 3.2\% en $4.2 \%$ ( $p=.572)$. Met gebruik van de Endurant stentgraft in de handen van ervaren operateurs is er geen verschil in uitkomst tussen symptomatische AAA en electieve asymptomatische AAA patiënten na endovasculaire behandeling.

In Hoofdstuk 4 werden de verschillen in uitkomst na EVAR onderzocht bij gebruik van algehele (GA), regionale (RA) of lokale (LA) anesthesie. Een retrospectieve analyse van ENGAGE data werd uitgevoerd. GA werd toegepast in 785 (62\%) patiënten, RA in 331 (27\%) patiënten en LA in 145 (11\%) patiënten. Multivariate logistische regressie analyses werden gebruikt om te corrigeren voor mogelijke confounders. Er waren opvallend veel verschillen tussen geografische regio's bij de toepassing van type anesthesie. Bovendien werd een hogere ASA klasse geassocieerd met een voorkeur voor gebruik van GA. De operatieduur bleek korter bij gebruik van LA $(80.4 \pm 40.0 \mathrm{~min}$.) in vergelijking tot RA $(94.2 \pm 41.6$ min., gecorrigeerde $p=.001)$ en GA (105.3 \pm 46.0 min., gecorrigeerde $p<.001)$. Opname op de IC was 
minder vaak het geval bij RA dan bij GA (gecorrigeerde OR 0.71, 95\% Cl 0.53 tot $0.97, p=.030$ ) en LA (gecorrigeerde OR $0.51,95 \% \mathrm{Cl} 0.33$ tot $0.79, p=.002$ ). Postoperatieve opnameduur was significant korter voor RA en LA dan voor GA (gecorrigeerde $p=.003$ en $p=.010$, respectievelijk). Het technisch succes percentage werd niet gecompromitteerd door het gebruik van lokale of regionale anesthesie technieken. Het type anesthesie dat werd toegepast voor EVAR heeft geen effect op perioperatieve mortaliteit, morbiditeit of het optreden van technische complicaties. Echter, het gebruik van lokale of regionale anesthesie voor EVAR lijkt een gunstig effect te hebben op operatieduur, ICU opname en postoperatieve opnameduur. Voorkeur voor het gebruik van locoregionale anesthesie voor EVAR is geadviseerd, waarbij de keuze voor algehele anesthesie wordt beperkt tot patiënten met specifieke contra-indicaties voor lokale en regionale anesthesie.

\section{DEEL TWEE - Overstenten van de arterie iliaca interna}

Om verzekerd te zijn van adequate distale sealing van de EVAR stentgraft in een korte of aneurysmatische arterie iliaca communis (AIC) wordt de EVAR poot vaak verlengd tot in de arterie iliaca externa (AIE). Hierbij wordt dan de origo van de arterie iliaca interna (AII) bedekt door de stentgraft. Ondanks gebrek aan wetenschappelijk bewijs wordt coiling van de All voorafgaand aan de EVAR procedure beschouwd als de standaard behandeling en preventieve maatregel tegen optreden van Type-II endoleak.

Hoofdstuk 5 betwist het beschikbare wetenschappelijk bewijs voor deze preventieve coilembolisatie door analyse van de resultaten van routinematig overstenten van de afgang van de All zonder deze eerst te coilen. Data van 32 opeenvolgende patiënten ( $96.9 \%$ mannen met een gemiddelde leeftijd van 73.0 jaar) bij wie deze routine werd toegepast werd geanalyseerd. Morfologische kenmerken van het aneurysma werden bepaald op een preoperatieve CT scan. Bij inclusie was de gemiddelde diameter mid-AIC $33.5 \pm 16.8 \mathrm{~mm}$ en presenteerden 7 patiënten zich met een geruptureerd aneurysma. In alle gevallen was er sprake van een patente All voor deze werd overstent. Ongeplande bedekking van de All gebeurde in 4 casus. Gemiddelde follow-up duur was 14.3 \pm 7.4 maanden. Gedurende followup zijn er 8 overlijdens gerapporteerd, maar géén ten gevolge van het overstenten van de All. Zeven (22.6\%) patiënten hadden last van bil-claudicatie. In 2 van hen was sprake van persisterende klachten na 6 maanden, dit waren beide patiënten waarin de All bilateraal was 
overstent. Er werd een literatuur review verricht om onze resultaten in perspectief te zetten. De incidentie van bil-claudicatie viel binnen de marges zoals gerapporteerd in studies over All overstenting waar eveneens geen coiling werd toegepast, maar was lager dan de incidentie die werd gerapporteerd in de meerderheid van de studies over coil embolisatie. Belangrijk is dat in onze serie geen sprake was van optreden van Type-I of -II endoleaks gerelateerd aan All overstenting. Ook werd groei van het aneurysma in geen geval gezien. In conclusie van onze resultaten stelden we dat een strategie van endovasculaire behandeling van aorto-iliacale en iliacale aneurysmata zonder preventieve coil-embolisatie van de All veilig en effectief is, en dat het mogelijk complicaties helpt te reduceren. Desalniettemin, een grote vergelijkende studie met langere follow-up duur is nodig om onze resultaten te bevestigen.

Hoofdstuk 6 beschrijft de resultaten van een dergelijk studie. Patiënten waarin de Endurant Stent Graft is geplaatst tot voorbij de origo van één of beide Alls werden retrospectief geïdentificeerd uit de ENGAGE database. Vervolgens werden deze patiënten onderverdeeld in casus waarin preventieve All embolisatie - met coils of pluggen - was verricht (CE) en casus waarin All embolisatie niet was verricht (NE). In 197 patiënten werden 225 arteria iliacae internae overstent, verdeeld in 91 (40.4\%) NE-casus en 134 (59.6\%) CE-casus. Beide groepen toonden vergelijkbare baseline karakteristieken en hadden vergelijkbare follow-up duur tot laatste beeldvorming $(665.2 \pm 321.7$ dagen voor CE-patiënten, $641.6 \pm 327.6$ dagen voor NE-patiënten; $p=.464)$. Van groot belang is dat morfologie ten aanzien van proximale, midden en distale AIC afmetingen en kronkeligheid van het vat equivalent was in beide groepen, waardoor de groepen geschikt zijn voor vergelijkende analyses. Behoudens een langere operatieduur (23 minuten) in CE-patiënten, werden geen andere verschillen in procedure aangetoond. Gedurende follow-up periode kwamen All-gerelateerde endoleaks spaarzaam voor en even vaak in beide groepen (CE 5.5\% versus NE 3.0\%; $p=.346$ ). Secundaire ingrepen ter behandeling van All-gerelateerde endoleaks werden 2 maal uitgevoerd in de CE-groep en 3 maal in de NE-groep. Late endoleaks anderszins gebeurde vaker in de CE-groep in vergelijking tot de NE-groep, respectievelijk $25.0 \%$ versus $15.0 \%$, $p=.080$. Secundaire ingrepen voor andere redenen dan IIA-gerelateerde endoleaks gebeurden in $7.5 \%$ of NE-casus en $15.4 \%$ of CE-casus $(p=.057)$, merendeels voor occlusies in de ipsilaterale poot van de stentgraft. Tijdens follow-up overleden 19 NE-patiënten en 9 CE- 
patiënten, hetgeen geen significant verschil is $(p=.225)$, en géén van overlijdens waren direct of indirect te relateren aan overstenten van de IIA. Daarnaast werd geen melding gemaakt van gluteus necrose en darmischemie. Door een vermoedelijke onderrapportage van het optreden van bil-claudicatie en erectieproblemen, konden hieraan helaas geen conclusies worden verbonden. Hoofdstuk 6 representeert de grootste vergelijkende studie over dit onderwerp tot dusver, en daarmee het sterkst beschikbare wetenschappelijk bewijs. Overstenten van de All zonder preventieve coil-embolisatie leidt niet tot toename van de incidentie van endoleaks of geassocieerde secundaire ingrepen. Het achterwege laten van coil-embolisatie is mogelijk een kosteneffectieve strategie in gevallen dat overstenten van de All noodzakelijk is, als in acht wordt genomen dat embolisatie kostbaar is en er vaak meerdere ingrepen met röntgendoorlichting nodig zijn.

\section{DEEL DRIE - Technische complicaties na EVAR: hoe te behandelen en hoe te voorkomen.}

EVAR behandeling komt met haar eigen technische complicaties, die vaak secundair ingrijpen behoeven. Met doorontwikkelde stentgrafts en een steeds beter begrip van behandeling van technische complicaties daalt de incidentie van nodige secundaire ingrepen. Deze dalende trend wordt geremd door het steeds verleggen van de grenzen van anatomische complexiteit waarin EVAR wordt toegepast.

Hoofdstuk 7 is een review naar het optreden en behandelen van technische complicaties van EVAR in de hedendaagse praktijk en de ontwikkelingen hiervan in de tijd genomen. Door het dreigende risico op ruptuur is de behandeling van Type-I endoleaks een vereiste. De behandelingsopties zijn het zekeren van de seal met transluminale ballon angioplastiek (PTA) en verlengen van de stentgraft. Als er zeer beperkte sprake is van AAA groei kunnen Type-II endoleaks met een afwachtend beleid behandeld worden. Indien vereist, zijn transarteriële of translumbale embolisatie en injectie van Onyx lijm opties voor behandeling. Meer invasieve oplossingen zijn endoscopisch of operatief ligeren van lumbale en mesenteriale arteriën. Alle Type-III endoleaks dienen geadresseerd te worden met een extra stentgraft die het defect overbrugt. Migratie van een stentgraft naar distaal wordt nog zelden gezien bij gebruik van stentgrafts van de laatste generatie. Om verdere migratie tegen te gaan kunnen grote stents of endostaples gebruikt worden om de verbinding tussen de stentgraft en de wand van de aorta te zekeren. Steeds vaker wordt occlusie van iliacale poten van de 
stentgraft gezien. Mogelijk wordt dit veroorzaakt doordat verdere ontwikkeling naar kleiner profiel endograft systemen het mogelijk maakt EVAR toe te passen in kleinere en kronkelige iliacae. In het algemeen worden secundaire ingrepen na EVAR steeds minder vaak gezien, en wanneer ze noodzakelijk zijn behoren endovasculaire mogelijkheden steeds vaker tot behandelingsmogelijkheden van eerste keus.

Onafhankelijke studies naar de prestaties van EVAR in uitdagende anatomie zijn noodzakelijk om de veiligheid en effectiviteit aan te tonen van de laatste generatie aan stentgrafts. Dit is essentieel om weloverwogen beslissingen te kunnen maken in de optimale behandeling van AAAs. In Hoofdstuk 8 wordt het doel en ontwerp van de EAGLE Registry beschreven. Deze studie is geïnitieerd door artsen zelf. De EAGLE Registry is een prospectieve observatie studie die er naar streeft 250 patiënten te includeren uit 20 ervaren centra wereldwijd. Het doel is om kritisch te onderzoeken wat de prestaties zijn van de Endurant (II) Stent Graft in anatomisch uitdagende AAAs. EAGLE includeert patiënten met uitdagende angulatie of lengte van de infrarenale aorta hals. Om het risico op selectie bias te minimaliseren en de kwaliteit van data te maximaliseren wordt de geschiktheid voor inclusie in EAGLE vastgesteld door een onafhankelijk CORE lab en wordt grote inspanning geleverd om opeenvolgende inclusie van uitdagende casus te verzekeren. Geruptureerde AAAs worden niet in de studie opgenomen. De EAGLE database is ontworpen om samengevoegd te kunnen worden met de lopende ENGAGE database en zo vergelijkende studies mogelijk te maken. Primaire uitkomstmaten zijn succesvolle behandeling na 30 dagen, 12 maanden en jaarlijks daarna tot 5 jaar na de implantatie van de stentgraft. EAGLE is vrij recent gesloten voor inclusie en zal haar eerste resultaten spoedig presenteren. 


ADDENDA 

VALORISATION 


\section{VALORISATION}

\section{Introduction}

An abdominal aortic aneurysm (AAA) is a focal dilatation of the aorta to at least 1.5 times its normal diameter. The normal diameter of the infrarenal aorta is approximately $20 \mathrm{~mm}$, therefore an aortic diameter of $30 \mathrm{~mm}$ or larger is considered being aneurysmatic. AAAs are a significant health challenge with an estimated incidence of $20-40$ cases per 100,000 population per year. Its more commonly seen in men than in women, with a prevalence of $1.3 \%$ to $8.9 \%$ in males and $1.0 \%$ tot $2.2 \%$ in females. The prevalence of AAA in The Netherlands is approximately 90.000 among people older than 55 years of age. Important risk factors for the occurrence of AAA are gender, age and smoking habits.

An AAA is a progressive disease, which if left untreated eventually leads to rupture of the aneurysm with massive bleeding and consequently death. To date, AAAs are responsible for $1.3 \%$ of all deaths among men aged between $65-85$ years in developed countries. In The Netherlands, each year approximately 850 persons die of a ruptured aneurysm. Since AAAs generally exists without symptoms, the AAA related mortality is probably underestimated.

The risk of rupture increases with the aneurysm diameter. Initial treatment of an AAA is aimed at preventing rupture. Because treatment itself also comes with a risk of mortality and morbidity, a selected treatment policy is constructed. A preventative aneurysm repair is indicated when the threshold diameter is reached (55mm in men and $52 \mathrm{~mm}$ in women), if rapid aneurysm growth is observed ( $>5 \mathrm{~mm}$ per 6 months in AAAs $>40 \mathrm{~mm}$ ) or if the aneurysm becomes symptomatic (abdominal or back pain). AAAs are responsible for approximately 7.000 hospital admissions yearly in The Netherlands.

Two modalities of AAA treatment are available; conventional open surgical repair or minimally invasive endovascular repair (EVAR). In open repair the aneurysmatic aorta is replaced by a synthetic graft. This treatment requires laparotomy, clamping of the aorta and is accompanied by substantial blood loss, and is consequently associated with a perioperative mortality of $2 \%$ to $5 \%$ and significant morbidity. In EVAR treatment a synthetic 
stentgraft is fed from femoral artery access in the groin through the aorta up to the AAA neck and subsequently unfolded, excluding the aneurysm sac from blood flow and pressure. Initially, EVAR was considered to be an alternative treatment for those AAA patients not suitable for open repair due to severe morbidities. Meanwhile, EVAR has proven to be a feasible and safe technique, showing decreased mortality and morbidity rates compared to conventional open treatment. EVAR now has become the treatment of preference for patients with infrarenal AAA.

Despite the promising results of EVAR perioperatively and in the short-term, complications unique for endovascular treatment cause EVAR to be less beneficial in the longer term. Also, a substantial proportion (40\%) of AAA patients that require repair fall outside stringent anatomic criteria that make treatment with commercially available stentgrafts suitable. Improvement of EVAR treatment is necessary to enhance outcomes of AAA patients. The technology of EVAR is a dynamic ever-changing endeavour. The challenge is to decrease complications and reinterventions, while safely treating more complex anatomy, especially those cases unfit for open repair. In the mean time hold dear to resource-effective strategies that do not include technically complex and costly interventions when they are not necessary. Both patients and society as a whole benefit from simply applicable and affordable techniques for AAA repair. Well-designed registries that closely monitor the performance of new graft designs and new endovascular techniques are therefore crucial in making balanced judgement about the optimal management of abdominal aortic aneurysms.

\section{Relevance of the scientific results in this thesis}

This thesis consists of three main parts. Part one focuses on the perioperative outcome of patients included in the ENGAGE registry. It describes the outcomes of a contemporary stent graft devices in current practice, and compares feasibility and outcome of EVAR with different anaesthetic modalities and outcome of EVAR in more urgent cases.

With the fast changing stentgraft designs it is important to keep hold on the performance of contemporary EVAR devices and put these results in perspective to older generations of devices en conventional open surgical AAA treatment. Chapter 2 describes the performance 
of the Endurant Stent Graft. Within the real-world ENGAGE Registry perioperative and oneyear results are promising. Complication and reintervention rates compare beneficial with those reported in the landmark EVAR-1, DREAM and OVER trails. This strengthens the evidence for the preferential use of EVAR over conventional open surgical repair whenever AAA treatment is indicated. Chapter 3 represents the largest comparative analyses between EVAR outcome in symptomatic and asymptomatic AAA patients. It shows that with the use of contemporary devices and technical proficiency of EVAR, the outcome of urgent EVAR in symptomatic cases is not different from the outcome of elective EVAR. Feasibility of EVAR under regional or local anaesthesia has been proven 20 years ago, however there is still no consensus on which type of anaesthesia is most suitable. Chapter 4 strengthens the evidence in favour of a strategy based on preferential use of locoregional anaesthesia for EVAR. It shows that type of anaesthesia used for EVAR has no influence on technical success and perioperative mortality and morbidity, but that the use of local or regional anaesthesia appears to be beneficial concerning procedural time, ICU admission, postoperative hospital stay and recovery.

The focus in part two of this thesis is on the handling of the ostium of the internal iliac artery (IIA) whenever coverage is indicated. It questions if treatment with more complex solutions is really necessary or if iliac stenting with the omission of coil embolisation is also safe to perform. A review of literature in Chapter 5 shows that so-feared IIA-related endoleaks following IIA stentgraft coverage without prior coil embolisation are rarely reported. Suggested pre-emptive coil embolisation as a preventative measure related-endoleaks may therefore be unnecessary. Furthermore, results from a strategy in which stent coverage of the IIA was routinely performed without prior coil embolisation show that this strategy in EVAR treatment of aorto-iliac and iliac aneurysms is safe and effective, and may reduce complications. Chapter 6 confirms these conclusions in a comparative analysis from the ENGAGE Registry that shows that the omission of coil embolisation in case of IIA coverage does not increase the incidence of endoleaks or related secondary interventions. Since this is the largest comparative study on the topic, and therefore the strongest evidence to date it may imply abandoning of pre-emptive coil embolisation as a standard regimen. 
In part three of this thesis an overview is given on the current management and prevention of complications that are unique for EVAR. Chapter 7 describes the evolution of occurrence and treatment options of all types of endoleaks, device migration, stent fractures, graft detoriation, or even persistent aneurysm growth that EVAR patients may experience. Advanced stent graft designs and increased understanding of management of these technical complications are declining the incidence rate for the necessity of secondary interventions, which is considered the down-side of EVAR and matter of great concern in the landmark trials that compare EVAR with open repair. Furthermore, in Chapter 8 a study design is presented to give more insight in the outcome of EVAR with contemporary devices in patients with challenging AAA morphology.

\section{Innovation and future}

Randomized controlled trials (RCTs) are considered the gold standard in the hierarchy of research designs for evaluating the efficacy and safety of a treatment intervention. Results of RCTs, however, may not reflect 'real world' since patient inclusion is subject to strict criteria, and can therefore have limited applicability to individual patients in clinical setting. Moreover, one must question if RCT design is feasible in qualifying outcome of EVAR in view of the contemporary preference for EVAR and the swift evolution in stent graft designs. Large high-quality, well-designed observational studies are increasingly believed to provide complementary evidence to RCTs. They can assess treatment effectiveness in patients encountered in day-to-day clinical practice because of the use of larger and more heterogeneous populations with common comorbidities and longer follow-up periods. A mandatory registry on AAA-treatment that is globally supported by doctors and is financially supported governments and industries might be the solution for creating a benchmark for future treatment and qualifying performance of new devices.

This thesis and future research contributes to the understanding of AAA treatment and the development of national and international guidelines that give guidance to the optimal treatment of abdominal aortic aneurysms. Above all making AAA disease a less lethal and more bearable disease. 

DANKWOORD 


\section{DANKWOORD}

Mijn proefschrift is klaar. Eindelijk! Wat een heerlijk gevoel en wat een opluchting vooral. Het heeft een stuk langer geduurd dan gepland, maar is de tijd dan toch aangebroken waarin ik mijn laptop thuis kan laten zonder me hier schuldig over te voelen. Wat een rust! Natuurlijk, een proefschrift schrijven - ook al duurt dat 8 jaar - kun je niet alleen. Vele mensen hebben een bijdrage gehad in de totstandkoming van dit werk, bewust of onbewust. Al deze mensen wil ik graag hartelijk bedanken.

Allereerst dank aan alle patiënten met aneurysmatisch vaatlijden die wereldwijd hun toestemming hebben gegeven voor deelname aan onze studie en wiens ervaringen en ziektebeloop de basis mochten zijn voor dit proefschrift. Dank ook aan alle vaatchirurgen die de moeite hebben genomen om alle gebeurtenissen perioperatief en in het traject erna te rapporteren. Ook dank aan de datamanagers die er op hebben toegezien dat de data juist en volledig in de database terecht kwam, hetgeen essentieel is voor de kwaliteit van ons onderzoek en wat maakt dat onze conclusies ook hout snijden.

Prof. dr. J.A.W. Teijink, beste Joep. Een gecharterd vliegtuig, hondenraces en een dwaze stapavond in het altijd bruisende Galway was mijn eerste kennismaking met de vaatchirurgie. Toen had ik niet durven hopen dat mijn bijbaan als 'dia-doorklikker' tijdens de EVAR-themadagen uiteindelijk zou resulteren in dit proefschrift. Je bood mij een baan als fulltime onderzoeker en een promotietraject met het meest sexy onderwerp van de vaatchirurgie. De precieze invulling van onderzoek onder de vleugels van Joep in het Catharina Ziekenhuis moest nog worden vorm gegeven, maar kosten noch moeite werden gespaard om de vaatchirurgische 'onderzoekstrein' aan de boemel te krijgen. Inmiddels diverse onderzoekslijnen, meerdere proefschriften en tientallen publicaties verder dendert deze sneltrein met locomotief Teijink nog steeds voort. Niet verwonderlijk dat jou dit al snel een prachtig hoogleraarschap opleverde. Joep, jouw eindeloze energie, enthousiasme en overredingskracht zijn van onschatbare waarde geweest tijdens mijn promotietraject. Jouw gedrevenheid, grootsheid en snelheid in het uitwerken van steeds weer nieuwe ideeën verdienen groot respect. Dank voor de steun en het vertrouwen dat je met vanaf het prille 
begin in mij hebt gehad en gedurende de rit bent blijven houden ook al verliep de afrondende fase van mijn promotietraject naar jouw smaak ongetwijfeld veel te traag. Ik heb in de afgelopen jaren zowel op onderzoeksgebied, in de kliniek en daarbuiten veel van je mogen leren. Hopelijk kan ik dat in de aankomende jaren nog veelvuldig blijven doen.

Prof. dr. M.R.H.M. van Sambeek, beste Marc. Dank dat je de tijd genomen hebt om altijd kritisch naar de stukken te kijken. Wilde plannen met een wirwar aan ideeën kun jij feilloos terugbrengen tot waar het in de kern om draait. Waar ik in het opstellen van de artikelen soms de weg kwijt was wist jij mij weer in de juiste richting te sturen. Jij hebt mij laten zien dat je in de wereld van de wetenschap en industrie vaak sneller je doel bereikt met diplomatie. Je internationale connecties hebben daar ongetwijfeld ook aan bijgedragen. Wat fantastisch en terecht dat ook jij inmiddels een leerstoel verworven hebt. Gelukkig heb ik in de afgelopen jaren ook wat ruwe kanten van je mogen meemaken. Zo kan ik mij een anekdote herinneren die je ooit verteld hebt tijdens het openingsdiner van mijn allereerste Catharina Winterbijscholing. lets met gordijnen. Ook onze trip naar het VEITH congres in New York vond ik memorabel. Marc, dank voor alle tijd en moeite die je in dit werk gestoken hebt.

Dr. Ph.W.M. Cuypers, beste Philippe. Dank voor je steun en begeleiding tijdens dit promotietraject. In de operatiekamer, maar ook daarbuiten ben je een voorbeeld voor mij. Soms wat lastiger benaderbaar, maar altijd even oprecht en eerlijk. Wilde theorieën en gedachtenkronkels die weinig hout sneden, weet jij met een paar woorden neer te sabelen. Je uitgesproken mening en ervaring zijn van grote waarde geweest in de diverse manuscripten. Tijdens onze reis naar ISET in Miami heb ik je beter en van een heel andere kant leren kennen. Ik heb een gouden tijd beleefd in het Fontainebleau Hotel en op de Everglades. Inmiddels heb ik begrepen dat je mij ook op een aantal cruciale momenten gedurende de opleiding gesteund hebt. Veel dank hiervoor. Hopelijk mag ik in de toekomst nog veel van je leren.

To all co-authors, Prof. dr. Tom L. Forbes, Prof. dr. Dittmar Böckler, Dr. Patrick J. Peeters, Prof. dr. Vicente Riambau, Dr. Paul Hayes, Dr. Anco Vahl, Dr. Bianca L.W. Bendermacher, Dr. Edith M. Willigendael, Dr. Jan A. Ten Bosch, Dr. Pieter P.H.L. Broos. I do gracefully 
appreciate your critical and most valuable feedback as a contribution to all our manuscripts. Without you there would be no thesis! Without a thesis I would not be standing here today!

Graag zou ik de leden van de beoordelingscommissie, voorzitter prof. dr. Martin Prins, prof. dr. Geert-Willem W.H. Schurink, prof. dr. Hence J.M. Verhagen en dr. Joost A. van Herwaarden, willen bedanken voor de tijd en de bereidheid dit proefschrift kritisch te beoordelen op haar wetenschappelijke waarde en voor de kans dit proefschrift tot een hoger niveau te tillen.

Mijn opleiders Heelkunde, prof. dr. Laurents P.S. Stassen, dr. Simon Nienhuijs en dr. Heinrich M.J. Janzing. Het makkelijkste lijkt me het opleiden van studenten die zonder blikken of blozen door hun opleiding razen, maar de meeste voldoening en dankbaarheid kan behaald worden door een loods te zijn voor degene die dit soms het hardste nodig hebben. De haven is in zicht nu ook dit is afgerond. Dank voor jullie ondersteuning en geloof in mijn kunnen.

Mijn opleiders Vaatchirurgie, drs. J.W.M Elshof, drs. M.G. Samyn, drs. R.J.L. Janssen, beste Jan-Willem, Martine en Roel. Mijn differentiatie tot vaatchirurg mocht bij jullie van start gaan. Op een zorgvuldige wijze leren jullie mij de fijne kneepjes van het vak. Elke dag leer ik weer nieuwe dingen en langzaam maar gestaag probeer ik mij de Leuvense en Tilburgse school eigen te maken. Ik heb het ontzettend naar mijn zin en mede door jullie nog geen moment spijt gehad van mijn keuze voor de vaatchirurgie te gaan. Dank voor jullie inzet als opleiders en dat jullie de tijd en moeite nemen me te kneden tot vaatchirurg. Ik hoop nog vele uren met jullie aan de operatietafel door te brengen en te leren.

Graag wil ik ook de leden van de maatschap Chirurgie van het Catharina Ziekenhuis bedanken die ik nog niet genoemd heb. Beste Harm, Frans, Alexander, Grard, Jean-Paul, Ignace, Yvonne, Misha en Gust. Ik ben trots dat ik als semi-arts, arts-onderzoeker en AIOS deel heb mogen uitmaken van jullie kliniek. Jullie enthousiasme en gedrevenheid de hoogste kwaliteit aan complexe zorg te willen leveren, gecombineerd met een hoog volume aan ingrepen, wetenschappelijke ambities en een gezonde portie aan Brabantse gezelligheid 
haalt het beste uit de assistenten en maakt 't Cathrien zo'n gewilde en fijne plek om in opleiding te zijn.

Ook wil ik de leden van de maatschap Chirurgie van het VieCuri Medisch Centrum bedanken die ik nog niet heb genoemd. Beste Charles, Joop, Paul, Arvid, Frits en Jeroen. Dank dat ik mijn opleiding tot chirurg in jullie kliniek mocht voorzetten. Ondanks dat jullie mij nog maar kort kennen en ik natuurlijk een beetje de vreemde eend in de bijt ben, staan jullie met open armen klaar om mij jullie chirurgische kennis en visie over te brengen. Ik voel me welkom in Venlo, dank hiervoor.

Polimedewerkers Chirurgie en medewerkers vaatlaboratorium Catharina Ziekenhuis. Beste Marga, Hannie, Jose, Nicole, Ine, Cindy, Helga, Dyanne, Ynette, Joyce, Silvie, Milou, Nicole, Arianne, Rukiye, Jolien, Olga, Anja, Yvonne en Lisanne. Dank voor jullie ondersteuning in de totstandkoming van mijn onderzoek en dit proefschrift. Ook dank voor jullie ondersteuning tijdens mijn jaren in de kliniek. Een korte uitleg volstaat en jullie regelen het, een luxe om zo'n club aan ondersteunende medewerkers achter je te hebben. Uit ervaring kan ik zeggen dat dit zeldzaam is. Het is een verademing geweest om met jullie te mogen werken.

Roy, Jeroen, Toon, Gio, Viola en Debra. Dank dat jullie mij de kans hebben geboden met ENGAGE aan de slag te gaan. Daar waar mogelijk hebben jullie elk op je eigen manier een bijdrage geleverd en zijn jullie van grote waarde geweest in de voltooiing van dit werk.

Natuurlijk wil ik ook de arts-assistenten en oud assistenten Chirurgie Catharina Ziekenhuis bedanken. Het is fantastisch om deel uit te mogen maken van de club Heelkunde Helden. Een hechte groep collega's die elkaar bijstaan waar nodig, maar die vooral zorgen voor een ontspannen en fijne werksfeer. Naast hard werken is ook niemand vies van een mooi fiske op z'n tijd. De winterbijscholingen en assistentenweekenden zijn fenomenaal. Ik kijk al weer uit naar volgende edities.

Arts-assistenten Chirurgie VieCuri Medisch Centrum. Natuurlijk anders dan Eindhoven, maar eveneens een super fijne club op mee samen te mogen werken. Mede dankzij jullie voel ik me erg welkom in Venlo en heb ik enorme sprongen kunnen maken. Dank jullie wel. 
Teamgenoten van het Catharina Bedrijfshockeyteam. Zeven jaar geleden hebben we het team opnieuw leven in geblazen en inmiddels is ons team een geduchte tegenstander bij de Eindhovense bedrijfshockeycompetitie. De maandagavonden zijn voor mij altijd een gelegenheid om op een sportieve manier wat stoom af te blazen. Het team zou de laatste paar jaar niet zo levend geweest zijn zonder de inzet van Rianne Grotenhuis. Dit jaar gaan we voor het vierde kampioenschap op rij!

De medewerkers van Gezondheidscentrum Reeshof. Dank dat het afgelopen jaar steeds met mijn laptop een kamer mocht komen bezetten voor de laatste loodjes. Zonder die lege kamer weg van huis en alle afleiding was het niet gelukt. De koffie was heerlijk.

Oud-huischgenoten der Heerenhuis Adrianus. De tijd van ongesteldheid is voorbij en het rode gevaar voor even geweken. Met onnoemelijk veel mooie herinneren kijk ik terug op mijn studententijd in het oudste en enige echte Maastrichtse Heerenhuis. Nog altijd springlevend! Als ik tijdens het schrijven van dit proefschrift mijn inspiratie even kwijt was, hoefde ik maar een Almanak open te slaan om mijzelf op te laden voor een volgend hoofdstuk. Zet 14 december 2018 maar bij de gedenkwaardige data!

Mede-promovendi en mijn kamergenoten van het onderzoekhok. Dr. P.P.H.L. Broos en dr. H..J. Fokkenrood, beste Pieter en Hugo. Jullie kwamen na enige tijd het onderzoeksteam versterken Hugo als Perifere Jongen, Pieter als Aortaboy. Jullie commentaar en ideeën zijn van grote waarde geweest voor dit manuscript. De diverse congresbezoeken ongekend mooi. Jaloersmakend natuurlijk dat jullie je boekje dan ook veel eerder klaar hadden dan ik. Pieter, misschien kun je me onder het genot van een dikke sigaar en een kopje very very strong tea nog eens uitleggen hoe ik dit beter had moeten aanpakken.

Dr. N. Verhofstad, beste Nicolle. Dank voor je steun gedurende het hele traject. Eerst als kamergenoot in ons onderzoekhok, later vooral in een coördinerende rol. De telefoontjes en mailtjes zo af en toe om de machine weer aan de gang te krijgen hebben uiteindelijk goed geholpen. Dank ook voor je hulp in het afhandelen van de administratieve rompslomp deze laatste paar maanden. 
Mw. H.C. van Dalen, beste Daniëlle. Zo trots dat jij mijn paranimf wil zijn. Bewoner van het onderzoekhok van het begin, de eerste paar jaren mijn vaste maatje voor elk congresbezoek en samen de drijvende kracht achter het bedrijfshockeyteam. Altijd in voor een feestje, maar ook goed voor een serieus gesprek. Je vertelde me nog niet zo super lang gelden dat je nog echt geen zin had om te trouwen of in kinderen, want je leven zou daarna compleet voorbij zijn. Ik dacht dat dat wel mee zou vallen. Toch grappig om te zien dat je eerder trouwde dan ik en dat je mij in aantal kinderen binnenkort al passeert. Hopelijk blijven die twee kleintjes nog even daar waar ze zitten tot dit feestje achter de rug is.

Dr. G.J. Lauret, beste Gert-Jan. Partner in crime vanaf het eerste uur. Niet zo verwonderlijk dat ik jou vroeg mijn paranimf te zijn en gelukkig kon je het inpassen in je drukke agenda als kersverse vaatchirurg. Ondanks dat onze onderzoeksterreinen verschilden, konden we uren sparren over de opzet en aanpak van een nieuwe studie en het ontwerp van een poster. Elke nieuweling in ons onderzoekhok moest eerst de vuurdoop doorstaan en we delen de passie voor goede, verse koffie en gynaecologen. Als paranimf op jouw promotie heb ik de belofte gedaan ook te promoveren. Dat ging me minder gemakkelijk af dan jij, maar hier staan we dan. Gert, dank voor alle steun tijdens dit traject.

Vrienden van de Metz, beste Christophe, Rik, Willem, Stijn, Dirk, Roderick, Maarten, Philip. $\mathrm{Na}$ een fantastische schooltijd in Tilburg, waaiden we uit over het land voor onze studies. Inmiddels hebben we allemaal een totaal verschillende, maar even succesvolle carrière, een bloedschone vrouw en een prachtig gezin. We spreken of zien elkaar helaas niet dagelijks meer. Daarom is het zo mooi dat als we elkaar zien het lijkt het alsof we elkaar gisteren nog gesproken hebben en elk weekendje of stapavond is weer als vanouds. Nog mooier is het dat iedereen met zijn gezin toch weer richting Brabant trekt. De Metz-weekenden in januari houden we in stand en daarmee onze lieve Wouter levend. Ik verheug me nu al op vakanties met onze gezinnen samen. Vrienden voor het leven!

Lieve schoonfamilie, beste Riemer, Wieger, Maartje en Claire. De eerste kennismaking was natuurlijk even schrikken, twee oudere broers, jullie kleine zusje en allebei minstens een kop groter. Toch werd ik warm ontvangen in jullie familie en kunnen we het goed met elkaar vinden. In de afgelopen jaren veel droevige, maar gelukkig ook veel blije gebeurtenissen 
mogen meemaken, waarbij we altijd op jullie steun konden rekenen. Fantastisch om te zien hoe onze kinderen samen opgroeien met hun neefjes en nichtjes. Hopelijk gaan we nog vele mooie momenten meemaken en gaat onze goede band nooit verloren.

Natuurlijk mijn broers en zusje en d'n kouwe kant. Lieve familie, lieve Sjoerd, Ewout, Freija, Marjanne, Annelieke en Gijs. Ondanks dat de afstand Eindhoven - Amsterdam soms wat groot is om de dagelijkse beslommeringen nauwgezet bij te houden, is het fijn dat jullie interesse tonen in wat ons bezig houdt, zijn jullie altijd van de partij bij belangrijke gebeurtenissen in ons leven en hebben jullie toch een belangrijk aandeel in de levens van onze kinderen. Trots om te zien dat iedereen zo druk bezig is met zijn carrière en dat dit iedereen ook lukt. Met het afsluiten van dit proefschrift komen er hopelijk zeeën van tijd vrij en kan de overtocht naar de hoofdstad weer vaker gemaakt worden. We zullen elkaar sowieso wel weer vaker gaan zien en spreken nu onze levens meer op elkaar gaan lijken. Onlangs werden wij verblijd met het nieuws dat er een klein neefje of nichtje op komst is en volgens mij heeft de rest ook concrete plannen dit voorbeeld te volgen. Fantastisch, want er is niets leuker dan kinderen en niets belangrijker dan familie.

Lieve Charlotte, lieve schoonmoeder en oma van onze kindjes. Dank dat je zo fijne oma bent en dank dat we met ons gezin altijd welkom zijn in Helmond voor een borrel of diner. Zonder jouw hulp op de vaste oppasdagen, maar ook op alle andere momenten dat je ons uit de brand helpt hadden wij nooit de tijd kunnen vinden om onze proefschriften te voltooien. Groot respect hoe jij na het overlijden van Rien in je eentje al die balletjes in de lucht weet te houden en ook zo nu en dan nog tijd voor jezelf weet vrij te maken. Samen met hun neefjes en nichtjes genieten onze kinderen altijd weer om bij je te zijn.

Lieve pappa en mamma. Dank dat jullie me altijd gesteund hebben om te bereiken wat ik voor ogen heb. Jullie hebben mij gesteund in mijn studie, keus tot specialisatie en dit promotietraject. Daar waar nodig zijn jullie in de bres gesprongen voor Anne-Lotte en mij om onze proefschriften af te kunnen ronden. Met trots kijk ik naar hoe onze kinderen zo verzot zijn op hun opa en oma en jullie op hen. Ze boffen dan ook met zo'n vitale opa en oma die hen overal mee naar toe nemen en altijd voor ze klaar staan. Wij ook, want zonder jullie hulp hadden we met ons gezin niet kunnen bereiken wat we tot noch toe bereikt hebben. Heel 
veel dank hiervoor en voor de toekomst, want ik hoop dat onze kinderen en alles wat nog in de maak is nog lang van jullie kan genieten. Ik hoop dat jullie trots zijn, maar bovenal opgelucht dat dit promotietraject nu dan eindelijk is afgerond.

Liefste Pepijn en Philou. Wat hou ik van jullie en wat ben ik ongelooflijk dankbaar dat jullie in ons leven zijn gekomen. Elke dag geniet ik als ik jullie zie. Pepijn, jij maakte mij pappa. Een moment en een gevoel dat niet te evenaren is. Vol trots luister ik naar je verhalen en zie ik je van alles uitvinden. Wijsneus. Mijn beste vriend. Wat wordt je snel groot en ontwikkel je jezelf in een razend tempo. Kon je voor altijd maar dat kleine mannetje blijven dat lekker op mijn schoot kruipt om geknuffeld te worden, maar tegelijkertijd ben ik erg benieuwd hoe jij het volgend jaar school gaat beleven. Philou, mijn lieve kleine meisje. Jouw lieve lach maakt mij altijd vrolijk en er is er maar één die elke keer weer zo enthousiast is mij weer te zien nadat ik vijf minuten weg ben geweest. Op het moment dat ik dit schrijf zijn we op reis door Nieuw-Zeeland en Bali en ik zie je groeien met de dag. Jammer, want ook jij zou eigenlijk voor altijd klein en schattig moeten blijven. Toch kan ik niet wachten om de eerste verhalen uit jouw mond te horen. Wij zijn ongelofelijk blij met jullie.

Allerliefste Anne-Lotte. Zonder jou was dit natuurlijk nooit gelukt. Dank voor je geduld, dank voor je begrip, dank voor je onvoorwaardelijke steun, dank dat je zo'n fantastische vrouw bent en zo'n geweldige moeder. Ik had mij niets beter durven wensen. Na onze studies sloegen we een traject in waar promoveren onderdeel van uitmaakt. Beide hoopten we ons promotietraject zo snel mogelijk af te kunnen ronden om ons dan zo snel mogelijk volledig op de kliniek te kunnen focussen zonder tijd te kort te komen voor ons sociale leven. Ook al hebben we ons proefschrift beide later afgerond dan gehoopt, ik ben ontzettend trots dat het ons beide is gelukt. Extra trots op jou dat je een jaar eerder klaar was dan ik, je tussendoor ook nog de twee prachtigste kinderen op de wereld hebt gezet en je direct aansluitend aan je opleiding een prachtige maatschap plek in 's-Hertogenbosch hebt weten te veroveren. Wat zal de afronding van nu ook mijn proefschrift een ongelooflijke rust geven in ons leven. Geen noodzaak meer om alle lege gaatjes in onze agenda's op te vullen met typewerk. Tijd om weer ten volle van onze vrienden, onze familie, ons gezin en van elkaar te gaan genieten. Met onze kleine wereldreis zijn we in ieder geval goed van start gegaan. We maken er iets moois van. Ik hou enorm veel van je! 

LIST OF PUBLICATIONS 


\section{PEER REVIEWED PULBLICATIONS}

1. R.A. Stokmans, J.A.W. Teijink, P.W.M. Cuypers, V. Riambau, M.R.H.M. van Sambeek. No differences in perioperative outcome between symptomatic and asymptomatic AAA's after EVAR: An analysis from the ENGAGE Registry. Eur J Vasc Endovasc Surg. 2012 Jun; 43(6):667-73. [Epub 2012 Mar 21]

2. R.A. Stokmans, J.A.W. Teijink, T.L. Forbes, D. Böckler, P.J. Peeters, V. Riambau, P.D. Hayes, M.R.H.M. van Sambeek. Early results from the ENGAGE Registry: Real world performance of the Endurant Stent Graft for endovascular AAA repair in 1262 patients. Eur J Vasc Endovasc Surg. 2012 Oct; 44(4):367-75. [Epub 2012 Jul 24]

3. B.L.W. Bendermacher, R.A. Stokmans, Ph.W.M. Cuypers, J.A.W. Teijink, M.R.H.M van Sambeek. EVAR reintervention management strategies in contemporary practice. J Cardiovasc Surg (Torino). 2012 Aug; 53(4):411-8. [Epub 2012 Aug 06]

4. M.C.A. Wegdam-Blans, R.A. Stokmans, J.H.T. Tjhie, J.M. Korbeeck, M.P. Koopmans, S.M.A.A. Evers, P.H. van de Voort, J.A.W. Teijink. Targeted screening as a tool for early detection of chronic $Q$ fever patients after a large outbreak. Eur J Clin Microbiol Infect Dis. 2013 Mar; 32(3):353-9. [Epub 2012 Sep 26]

5. R.A. Stokmans, E.M. Willigendael, J.A.W. Teijink, J.A. Ten Bosch, M.R.H.M. van Sambeek, Ph.W.M. Cuypers. Challenging the evidence for pre-emptive coil embolisation of the internal iliac artery during endovascular aneurysm repair. Eur J Vasc Endovasc Surg. 2013 Mar; 45(3):220-6. [Epub 2013 Jan 07]

6. R.A. Stokmans, E.M. Willigendael, J.A.W. Teijink, J.A. Ten Bosch, M.R.H.M. van Sambeek, Ph.W.M. Cuypers. Challenging the evidence for pre-emptive coil embolisation of the internal iliac artery during endovascular aneurysm repair. J Vasc Surg. 2013 Mar; 57(3):895. 
S.P. Nicolaï, L.M. Kruidenier, B.L. Bendermacher, M.H. Prins, R.A. Stokmans, P.P. Broos, J.A. Teijink. Ginko biloba for intermittent claudication. Cochrane Database Syst Rev. 2013 Jun 6;6:CD006924. [Epub 2013 Jun 06]

8. R.A. Stokmans, P.W. Cuypers, M.R. van Sambeek, J.A. Teijink. Respons to 'Re. Internal iliac artery coverage during endovascular aneurysm repair'. Eur J Vasc Endovasc Surg. 2013 Oct; 46(4):495-6. [Epub 2013 Jul 20]

9. A.L.W.M. Coolen, A.M.J. van Oudheusden, H.W.F. van Eijndhoven, T.P.F.M. van der Heijden, R.A. Stokmans, B.W.J. Mol, M.Y. Bongers. A comparison of complications between open abdominal sacrocolpopexy and laparoscopic sacrocolpopexy for the treatment of vault prolapse. Obstet Gynecol Int. 2013 Nov; 2013:528636. [Epub 2013 Sep 26]

10. S.Pouwels, R.A. Stokmans, E.M. Willigendael, S.W. Nienhuijs, C. Rosman, B. van Ramshorst, Joep A.W. Teijink. Preoperative exercise therapy for elective major abdominal surgery: a systematic review. Int J Surg. 2014; May; 12(12):134-40. [Epub 2013 Dec 8]

11. R.A. Stokmans, P.P.H.L. Broos, Ph.W.M. Cuypers, T.L. Forbes, A.C. Vahl, P. Swartbol, M.R.H.M. van Sambeek, J.A.W. Teijink. Rationale and design of the EAGLE Registry: Endovascular Abdominal Aortic Aneurysm Repair with the Endurant Stent Graft in Challenging Anatomy, a Global Experience. J Cardiovasc Surg (Torino). 2014 Oct; 55(5):699-704. [Epub 2014 May 21]

12. P.P.H.L. Broos, R.A. Stokmans, S.M. van Sterkenburg, G. Torsello, F. Vermassen, Ph.W. M. Cuypers, M.R.H.M. van Sambeek, J.A.W. Teijink. Performance of the Endurant stent graft in challenging anatomy. J Vasc Surg. 2015 Aug;62(2):312-8. [Epub 2015 May 1]

13. P.P.H.L. Broos, R.A. Stokmans, Ph.W.M. Cuypers, M.R.H.M. van Sambeek, J.A.W. Teijink, ENGAGE Investigators. Effects of anesthesia type on perioperative outcome after endovascular aneurysm repair. J Endovasc Ther. 2015 Oct;22(5):770-7. [Epub 2015 Aug 14] 
14. P.P.H.L. Broos, Y.W. 't Mannetje, R.A. Stokmans, S. Houterman, G. Corte, Ph.W.M. Cuypers, J.A.W. Teijink, M.R.H.M. van Sambeek. A 15-year single-center experience of endovascular repair for elective and ruptured abdominal aortic aneurysms. J Endovasc Ther. 2016 Aug;23(4):566-73. [Epub 2016 May 13]

15. J.A. Ten Bosch, S.W. Koning, E.M. Willigendael, M.R.H.M. van Sambeek, R.A. Stokmans, M.H. Prins, J.A.W. Teijink. Symptomatic abdominal aortic aneurysm repair, to wait or not to wait. J Cardiovasc Surg (Torino). 2016 Dec;57(6):830-38. [Epub 2013 Jul 18]

16. R.A. Stokmans, P.P.H.L. Broos, M.R.H.M. van Sambeek, J.A.W. Teijink, Ph.W.M. Cuypers. Overstenting the hypogastric artery during endovascular aneurysm repair with and without prior coil embolization: a comparative analysis from the ENGAGE Registry. J Vasc Surg. 2018 Jan;67(1): 134-41. [Epub 2017 Jun 27]

17. Y.W. 't Mannetje, P.P.H.L. Broos, J.A.W. Teijink, R.A. Stokmans, Ph.W.M. Cuypers, M.R.H.M. van Sambeek. Mid-term follow-up results after abandoning routine preemptive coil embolization of the internal iliac artery during endovascular aneurysm repair. J Endovasc Ther; [Epub ahead of print]

\section{BOOK CHAPTERS}

1. Pieter P.H.L. Broos, Rutger A. Stokmans, Bianca L.W. Bendermacher, Philippe W.M. Cuypers, Marc R.H.M. van Sambeek, Joep A.W. Teijink. Endovascular Aneurysm Repair in Challenging Anatomy. In Daniel Fischhof, Franz Hatig (ed.), Aortic Aneurysms: Risk Factors, Diagnosis, Surgery \& Repair. New York: Nova Science Publishers, Inc. Pub. 2013. ISBN: 978-1-62618-459-6. 

CURRICULUM VITAE 


\section{CURRICULUM VITAE}

Rutger Stokmans werd op 11 december 1984 geboren in Maastricht. Hij groeide op in Tilburg als oudste in een gezin van drie zonen en een dochter. Na het behalen van zijn VWO diploma aan het Theresialyceum in 2003, begon hij aan zijn studie Geneeskunde aan de Universiteit van Maastricht. Tijdens zijn studie volgde hij onder meer co-schappen chirurgie in het Mulago Hospital in Kampala, Oeganda (supervisor prof. dr. Antony M. Gakwaya) en in het Academic Hospital in Pretoria,

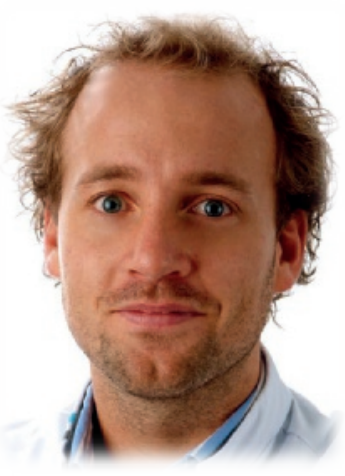
Zuid-Afrika (supervisor prof. dr. Jan H.R. Becker). Buiten het standaard curriculum om is hij samen met de Rotary Doctors door Kenia getrokken om in rurale gebieden kliniek te houden.

$\mathrm{Na}$ het afronden van zijn arts-examen in augustus 2010 startte hij als arts-onderzoeker bij de afdeling vaatchirurgie in het Catharina Ziekenhuis te Eindhoven. In het verlengde hiervan volgde een promotietraject onder leiding van prof. dr. Joep A.W. Teijink, prof. dr. Marc R.H.M. van Sambeek en dr. Philippe W.M. Cuypers, hetgeen geresulteerd heeft in dit proefschrift. Het leeuwendeel van de wetenschappelijke publicaties is gepresenteerd op diverse internationale congressen in Europa en de Verenigde Staten. Voor enkele hiervan ontving hij prijzen.

In juli 2013 werd hij aangenomen voor de opleiding Heelkunde. Na de eerste twee jaar van zijn opleiding tot algemeen chirurg gevolgd te hebben in het Maastricht Universitair Medisch Centrum (opleider prof. dr. Laurents P.S. Stassen) keerde hij terug naar het Catharina Ziekenhuis om zijn opleiding daar te vervolgen (opleider dr. Simon W. Nienhuijs). Inmiddels is hij werkzaam als AIOS in het VieCuri Ziekenhuis te Venlo en is gestart met differentiatie tot vaatchirurg (opleiders dr. Heinrich M.J. Janzing en drs. Jan-Willem M. Elshof).

Rutger is in 2014 getrouwd met zijn geliefde Anne-Lotte. Samen hebben zij twee prachtige kinderen; een zoon genaamd Pepijn (2015) en een dochter genaamd Philou (2017). 


